\title{
WestVirginiaUniversity
}

THE RESEARCH REPOSITORY @ WVU

Graduate Theses, Dissertations, and Problem Reports

2003

\section{Relational project modeling and risk projection framework}

Brian D. Gould

West Virginia University

Follow this and additional works at: https://researchrepository.wvu.edu/etd

\section{Recommended Citation}

Gould, Brian D., "Relational project modeling and risk projection framework" (2003). Graduate Theses, Dissertations, and Problem Reports. 1375.

https://researchrepository.wvu.edu/etd/1375

This Thesis is protected by copyright and/or related rights. It has been brought to you by the The Research Repository @ WVU with permission from the rights-holder(s). You are free to use this Thesis in any way that is permitted by the copyright and related rights legislation that applies to your use. For other uses you must obtain permission from the rights-holder(s) directly, unless additional rights are indicated by a Creative Commons license in the record and/ or on the work itself. This Thesis has been accepted for inclusion in WVU Graduate Theses, Dissertations, and Problem Reports collection by an authorized administrator of The Research Repository @ WVU. For more information, please contact researchrepository@mail.wvu.edu. 


\title{
RELATIONAL PROJECT MODELING AND RISK PROJECTION FRAMEWORK
}

\author{
Brian D. Gould \\ Thesis submitted to the College of \\ Engineering and Mineral Resources at \\ West Virginia University in partial \\ fulfillment of the requirements for the \\ degree of \\ Master of Science \\ in \\ Computer Science
}

John Atkins, Ph.D., Chair

Lawrence Jacowitz, Ph.D.

James Mooney, Ph.D.

Lane Department of Computer Science and Electrical Engineering

Morgantown, West Virginia

2003

Keywords: Project Management, Decision Support, Risk Analysis Copyright 2003 Brian D. Gould 


\title{
Abstract \\ RELATIONAL PROJECT MODELING AND RISK PROJECTION FRAMEWORK
}

\author{
Brian D. Gould
}

The relational project modeling and risk projection framework enables a projection of the consequences of initial project schedules and schedule changes with respect to risk realization in resource constrained project environments, and the identification of unrecognized schedule risks implied by those schedules. 


\section{ACKNOWLEDGMENTS}

The author wishes to express sincere appreciation to Professors Atkins, Jacowitz, and Mooney for their assistance in the preparation of this manuscript. In addition, special thanks to my wife, Shu Bao, and my parents, Karen and David Gould whose support and understanding were invaluable during the course of this research. 


\section{TABLE OF CONTENTS}

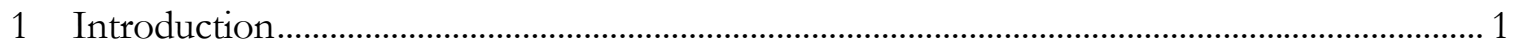

The current state of software project management ..................................................................... 1

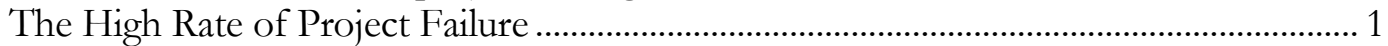

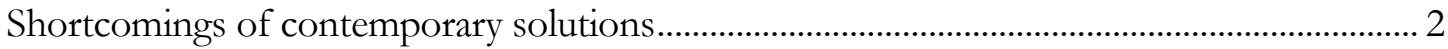

Qualitative vs. Quantitative methods ............................................................................. 2

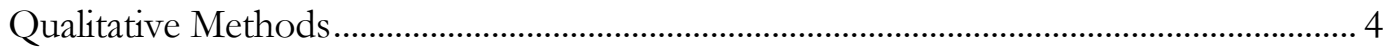

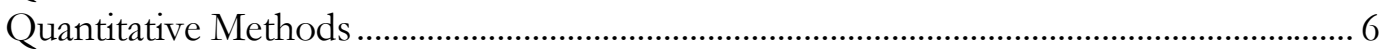

Difficulties with Historical data ...................................................................................... 7

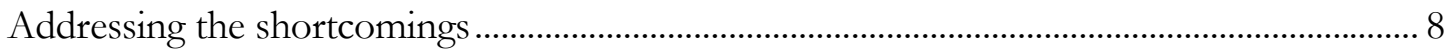

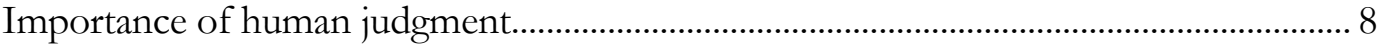

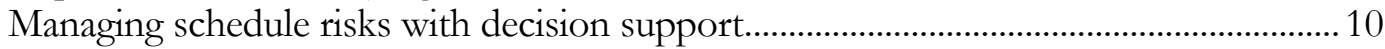

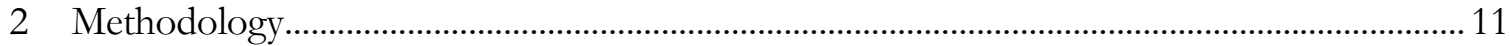

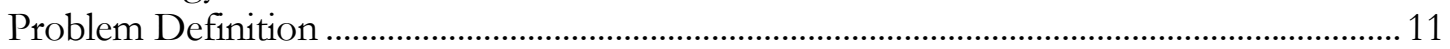

Overview of the Relational Project Modeling and Risk Projection Framework .................... 12

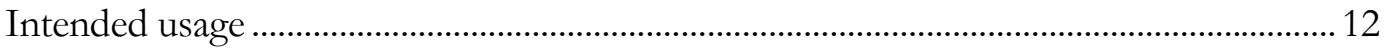

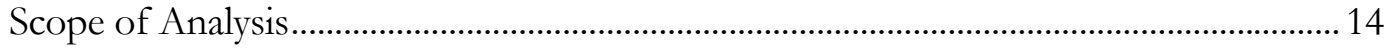

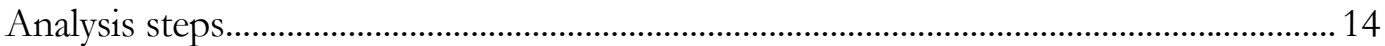

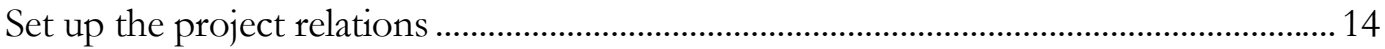

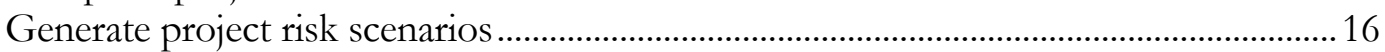

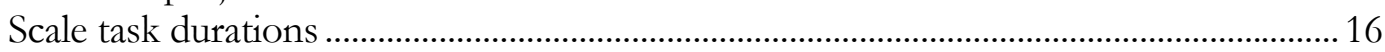

Generate the project network and perform CPM calculations............................................ 17

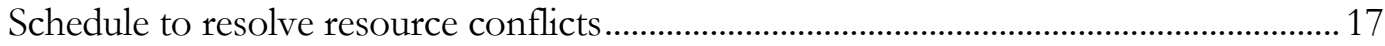

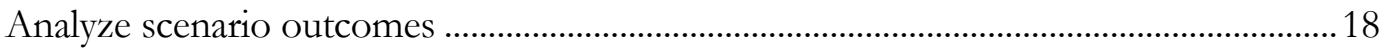

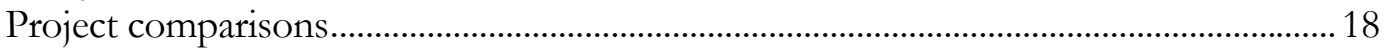

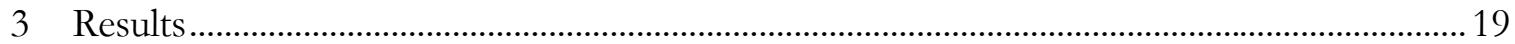

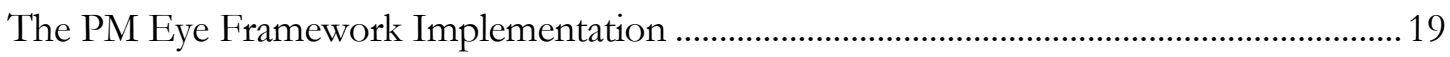

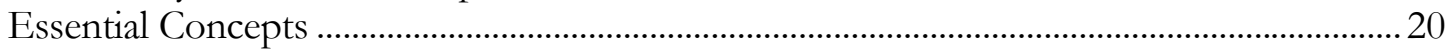

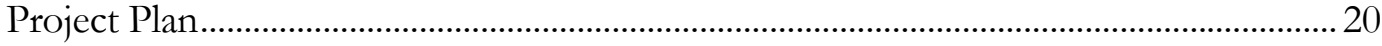

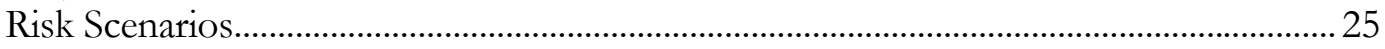

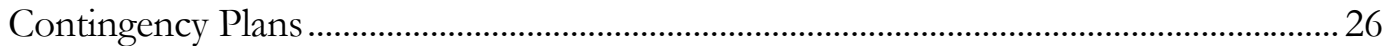

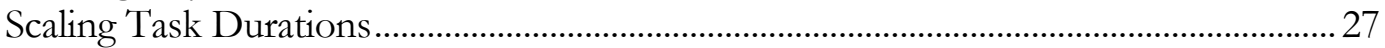

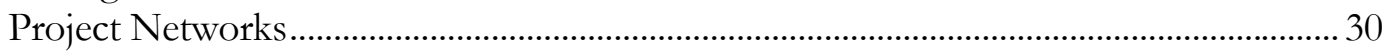

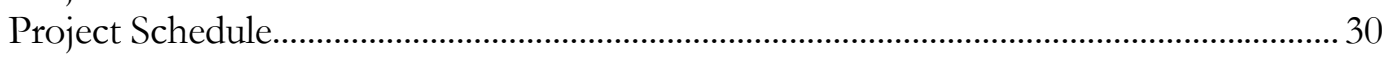

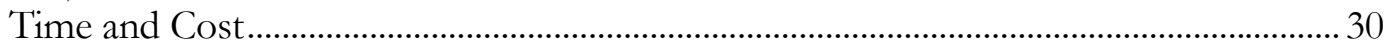

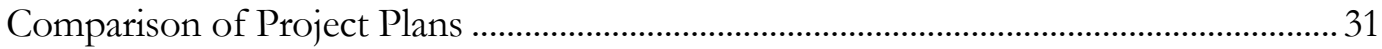

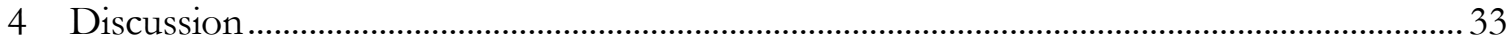

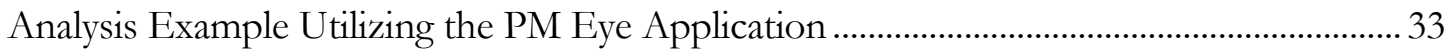

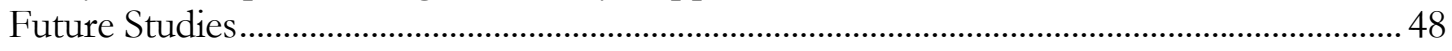




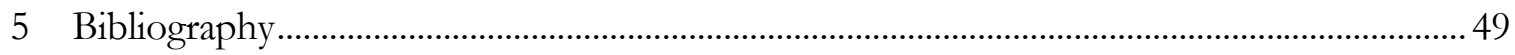

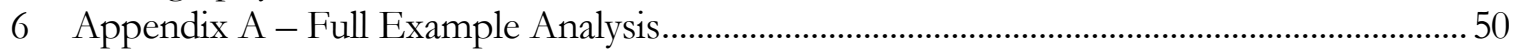

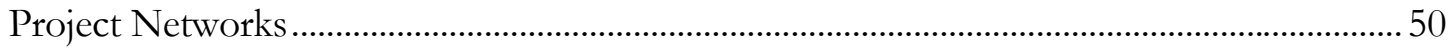

Client Server Application v1 - Base Scenario Project Network ......................................... 50

Client Server Application v1 - Scenario 1 Project Network................................................. 51

Client Server Application v1 - Scenario 2 Project Network............................................... 52

Client Server Application v1 - Scenario 3 Project Network................................................. 53

Client Server Application v1 - Scenario 4 Project Network................................................ 54

Client Server Application v1 - Scenario 5 Project Network................................................. 55

Client Server Application v1 - Scenario 6 Project Network................................................. 56

Client Server Application v1 - Scenario 7 Project Network................................................ 57

Client Server Application v2 - Base Scenario Project Network …………………………... 58

Client Server Application v2 - Scenario 1 Project Network................................................ 59

Client Server Application v2 - Scenario 2 Project Network....................................................... 60

Client Server Application v2 - Scenario 3 Project Network........................................................ 61

Client Server Application v2 - Scenario 4 Project Network........................................................ 62

Client Server Application v2 - Scenario 5 Project Network........................................................ 63

Client Server Application v2 - Scenario 6 Project Network....................................................... 64

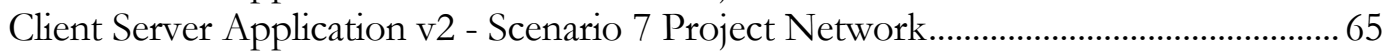

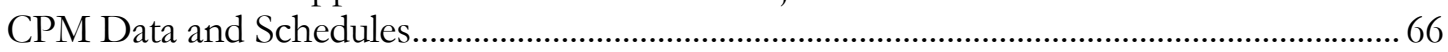

Client Server Application v1 - Base Scenario CPM Data and Schedule ...............................66 66

Client Server Application v1 - Scenario 1 CPM Data and Schedule ...................................68

Client Server Application v1 - Scenario 2 CPM Data and Schedule .................................70

Client Server Application v1 - Scenario 3 CPM Data and Schedule ................................. 72

Client Server Application v1 - Scenario 4 CPM Data and Schedule .................................74

Client Server Application v1 - Scenario 5 CPM Data and Schedule .................................76

Client Server Application v1 - Scenario 6 CPM Data and Schedule ................................78

Client Server Application v1 - Scenario 7 CPM Data and Schedule .................................8 80

Client Server Application v2 - Base Scenario CPM Data and Schedule .......................... 82

Client Server Application v2 - Scenario 1 CPM Data and Schedule ................................. 84

Client Server Application v2 - Scenario 2 CPM Data and Schedule ................................. 86

Client Server Application v2 - Scenario 3 CPM Data and Schedule ................................ 88

Client Server Application v2 - Scenario 4 CPM Data and Schedule ................................ 90

Client Server Application v2 - Scenario 5 CPM Data and Schedule ................................ 92

Client Server Application v2 - Scenario 6 CPM Data and Schedule ................................ 94

Client Server Application v2 - Scenario 7 CPM Data and Schedule ................................ 96

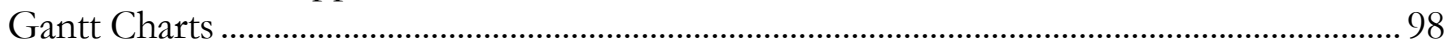

Client Server Application v1 - Base Scenario Gantt Chart.................................................. 98

Client Server Application v1 - Scenario 1 Gantt Chart......................................................... 99

Client Server Application v1 - Scenario 2 Gantt Chart...................................................... 100

Client Server Application v1 - Scenario 3 Gantt Chart......................................................101

Client Server Application v1 - Scenario 4 Gantt Chart....................................................102 


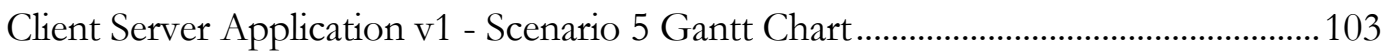

Client Server Application v1 - Scenario 6 Gantt Chart ....................................................... 104

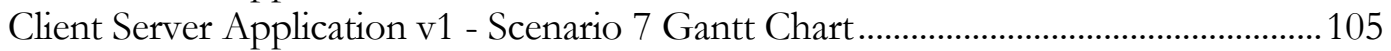

Client Server Application v2 - Base Scenario Gantt Chart...................................................106

Client Server Application v2 - Scenario 1 Gantt Chart ...........................................................107

Client Server Application v2 - Scenario 2 Gantt Chart ....................................................108

Client Server Application v2 - Scenario 3 Gantt Chart ....................................................109

Client Server Application v2 - Scenario 4 Gantt Chart ......................................................... 110

Client Server Application v2 - Scenario 5 Gantt Chart ..........................................................111

Client Server Application v2 - Scenario 6 Gantt Chart ..................................................112

Client Server Application v2 - Scenario 7 Gantt Chart ........................................................113

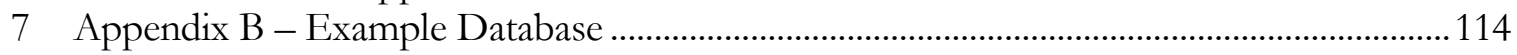

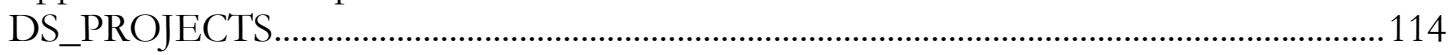

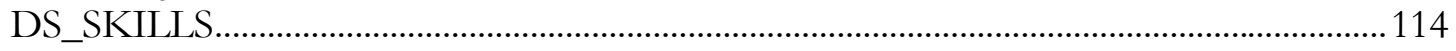

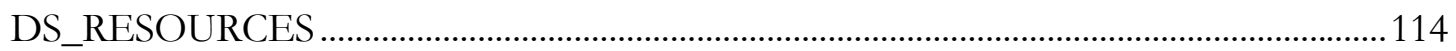

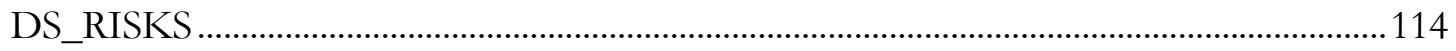

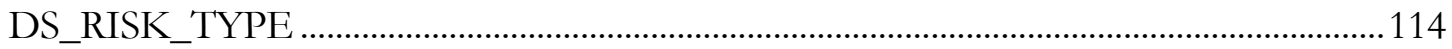

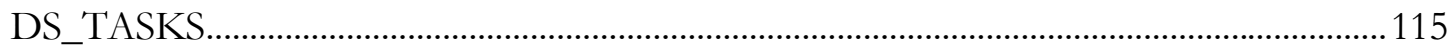

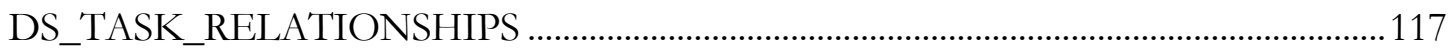

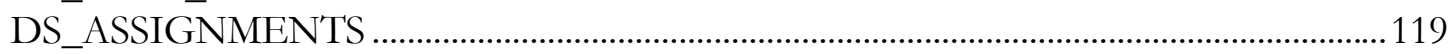

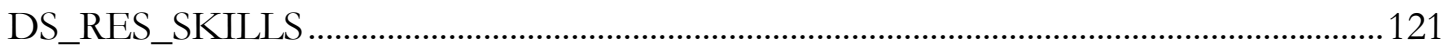

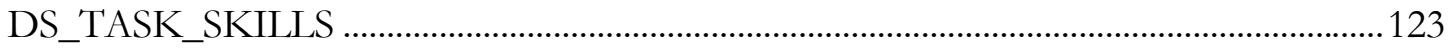

8 Appendix C - Source Code ...................................................................................................126

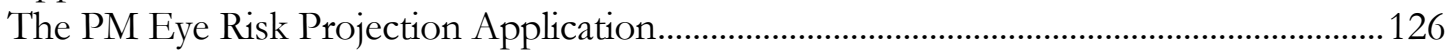

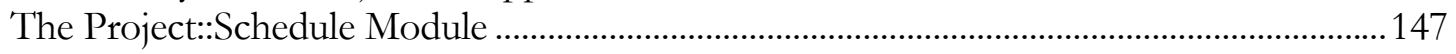

The Project::Grapher Module ................................................................................................155 


\section{LIST OF FIGURES}

Figure 3-1 Example of the Project relation ……….......................................................................... 21

Figure 3-2 Example of the Risk Relation ....................................................................................... 21

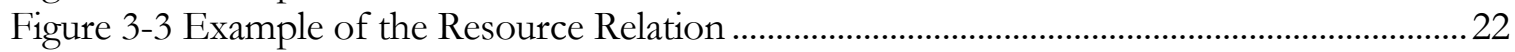

Figure 3-4 Example of the Skill Relation ....................................................................................... 22

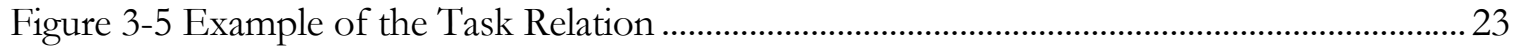

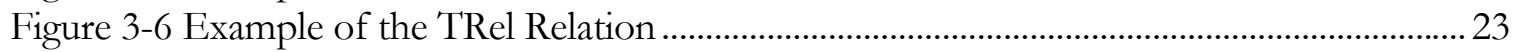

Figure 3-7 Example of the Assign Relation........................................................................................ 24

Figure 3-8 Example of the RSkill Relation ....................................................................................... 24

Figure 3-9 Example of the TSkill Relation ...................................................................................... 25

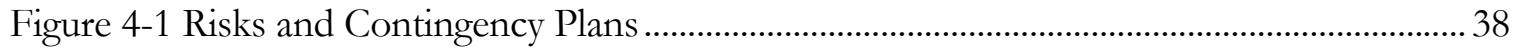

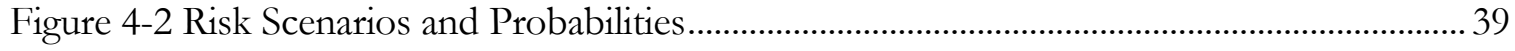

Figure 4-3 Project Network of the Base Scenario ............................................................................... 40

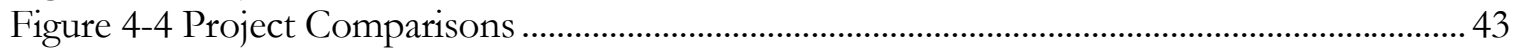

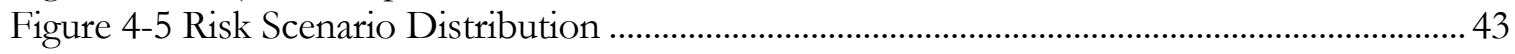

Figure 4-6 Project Time Comparisons Graph ................................................................................. 44

Figure 4-7 Project Cost Comparisons Graph................................................................................... 44

Figure 4-8 Best and Worst Case Time Comparisons........................................................................ 45

Figure 4-9 Best and Worst Case Cost Comparisons........................................................................ 45

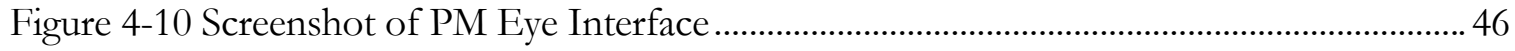

Figure 4-11 Time, Cost, and Probability Comparison Chart View for Project 1 ........................ 46

Figure 4-12 Time, Cost, and Probability Comparison Chart View for Project 2 ......................... 47

Figure 4-13 Gantt Chart View of Project 2 ………............................................................................ 47

Figure 6-1 Client Server Application v1 - Base Scenario Project Network ................................... 50

Figure 6-2 Client Server Application v1 - Scenario 1 Project Network ........................................... 51

Figure 6-3 Client Server Application v1 - Scenario 2 Project Network ......................................... 52

Figure 6-4 Client Server Application v1 - Scenario 3 Project Network .......................................... 53

Figure 6-5 Client Server Application v1 - Scenario 4 Project Network ........................................ 54

Figure 6-6 Client Server Application v1 - Scenario 5 Project Network ......................................... 55

Figure 6-7 Client Server Application v1 - Scenario 6 Project Network ………………………........ 56

Figure 6-8 Client Server Application v1 - Scenario 7 Project Network ........................................... 57

Figure 6-9 Client Server Application v2 - Base Scenario Project Network ...................................58

Figure 6-10 Client Server Application v2 - Scenario 1 Project Network ........................................ 59

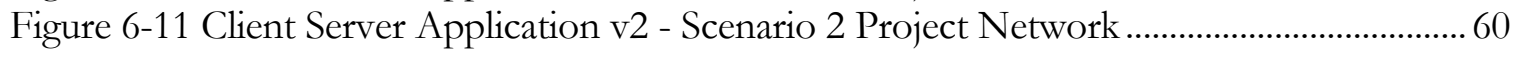

Figure 6-12 Client Server Application v2 - Scenario 3 Project Network ....................................... 61

Figure 6-13 Client Server Application v2 - Scenario 4 Project Network .......................................... 62

Figure 6-14 Client Server Application v2 - Scenario 5 Project Network ....................................... 63

Figure 6-15 Client Server Application v2 - Scenario 6 Project Network ......................................... 64

Figure 6-16 Client Server Application v2 - Scenario 7 Project Network ........................................ 65 


\section{LIST OF TABLES}

Table 3-1 Cost outcomes of two projects with four risk scenarios.................................................. 32

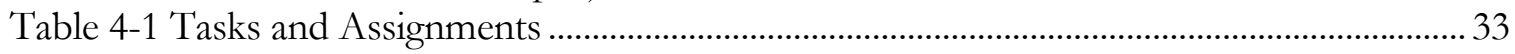

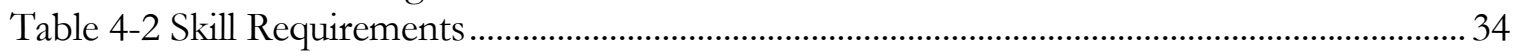

Table 4-3 Skill Profiles of Project Team Members ........................................................................... 35

Table 4-4 Skill Profiles of Additional Team Members .......................................................................... 37

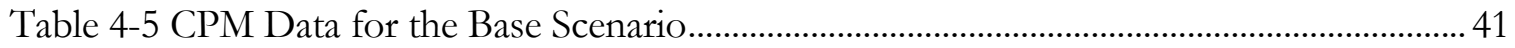

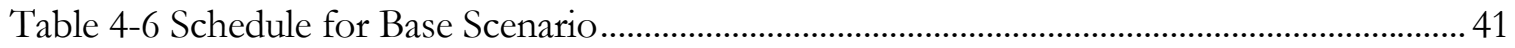

Table 6-1 Client Server Application v1 - Base Scenario CPM Data ................................................66

Table 6-2 Client Server Application v1 - Base Scenario Schedule......................................................67

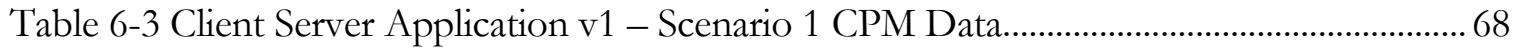

Table 6-4 Client Server Application v1 - Scenario 1 Schedule ..........................................................69

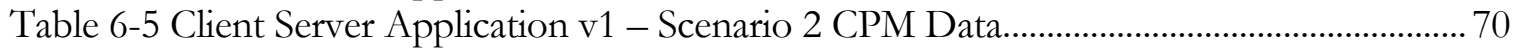

Table 6-6 Client Server Application v1 - Scenario 2 Schedule ....................................................... 71

Table 6-7 Client Server Application v1 - Scenario 3 CPM Data...................................................... 72

Table 6-8 Client Server Application v1 - Scenario 3 Schedule .......................................................... 73

Table 6-9 Client Server Application v1 - Scenario 4 CPM Data........................................................ 74

Table 6-10 Client Server Application v1 - Scenario 4 Schedule.......................................................... 75

Table 6-11 Client Server Application v1 - Scenario 5 CPM Data ..................................................... 76

Table 6-12 Client Server Application v1 - Scenario 5 Schedule.......................................................... 77

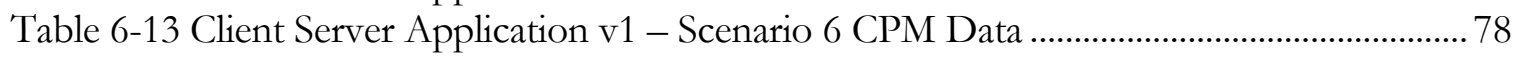

Table 6-14 Client Server Application v1 - Scenario 6 Schedule......................................................... 79

Table 6-15 Client Server Application v1 - Scenario 7 CPM Data ................................................... 80

Table 6-16 Client Server Application v1 - Scenario 7 Schedule...................................................... 81

Table 6-17 Client Server Application v2 - Base Scenario CPM ....................................................... 82

Table 6-18 Client Server Application v2 - Base Scenario Schedule ............................................... 83

Table 6-19 Client Server Application v2 - Scenario 1 CPM Data .................................................. 84

Table 6-20 Client Server Application v2 - Scenario 1 Schedule...................................................... 85

Table 6-21 Client Server Application v2 - Scenario 2 CPM Data .................................................. 86

Table 6-22 Client Server Application v2 - Scenario 2 Schedule....................................................... 87

Table 6-23 Client Server Application v2 - Scenario 3 CPM Data ................................................... 88

Table 6-24 Client Server Application v2 - Scenario 3 Schedule....................................................... 89

Table 6-25 Client Server Application v2 - Scenario 4 CPM Data ................................................. 90

Table 6-26 Client Server Application v2 - Scenario 4 Schedule...................................................... 91

Table 6-27 Client Server Application v2 - Scenario 5 CPM Data ............................................... 92

Table 6-28 Client Server Application v2 - Scenario 5 Schedule.......................................................... 93 
Table 6-29 Client Server Application v2 - Scenario 6 CPM Data .................................................. 94

Table 6-30 Client Server Application v2 - Scenario 6 Schedule........................................................ 95

Table 6-31 Client Server Application v2 - Scenario 7 CPM Data ..................................................... 96

Table 6-32 Client Server Application v2 - Scenario 7 Schedule...................................................... 97 


\section{Introduction}

\section{The current state of software project management}

The High Rate of Project Failure

Citing a 1995 survey, Addison and Vallabh [1] state that only one sixth of all software projects are completed on time and within budget, one third of all projects were cancelled and over half were considered "challenged." Citing another 1998 study, they also suggest that this high failure rate is due to managers not taking cautious measures to assess and manage risks involved in software projects. As a response to these discouraging statistics, the discipline of risk management, as applied to software projects, has gained great acceptance among project managers in an attempt to come to terms with and manage the wide variety of risks pertinent to the development of software systems.

Chapman and Ward [4] define project risk as "the implications of the existence of significant uncertainty about the level of project performance achievable." Risks as such are any factors that can affect project performance when this effect is uncertain and significant in its impact, and range from general external factors such as the level of managerial and user commitment to the uncertainty surrounding project scheduling and estimation. If project performance is to be repeatable and predictable, the identification and management of risks must consist of methodical and disciplined processes. A variety of frameworks and methodologies for risk analysis and management have been proposed, qualitative and quantitative, formal and informal.

At best, unchecked project risk relegates forecasts of project cost and duration to the status of guesswork. At worst, unmanaged project risk can lead to a cascade of unforeseen consequences that ultimately dooms the effort altogether. In the absence of an effective risk management process, project managers and their teams continually find themselves engaged in a reactive struggle to fend off the consequences of unmitigated risks, or in the case of sufficiently proactive groups engaged in a haphazard effort to address issues as they are raised by conscientious and forward thinking team members. In either case, it is not possible to achieve the predictable level of project performance required to realize the intended benefits of advanced planning. [1] 
However, the benefits of risk management do not come without a cost. Successful risk management requires time, commitment, and effort on the part of project teams, as well as the support of management. Where an organization's culture tends toward a reactive stance, the associated costs of enacting such a process are formidable, and even a mature organization with proactive management and project teams must exhibit much discipline in order to reap the large-scale benefits of systematic risk management across multiple projects in the long term. [4]

\section{Shortcomings of contemporary solutions}

\section{Qualitative vs. Quantitative methods}

In the words of the British physicist William Kelvin

"I often say that when you can measure what you are speaking about, and express it in numbers, you know something about it; but when you cannot measure it, when you cannot measure it, when you cannot express it in numbers, your knowledge is of meager and unsatisfactory kind; it may be the beginning of knowledge, but you have scarcely, in your thoughts, advanced to the stage of Science, whatever the matter may be."

This quote captures the essence of the central debate in risk management in relation to projects. The widely varying nature of the risks associated with project performance makes it extremely difficult to create a practical and comprehensive theoretical framework for the analysis of risks in a purely quantitative sense [4].

Since the $19^{\text {th }}$ century, there has been significant debate concerning quantitative and qualitative paradigms. Within the physical sciences, methods evolved from the assumptions of logical positivism, which soon became the essence of science, emphasizing the collection and objective verification of "hard" data. Mathematical and statistical methods of analysis, working from probabilistic and inferential assumptions, were utilized to explain, predict, and control phenomena. [11]. 
Given the history of these successful and respected techniques, quantitative risk analysis has enjoyed significant cachet among risk analysis practitioners, in lieu of methods of qualitative risk analysis. The quantitative methods are commonly thought to be more objective, being based on models and metrics, where qualitative methods are clearly more subjective [4].

Despite this, quantitative models with their specifically quantifiable results can result in risk analysts underestimating the interdependency of project risks. Risk exposure metrics, quantitatively or qualitatively arrived at, are undermined by some uncertainties. The perception of risk impact and risk probability is plagued by subjective evaluations and then utilized in formal mathematical operations. This manipulation of such values of indeterminate validity can render such seemingly positivistic results practically unworkable. The quantitative methods of risk analysis are also undermined by an additional factor. Commonly used quantitative techniques marginalize the intuitive considerations creating an "illusion of accuracy", when true accuracy in a positivistic sense is in reality a practical impossibility. In the case of less formal and more subjective qualitative analyses, the quality of decisions is enhanced despite this, since intuitive estimates are certainly a more worthy basis for informed decisions than no estimates of risk exposure at all. [13]

To detail the specifics of the shortcomings of purely quantitative methods further, according to Padayachee [13]:

1. Some types of risks have a general effect on the entire project and cannot be modeled in terms of cause and effect relationships or dependencies.

2. Some risks are not well suited to quantitative representation

3. Even when risks can be quantified, it may be difficult to trace and quantify the effects of their realization with regard to the project as a whole.

4. It is difficult to model the complexities of the actuality of a given risk, leading to oversimplified abstractions.

5. Even though it is possible to consider risks using well-known statistical methods, the lack of historical data regarding most types of risk leads to a lack of credibility when such methods are used, and may lead in some cases to a dangerous illusion of control. 
6. The benefits of utilizing a quantitative method in risk analysis may be outweighed by the costs of utilizing the methodology, in terms of the time and effort required to adequately capture the details required for its valid application.

In light of these issues, many organizations choose a qualitative approach to risk management. Although qualitative analyses may be perceived to lack the legitimacy imparted by purely quantitative methods, which are generally highly esteemed in business and engineering environments, a number of researchers have made a case for its usefulness [4].

\section{Qualitative Methods}

Qualitative methods are generally more intuitive and easily integrated into existing software development processes, and are able to accommodate the complexities of the reality of a project by leveraging the unquantifiable experience of the project team. Advocates of qualitative risk management methods have also pointed out that although a numerical analysis may enjoy a privileged status, all too often the misapplication of quantitative methods, or the overestimation of their accuracy (due in part to the status that such methods enjoy) may result in the mismanagement of risks [4].

Most qualitative risk processes involve roughly the following steps:

1. The organization keeps a checklist of potential project risks that project team members will use as a reference point during their risk management activities. This list is updated and refined over the course of many projects and reflects the accumulated knowledge of the organization regarding project risk.

2. Project team members participate in several sessions of risk identification, where risks pertinent to the project are identified, documented, and assigned a scalar value for the following attributes: probability, priority, and impact on the project.

3. In subsequent sessions, a risk response plan and responsible party are assigned to each risk. The parties so assigned are given the responsibility for addressing the risk in a manner appropriate to the nature of the risk.

4. Throughout the project the identified risks are tracked by project management with the risk owners reporting on the status of their assigned risks. Further sessions of 
risk identification, evaluation, and assignment may take place at various stages of the project in order to manage emerging risks and reevaluate identified risks that have changed or require new management strategies.

According to Chapman and Ward [4], approaches such as this are often taken on the grounds that a 'quick-and-dirty' approach can yield substantial benefits despite its conceptual shortcomings. However they caution that the following are potentially serious shortcomings of this approach:

1. Important interdependencies between risk drivers are not readily highlighted.

2. A list, particularly a long one, provides limited guidance on the relative importance of individual risk drivers.

3. Individual entries may encompass a number of important, separate risk drivers implicitly.

4. Risk drivers not on the list are likely to be ignored.

5. The list of risk drivers may be more appropriate for some projects than others.

6. Individual risk drivers may be described in insufficient detail to avoid ambiguity and varying interpretations.

Despite these shortcomings, this approach remains a viable and attractive option for many organizations for a number of reasons. It is readily acknowledged by most project management practitioners that where more quantitatively rigorous means are not available or practical, it is better to utilize a limited methodology than to have none at all [13]. Most quantitative methods of risk analysis also require a significant level of expertise that may not be available to the organization. The successful utilization of a complicated risk management methodology is also dependent to a great extent upon its viability in the context of a particular organizational culture. With resource and time constraints, project teams are often unwilling or unable to adopt complicated risk processes due to the high overhead in terms of effort or the cultural resistance in reactive project environments. 


\section{Quantitative Methods}

A number of project planning methodologies exist that explicitly utilize primarily quantitative risk analysis methods, most of which are extensions of the PERT methodology, which was developed for use in the US Navy's Polaris Missile projects. The complexity of the Polaris projects was such that the analysis of project dependencies and projection of completion dates required a much more abstract and conceptually sophisticated tool than the simplistic graphical timelines of the Gantt chart. Additionally, the Polaris project was to be completed in the shortest amount of time possible, and due to the nature of research and development (a large component of the Polaris project), it was necessary to utilize a tool that could accommodate activities of indeterminate duration. PERT allows for multiple estimates of completion time, and provides a range of possible completion dates based on a statistical analysis of the most likely completion time ranges for each individual task. This planning technique utilizes an explicitly quantitative model of schedule risks, and is not generally applicable to the majority of risk types identified above, although to a certain extent other risks may be implicit in the selection of probability distributions on a task basis [14].

The statistical distribution upon which PERT is based is known as the Beta distribution. The Beta distribution looks and behaves much like the normal distribution when the realistic time estimate is exactly centered between the optimistic and pessimistic estimates. When the realistic estimate is closer to the optimistic than to the pessimistic, the Beta distribution becomes positively skewed, and when the realistic estimate is closer to the pessimistic than to the optimistic, the Beta distribution becomes negatively skewed. This difference allows a better fit of real-world data to activities than would the normal distribution. When activities that are Beta distributed are summed, the result approaches the normal distribution that can then be used to estimate completion times [14].

According to Chapman and Ward [4], there are several key shortcomings of the basic PERT models. The assumption that the probability distributions of tasks are causally and statistically independent is problematic, and leads to oversimplification of the impact of realized schedule risks. This flaw has been recognized and addressed in the Generalized PERT, which uses embedded decision trees in the PERT network to accommodate causal activity dependencies. Other shortcomings of the model have been addressed through GERT 
(Graphical Evaluation and Review Technique) by employing a Markov process model, to track

the 'state' of the project and rates of progress for specific tasks, to provide more direct estimates of task duration. Another key shortcoming is addressed by the SCERT (Synergistic Contingency Evaluation and Review Technique) approach. This approach takes into account the nature of the risk realized as a prelude to considering effective responses, which involves the embedding of a fault tree or event tree model in a GERT model [14].

Another issue that has been raised regarding these probabilistic planning methods is the fact that the utilization of probability distributions assumes the existence of a sufficiently large sample size for legitimacy. In the absence of historical data related to specific activities such estimations are somewhat suspect in a theoretical sense. This significant concern has been addressed fairly successfully through the use of Monte Carlo simulation techniques also known as "simulation by random sampling". In Monte Carlo simulation, random values are repeatedly generated for each variable in the model, and the outcomes collected, yielding an overall distribution for the simulation, which is then used as a decision tool in evaluating the general viability of the project model.

\section{Difficulties with Historical data}

There are a number of obstacles to the collection of accurate historical data related to projects. The collection, scrubbing, storage, analysis, and reporting of useful historical software project data, is non-trivial and requires among other things, organizational commitment at all levels, full time staffing to support the effort, significant cost increases, and perhaps most unfortunately the collected data will always be suspect for a number of reasons. These factors can be daunting to almost any software development organization, and with the increasing market pressures of the software industry to cut costs and decrease the length of development cycles, such collection and analysis efforts all too frequently must take a back-seat to more immediate and pragmatic considerations. [3]

In a report detailing the lessons learned from 25 years of collecting and analyzing software project data at the NASA Software Engineering Laboratory (SEL) (one of the landmark efforts in the development of useful software project and process metrics), Basili, et al, [3] indicate that their data collection and processing efforts incurred a $10 \%$ overhead cost to 
projects. Collection costs were initially around 5\% and gradually dropped to $1 \%$ to $2 \%$ of development costs, but taking into account the analysis function of the SEL, costs overall remained at approximately 10\%, including analysis, measurement, and report generation.

To summarize the pertinent lessons learned in the SEL study [3]:

1. Data collection requires a rigorous process and professional staff.

2. You must compromise in asking for only as much information as is feasible to obtain.

3. Establishing a baseline of an organization's products, processes, and goals is critical to any improvement program.

4. The accuracy of the measurement data will always be suspect, but you have to learn to live with it and understand its limitations.

5. Having a shared commitment over research and development is vital for success.

6. Having upper management support is important for continued success.

7. Staff training in data collection is a never-ending vigil. As important as data collection is, it still takes second place to deadlines.

With regard to the utilization of existing quantitative positivistic methods, the complications arising from this are clear. Organizations intending to utilize a purely quantitative approach to risk management based on historical data must be willing to incur greater project overhead costs, foster broad organizational support for the collection and utilization of data, dedicate resources to the ongoing task of collection, analysis, reporting and staff training, and possess foresight in the proper measurements to be made. Even organizations willing and able to make the necessary commitments and expenditures must still contend with the likelihood that the data so collected is not entirely accurate.

\section{Addressing the shortcomings}

Importance of human judgment

Mizuno, et al [9] attempted to characterize risky projects using the data sets from previous projects, but were not successful. Initially trying to correlate between software metrics and risky projects and faced with discouraging results, they then changed their approach and attempted a qualitative characterization by acquiring information regarding perceived project 
risk factors from project managers and senior managers. Their questionnaire was designed to capture intuitive knowledge regarding risky projects, and was then distributed to project managers. The responses were collected, subjected to a statistical analysis. Using a logistic regression analysis, the risk assessment data set was used as a basis for a logistic model that was shown to be statistically significant. An analysis of the constructed model showed that it was able to consistently predict risky projects in a new data set.

According to Chelst, in his "Critique of Decision Analysis in Survey Texts" [5], the purpose of a normative model should be to "update the intuition of a decision maker." In applications of models such as linear programming and decision analysis, enhanced insight is the purpose of the study. The structured approach of decision analysis tends to enhance communication and group learning in a group decision-making context. Similarly, Arnott has this to say on the subject of Quantitative Management [2]:

"Quantitative techniques are not magic, they are merely tools. What they can do, whether good, indifferent or downright bad, is introduce much-needed discipline to traditional methods. They are not inherently better than traditional subjective methods. After all, the human brain is a remarkable instrument. It is an analytic tool, capable of assessing the myriad influences on and implications of a thousand variables and factors. Quantitative tools tend to break down when weighing more than a handful of variables."

Another relevant perspective, this time regarding the nature of intelligence in heuristic search, was set forth in the 1975 Turing Award Lecture presented by Allen Newell and Herbert A. Simon [10]. In searching a space of possibilities in a game like chess, programs typically grow enormous search trees. However, the strongest human players rarely examine trees of more than one hundred branches. This economy of effort is achieved by branching sparsely and selectively. From the perspective of heuristic search, this is only possible by exhibiting greater selectivity in generating search possibilities, examining only the branches that are likely to reveal important information about the board position. The nature of intelligent search, they conclude, is not the capability of completely evaluating the space of possibilities, 
but the application of appropriate heuristics in choosing the appropriate possibilities to evaluate.

"The task of intelligence, then, is to avert the ever present threat of the exponential explosion of search. An intelligent system generally needs to supplement the selectivity of its solution generator with other information using techniques to guide search. The quality of performance depends on the characteristics both of the problem domains and of the symbol systems used to tackle them. Even in highly structured areas like linear programming, theory has been much more useful in strengthening the heuristics that underlie the most powerful solutions algorithms than in providing a deep analysis of complexity." [10]

\section{Managing schedule risks with decision support}

The economic pressures of today's software industry, not to mention the increasingly sophisticated nature of software development, mean increased complexity in decision-making processes. Additionally, instantaneous communications make organizational environments less predictable, reducing available time for the examination of data and relationships. Subsequently the data required for an in-depth quantitative analysis is difficult to obtain and quite often the analysis itself is impossible in the time available. Correspondingly, managers find themselves with a greater need for new decision support tools. It has therefore been suggested that decision support tools should allow a symbiosis of quantitative analytical tools with intuitive heuristics to allow insights about complex factors, and such tools can be used to test and verify intuition before decisions are made. 


\section{Methodology \\ Problem Definition}

Despite the sometimes discouraging conclusions of this introduction, one should not conclude that rigorous methods of project analysis and optimization should be discarded wholesale. Significant opportunities exist for the use of quantitative analysis in combination with quantitative and qualitative data, to augment and inform the judgments of project leadership. This paper proposes a framework for the analysis of project schedules and their relationship to project risk, and a description of a practical implementation of that framework. The purpose of this framework is to support structured reasoning and informed decisionmaking with regard to a project model that encompasses both quantitative and qualitative aspects. The implementation of this framework is intended to act as a decision support tool that is capable of providing timely results, cost efficiency, and sufficiently accurate estimates of cost and project time in a variety of projected risk scenarios.

The polarization of existing risk analysis and management techniques into relatively informal qualitative techniques and rigorous probabilistic decision analysis methodologies, is largely focused around two issues - the trade-offs between the two types of approaches in terms of practicality in the context of a variety of organizations and the debate between the relative merits and hazards of the fuzziness of qualitative methods as opposed to the sometimes misleading, although numerically precise, purely quantitative methods. Where quantitative/probabilistic approaches yield significant results at the high level of abstraction required for strategic decision analysis, and qualitative approaches yield significant results by virtue of their ease of use and generic applicability, there yet remains a middle ground where project management might benefit from a more rigorous project risk model than the purely qualitative, that is also more appropriate for support of tactical decisions regarding a project in progress.

The relational project modeling and risk projection framework enables a projection of the consequences of initial project schedules and schedule changes with respect to risk realization in resource-constrained project environments, and the identification of unrecognized schedule risks implied by those schedules. 
The framework proposed in this paper directly addresses the following functional goals:

1. Definition of a robust and flexible model of project-related data

2. Evaluation of project plans in terms of cost and estimated completion time.

3. Integration of relevant qualitative factors that may influence a project schedule.

4. Projection of the effects of realized risks in the context of project schedules, with consideration for contingency plans, and available resources and their skill levels.

5. Determination of a project's expected value with respect to cost and completion time.

The implementation of this framework attempts to present a practical, easy-to-use method to realize these goals. The method will:

1. Utilize straightforward and easily modified data relations as inputs to facilitate the use of existing project data.

2. Automate the construction of project networks from simple task precedence relations.

3. Provide rapid automated evaluation of the project-wide consequences of scheduling decisions.

4. Provide rapid projection of the effects of realized risks.

5. Present the analysis results in visual, numerical, and textual forms to support a variety of cognitive styles.

6. Provide a flexible platform that may be customized to use different heuristics, algorithms, scaling functions, etc.

This method is realized by the PM Eye decision support application, developed to illustrate the framework described in the following sections, and to exhibit the potential applications of the framework as a decision support tool for project managers. Utilizing the framework, PM Eye performs an automated analysis of project schedule data stored in a relational database and provides several analysis views.

\section{Overview of the Relational Project Modeling and Risk Projection Framework Intended usage}

The relational project modeling and risk projection framework is a means of evaluating the impact of risks on project schedules. Project data is considered in a relational form, which 
facilitates the evaluation of the complex attributes, relationships and dependencies of a project environment, acting as a bridge between project complexities and an analysis of the implications of those complexities. The integration of qualitative information about the skill sets of human resources is an important aspect of the framework, and is utilized to more effectively determine the impact of resource assignments in the context of a project schedule.

The framework, in its current form, is not intended as an estimation tool, but rather an augmentation of the reasoning and judgment of project leadership, allowing project managers to rapidly project the consequences of scheduling and staffing decisions in relation to hazards posed by project risk. The more rapidly and readily that decision makers can explore the space of possibilities and probabilities in a dynamic high-pressure environment, the more quickly and efficiently they can seek out improved configurations and deployments of their resources and communicate them to team members and stakeholders.

Much effort has been spent to identify optimal methods of producing optimal schedules and resource allocations, but the existence of an optimal project configuration that can be determined in advance rests upon the assumption that the environment in which that configuration will be communicated and enacted is to a great extent static and uniform. In the contemporary world of software development, such a static and uniform environment is a tenuous assumption.

One might posit that, rather than further developing methods of optimization with respect to a highly abstracted search space, greater gains may be had in some contexts by seeking innovative and structured ways to plumb the possibilities of the project environment by seeking to more closely model the realities of that environment. Because useful and accurate historical data is difficult to obtain, this requires, for the time being at least, the utilization of qualitative data, but it could be argued that the integration of qualitative and quantitative approaches is certainly no worse than the rigorous application of purely quantitative abstractions that fail to adequately capture the reality they seek to describe. 


\section{Scope of Analysis}

The projection of the interactions of project risks with scheduling and assignment decisions, effectively limits the risks that may be evaluated to those whose consequences directly impact the project schedule. For the purpose of illustrating the framework the following types of risks have been evaluated, although, as currently defined, any risk could be accommodated whose contingency plans involve the introduction of new tasks, dummy tasks (to represent delays or new dependencies), reassignment of tasks, or the precedence relationships between tasks.

1. Resource Availability - A critical resource becomes unavailable during the course of the project, in which case the contingency plan consists of reassignment of that resource's tasks to another.

2. External Delay - Introduction of schedule delays by a party external to the project, in which case the contingency plan is simply accommodating the delay in the project schedule.

Analysis steps

An analysis utilizing the project modeling and risk projection framework consists of the following stages:

1. Prepare project relations

2. Generate project risk scenarios

3. Scale task durations

4. Generate the project network

5. Perform CPM Calculations

6. Schedule to resolve resource conflicts

7. Analyze scenario outcomes

\section{Set up the project relations}

As stated previously, the flexibility of a relational representation of a project is well suited to capturing the complex relationships of a project environment. A general overview of the project entities that are to be described and their role in the framework follows, with a more detailed description of the project relations in later sections. The reader will note that there is some divergence in the representation of the relations described in these sections from 
the actual database utilized in the sample implementation of the framework, detailed in Appendix B - Example Database. The discussion of the project relations includes only the essential abstractions, while the actual implementation includes some data necessary for a practical application and makes some allowances for efficiency in the practically applied data model.

\section{Projects}

Projects are the entities that represent the totality of associated tasks, resources, skills, risks, and the relationships between them, and as such, are the subjects of the analysis - and subject to comparison via the analysis with other projects designed to achieve the same goals with the same risks. The projects to be compared may differ in terms of contingency plans, assignments, and tasks, but must be constructed to accomplish the same goals for such comparisons to be meaningful.

\section{Tasks}

Tasks are the basic elements of the project plan, and consist of the work packages that are to be completed during the course of the project. Each task is assigned a resource that possesses the skills required to successfully complete that particular task. Each required skill is assigned a weight, indicating its relative level of importance in successfully completing the task, and an ideal skill level. An idealized duration is also assigned to the task which represents the time taken to complete the task by a resource with a level of expertise in all required skills equal to the respective ideal skill levels mentioned above. Tasks are associated with a particular project, or in the case of the contingency plans corresponding to the project risks, are associated with a particular project and a particular risk. Tasks are also related to each other in addition to their association with a particular project or risk, in the sense that tasks must be given a temporal order, the constraints of which are given by successor relationships, such that a task must be scheduled and completed before all of its successors. It is from this last type of relationship that we are able to create the project network utilized in CPM calculations discussed in later sections.

\section{Resources and skills}

Resources are participants in the project, possessing skills that are brought to bear in the completion of tasks to which they are assigned. Their level of expertise in each skill is 
relevant in our analysis, and determine, to some extent, the actual duration of the tasks to which they are assigned. The assigned resource may affect the actual duration of their assigned tasks in the sense that being deficient or expert in the required skills will correspondingly influence positively or negatively the actual time taken to effectively complete the task - as opposed to the ideal duration of the task as described above.

\section{Risks}

In terms of our relational model, risks are entities which represent the potential for disruptions in the original conception of the project. Each risk is assigned a probability of occurrence and is associated with a particular project. The consequences of a realized risk are characterized as a contingency plan, which is in turn defined in terms of additional tasks to be completed, delays to be accommodated, assignments of resources to tasks, and changing precedence relationships between the tasks. The contingency plans are essentially a modification of the original project plan in order to accommodate or mitigate the disruption introduced by the realization of the associated risk.

\section{Generate project risk scenarios}

Project risks may be realized in various combinations, assuming that they are not mutually exclusive, and so we may define a set of risk scenarios that represent the various combinations of risk that could be realized during the course of a project. Each of these scenarios is assigned a probability, defined as the probability that the risks included in the scenario are realized and only those risks. Each scenario is also associated with a transformation of the original conception of the project to accommodate the contingency plans associated with the risks included in the scenario.

\section{Scale task durations}

At this stage of the analysis, the tasks and task assignments included in the risk scenarios for the project being analyzed have been determined, and it becomes possible to project the actual completion time of the included tasks. As described above, a resource assigned to a task possesses a set of skills with corresponding levels of personal expertise that affect the actual completion time of a task, diverging from the idealized duration of the task. By considering the skill's 'weight', or relative level of importance, and the difference between the ideal skill-level for that task, it is possible to project a reasonable estimate of the actual task 
duration. This divergence from the idealized durations of the tasks, as a consequence of the actual assignments corresponding to a particular risk scenario, allows us to project the effect of a set of realized risks with a greater sense of realism.

\section{Generate the project network and perform CPM calculations}

The task precedence relations defined for each risk scenario enables the generation of a project network that captures these relationships and is to be utilized in the CPM calculations necessary for creation of a project schedule that accommodates the contingency plans for each risk in the scenarios. The project networks is an acyclical directed graph, wherein each task is represented as an edge between nodes of the graph, and assigned attributes designating the duration, and start time and finish time for that task. For a detailed discussion of project networks, which is beyond the scope of this paper, the reader may consult the work of Weist and Levy [14]. Several effective project network creation algorithms exist and the reader is referred to the work of Fisher, et al [7] for a more detailed treatment of the problem. The selection of an appropriate algorithm to accomplish this stage of the analysis is largely a matter of implementation, and is thus not included in the discussion. The PM Eye implementation of the analysis framework described here utilizes the algorithm described by Fisher [7].

\section{Schedule to resolve resource conflicts}

It is in this stage that the consequences of the realized risks in each scenario are played out in terms of an actual schedule for the included tasks. Assuming that multitasking decreases the efficiency of a resource, tasks that are concurrently assigned to the same resource must be rescheduled to preserve that resources productivity rate and the consequences of that rescheduling throughout the project must be resolved. Although some adjustments to the productivity rate of a resource over the time span where they are required to multitask might be utilized to model this effect, doing so would incur greater computational costs, and with little advantage, since it is generally accepted that multitasking will involve a greater time penalty than temporally contiguous assignments.

The generation of a reasonably time-efficient schedule has received significant attention in the disciplines of management science and operations research, and the reader is referred to Elsayed and Nasr [6] for further information on this topic. Again the selection of an appropriate scheduling algorithm is primarily a matter of implementation, and beyond the 
scope of this paper. The PM Eye implementation, utilizes the relatively simplistic MINSLK scheduling heuristic which gives scheduling preference to tasks with less schedule slack, although more evolved implementations could provide heuristics of greater sophistication. The MINSLK heuristic was deemed adequate for illustrative purposes and ease of implementation at this early stage of development of the decision support tool.

\section{Analyze scenario outcomes}

The final stage of the analysis is the determination the project costs and completion times for each risk scenario, which are then used to create cost and time distributions for the project as whole. Since each project cost and project completion time are possible outcomes of the project and have an associated probability, which are the probabilities of the associated scenarios, the definitions of the cost and time distributions follow naturally. Given these distributions, expected values for cost and time can be determined readily.

\section{Project comparisons}

As stated previously, projects with identical goals and identical risks may be compared readily. There are comparable risk scenarios for each project and the efficiency of each scenario in terms of time and cost may be evaluated by comparing the time and cost outcomes associated with those scenarios. In addition, the relative merit of each project across all scenarios may be evaluated via a comparison of the expected time and cost values, which are determined by the distributions of the scenario outcomes. In all cases it may be assumed that lower completion times and costs are preferable, and an ordering of the projects or scenarios by those criteria can be considered an acceptable determination of a particular project's relative utility. 


\section{Results}

\section{The PM Eye Framework Implementation}

The PM Eye application was developed for Microsoft Win32 platforms with the ActiveState ActivePerl 5.8 Implementation of the Perl programming language and a Microsoft Access 2000 ODBC database. The graphical user interface was implemented using the Perl/Tk GUI toolkit. Project network visualization was made possible with the GraphViz 1.10 binary distribution for Win32 platforms.

Other publicly available Perl Modules utilized in the PM Eye Application include:

1. DBI

2. Data::Dumper

3. Graph::Directed

4. Tk::Graph

5. Tk::NoteBook

6. Tk::ProgressBar

7. Tk::Pane

PM Eye consists of the following software components:

1. Project Database - Stores multiple projects and their related tasks, resources, task relationships, project risks, and contingency plans, etc.

2. Event Driven GUI - Interface to database, analysis, and display functionality. Built using the Perl/Tk GUI toolkit.

3. Analysis Functions - Interacts with a relational database of project data. Automatically prepares projections of project risk scenarios from project data relations, and calculates the scenarios' probabilities, minimum times and costs, as well as the expected value of the project across all projected scenarios.

4. Graphing Module - Creates a graph representation of project schedules utilizing an algorithm developed by A.C.Fisher et al [7].

5. Scheduling Module - Assigns start times and calculates the critical path of schedules using standard CPM (Critical Path Method) calculations [14]. 
6. Set Manipulation Module - Provides set relationship and manipulation functions, utilized throughout the other modules and main program.

For simplicity of implementation and demonstration, the version of PM Eye developed to illustrate the Schedule Analysis Framework uses several computational simplifications of a project environment. A practical implementation of the framework would require a more detailed treatment of the environment; however, they are inessential to illustration of the central concepts of the framework.

1. Eight hour work day - A work day is assumed to consist of eight man-hours per resource, and the idealized durations of tasks are measured in units of one work day.

2. Contiguous work days - Project time is assumed to be uninterrupted, with resources working on tasks through a single eight hour shift over contiguous working days.

3. Uniform resource calendar - All resources are assumed to be available on all working days throughout the duration of the project.

4. One-to-one resource-task assignments - Tasks are assumed to have one and only one assigned resource throughout their duration.

5. Utilization of MINSLK scheduling heuristic - There are a number of scheduling heuristics that might be utilized for the purposes of a decision support application. The MINSLK heuristic, which prioritizes tasks to be scheduled by increasing total slack as determined by standard CPM network calculations, was chosen for its simplicity and speed.

\section{Essential Concepts}

Project Plan

A project plan is defined as:

1. A set of tasks and corresponding task durations.

2. The precedence relationships of the tasks

3. The resources assigned to complete the tasks, their compensation rates, and their levels of skill in their areas of expertise.

4. The risks associated with the project and their probabilities

5. The contingency plans associated with the project risks 


\section{Project}

A project is a tuple of the relation schema Project (P\#, PNAME) with primary key P\#.

1. P\# - unique project identifier

2. PNAME - Project Name

\begin{tabular}{|c|c|}
\hline P\# & PNAME \\
\hline 1 & $\mathrm{p} 1$ \\
\hline 2 & $\mathrm{p} 2$ \\
\hline
\end{tabular}

Figure 3-1 Example of the Project relation

Risks

A risk is a tuple of the relation schema Risk ( RK\#, P\#, RKNAME, PROB ) with primary key RK\#.

1. RK\# - unique risk identifier

2. P\#-project associated with the risk

3. RKNAME - risk name

4. PROB - probability of the risk's occurrence

\begin{tabular}{|c|c|c|c|}
\hline RK\# & P\# & RKNAME & PROB \\
\hline 1 & 1 & rk1 & 0.2 \\
\hline 2 & 1 & rk2 & 0.5 \\
\hline
\end{tabular}

Figure 3-2 Example of the Risk Relation

\section{Resources}

A resource is a tuple of the relation schema Resource (R\#, RNAME, RATE) with primary key

$\mathrm{R} \#$

1. $\mathrm{R} \#$ - unique resource identifier

2. RNAME - Resource Name

3. RATE - Billable rate of the resource in dollars per hour 


\begin{tabular}{|c|c|c|}
\hline R\# & RNAME & RATE \\
\hline 1 & $\mathrm{r} 1$ & $\$ 35$ \\
\hline 2 & $\mathrm{r} 2$ & $\$ 40$ \\
\hline
\end{tabular}

Figure 3-3 Example of the Resource Relation

\section{Skills}

A skill is a tuple of the relation schema Skill(S\#, SNAME) with primary key S\#

1. S\# - unique resource identifier

2. SNAME - skill name

\begin{tabular}{|c|c|}
\hline S\# & SNAME \\
\hline 1 & $\mathrm{~s} 1$ \\
\hline 2 & $\mathrm{~s} 2$ \\
\hline
\end{tabular}

Figure 3-4 Example of the Skill Relation

Tasks

A task is a tuple of the relation schema Task (T\#, P\#, PTID, TNAME, TDUR, RK\#) with primary key $\mathrm{T} \#$

1. T\# - unique task identifier

2. P\# - project associated with the task

3. PTID - task identifier relative to the associated project

4. TNAME - task name

5. TDUR - task duration in idealized work units

6. RK\# - risk associated with the task if it is designated as part of a contingency plan. 


\begin{tabular}{|c|c|c|c|c|c|}
\hline T\# & P\# & PTID & TNAME & TDUR & RK\# \\
\hline 1 & 1 & 1 & $\mathrm{a}$ & 1 & \\
\hline 2 & 1 & 2 & $\mathrm{~b}$ & 1 & \\
\hline 3 & 1 & 3 & $\mathrm{c}$ & 1 & \\
\hline 4 & 1 & 4 & $\mathrm{~d}$ & 1 & \\
\hline 5 & 1 & 5 & $\mathrm{e}$ & 1 & 1 \\
\hline 6 & 2 & 1 & $\mathrm{f}$ & 1 & \\
\hline 7 & 2 & 2 & $\mathrm{~g}$ & 1 & \\
\hline 8 & 3 & 1 & $\mathrm{~h}$ & 1 & \\
\hline 9 & 3 & 2 & $\mathrm{l}$ & 1 & \\
\hline
\end{tabular}

Figure 3-5 Example of the Task Relation

\section{Precedence Relationships}

A task is a tuple of the relation schema TRel (TR\#, P\#, PTID, TSUCC, RK\#) with primary key TR\#

1. TR\# - unique task relationship identifier

2. P\# - project associated with the task relationship

3. PTID - task identifier relative to the associated project

4. TSUCC - task identifier of a successor task in the associated project

5. RK\# - risk identifier indicating that the relationship belongs to a contingency plan associated with the project.

\begin{tabular}{|c|c|c|c|c|}
\hline TR\# & P\# & PTID & TSUCC & RK\# \\
\hline 1 & 1 & 1 & 2 & \\
\hline 2 & 1 & 2 & 4 & \\
\hline 3 & 1 & 3 & & \\
\hline 4 & 1 & 4 & & \\
\hline 5 & 1 & 4 & 5 & 1 \\
\hline 6 & 1 & 5 & & 1 \\
\hline 7 & 2 & 1 & 2 & \\
\hline 8 & 2 & 2 & & \\
\hline 9 & 3 & 1 & 2 & \\
\hline 10 & 3 & 2 & & \\
\hline
\end{tabular}

Figure 3-6 Example of the TRel Relation 


\section{Assignments}

An assignment is a tuple of the relation schema Assign (P\#, PTID, R\#, RK\#) with primary key $\{$ P\#, PTID, R\#\}

1. P\# - project associated with the assignment

2. PTID - task identifier of the task to be assigned relative to the associated project

3. $\mathrm{R} \#$ - resource identifier of the resource assigned to the task

4. RK\# - risk identifier indicating that this assignment belongs to a contingency plan associated with the project

\begin{tabular}{|c|c|c|c|}
\hline P\# & PTID & R\# & RK\# \\
\hline 1 & 1 & 1 & \\
\hline 1 & 2 & 2 & \\
\hline 1 & 3 & 1 & \\
\hline 1 & 4 & 2 & \\
\hline 1 & 2 & 1 & 2 \\
\hline 1 & 5 & 2 & 1 \\
\hline 2 & 1 & 1 & \\
\hline 2 & 2 & 2 & \\
\hline 3 & 1 & 1 & \\
\hline 3 & 2 & 2 & \\
\hline
\end{tabular}

Figure 3-7 Example of the Assign Relation

\section{Resource Skills}

A resource skill is a tuple of the relation schema RSkill(R\#, S\#, SKLVL) with primary key $\{\mathrm{R} \#, \mathrm{~S} \#\}$

1. R\# - identifier of the resource possessing the skill

2. S\# - identifier of the skill possessed by the resource

3. SKLVL - the level of the resource's expertise in the skill

\begin{tabular}{|c|c|c|}
\hline R\# & S\# & SKLVL \\
\hline 1 & 1 & 4 \\
\hline 1 & 2 & 3 \\
\hline 2 & 1 & 2 \\
\hline 2 & 2 & 5 \\
\hline
\end{tabular}

Figure 3-8 Example of the RSkill Relation 


\section{Required Skills}

A required skill for a task is a tuple of the relation schema

TSkill (P\#, PTID, S\#, TSLVL, WEIGHT) with primary key $\{$ P\#, PTID, S\# $\}$

1. $\mathrm{P \#} \mathrm{-} \mathrm{project} \mathrm{associated} \mathrm{with} \mathrm{the} \mathrm{skill} \mathrm{requirement}$

2. PTID - identifier of the task for which the skill is required.

3. $\mathrm{S \#} \mathrm{-} \mathrm{identifier} \mathrm{of} \mathrm{the} \mathrm{required} \mathrm{skill}$

4. TSLVL - the ideal skill level for a resource assigned to this task

5. WEIGHT - the relative importance of this skill for the successful completion of the task.

\begin{tabular}{|c|c|c|c|c|}
\hline P\# & PTID & S\# & TSLVL & WEIGHT \\
\hline 2 & 1 & 1 & 3 & 1 \\
\hline 2 & 2 & 1 & 4 & 1 \\
\hline
\end{tabular}

Figure 3-9 Example of the TSkill Relation

\section{Risk Scenarios}

Given a set of risks associated with a project, the project's risk scenarios represent the potential combination of realized risks during the course of the project. The risk scenarios are then members of risk set's power set, and represent situations where a subset of the risks are realized. For example:

Recalling the relation schema Risk ( RK\#, P\#, RKNAME, PROB ), consider the project $\mathrm{p}_{1}$ with identifier ' 1 ' and set of risk identifiers

$$
\mathrm{RK}_{1}=\{1,2\}=\{\mathrm{a} \mid(\exists \mathrm{b})(\exists \mathrm{c})(\exists \mathrm{d}) \operatorname{Risk}(\mathrm{abcd}) \wedge \mathrm{b}=1\}
$$

The set of risk scenarios $\mathrm{RS}_{1}$ is then the power set of $\mathrm{RK}_{1}$

$$
\mathrm{RS}_{1}=* \mathrm{RK}_{1}=\{\varnothing,\{1\},\{2\},\{1,2\}\}
$$


The element $\varnothing$ of the power set corresponds to the situation where no project risks are realized. Element $\{1\}$ corresponds the situation where only risk ' 1 ' is realized, $\{1,2\}$ to the situation where ' 1 ' and '2' are realized, etc. We define a mapping function $\operatorname{prob}(\mathrm{x})=\mathrm{y}$, with $\mathrm{x} \in \mathrm{RK}_{1}$ indicating the probability of risk $\mathrm{x}$ occurring during the course of the project given by:

$\{\mathrm{xy} \mid(\exists \mathrm{w})(\exists \mathrm{z}) \operatorname{Risks}(\mathrm{xwzy})\}$

A risk scenario is a set $S_{i} \in * R K_{1}$. Let $S_{1}=\varnothing$, corresponding to the base scenario with no realized risks. Let $\mathrm{S}_{\mathrm{i}}{ }^{\prime}=\left\{\mathrm{r} \mid \mathrm{r} \in \mathrm{RK}_{1}-\mathrm{S}_{\mathrm{i}}\right\}$. We then define the function $\operatorname{sprob}\left(\mathrm{S}_{\mathrm{i}}\right)$, $\mathrm{S}_{\mathrm{i}} \in * \mathrm{RK}_{1}$, the probability of a scenario's occurrence, given by:

$\operatorname{sprob}\left(\mathrm{S}_{\mathrm{i}}\right)=\Pi_{\mathrm{r} \in \mathrm{Si}} \operatorname{prob}(\mathrm{r}) * \Pi_{\mathrm{t} \in \mathrm{Si}^{\prime}} 1-\operatorname{prob}(\mathrm{t})$

The probability of the base scenario is a special case notated as

$\operatorname{sprob}\left(\mathrm{S}_{1}\right)=1-\sum_{\mathrm{i}>1} \operatorname{sprob}\left(\mathrm{S}_{\mathrm{i}}\right)$

\section{Contingency Plans}

For each risk associated with a project, contingency plans may be defined in order to reassign resources to different tasks, redefine existing tasks, alter the task precedence relationships, and/or add additional tasks to the project. The tasks, assignments, and task relationships of the contingency plans coexist with those of the base scenario in the relations and are distinguished by an association with a particular risk.

Consequently, we may define a transformation of the original project plan associated with each risk scenario, which includes additional tasks, task relationships, task-skill relationships, and reassignments, and may or may not involve the modification of existing tasks. Potentially distinct precedence, task, and assignment relations exist for each risk scenario defined for a project. 
Let $\mathrm{p}$ be a project identifier. Let $\mathrm{T}_{\mathrm{i}}, \mathrm{A}_{\mathrm{i}}, \mathrm{TR}_{\mathrm{i}}$, and $\mathrm{TS}_{\mathrm{i}}$ be the task, assignment, task precedence relations, and task skill relations defined for $\mathrm{S}_{\mathrm{i}}$, with schemas:

1. $\mathrm{T}_{\mathrm{i}}$ ( PTID, TNAME, TDUR)

2. $\mathrm{A}_{\mathrm{i}}(\mathrm{PTID}, \mathrm{R} \#)$

3. $\mathrm{TR}_{\mathrm{i}}$ ( PTID, TSUCC )

4. TS $_{\mathrm{i}}(\mathrm{PTID}, \mathrm{S} \#$, TSLVL, WEIGHT)

Recalling the relation schema Task (T\#, P\#, PTID, TNAME, TDUR, RK\#):

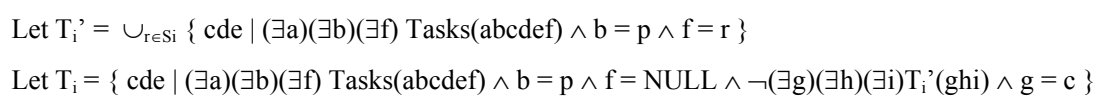

Recall the relation schema Assign (P\#, PTID, R\#, RK\#):

$$
\begin{aligned}
& \text { Let } A_{i}{ }^{\prime}=\cup_{r \in S i}\{b c \mid(\exists a)(\exists d) \text { Assign }(a b c d) \wedge a=p \wedge d=r\} \\
& \text { Let } A_{i}=\left\{b c \mid(\exists a)(\exists d) \text { Assign }(a b c d) \wedge a=p \wedge d=N U L L \wedge \neg(\exists e)(\exists f) A_{i}{ }^{\prime}(e f) \wedge e=b\right\}
\end{aligned}
$$

Recalling the relation schema TRel (TR\#, P\#, PTID, TSUCC, RK\#):

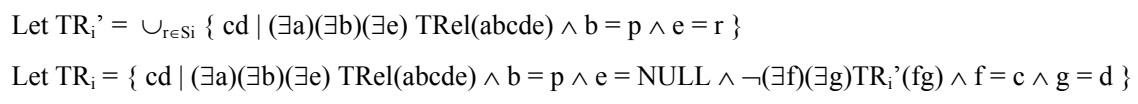

Recall the relation schema TSkill (P\#, PTID, S\#, TSLVL, WEIGHT):

Let $\operatorname{TS}_{\mathrm{i}}=\{$ bcde $\mid(\exists \mathrm{a}) \operatorname{TSkill}($ abcde $) \wedge \mathrm{a}=\mathrm{p}\}$

\section{Scaling Task Durations}

A number of methods might be proposed to scale tasks according to the skill levels of the assigned resource, and furthermore, other alternatives of task scaling that do not rely exclusively on such criteria are certainly possible. The method proposed here utilizes qualitative assessments of both a resource's level of expertise and the ideal skill level required to preserve the initial idealized estimate of the tasks duration as an actual duration, but more sophisticated methods could feasibly be developed that utilize some objective measure of skill 
(determined by testing or performance reviews) and historical data used to develop objectively defined relationships between levels of expertise and the work efficiency in certain types of tasks. The limitations of such approaches in general and the deficiencies of standardized testing in particular are well known, but could provide some benefit in this context.

The means suggested here are admittedly simplistic, and were developed with the intent of illustrating the possibilities of such an approach, rather than defining a canonical methodology for such evaluations. Practical implementations of this framework might include some facility for the definition of customizable functions to determine scaling functions, or at least provide the user with a rich feature set that enables the selection of the most appropriate function for a particular context. Practical implementations might also provide a high level of granularity in the application of the possible scaling functions, determining which tasks may be scaled and the specific method of scaling deemed appropriate for that type of task.

For our purposes of illustration, we propose the calculation of a general scaling factor for each task which is then applied to the ideal duration of the task. Scaling factors are calculated for each of a task's required skills and are weighted according to the relative importance of that skill. The unweighted scaling factors are proportional to the difference between the ideal skill level defined for the task and the level of expertise in that skill possessed by the assigned resource. The weighted scaling factors are then summed to produce a general scaling factor for the task.

In our example, we define the range of skill levels for tasks and resources alike as the integers $1 . .5$ with 1 representing beginner status, 5 representing expert status, and the others representing proportionately distributed intermediate skill levels between these extremes. The choice of a range of skill levels in this discussion is arbitrary, and could be substituted with others of a finer level of granularity.

Given the relations of a risk scenario's tasks $T_{i}$ and assignments $A_{i}$, and the relation of resources to skills RSkill and tasks to skills TSkill as described above, we proceed as follows.

Recall the relation schemas: 
1. RSkill(R\#, S\#, SKLVL)

2. $\mathrm{T}_{\mathrm{i}}$ (PTID, TNAME, TDUR)

3. $\mathrm{A}_{\mathrm{i}}(\mathrm{PTID}, \mathrm{R \#})$

4. TS $_{\mathrm{i}}(\mathrm{PTID}, \mathrm{S} \#$, TSLVL, WEIGHT)

We first define a function $\mathrm{f}(\mathrm{x})=\mathrm{y}$, such that $\mathrm{x}$ is the difference between a task's required skill level for a particular skill and the assigned resource's level of expertise for that skill. $\mathrm{f}(\mathrm{x})=\mathrm{y}$ is given by:

$\{x y \mid y=1.25$ if $x>0, y=0.75$ if $x<0, y=1.0$ if $x=0)$

Again this choice of scaling functions serves a primarily illustrative purpose, and translates to the assumption that resources working on a task above or below their skill level will take $25 \%$ longer or shorter than an ideally skillful resource.

We now define a weighted scaling factor function, wsfactor $(\mathrm{x}, \mathrm{y})=\mathrm{z}$ such that $\mathrm{x}$ is a project task ID in the task relation $\mathrm{T}_{\mathrm{i}}$, and $\mathrm{y}$ is skill ID in $\mathrm{TS}_{\mathrm{i}}$, and defined by the relation given by

$\left\{\mathrm{xyz} \mid(\exists \mathrm{a})(\exists \mathrm{b})(\exists \mathrm{c})(\exists \mathrm{d})\left(\mathrm{A}_{\mathrm{i}}(\mathrm{xa}) \wedge \operatorname{RSkill}(\mathrm{ayb}) \wedge \mathrm{TS}_{\mathrm{i}}(\mathrm{xycd}) \wedge \mathrm{z}=\mathrm{d} * \mathrm{f}(\mathrm{c}-\mathrm{b})\right)\right\}$

Let $\mathrm{X}_{\mathrm{i}}=\left\{\mathrm{xy} \mid(\exists \mathrm{a})(\exists \mathrm{b}) \mathrm{TS}_{\mathrm{i}}(\mathrm{xyab})\right\}$. We define the general scaling function $\operatorname{gfactor}(\mathrm{x})=\mathrm{y}$, where $\mathrm{x}$ is a project task ID in $\mathrm{T}_{\mathrm{i}}$, given by:

$\operatorname{gfactor}(\mathrm{x})=\sum_{\mathrm{z} \in\{\mathrm{z} \mid \mathrm{Xi}(\mathrm{xz})\}}$ wsfactor(x,y)

Finally we can define the relation of scaled tasks $\mathrm{T}_{\mathrm{i}}^{\text {scaled }}$ with schema $\mathrm{T}_{\mathrm{i}}^{\text {scaled }}$ ( PTID, TNAME, TDUR ) given by:

$$
\mathrm{T}_{\mathrm{i}}^{\text {scaled }}=\{\mathrm{xyz} \mid(\exists \mathrm{a}) \operatorname{Ti}(\mathrm{xya}) \wedge \mathrm{z}=\operatorname{gfactor}(\mathrm{x}) * \mathrm{a}\}
$$




\section{Project Networks}

For each risk scenario $S_{i}$, we may construct a project network $G_{i}$ from the task relationships relation $\mathrm{TR}_{\mathrm{i}}$. For a description of an algorithmic means of creating a project network see Computer Construction of Project Networks, Fisher, et al [7]. The inputs to Fisher's algorithm can be readily prepared by means of the $\mathrm{TR}_{\mathrm{i}}$ relation described above. For the purposes of this discussion, we will assume $\mathrm{G}_{\mathrm{i}}$ to be a CPM project network capturing the task relationships defined in the relation $\mathrm{TR}_{\mathrm{i}}$.

\section{Project Schedule}

For each risk scenario $S_{i}$, we may also construct a project schedule which is a relation Schedule $_{\mathrm{i}}$ defined as follows:

Schedule $_{\mathrm{i}}$ (PTID, ES, EF)

1. PTID - task identifier relative to the associated project

2. ES - early start time of the task

3. EF - early finish time of the task

The creation of an appropriate schedule relation may be accomplished by a number of means, which are outside the scope of this discussion. For a description of relevant scheduling methods see Heuristics for Resource Constrained Scheduling, Elsayed and Nasr [6].

For our purposes, we assume that the schedule produced is constrained such that a resource may not have more than one task assigned at any given time during the project.

\section{Time and Cost}

There is a minimum cost and a minimum time associated with each risk scenario. In order to calculate the cost we first define the mapping functions assignment $(\mathrm{x})=\mathrm{y}$ where $\mathrm{x}$ is $\mathrm{a}$ task identifier, $\operatorname{rate}(\mathrm{x})=\mathrm{y}$ where $\mathrm{x}$ is a resource identifier, and duration $(\mathrm{x})=\mathrm{y}$ where $\mathrm{x}$ is $\mathrm{a}$ project task identifier.

Recalling the relation schemas...

1. Resource(R\#, RNAME, RATE) 
2. $\mathrm{A}_{\mathrm{i}}(\mathrm{PTID}, \mathrm{R} \#)$

3. $\mathrm{T}_{\mathrm{i}}$ ( PTID, TNAME, TDUR)

4. Schedule $_{i}$ (PTID, ES, EF )

We specify Assignment $(\mathrm{x})=\mathrm{y}$ with the relation $\left\{\mathrm{xy} \mid \mathrm{A}_{\mathrm{i}}(\mathrm{xy})\right\}$, Rate $(\mathrm{x})=\mathrm{y}$ with the relation $\{x y \mid(\exists z) \operatorname{Resource}(x z y)\}$ and $\operatorname{Duration}(\mathrm{x})=\mathrm{y}$ with the relation $\left\{\mathrm{xy} \mid(\exists \mathrm{z}) \mathrm{T}_{\mathrm{i}}(\mathrm{xzy})\right\}$.

Let $\mathrm{U}_{\mathrm{i}}$ be the set of task identifiers of tasks in the schedule relation Schedule $\mathrm{i}_{\mathrm{i}}$, given by $\mathrm{U}_{\mathrm{i}}=\left\{\mathrm{u} \mid(\exists \mathrm{v})(\exists \mathrm{w})\right.$ Schedule $\left._{\mathrm{i}}(\mathrm{uvw})\right\}$. Let $\mathrm{V}_{\mathrm{i}}$ be the set of the early finishes of all tasks in the schedule, Schedule ${ }_{\mathrm{i}}$, given by $\mathrm{V}_{\mathrm{i}}=\left\{\mathrm{v} \mid(\exists \mathrm{t})(\exists \mathrm{u})\right.$ Schedule $\left._{\mathrm{i}}(\mathrm{tuv})\right\}$. Let $\mathrm{w}$ be the number of hours in a work unit (e.g. $w=8$ for an eight hour work day using days as the work unit)

The cost of the risk scenario's schedule can now be defined as follows:

$\operatorname{cost}\left(\mathrm{S}_{\mathrm{i}}\right)=\sum_{\mathrm{u} \in \mathrm{Ui}} \operatorname{Rate}(\operatorname{Assignment}(\mathrm{u})) * \operatorname{duration}(\mathrm{u}) * \mathrm{w}$

$\operatorname{time}\left(\mathrm{S}_{\mathrm{i}}\right)=\max \left(\mathrm{V}_{\mathrm{i}}\right)$

\section{Comparison of Project Plans}

Different project plans can be created to achieve the same goal. These plans may consist of different tasks, resources, and assignments. Discrete, non-uniform, minimum time and minimum cost distributions can be created for a project plan and its risk scenarios, since each scenario is a discrete event with an associated probability. Subsequently, project plans designed to achieve the same goal can be compared, by calculating and comparing the expected value of the plans (across all risk scenarios) with respect to minimum time and cost.

An analysis of a project schedule with defined risks and established contingency plans for realized risks can be characterized as a problem in decision making under uncertainty with the opponents being the project manager given a set of possible project plans (of which the project manager must choose one) as pure strategies, and the state of nature being a combinatorial enumeration of the realized risks. Arranged in a table with the project plans on one axis with the risk scenarios on the other (Table 3-1), the intersections represent the 
outcomes of utilizing a specific schedule in opposition to a specific combination of realized risks. In game theoretical terms, each possible outcome may be assigned a utility ranking, based on the estimates of cost and/or completion time for that combination [12].

Table 3-1 Cost outcomes of two projects with four risk scenarios

\begin{tabular}{|c|c|c|c|c|}
\hline & S1 & S2 & S3 & S4 \\
\hline Project 1 & $\$ 20,000$ & $\$ 25,000$ & $\$ 22,000$ & $\$ 28,000$ \\
\hline Project 2 & $\$ 19,000$ & $\$ 22,000$ & $\$ 20,000$ & $\$ 25,000$ \\
\hline
\end{tabular}

We can now calculate the expected value of a project $\mathrm{p}$, with set of risks $\mathrm{RK}^{\mathrm{p}}$ and risk scenarios $\mathrm{RS}^{\mathrm{p}}=\left\{\mathrm{S}_{\mathrm{i}} \mid \mathrm{S}_{\mathrm{i}} \in * \mathrm{RK}^{\mathrm{p}}\right\}$. The expected project time EVT(p) is given by

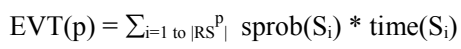

and similarly the expected project cost $\mathrm{EVC}(\mathrm{p})$ is given by

$\operatorname{EVC}(\mathrm{p})=\sum_{\mathrm{i}=1 \text { to } \mid \mathrm{RS}}{ }^{\mathrm{p}} \mid \operatorname{sprob}\left(\mathrm{S}_{\mathrm{i}}\right) * \operatorname{cost}\left(\mathrm{S}_{\mathrm{i}}\right)$

Project x may be considered 'preferred' over a project y if $\operatorname{EVT}(\mathrm{x})<\operatorname{EVT}(\mathrm{y})$ or $\mathrm{EVC}(\mathrm{x})<\mathrm{EVC}(\mathrm{y})$ if project time or project cost is deemed more significant, respectively. 


\section{Discussion}

\section{Analysis Example Utilizing the PM Eye Application}

Consider the following project scenario: A consulting company has contracted to design and develop a simple client-server database application. The project manager has estimated the tasks and assignments listed in Table 4-1. Required skills and ideal skill levels for the tasks are listed in Table 4-2. Available staff members for the project and their skills are listed in Table 4-3.

Table 4-1 Tasks and Assignments

\begin{tabular}{|l|l|}
\hline \multicolumn{1}{|c|}{ Task } & Assigned Resource \\
\hline Requirements Elicitation & Business Analyst \\
\hline Design & System Architect \\
\hline Specifications & System Architect \\
\hline Build Server Development Environment & System Administrator \\
\hline Build Testing and Integration Environment & System Administrator \\
\hline Develop Data Model & DBA A \\
\hline Prepare Test Data & DBA A \\
\hline Prepare Database Scripts & DBA A \\
\hline Create Test Database & DBA A \\
\hline Develop Stored Procedures & DBA A \\
\hline Client GUI Interface Design & GUI Designer \\
\hline Implement Server Daemon & Programmer A \\
\hline Implement Server Database Access Layer & Programmer A \\
\hline Implement Transaction Handlers & Programmer A \\
\hline Server Unit Testing and Debugging & Programmer A \\
\hline Client Server Integration & Programmer A \\
\hline Client Server Testing and Debugging & Programmer A \\
\hline Implement Client Application Framework & Programmer B \\
\hline Implement Simulated Client Server Communication & Programmer B \\
\hline Implement Core Client Objects & Programmer B \\
\hline Client Component Integration & Programmer B \\
\hline Client Unit Testing and Debugging & Programmer B \\
\hline Implement Client Network Communications & Programmer C \\
\hline Implement Client GUI & Programmer D \\
\hline Quality Assurance Testing & QA \\
\hline & \\
\hline
\end{tabular}


Table 4-2 Skill Requirements

\begin{tabular}{|c|c|c|c|}
\hline Task & Skills & Weight & Ideal Skill Level \\
\hline \multirow[t]{2}{*}{ Requirements Elicitation } & UML & 0.2 & 3 \\
\hline & Requirements Analysis & 0.8 & 3 \\
\hline \multirow[t]{4}{*}{ Design } & Data Modeling & 0.1 & 2 \\
\hline & Systems Analysis & 0.4 & 4 \\
\hline & UML & 0.1 & 4 \\
\hline & Requirements Analysis & 0.4 & 4 \\
\hline \multirow[t]{4}{*}{ Specifications } & UML & 0.2 & 4 \\
\hline & Data Modeling & 0.1 & 2 \\
\hline & Requirements Analysis & 0.4 & 4 \\
\hline & Systems Analysis & 0.3 & 4 \\
\hline \multirow[t]{4}{*}{ Build Server Development Environment } & Oracle $9 \mathrm{i}$ & 0.1 & 3 \\
\hline & UNIX & 0.4 & 3 \\
\hline & Server Hardware & 0.4 & 3 \\
\hline & Networking & 0.1 & 3 \\
\hline \multirow[t]{4}{*}{ Build Testing and Integration Environment } & Server Hardware & 0.4 & 3 \\
\hline & Networking & 0.1 & 3 \\
\hline & UNIX & 0.4 & 3 \\
\hline & Oracle $9 \mathrm{i}$ & 0.1 & 3 \\
\hline \multirow[t]{6}{*}{ Develop Data Model } & Oracle $9 \mathrm{i}$ & 0.2 & 4 \\
\hline & PL/SQL & 0.2 & 4 \\
\hline & Requirements Analysis & 0.2 & 3 \\
\hline & Data Modeling & 0.3 & 4 \\
\hline & UNIX & 0.05 & 3 \\
\hline & UML & 0.05 & 3 \\
\hline \multirow[t]{4}{*}{ Prepare Test Data } & PL/SQL & 0.3 & 3 \\
\hline & Requirements Analysis & 0.3 & 3 \\
\hline & UNIX & 0.1 & 3 \\
\hline & Oracle $9 \mathrm{i}$ & 0.3 & 3 \\
\hline \multirow[t]{3}{*}{ Prepare Database Scripts } & UNIX & 0.1 & 2 \\
\hline & PL/SQL & 0.45 & 3 \\
\hline & Oracle 9i & 0.45 & 2 \\
\hline \multirow[t]{2}{*}{ Create Test Database } & UNIX & 0.1 & 2 \\
\hline & Oracle $9 \mathrm{i}$ & 0.9 & 3 \\
\hline \multirow[t]{4}{*}{ Develop Stored Procedures } & UNIX & 0.1 & 2 \\
\hline & PL/SQL & 0.4 & 4 \\
\hline & Requirements Analysis & 0.2 & 3 \\
\hline & Oracle $9 \mathrm{i}$ & 0.3 & 4 \\
\hline \multirow[t]{4}{*}{ Implement Server Daemon } & Systems Analysis & 0.2 & 3 \\
\hline & Network Programming & 0.4 & 4 \\
\hline & $\mathrm{C}++$ & 0.3 & 3 \\
\hline & UNIX & 0.1 & 2 \\
\hline \multirow[t]{4}{*}{ Implement Server Database Access Layer } & Systems Analysis & 0.2 & 3 \\
\hline & PL/SQL & 0.3 & 3 \\
\hline & UNIX & 0.1 & 2 \\
\hline & $\mathrm{C}++$ & 0.4 & 3 \\
\hline \multirow[t]{4}{*}{ Implement Transaction Handlers } & UNIX & 0.1 & 2 \\
\hline & Systems Analysis & 0.2 & 3 \\
\hline & $\mathrm{C}++$ & 0.3 & 3 \\
\hline & Network Programming & 0.4 & 4 \\
\hline \multirow[t]{4}{*}{ Server Unit Testing and Debugging } & UNIX & 0.1 & 2 \\
\hline & PL/SQL & 0.3 & 3 \\
\hline & Network Programming & 0.3 & 3 \\
\hline & $\mathrm{C}++$ & 0.3 & 3 \\
\hline \multirow[t]{4}{*}{ Client GUI Interface Design } & Usability & 0.2 & 4 \\
\hline & Graphic Design & 0.2 & 3 \\
\hline & UML & 0.2 & 2 \\
\hline & Requirements Analysis & 0.4 & 3 \\
\hline \multirow[t]{4}{*}{ Implement Client Application Framework } & Usability & 0.1 & 3 \\
\hline & $\mathrm{C}++$ & 0.3 & 3 \\
\hline & Systems Analysis & 0.3 & 3 \\
\hline & UML & 0.3 & 2 \\
\hline
\end{tabular}




\begin{tabular}{|c|c|c|c|}
\hline Task & Skills & Weight & Ideal Skill Level \\
\hline \multirow[t]{3}{*}{ Implement Simulated Client Server Communication } & Systems Analysis & 0.2 & 3 \\
\hline & Network Programming & 0.4 & 3 \\
\hline & $\mathrm{C}++$ & 0.4 & 3 \\
\hline \multirow[t]{3}{*}{ Implement Client Network Communications } & Systems Analysis & 0.2 & 3 \\
\hline & $\mathrm{C}++$ & 0.4 & 3 \\
\hline & Network Programming & 0.4 & 3 \\
\hline \multirow[t]{2}{*}{ Implement Client GUI } & Usability & 0.4 & 3 \\
\hline & $\mathrm{C}++$ & 0.6 & 3 \\
\hline \multirow[t]{3}{*}{ Implement Core Client Objects } & Systems Analysis & 0.4 & 3 \\
\hline & $\mathrm{C}++$ & 0.4 & 3 \\
\hline & UML & 0.2 & 2 \\
\hline \multirow[t]{2}{*}{ Client Component Integration } & Systems Analysis & 0.6 & 3 \\
\hline & $\mathrm{C}++$ & 0.4 & 3 \\
\hline \multirow[t]{2}{*}{ Client Unit Testing and Debugging } & Systems Analysis & 0.6 & 3 \\
\hline & $\mathrm{C}++$ & 0.4 & 3 \\
\hline \multirow[t]{5}{*}{ Client Server Integration } & Systems Analysis & 0.3 & 4 \\
\hline & Network Programming & 0.2 & 3 \\
\hline & UNIX & 0.1 & 3 \\
\hline & PL/SQL & 0.1 & 3 \\
\hline & $\mathrm{C}++$ & 0.3 & 3 \\
\hline \multirow[t]{5}{*}{ Client Server Testing and Debugging } & Systems Analysis & 0.3 & 4 \\
\hline & Network Programming & 0.2 & 3 \\
\hline & PL/SQL & 0.1 & 3 \\
\hline & $\mathrm{C}++$ & 0.3 & 3 \\
\hline & UNIX & 0.1 & 3 \\
\hline \multirow[t]{2}{*}{ Quality Assurance Testing } & Usability & 0.4 & 3 \\
\hline & QA Testing & 0.6 & 3 \\
\hline
\end{tabular}

Table 4-3 Skill Profiles of Project Team Members

\begin{tabular}{|c|c|c|}
\hline Resource & Skill & Level \\
\hline \multirow[t]{2}{*}{ Business Analyst } & UML & 2 \\
\hline & Requirements Analysis & 3 \\
\hline \multirow[t]{4}{*}{ System Architect } & Systems Analysis & 4 \\
\hline & UML & 3 \\
\hline & Data Modeling & 2 \\
\hline & Requirements Analysis & 4 \\
\hline \multirow[t]{8}{*}{ System Administrator } & Oracle $9 \mathrm{i}$ & 2 \\
\hline & UML & 2 \\
\hline & Data Modeling & 1 \\
\hline & Networking & 4 \\
\hline & UNIX & 4 \\
\hline & Server Hardware & 4 \\
\hline & PL/SQL & 3 \\
\hline & Requirements Analysis & 2 \\
\hline \multirow[t]{7}{*}{ DBAA } & Oracle $9 \mathrm{i}$ & 5 \\
\hline & UML & 2 \\
\hline & Data Modeling & 5 \\
\hline & UNIX & 3 \\
\hline & $\mathrm{XML}$ & 3 \\
\hline & PL/SQL & 5 \\
\hline & Requirements Analysis & 3 \\
\hline \multirow[t]{4}{*}{ GUI Designer } & Graphic Design & 3 \\
\hline & Usability & 4 \\
\hline & UML & 1 \\
\hline & Requirements Analysis & 2 \\
\hline \multirow[t]{4}{*}{ Programmer A } & UNIX & 4 \\
\hline & XML & 4 \\
\hline & $\mathrm{C}++$ & 4 \\
\hline & PL/SQL & 3 \\
\hline
\end{tabular}




\begin{tabular}{|c|c|c|}
\hline Resource & Skill & Leve \\
\hline & Network Programming & 5 \\
\hline & Systems Analysis & 4 \\
\hline & UML & 3 \\
\hline & Requirements Analysis & 3 \\
\hline & Data Modeling & 2 \\
\hline \multirow[t]{9}{*}{ Programmer B } & Usability & 1 \\
\hline & UNIX & 2 \\
\hline & $\mathrm{XML}$ & 2 \\
\hline & $\mathrm{C}++$ & 4 \\
\hline & PL/SQL & 2 \\
\hline & Network Programming & 2 \\
\hline & Systems Analysis & 3 \\
\hline & UML & 1 \\
\hline & Requirements Analysis & 2 \\
\hline \multirow[t]{7}{*}{ Programmer C } & UNIX & 4 \\
\hline & XML & 2 \\
\hline & $\mathrm{C}++$ & 2 \\
\hline & Network Programming & 5 \\
\hline & Systems Analysis & 2 \\
\hline & UML & 1 \\
\hline & Requirements Analysis & 2 \\
\hline \multirow[t]{5}{*}{ Programmer D } & Usability & 4 \\
\hline & UNIX & 1 \\
\hline & $\mathrm{C}++$ & 1 \\
\hline & Systems Analysis & 1 \\
\hline & Requirements Analysis & 2 \\
\hline \multirow[t]{2}{*}{ QA } & Usability & 3 \\
\hline & QA Testing & 5 \\
\hline
\end{tabular}

The development of the client and server will take place in parallel, with two technical leads, Programmer A and Programmer B, the most skilled team members, taking the lead in the development of the client and server respectively. However, the project manager anticipates some complications while scheduling the project. It is somewhat likely that two team members, DBA A and Programmer B, will be assigned to a higher priority project by IT management and may be unavailable to work on the client-server database application.

As a backup plan for this eventuality, the project manager plans to reassign DBA A's tasks to the technical lead for the server application, Programmer A, since Programmer A is the only staff member with sufficient expertise to take on DBA A's responsibilities. Programmer A is not as proficient in database technologies as the DBA, and the project manager expects the reassigned tasks to require additional time as a result. Similarly, in the event that Programmer B is unavailable, his tasks will be reassigned to Programmer C, who has the right skill set for the tasks, although a lower level of proficiency. Similarly to the other reassignment, some resulting delays are expected here as well. 
There is also the possibility that a particular stakeholder from the client company, well known at the consulting firm, for micromanaging the design of the GUI and delaying the signoff on the design, will play a prominent role in the development effort. Historically speaking, the representative for the client company for the project has previously introduced significant delays by requesting modifications to the graphical user interface of previous applications and the project manager estimates that delays of approximately two weeks in the development of the client application could be expected in the event that this particular individual is assigned to represent the client in this project. Subsequently, the project manager defines the risks and contingency plans listed in Figure 4-1, as being pertinent to the project at hand.

From a scheduling perspective, the contingency plans for the availability risks of the resources have the potential to impact the schedule significantly since the backup resources are not as skilled as the preferred resources for the tasks. Additionally, some rescheduling might be required because of concurrent task assignments for those resources, which are already scheduled for several tasks during the project. Consequently, the project manager decides to explore the possibility of obtaining additional team members for the project. The project manager develops skill profiles (Table 4-4), based on two recently interviewed applicants, for two new team members to take the place of the unavailable resources.

Table 4-4 Skill Profiles of Additional Team Members

\begin{tabular}{|c|l|c|}
\hline Resource & \multicolumn{1}{|c|}{ Skill } & Level \\
\hline DBA B & Oracle 9i & 4 \\
\hline & UNIX & 3 \\
\hline & XML & 3 \\
\hline & PL/SQL & 4 \\
\hline & UML & 2 \\
\hline & Data Modeling & 4 \\
\hline & Requirements Analysis & 3 \\
\hline & & \\
\hline Programmer E & Usability & 1 \\
\hline & UNIX & 2 \\
\hline & XML & 2 \\
\hline & C++ & 3 \\
\hline & PL/SQL & 2 \\
\hline & Network Programming & 2 \\
\hline & Systems Analysis & 3 \\
\hline & UML & 1 \\
\hline & Requirements Analysis & 2 \\
\hline
\end{tabular}


The project manager then defines a second version of the original project, with the only difference being a change in the contingency plans to reassign tasks to the two potential team members, instead of Programmer A and Programmer C. By performing an analysis and comparison of both versions of the project, the project manager hopes to determine the potential impact of these scheduling and staffing decisions, in light of the risks involved.

Figure 4-1 Risks and Contingency Plans

\begin{tabular}{|l|l|}
\hline Project v1 \\
\hline Realized Risks & Contingency Plan \\
\hline $\begin{array}{l}\text { DBA A is } \\
\text { unavailable }\end{array}$ & $\begin{array}{l}\text { Reassign tasks to } \\
\text { Programmer A }\end{array}$ \\
\hline $\begin{array}{l}\text { Executive sign-off } \\
\text { on GUI is delayed }\end{array}$ & $\begin{array}{l}\text { Accommodate delay } \\
\text { in project schedule }\end{array}$ \\
\hline $\begin{array}{l}\text { Programmer B is } \\
\text { unavailable }\end{array}$ & $\begin{array}{l}\text { Reassign tasks to } \\
\text { Programmer C }\end{array}$ \\
\hline
\end{tabular}

\begin{tabular}{|l|l|}
\hline \multicolumn{2}{|l|}{ Project v2 } \\
\hline Realized Risks & Contingency Plan \\
\hline $\begin{array}{l}\text { DBA A is } \\
\text { unavailable }\end{array}$ & $\begin{array}{l}\text { Reassign tasks to } \\
\text { DBA B }\end{array}$ \\
\hline $\begin{array}{l}\text { Executive sign-off } \\
\text { on GUI is delayed }\end{array}$ & $\begin{array}{l}\text { Accommodate delay } \\
\text { in project schedule }\end{array}$ \\
\hline $\begin{array}{l}\text { Programmer B is } \\
\text { unavailable }\end{array}$ & $\begin{array}{l}\text { Reassign tasks to } \\
\text { Programmer E }\end{array}$ \\
\hline
\end{tabular}

Given the three project risks, PM Eye generates a total of eight risk scenarios shown in Figure 4-2, including the base scenario with no realized risks. The assigned probabilities of each risk are arrived at through discussion with the project staff, and the probabilities of the scenarios are calculated as described in the results section above.

Based on the project data stored in a relational database (see Appendix B - Example Database for a full description of the project data), PM Eye generates project networks for each risk scenario of both projects. Figure 4-3 shows the project network generated for the base scenario of the first version of the project - Table 4-5 and Table 4-6 show the associated CPM calculations and schedule. Full analysis results for all scenarios of both projects are listed in Appendix A - Full Example Analysis. 


\begin{tabular}{|l|r|}
\hline Base Scenario & Probability \\
\hline Realized Risks & N/A \\
\hline None & \\
\hline & \\
\hline Scenario Probability: & 0.105 \\
\hline
\end{tabular}

\begin{tabular}{|c|c|}
\hline Scenario 4 & \\
\hline Realized Risks & Probability \\
\hline DBA $A$ is unavailable & 0.5 \\
\hline Programmer B is unavailable & 0.3 \\
\hline Scenario Probability: & 0.045 \\
\hline
\end{tabular}

\begin{tabular}{|l|r|}
\hline Scenario 1 \\
\hline Realized Risks & Probability \\
\hline DBA A is unavailable & 0.5 \\
\hline & \\
\hline Scenario Probability: & 0.105 \\
\hline
\end{tabular}

\begin{tabular}{|l|r|}
\hline Scenario 5 \\
\hline Realized Risks & Probability \\
\hline DBA A is unavailable & 0.5 \\
\hline $\begin{array}{l}\text { Executive sign-off on GUI is } \\
\text { delayed }\end{array}$ & 0.7 \\
\hline & \\
\hline Scenario Probability: & 0.245 \\
\hline
\end{tabular}

\begin{tabular}{|l|r|}
\hline Scenario 2 & Probability \\
\hline Realized Risks & \\
\hline Programmer B is unavailble & \\
\hline & \\
\hline Scenario Probability: & 0.3 \\
\hline
\end{tabular}

\section{Scenario 6}

Realized Risks

Executive sign-off on GUI is delayed

\begin{tabular}{|l|r|}
\hline Programmer B is unavailable & 0.3 \\
\hline & \\
\hline Scenario Probability: & 0.105 \\
\hline
\end{tabular}

\section{Scenario 3}

Realized Risks

Executive sign-off on GUI is delayed

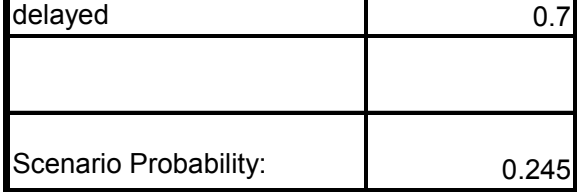

\begin{tabular}{|l|r|}
\hline Scenario 7 \\
\hline Realized Risks & Probability \\
\hline DBA A is unavailable & 0.5 \\
\hline $\begin{array}{l}\text { Executive sign-off on GUI is } \\
\text { delayed }\end{array}$ & 0.7 \\
\hline Programmer B is unavailable & 0.3 \\
\hline & \\
\hline Scenario Probability: & 0.105 \\
\hline
\end{tabular}

Figure 4-2 Risk Scenarios and Probabilities 


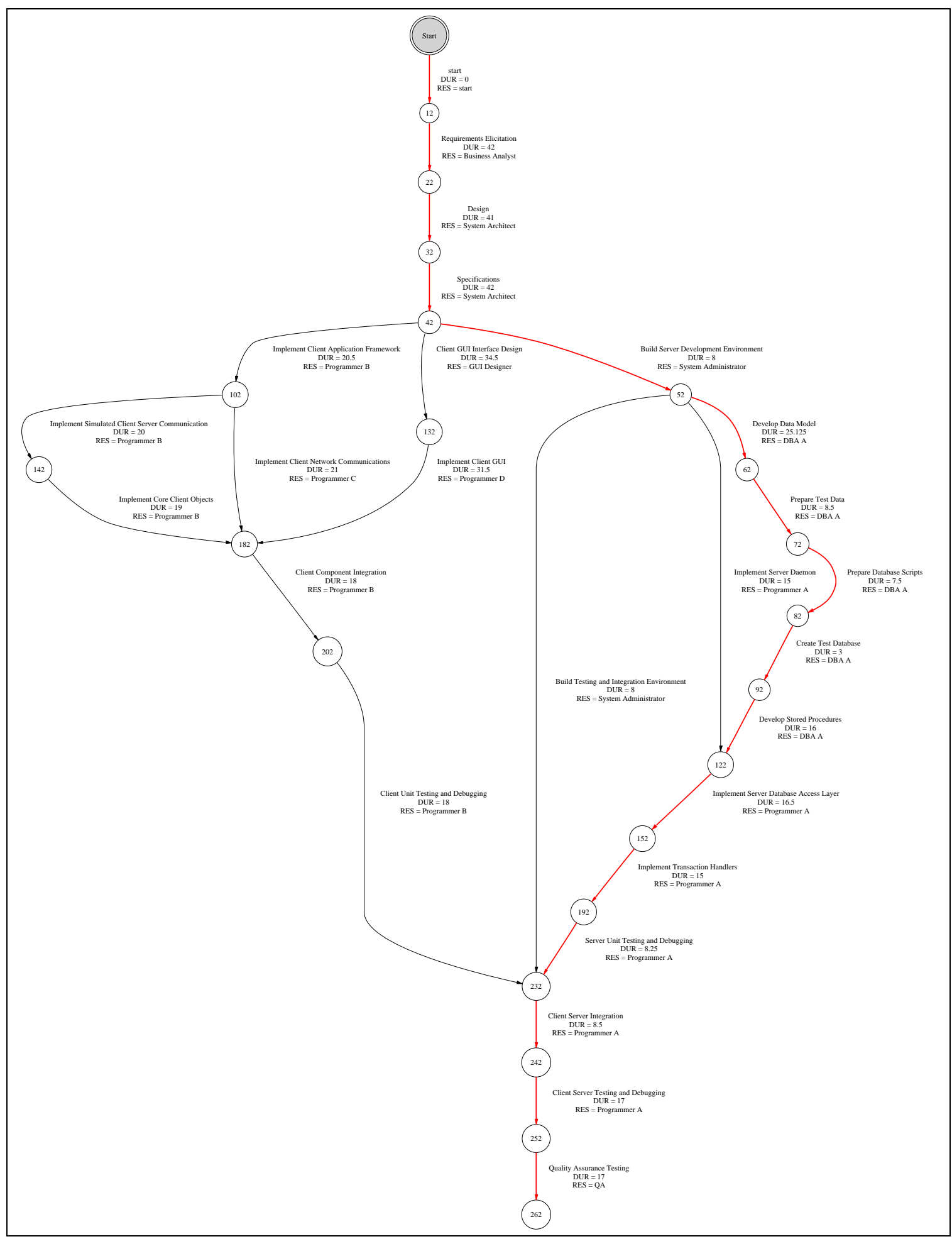

Figure 4-3 Project Network of the Base Scenario 
Table 4-5 CPM Data for the Base Scenario

\begin{tabular}{|c|c|c|c|c|c|c|c|c|c|c|}
\hline CP & ES & EF & LS & LF & TS & FS & DUR & $\cos T$ & RESOURCE & TASK NAME \\
\hline * & 0 & 0 & 0 & 0 & 0 & 0 & 0 & $\$ 0.00$ & start & start \\
\hline * & 0 & 42 & 0 & 42 & 0 & 0 & 42 & $\$ 33,600.00$ & Business Analyst & Requirements Elicitation \\
\hline * & 42 & 83 & 42 & 83 & 0 & 0 & 41 & $\$ 41,000.00$ & System Architect & Design \\
\hline \multirow[t]{3}{*}{ * } & 83 & 125 & 83 & 125 & 0 & 0 & 42 & $\$ 42,000.00$ & System Architect & Specifications \\
\hline & 125 & 145.5 & 137.4 & 157.9 & 12.4 & 0 & 20.5 & $\$ 16,400.00$ & Programmer B & Implement Client Application Framework \\
\hline & 125 & 159.5 & 130.9 & 165.4 & 5.9 & 0 & 34.5 & $\$ 20,700.00$ & GUI Designer & Client GUI Interface Design \\
\hline \multirow[t]{3}{*}{ * } & 125 & 133 & 125 & 133 & 0 & 0 & 8 & $\$ 6,400.00$ & System Administrator & Build Server Development Environment \\
\hline & 133 & 148 & 178.1 & 193.1 & 45.1 & 45.1 & 15 & $\$ 18,000.00$ & Programmer A & Implement Server Daemon \\
\hline & 133 & 141 & 224.9 & 232.9 & 91.9 & 91.9 & 8 & $\$ 6,400.00$ & System Administrator & Build Testing and Integration Environment \\
\hline * & 133 & 158.1 & 133 & 158.1 & 0 & 0 & 25.1 & $\$ 25,125.00$ & DBA A & Develop Data Model \\
\hline * & 158.1 & 166.6 & 158.1 & 166.6 & 0 & 0 & 8.5 & $\$ 8,500.00$ & DBA A & Prepare Test Data \\
\hline * & 166.6 & 174.1 & 166.6 & 174.1 & 0 & 0 & 7.5 & $\$ 7,500.00$ & DBA A & Prepare Database Scripts \\
\hline * & 174.1 & 177.1 & 174.1 & 177.1 & 0 & 0 & 3 & $\$ 3,000.00$ & DBA A & Create Test Database \\
\hline * & 177.1 & 193.1 & 177.1 & 193.1 & 0 & 0 & 16 & $\$ 16,000.00$ & DBA A & Develop Stored Procedures \\
\hline * & 193.1 & 209.6 & 193.1 & 209.6 & 0 & 0 & 16.5 & $\$ 19,800.00$ & Programmer A & Implement Server Database Access Layer \\
\hline * & 209.6 & 224.6 & 209.6 & 224.6 & 0 & 0 & 15 & $\$ 18,000.00$ & Programmer A & Implement Transaction Handlers \\
\hline \multirow[t]{7}{*}{ * } & 224.6 & 232.9 & 224.6 & 232.9 & 0 & 0 & 8.3 & $\$ 9,900.00$ & Programmer A & Server Unit Testing and Debugging \\
\hline & 159.5 & 191 & 165.4 & 196.9 & 5.9 & 0 & 31.5 & $\$ 25,200.00$ & Programmer D & Implement Client GUI \\
\hline & 145.5 & 165.5 & 157.9 & 177.9 & 12.4 & 0 & 20 & $\$ 16,000.00$ & Programmer B & Implement Simulated Client Server Communication \\
\hline & 145.5 & 166.5 & 175.9 & 196.9 & 30.4 & 24.5 & 21 & $\$ 12,600.00$ & Programmer C & Implement Client Network Communications \\
\hline & 165.5 & 184.5 & 177.9 & 196.9 & 12.4 & 6.5 & 19 & $\$ 15,200.00$ & Programmer B & Implement Core Client Objects \\
\hline & 191 & 209 & 196.9 & 214.9 & 5.9 & 0 & 18 & $\$ 14,400.00$ & Programmer B & Client Component Integration \\
\hline & 209 & 227 & 214.9 & 232.9 & 5.9 & 5.9 & 18 & $\$ 14,400.00$ & Programmer B & Client Unit Testing and Debugging \\
\hline * & 232.9 & 241.4 & 232.9 & 241.4 & 0 & 0 & 8.5 & $\$ 10,200.00$ & Programmer A & Client Server Integration \\
\hline * & 241.4 & 258.4 & 241.4 & 258.4 & 0 & 0 & 17 & $\$ 20,400.00$ & Programmer A & Client Server Testing and Debugging \\
\hline \multirow[t]{4}{*}{ * } & 258.4 & 275.4 & 258.4 & 275.4 & 0 & 0 & 17 & $\$ 6,800.00$ & QA & Quality Assurance Testing \\
\hline & & & & & & & & & & \\
\hline & & & & & & & & & & Project Length (non-adjusted): 275.4 days \\
\hline & & & & & & & & & & Total Cost: $\$ 427525.00$ \\
\hline
\end{tabular}

Table 4-6 Schedule for Base Scenario

\begin{tabular}{|l|l|l|l|}
\hline \multicolumn{1}{|c|}{ ES } & \multicolumn{1}{|c|}{ EF } & \multicolumn{1}{|c|}{ RESOURCE } & \multicolumn{1}{c|}{ TASK NAME } \\
\hline 0 & 0 & start & start \\
\hline 0 & 42 & Business Analyst & Requirements Elicitation \\
\hline 42 & 83 & System Architect & Design \\
\hline 83 & 125 & System Architect & Specifications \\
\hline 125 & 133 & System Administrator & Build Server Development Environment \\
\hline 125 & 159.5 & GUI Designer & Client GUI Interface Design \\
\hline 125 & 145.5 & Programmer B & Implement Client Application Framework \\
\hline 133 & 158.1 & DBA A & Develop Data Model \\
\hline 159.5 & 191 & Programmer D & Implement Client GUI \\
\hline 145.5 & 165.5 & Programmer B & Implement Simulated Client Server Communication \\
\hline 145.5 & 166.5 & Programmer C & Implement Client Network Communications \\
\hline 133 & 148 & Programmer A & Implement Server Daemon \\
\hline 133 & 141 & System Administrator & Build Testing and Integration Environment \\
\hline 158.1 & 166.6 & DBA A & Prepare Test Data \\
\hline 165.5 & 184.5 & Programmer B & Implement Core Client Objects \\
\hline 166.6 & 174.1 & DBA A & Prepare Database Scripts \\
\hline 191 & 209 & Programmer B & Client Component Integration \\
\hline 174.1 & 177.1 & DBA A & Create Test Database \\
\hline 209 & 227 & Programmer B & Client Unit Testing and Debugging \\
\hline 177.1 & 193.1 & DBA A & Develop Stored Procedures \\
\hline 193.1 & 209.6 & Programmer A & Implement Server Database Access Layer \\
\hline 209.6 & 224.6 & Programmer A & Implement Transaction Handlers \\
\hline 224.6 & 232.9 & Programmer A & Server Unit Testing and Debugging \\
\hline 232.9 & 241.4 & Programmer A & Client Server Integration \\
\hline 241.4 & 258.4 & Programmer A & Client Server Testing and Debugging \\
\hline 258.4 & 275.4 & QA & Quality Assurance Testing \\
\hline & & & \\
\hline & & & Project Length (adjusted): 275.4 days \\
\hline & & & Total Cost: \$427525.00 \\
\hline
\end{tabular}


Figure 4-4 shows a comparison of the costs, completion times, and expected values of the projects. A glance at the expected values calculated for each project clearly shows that some significant time and cost savings for the project can be expected, with the addition of the two new team members in project 2. The difference in expected costs and completion time between project 1 and project 2 are $\$ 23,240.00$ and 18.5 days respectively. The difference between the worst and best time and cost outcomes of project 1, are 38.9 days and $\$ 44,535.00$ respectively, while project 2's best and worst are a significantly less worrisome 12.1 days and $\$ 10,025.00$. According to the analysis, it is likely that the project manager could make a convincing case for the acquisition of the additional resources. The fact that one of the worst outcomes in both time and cost is associated with Risk Scenario 5, which has an approximately $25 \%$ probability of being realized, adds extra weight to the desirability of taking the course of action described by project 2 . 


\begin{tabular}{|c|c|c|c|c|c|c|c|c|c|}
\hline \multicolumn{10}{|c|}{ Time Comparison: } \\
\hline & so & s1 & s2 & S3 & S4 & S5 & s6 & S7 & EV \\
\hline Proj 1 & 275.4 & 314.3 & 309.5 & 283.5 & 314.3 & 314.3 & 309.5 & 314.3 & 301.9 days \\
\hline Proj 2 & 275.4 & 284.1 & 275.4 & 283.5 & 284.1 & 284.1 & 287.5 & 287.5 & 283.4 days \\
\hline
\end{tabular}

\begin{tabular}{|c|c|c|c|c|c|c|c|c|c|}
\hline \multicolumn{1}{c}{ Cost Comparison: } & \multicolumn{10}{c|}{ S0 } & S1 & S2 & S3 & S4 & S5 & S6 & S7 & EV \\
\hline Proj 1 & 427525 & 468260 & 423725 & 427525 & 464460 & 468260 & 423725 & 464460 & $\$ 446,752.50$ \\
\cline { 2 - 10 } Proj 2 & 427525 & 422500 & 422525 & 427525 & 417500 & 422500 & 422525 & 417500 & $\$ 423,512.50$ \\
\hline
\end{tabular}

Figure 4-4 Project Comparisons

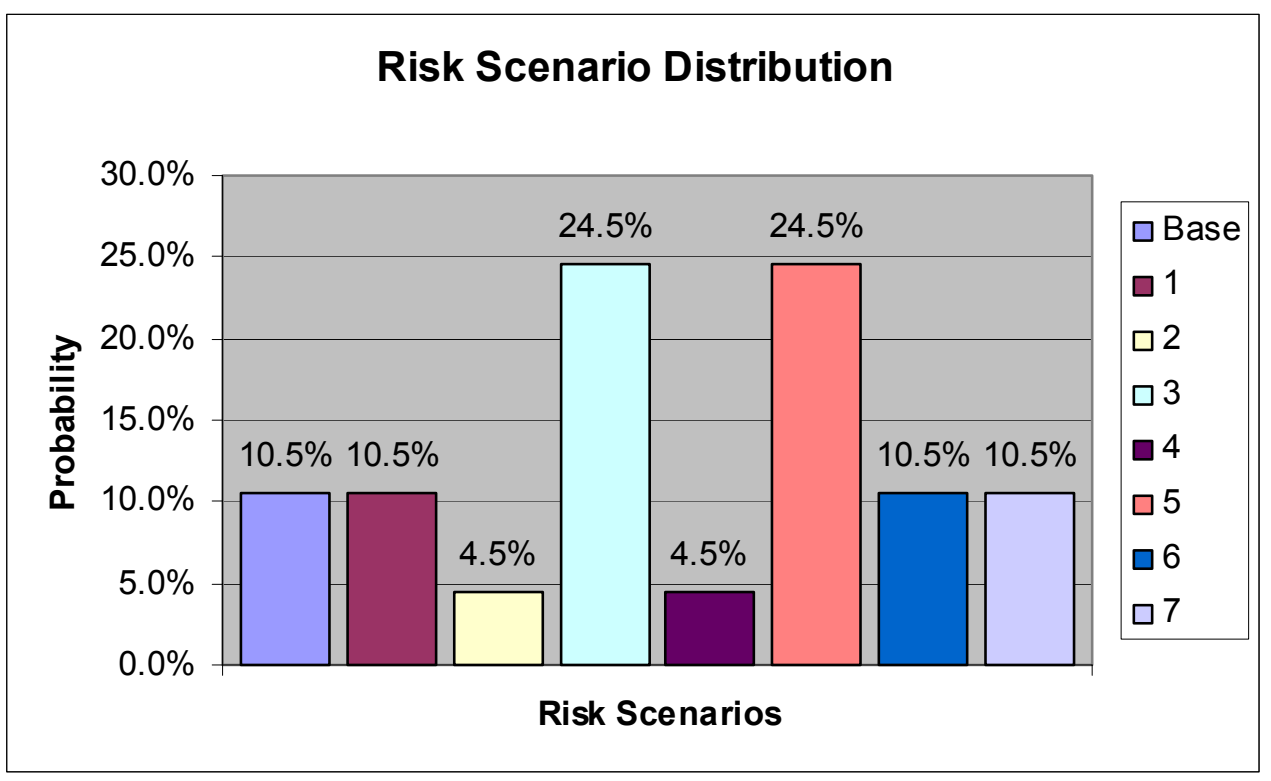

Figure 4-5 Risk Scenario Distribution 


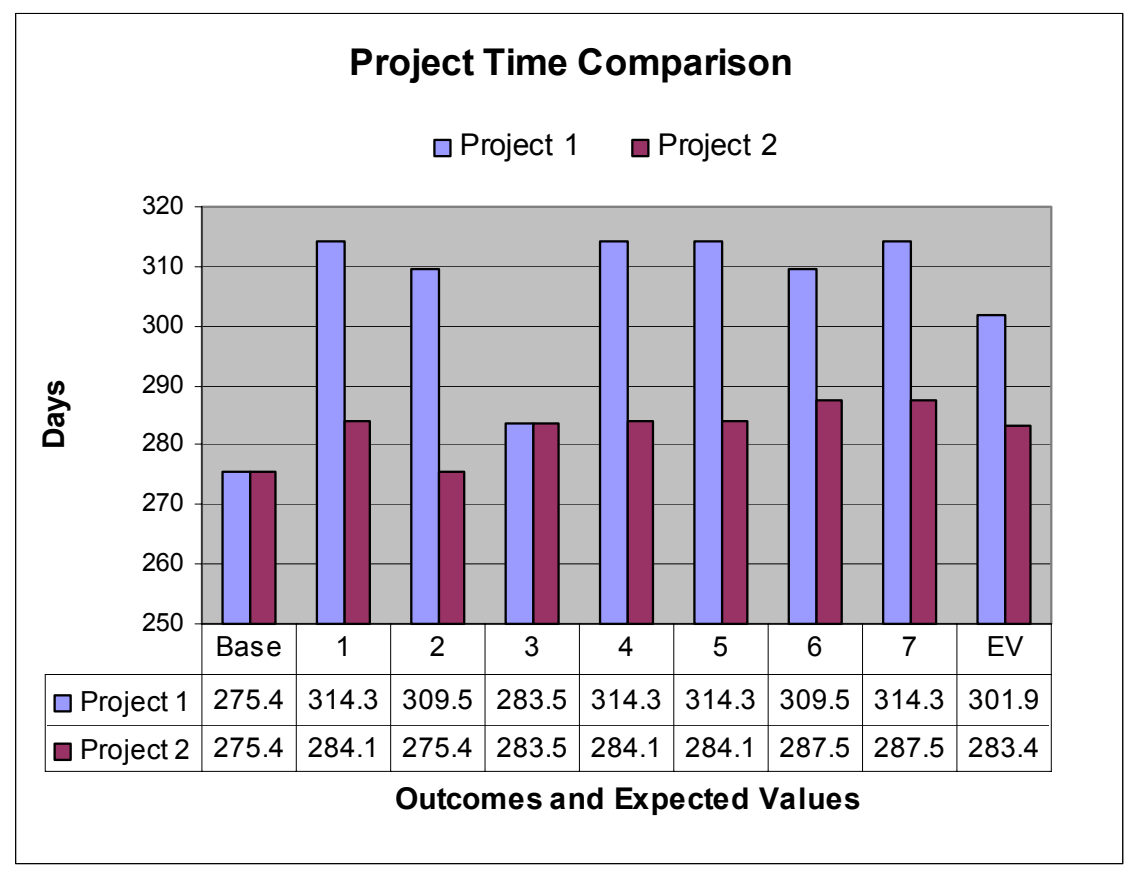

Figure 4-6 Project Time Comparisons Graph

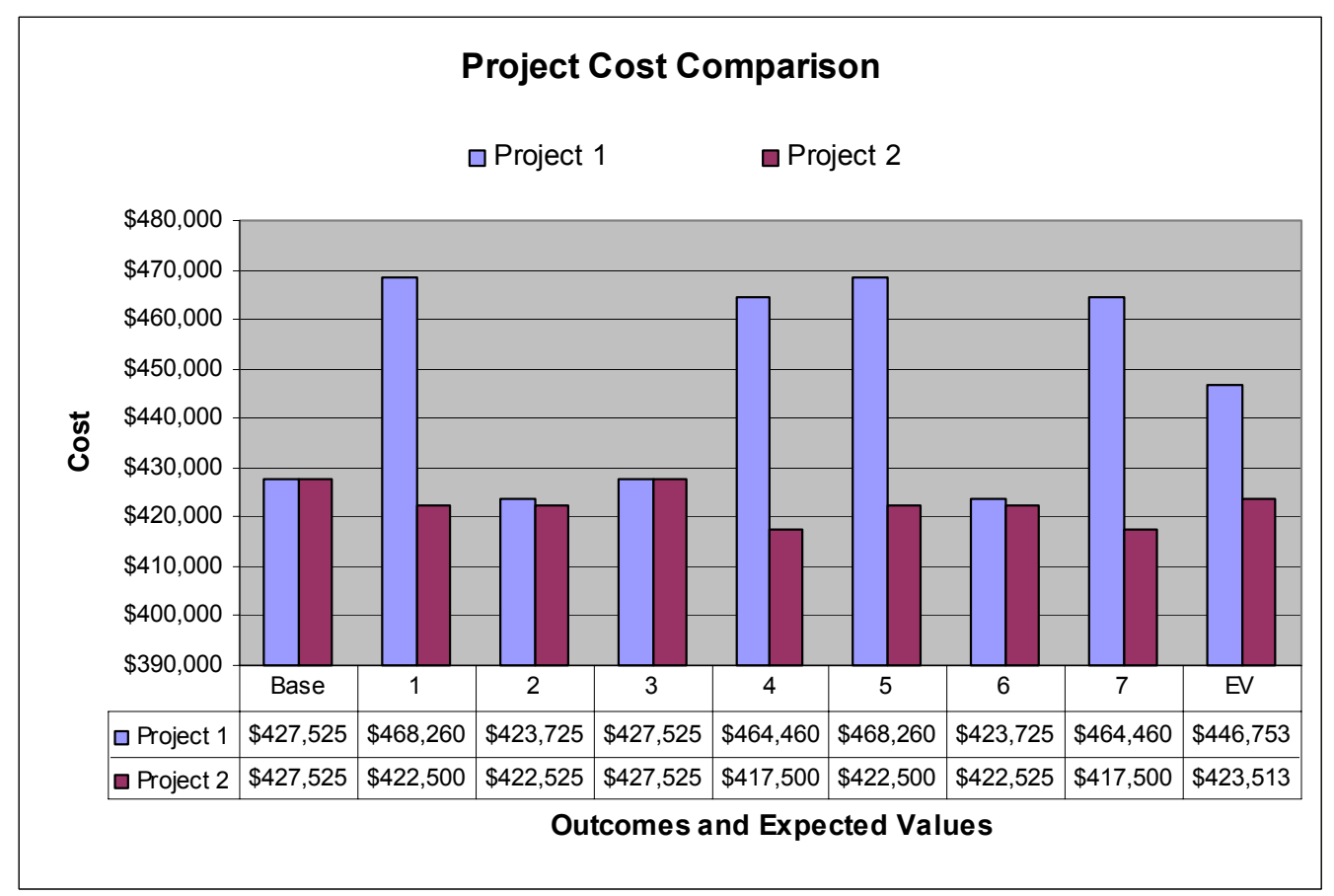

Figure 4-7 Project Cost Comparisons Graph 


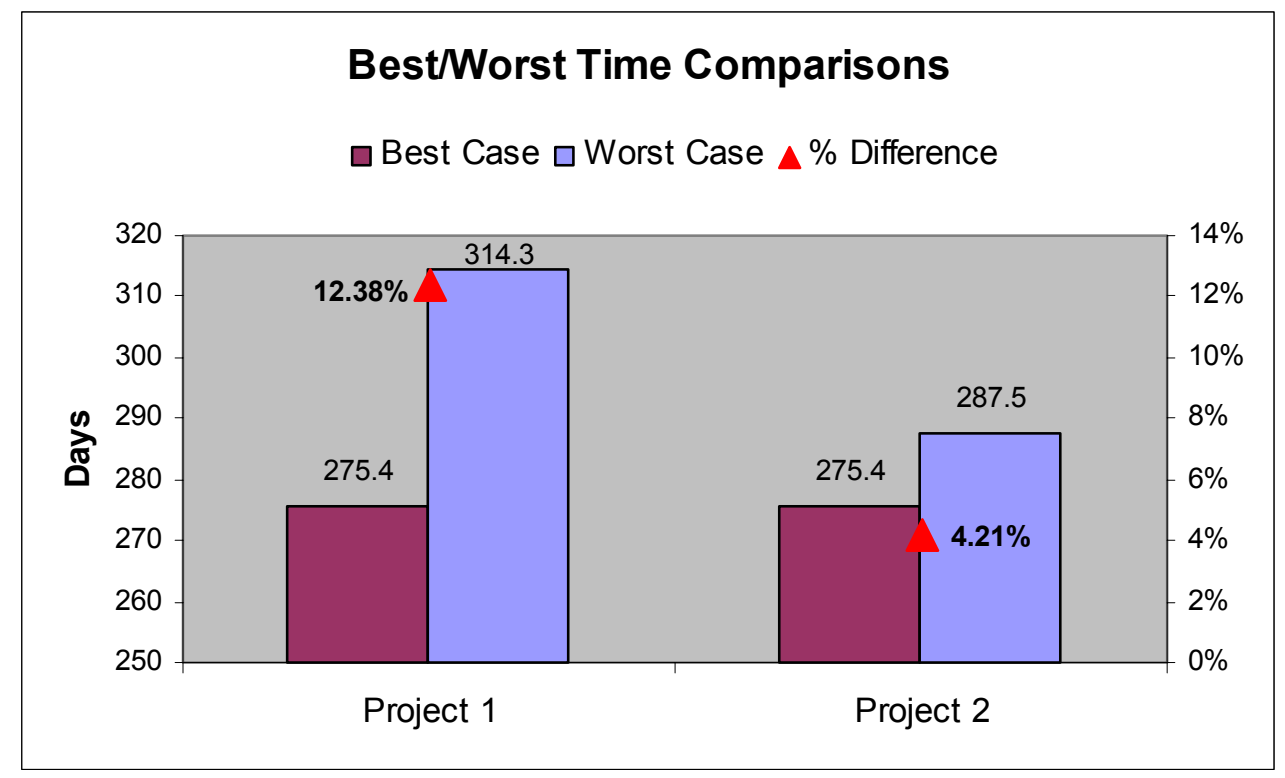

Figure 4-8 Best and Worst Case Time Comparisons

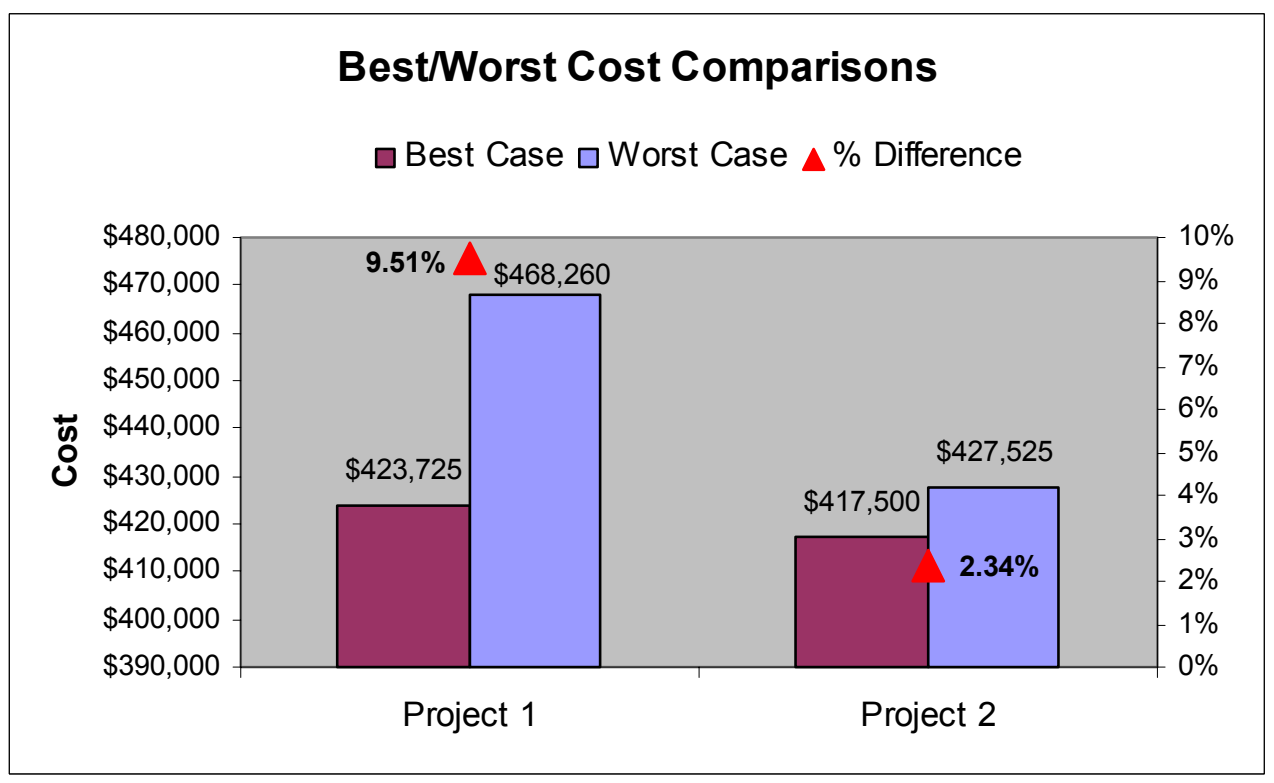

Figure 4-9 Best and Worst Case Cost Comparisons 


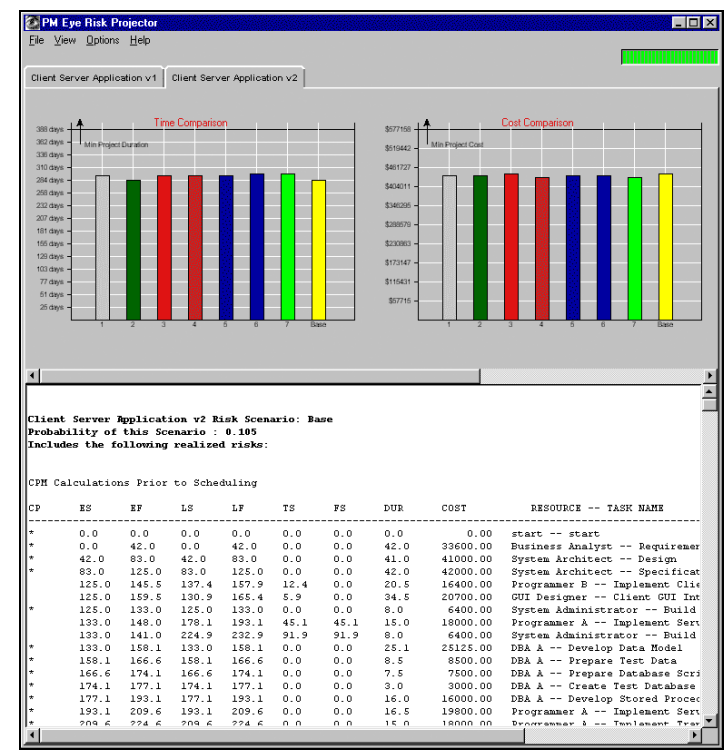

Figure 4-10 Screenshot of PM Eye Interface

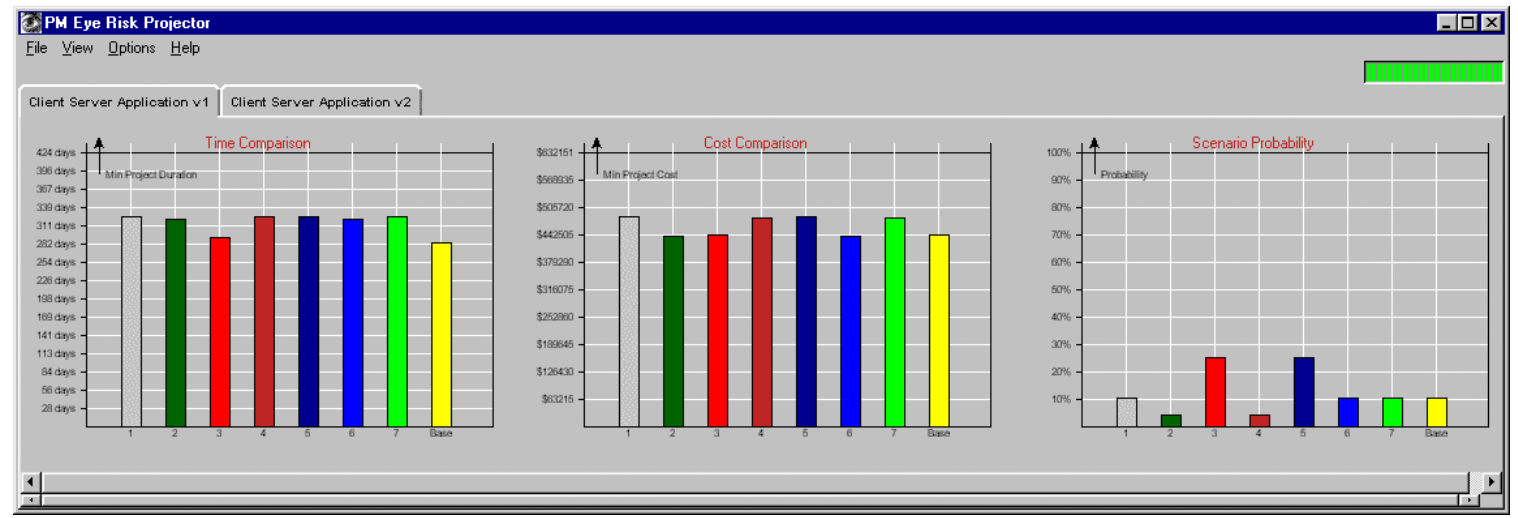

Figure 4-11 Time, Cost, and Probability Comparison Chart View for Project 1 


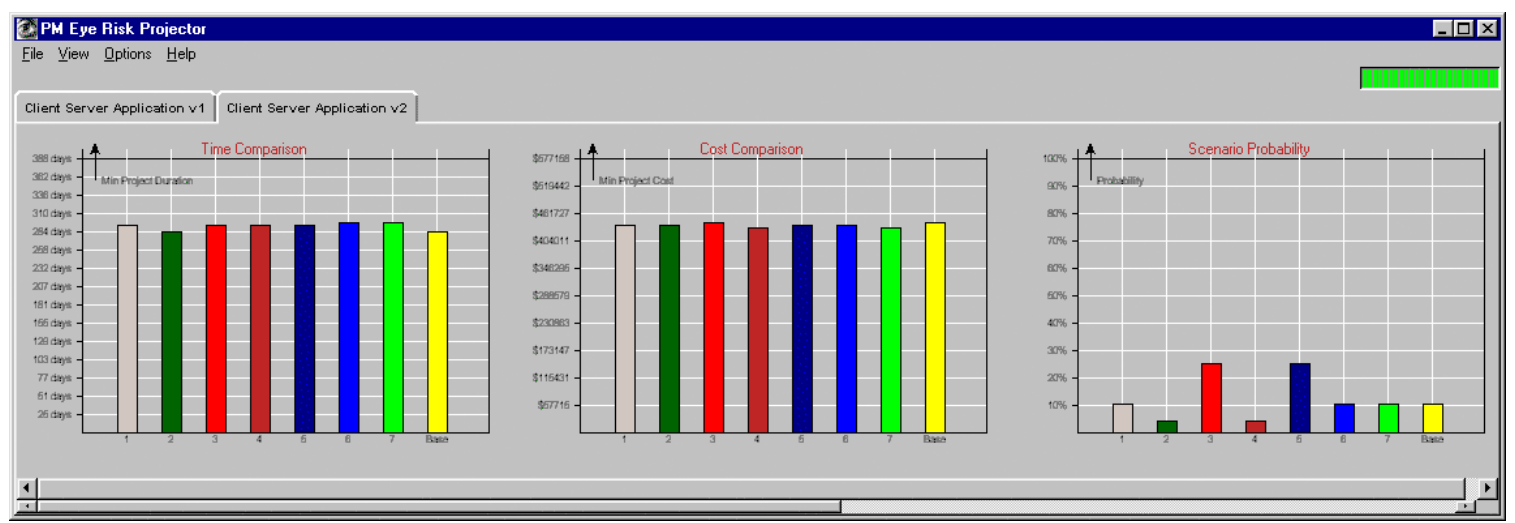

Figure 4-12 Time, Cost, and Probability Comparison Chart View for Project 2

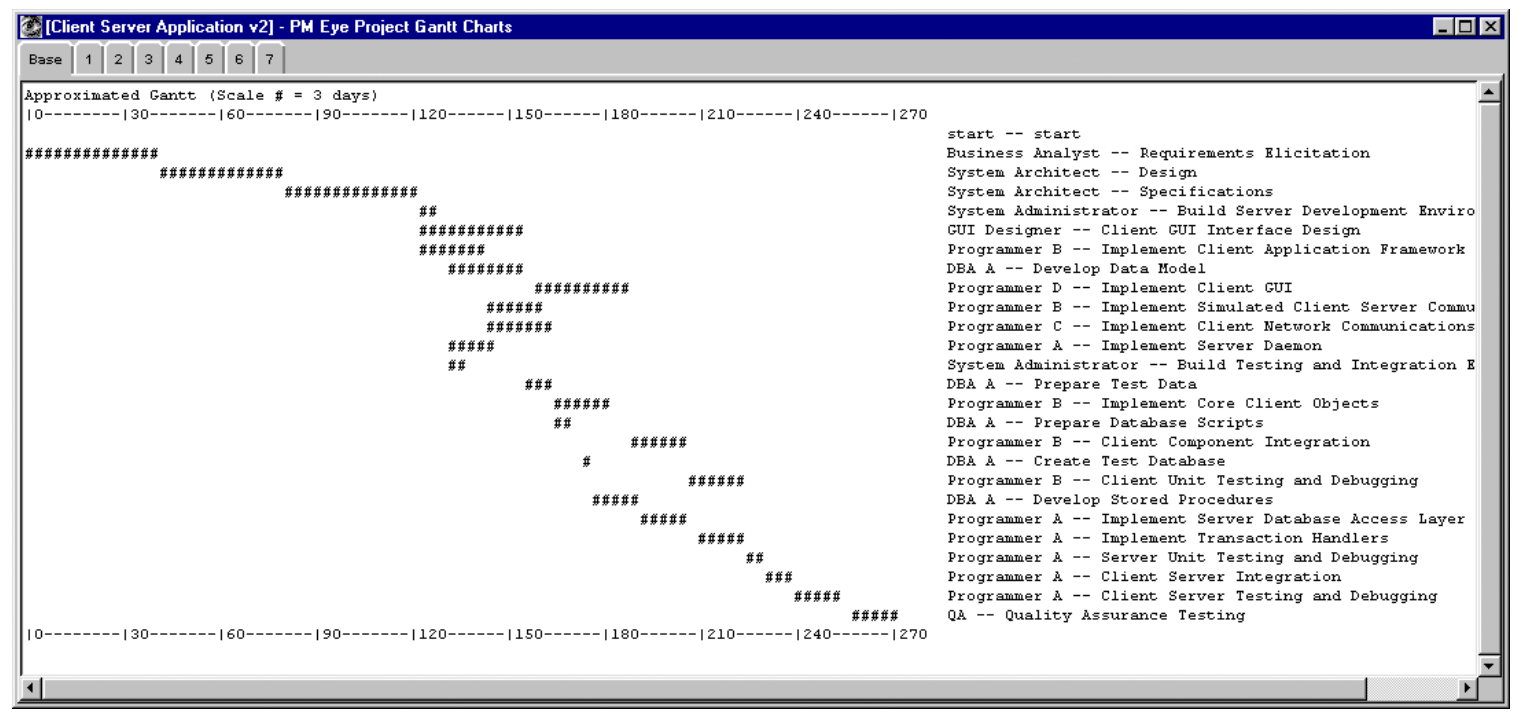

Figure 4-13 Gantt Chart View of Project 2 


\section{Future Studies}

There are a number of potential extensions to the analysis framework and its implementation as a decision support application, that may be worthy of further investigation.

1. PERT-style Probabilistic Analysis - The framework, as described in this paper, suffers from some rigidity in the calculation of completion time estimates. The integration of PERT-like probabilistic time estimates could provide more flexibility and upper/lower bounds for project completion time.

2. Monte Carlo Analysis and Project Simulation - In addition to the deterministic analysis offered by the framework, the integration of Monte Carlo analysis tools, along with the probabilistic PERT time estimates, could provide the ability to perform simulations of projects and generate cost and time outcomes by these means.

3. Provision of additional scheduling heuristics - There are many scheduling heuristics that could be utilized in the scheduling step of the analysis, of which the one used in the PM Eye application, MINSLK, is one of the simplest. The use of more sophisticated scheduling heuristics could generate schedules that are more true to the real-life scheduling decisions that a project manager would be inclined to make in a hand-crafted schedule, thereby providing a more realistic estimate of the completion time a project.

4. Allow the assignment of multiple resources to tasks - The current implementation of the framework, only allows one-to-one assignments of resources and tasks. A more practical implementation could permit multiple assignments, and perform the necessary calculations to scale the duration of tasks to account the corresponding increase in productivity.

5. Interactive creation and comparison of project variations - Allowing the user to interactively create variations of projects in the database could enable the rapid evaluation of what-if scenarios, and increase the potential for gleaning useful insights. 


\section{Bibliography}

\begin{tabular}{|c|c|}
\hline [1] & $\begin{array}{l}\text { Addison, Tom; Vallabh, Seema } \\
\text { Controlling software project risks: an empirical study of methods used by experienced project managers } \\
\text { Proceedings of the } 2002 \text { annual research conference of the South African institute of computer scientists and } \\
\text { information technologists on Enablement through technology; } 2002\end{array}$ \\
\hline [2] & $\begin{array}{l}\text { Arnott, Robert D. } \\
\text { Quantitative Management in the Coming Decade } \\
\text { Financial Analysts Journal; May/Jun94, Vol. } 50 \text { Issue 3, p6, 6p }\end{array}$ \\
\hline [3] & $\begin{array}{l}\text { Basili, Victor R.; McGarry, Frank E.; Pajerski, Rose; Zelkowitz, Marvin V. } \\
\text { Lessons learned from } 25 \text { years of process improvement: the rise and fall of the NASA software engineering laboratory } \\
\text { Proceedings of the 24th international conference on Software engineering, } 2002\end{array}$ \\
\hline [4] & $\begin{array}{l}\text { Chapman, Chris; Ward, Stephen } \\
\text { Project Risk Management: Processes, Techniques and Insights } \\
\text { John Wiley \& Sons, } 1996\end{array}$ \\
\hline [5] & $\begin{array}{l}\text { Chelst, Kenneth } \\
\text { Can't See the Forest Because of the Decision Trees: a Critique of Decision Analysis in Survey Texts } \\
\text { Interfaces, volume 28, number 2, } 1998\end{array}$ \\
\hline [6] & $\begin{array}{l}\text { Elsayed, E.A.; Nasr, N.Z. } \\
\text { Heuristics for resource-constrained scheduling } \\
\text { International Journal of Production Research, Mar/Apr86, Vol. } 24 \text { Issue } 2\end{array}$ \\
\hline [7] & $\begin{array}{l}\text { Fisher, A. C. } \\
\text { Computer construction of project networks } \\
\text { Communications of the ACM, volume 11, number 7, } 1968\end{array}$ \\
\hline [8] & $\begin{array}{l}\text { Gemmill, Douglas D. } \\
\text { Improving Resource-Constrained Project Schedules With Look-Ahead Techniques } \\
\text { Project Management Journal; Sep99, Vol. } 30 \text { Issue 3, p44, 12p }\end{array}$ \\
\hline $\begin{array}{l}\text { [9] } \\
\end{array}$ & $\begin{array}{l}\text { Mizuno, Osamu; Kikuno, Tohru; Takagi, Yasunari; Sakamoto, Keishi } \\
\text { Characterization of risky projects based on project managers' evaluation } \\
\text { Proceedings of the } 22 \text { nd international conference on Software engineering, } 2000\end{array}$ \\
\hline [10] & $\begin{array}{l}\text { Newell, Allen; Simon, Herbert A. } \\
\text { Computer Science as Empirical Inquiry: Symbols and Search } \\
\text { Communications of the ACM, Vol 19, Number 3, } 1976\end{array}$ \\
\hline [11] & $\begin{array}{l}\text { Onweugbuzie, Anthony J. } \\
\text { Why can't we all get along? Towards a framework, for unifying research paradigms } \\
\text { Education; Spring2002, Vol. } 122 \text { Issue 3, p518, 13p }\end{array}$ \\
\hline$[12]$ & $\begin{array}{l}\text { Luce, R. Duncan; Raiffa, Howard } \\
\text { Games and Decisions: Introduction and Critical Survey } \\
\text { Wiley, } 1957\end{array}$ \\
\hline [13] & $\begin{array}{l}\text { Padayachee, Keshnee } \\
\text { An interpretive study of software risk, management perspectives } \\
\text { Proceedings of the } 2002 \text { annual research conference of the South African institute of computer scientists and } \\
\text { information technologists on Enablement through technology, } 2002\end{array}$ \\
\hline [14] & $\begin{array}{l}\text { Wiest, Jerome D.; Levy, Ferdinand } \\
\text { A Management Guide to PERT/CPM with GERT/PDM/DCPM and Other Networks } \\
\text { Prentice-Hall, } 1977\end{array}$ \\
\hline
\end{tabular}




\section{Appendix A - Full Example Analysis}

\section{Project Networks}

Client Server Application v1 - Base Scenario Project Network

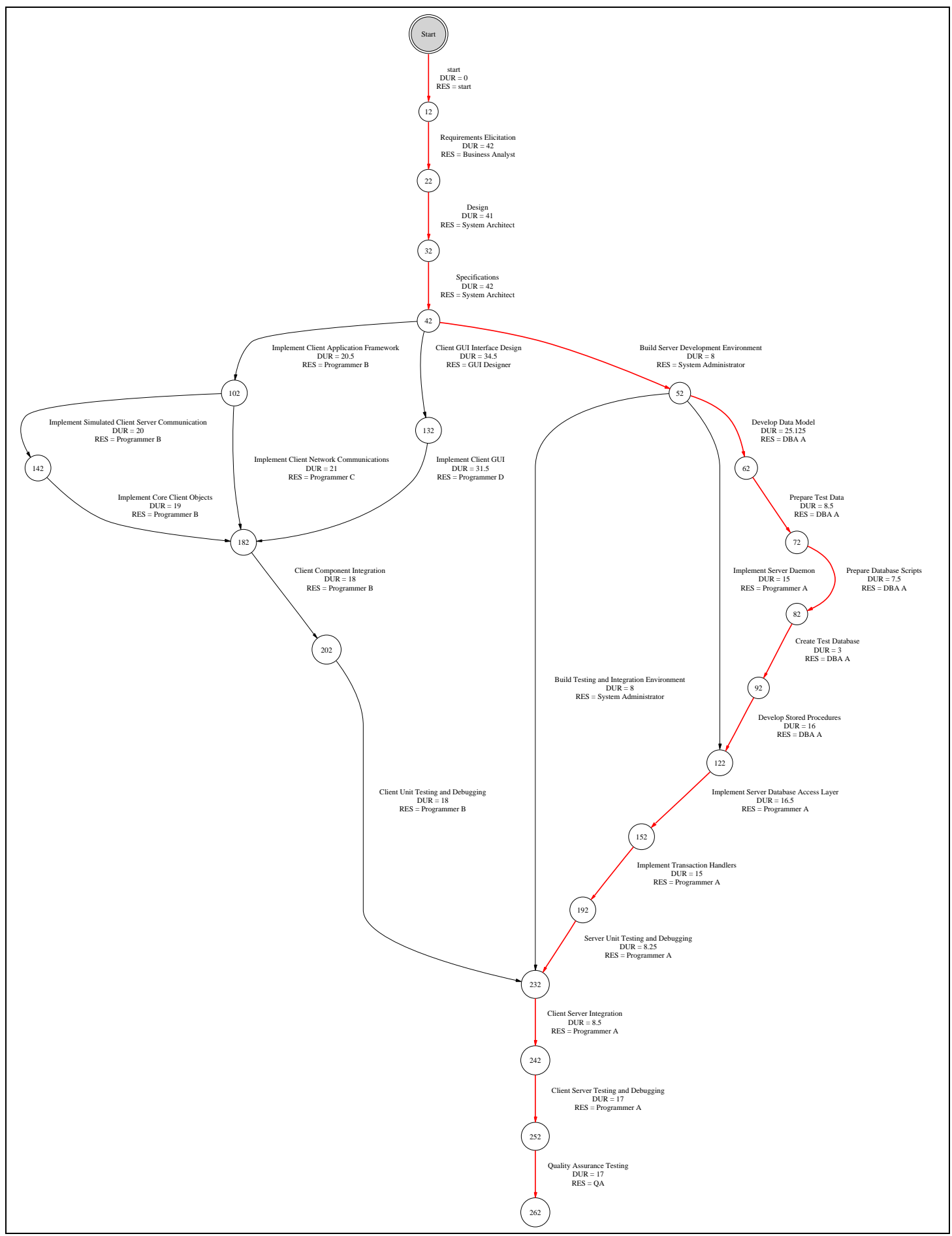

Figure 6-1 Client Server Application v1 - Base Scenario Project

Network 
Client Server Application v1 - Scenario 1 Project Network.

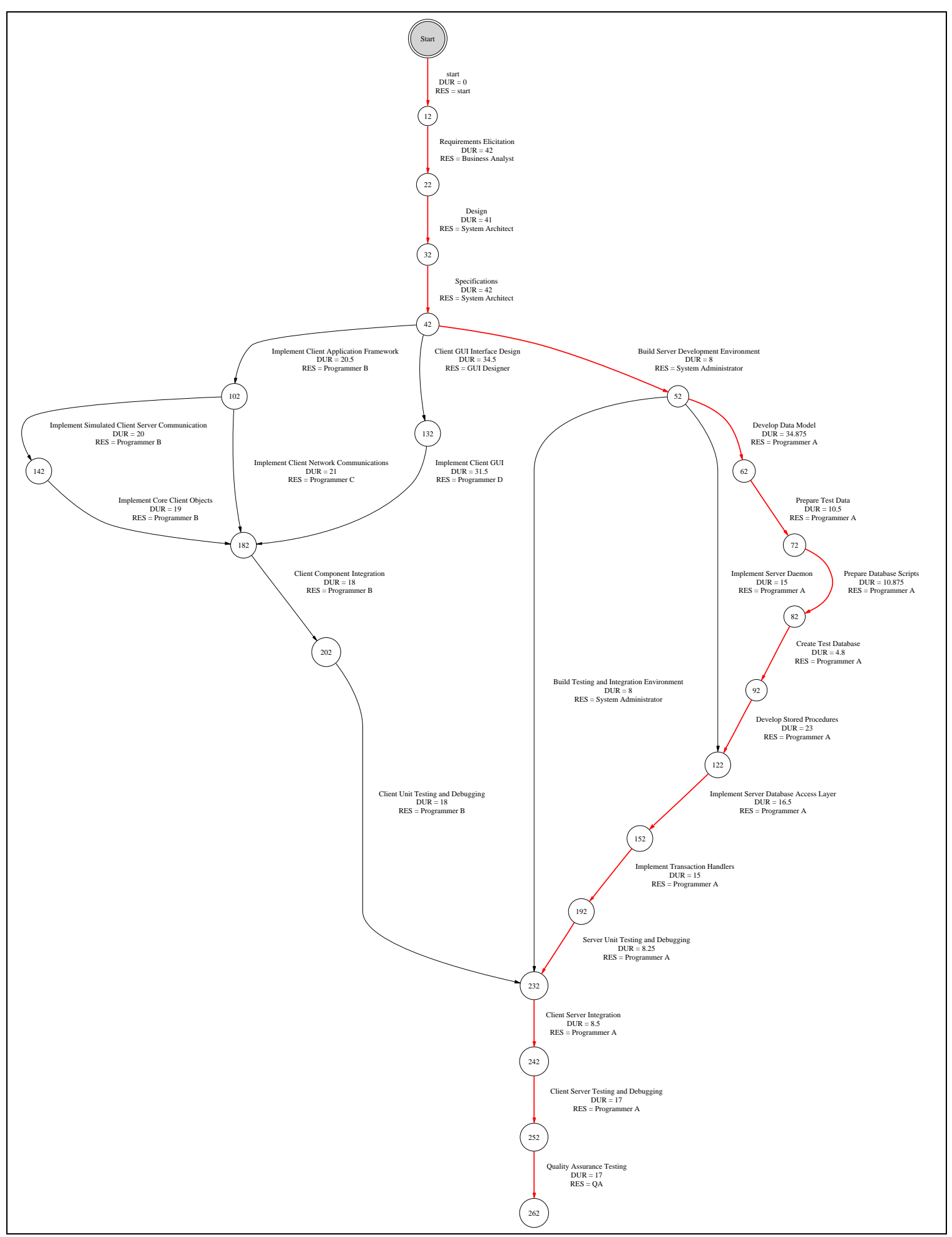

Figure 6-2 Client Server Application v1 - Scenario 1 Project Network 
Client Server Application v1 - Scenario 2 Project Network.

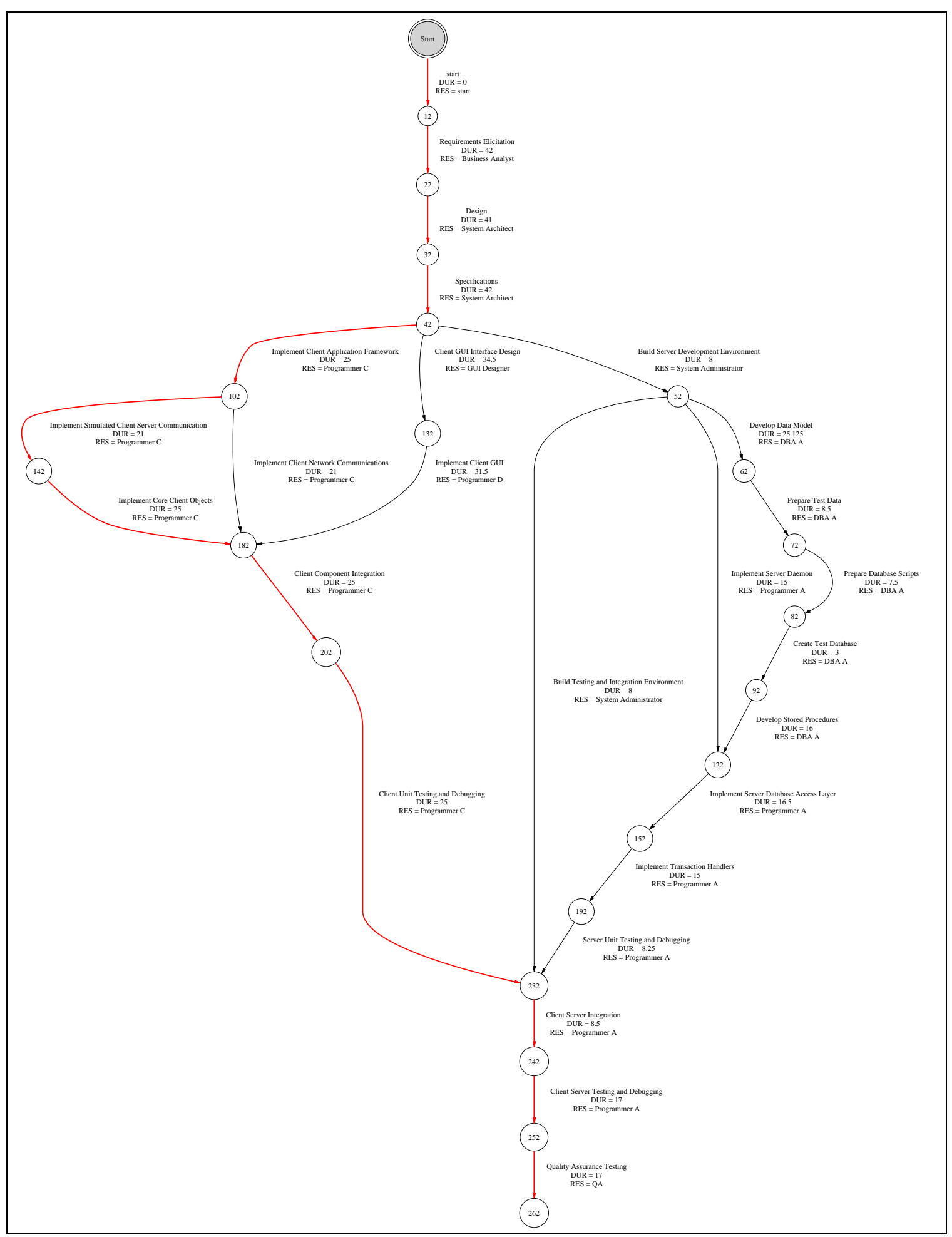

Figure 6-3 Client Server Application v1 - Scenario 2 Project Network 
Client Server Application v1 - Scenario 3 Project Network.

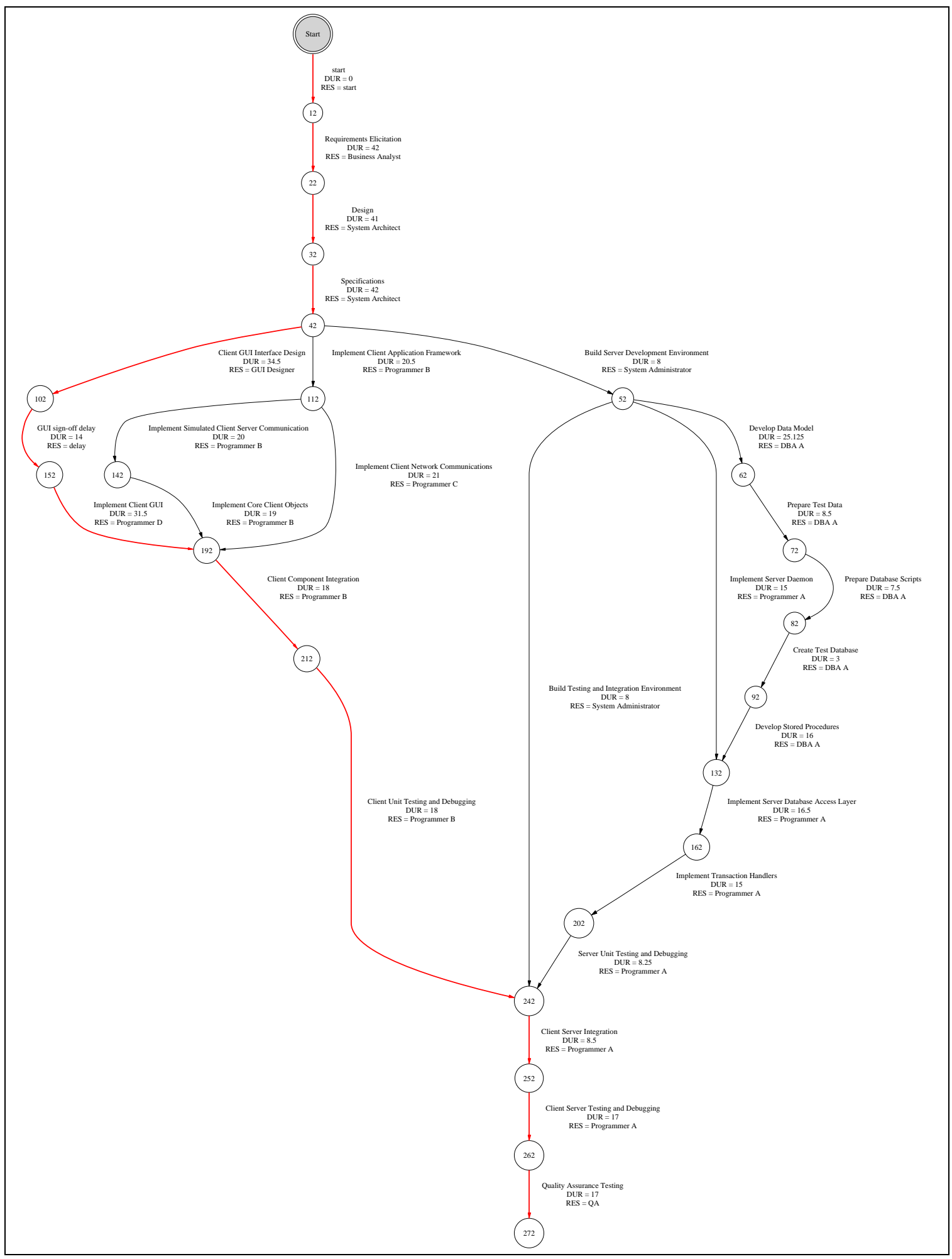

Figure 6-4 Client Server Application v1 - Scenario 3 Project Network 
Client Server Application v1 - Scenario 4 Project Network.

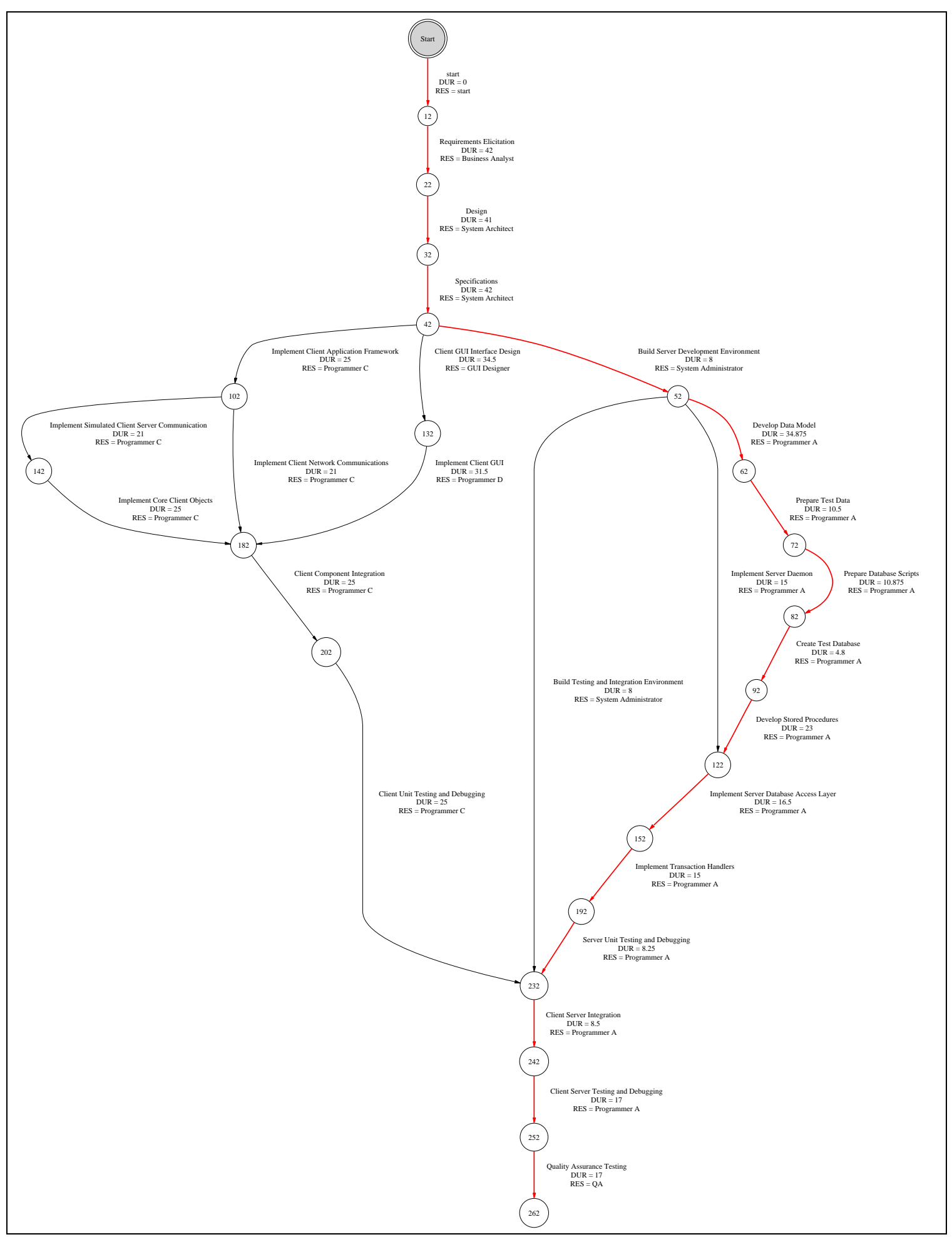

Figure 6-5 Client Server Application v1 - Scenario 4 Project Network 
Client Server Application v1 - Scenario 5 Project Network

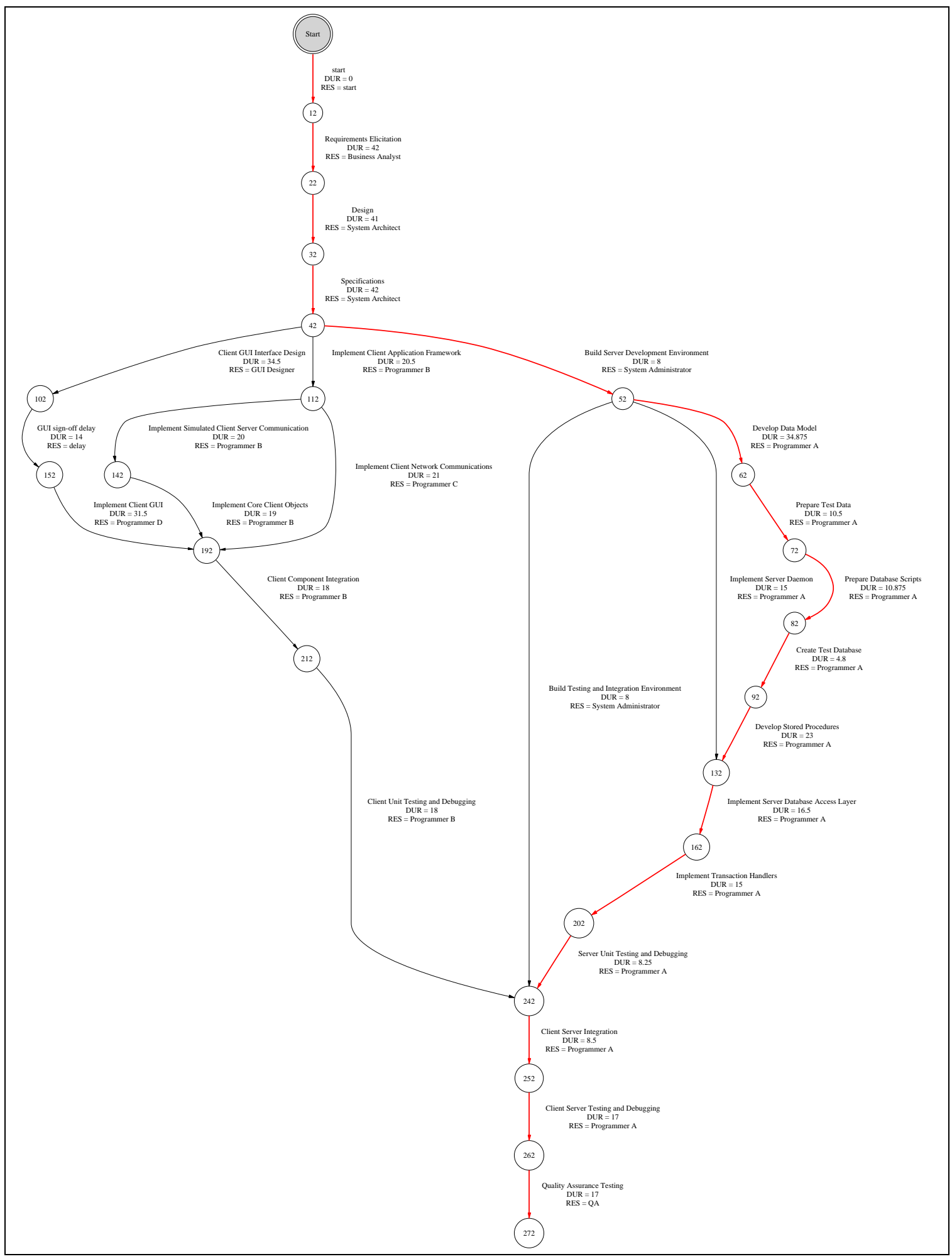

Figure 6-6 Client Server Application v1 - Scenario 5 Project Network 
Client Server Application v1 - Scenario 6 Project Network.

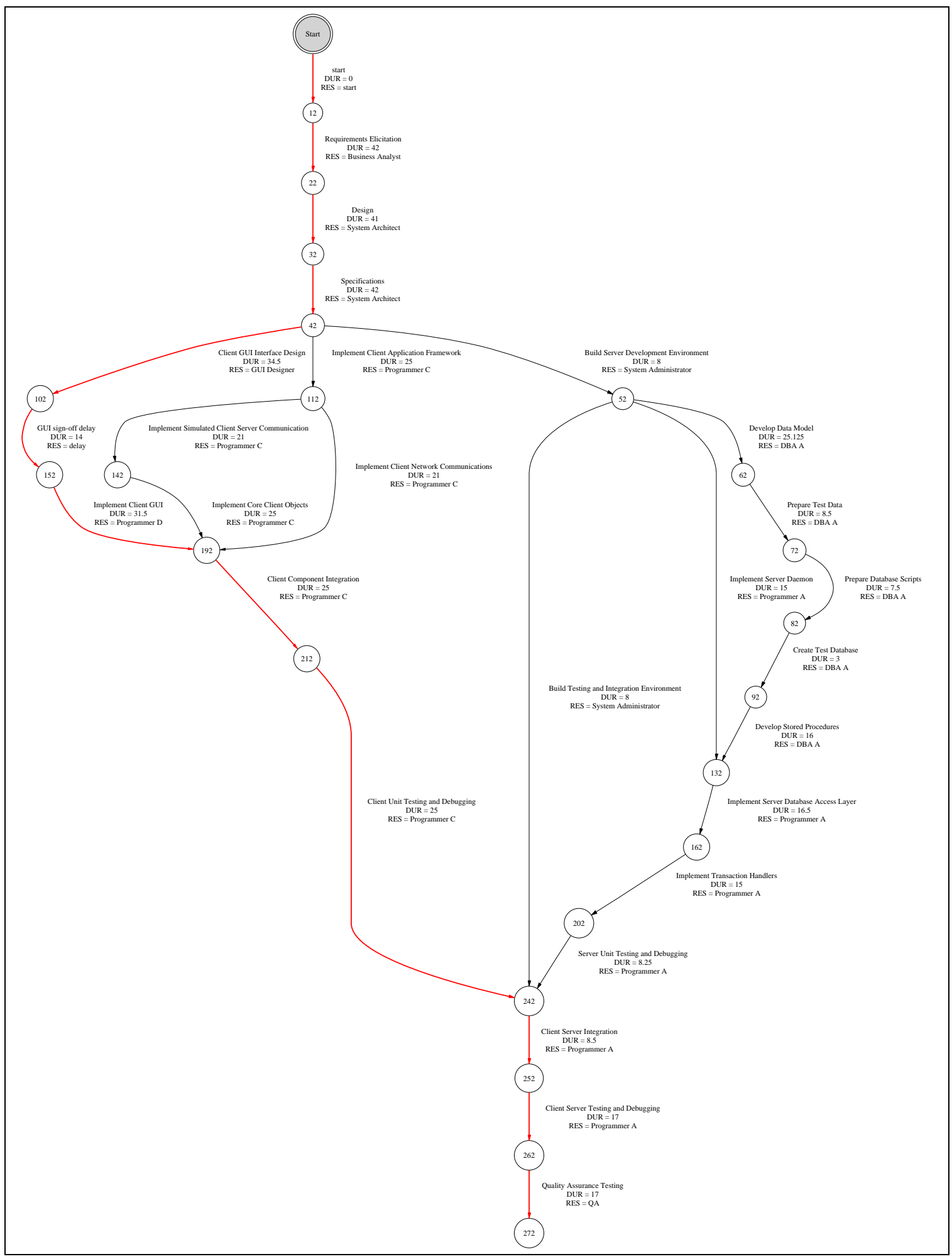

Figure 6-7 Client Server Application v1 - Scenario 6 Project Network 
Client Server Application v1 - Scenario 7 Project Network.

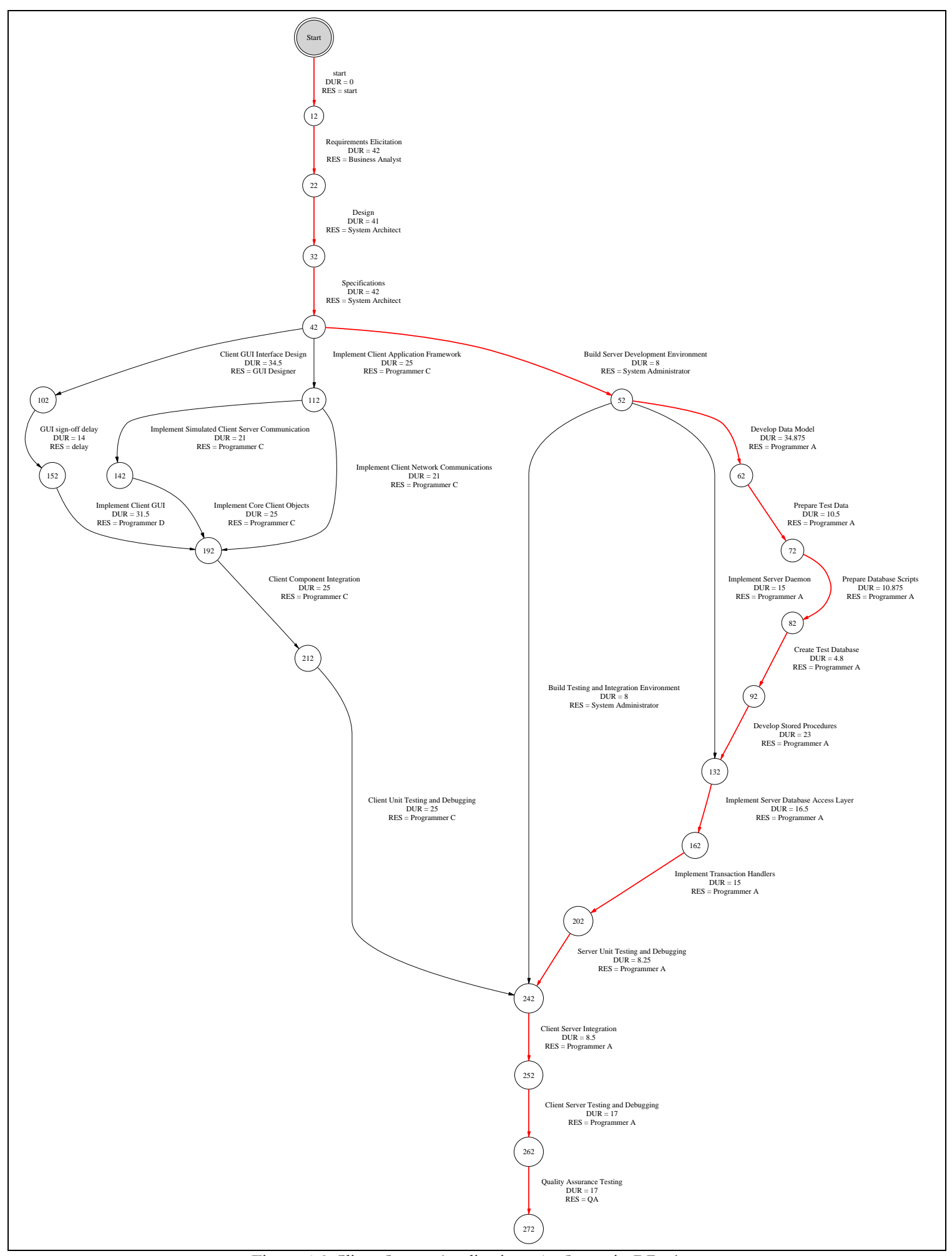

Figure 6-8 Client Server Application v1 - Scenario 7 Project Network 
Client Server Application v2 - Base Scenario Project Network

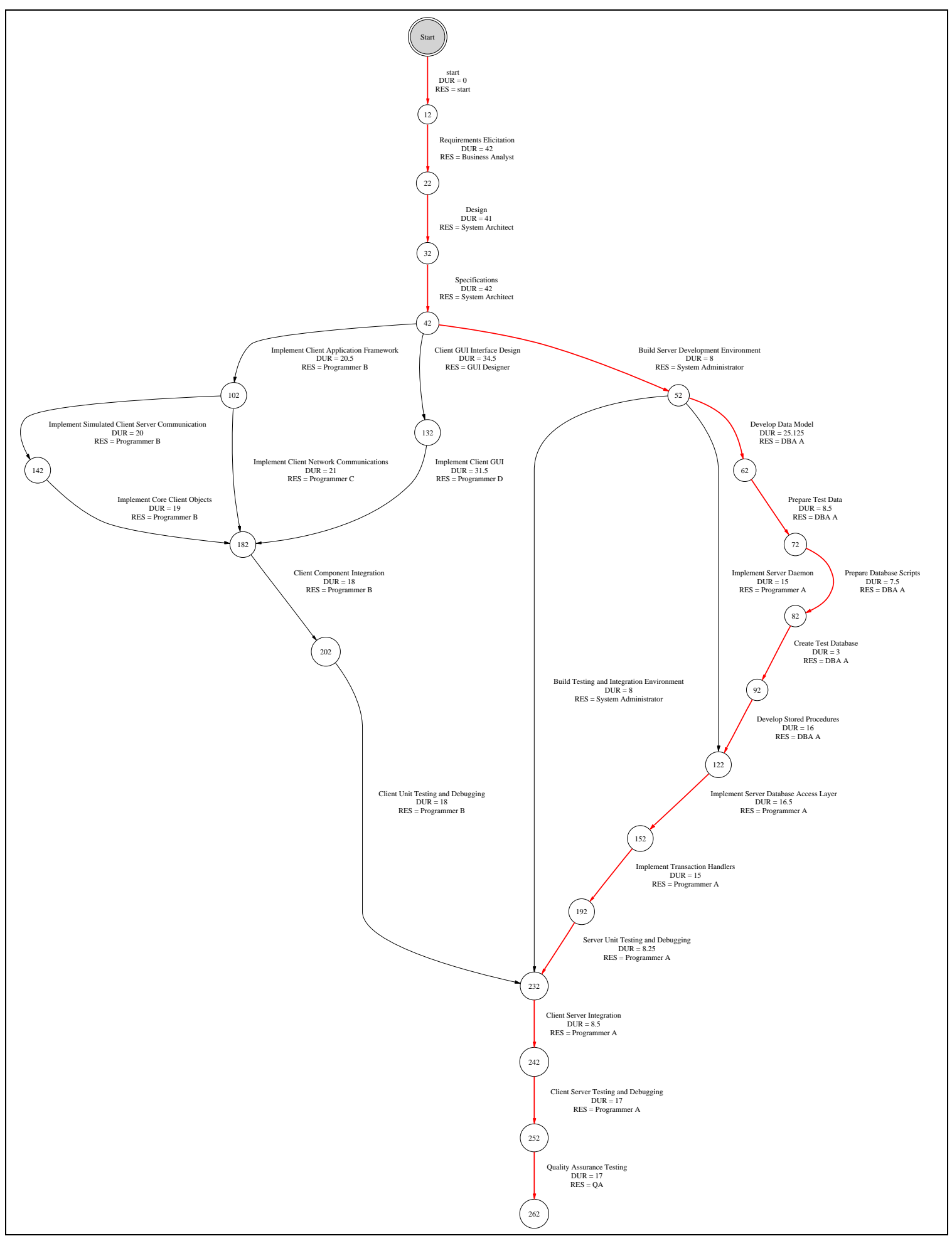

Figure 6-9 Client Server Application v2 - Base Scenario Project Network 
Client Server Application v2 - Scenario 1 Project Network.

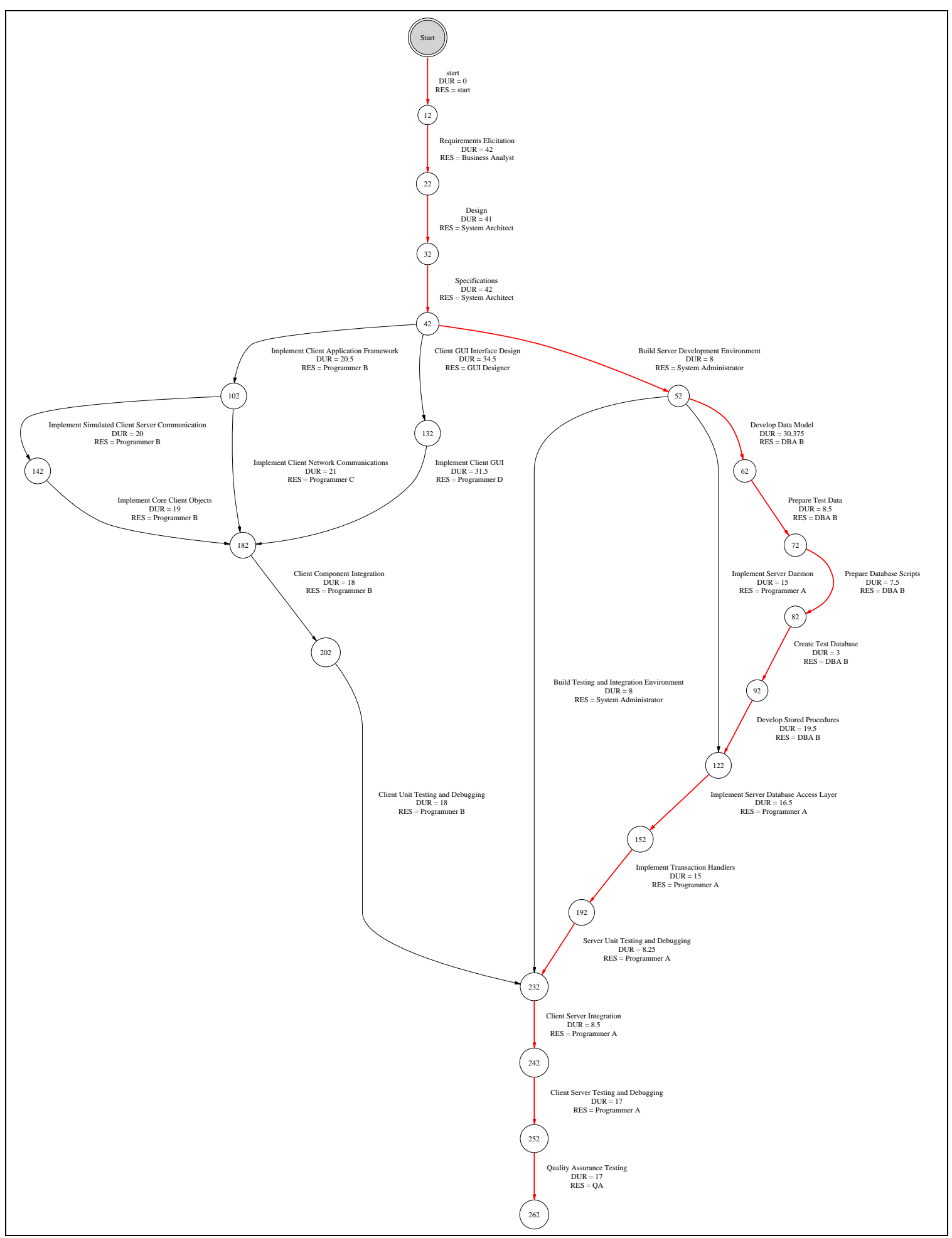

Figure 6-10 Client Server Application v2 - Scenario 1 Project Network 
Client Server Application v2 - Scenario 2 Project Network.

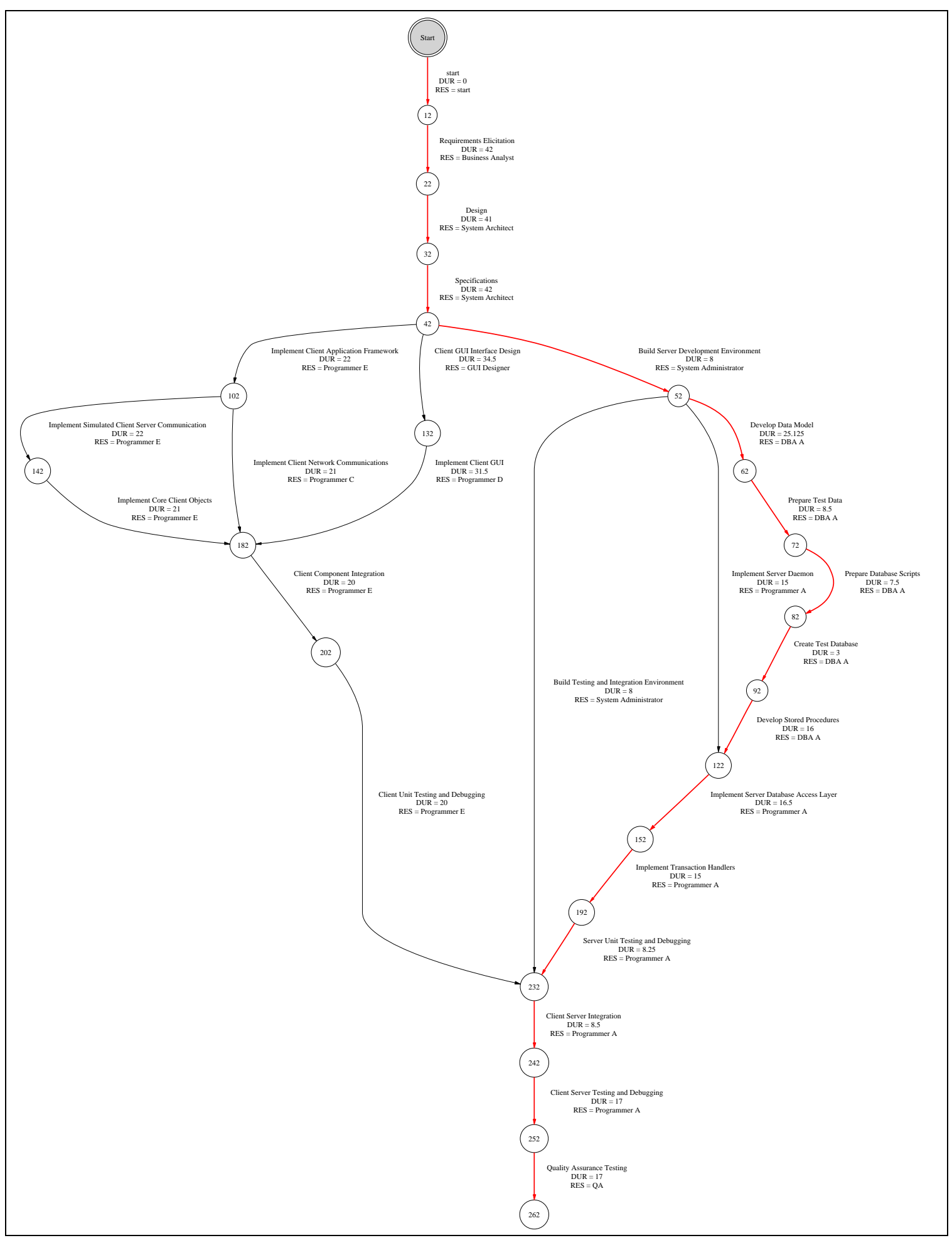

Figure 6-11 Client Server Application v2 - Scenario 2 Project Network 
Client Server Application v2 - Scenario 3 Project Network.

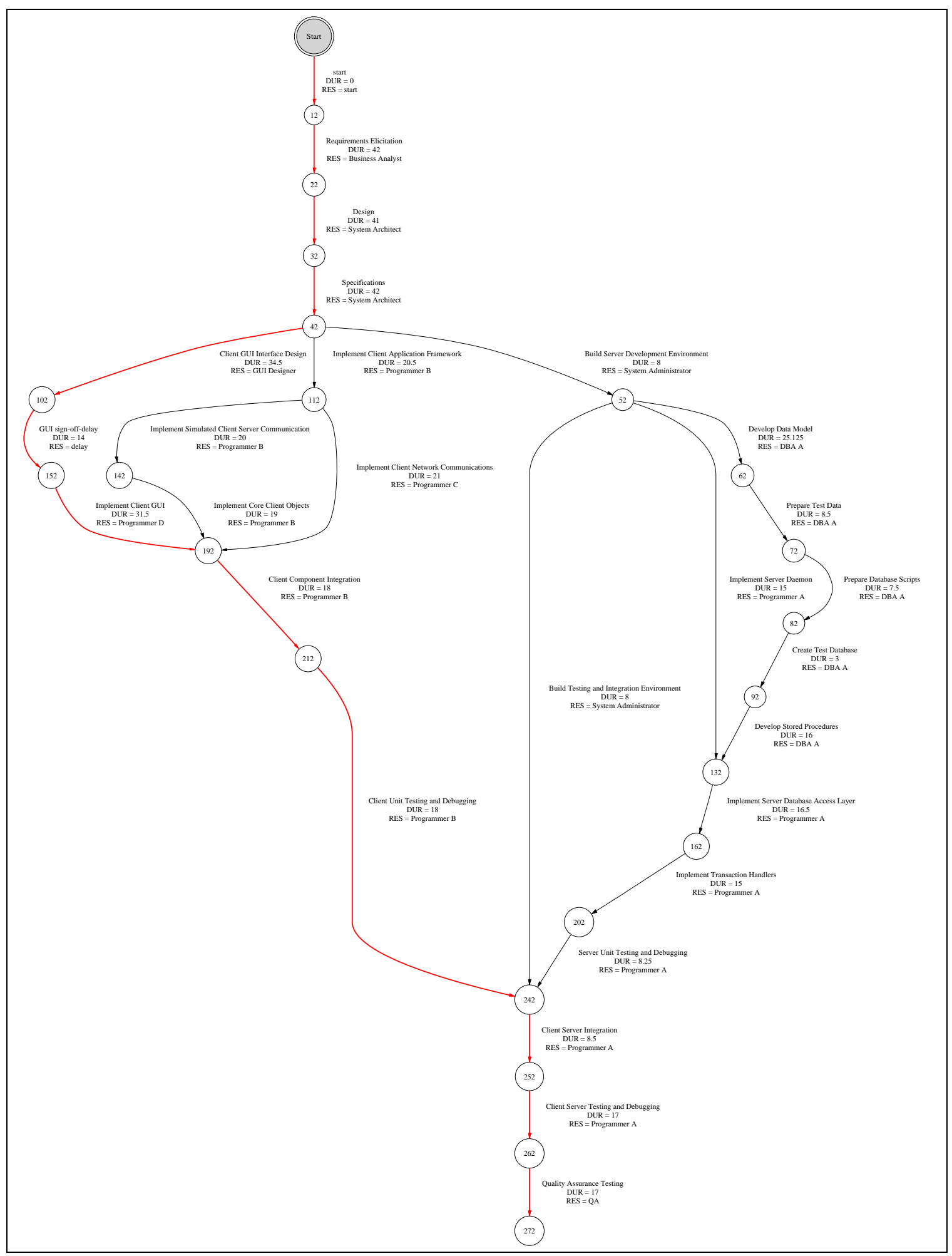

Figure 6-12 Client Server Application v2 - Scenario 3 Project Network 
Client Server Application v2 - Scenario 4 Project Network.

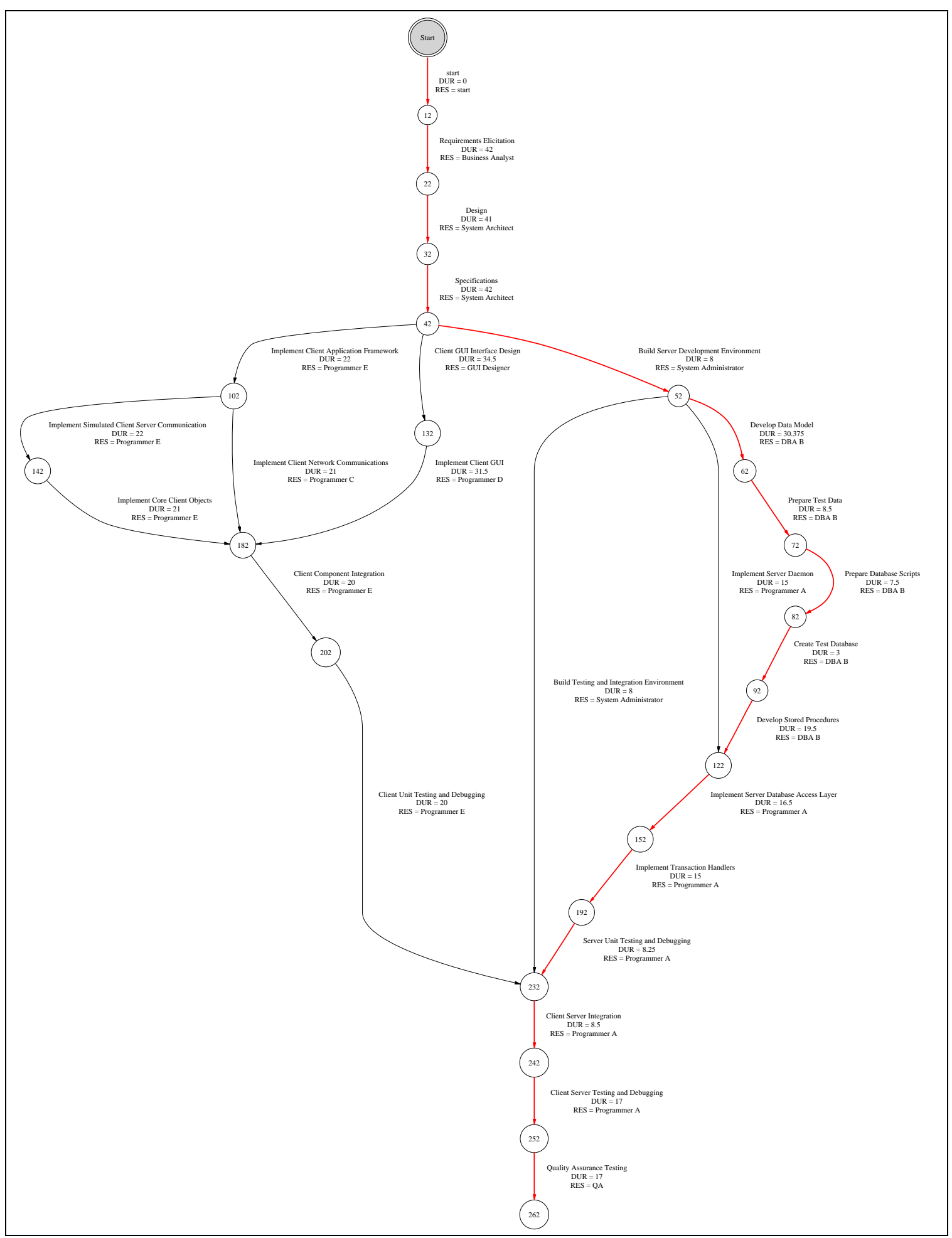

Figure 6-13 Client Server Application v2 - Scenario 4 Project Network 
Client Server Application v2 - Scenario 5 Project Network.

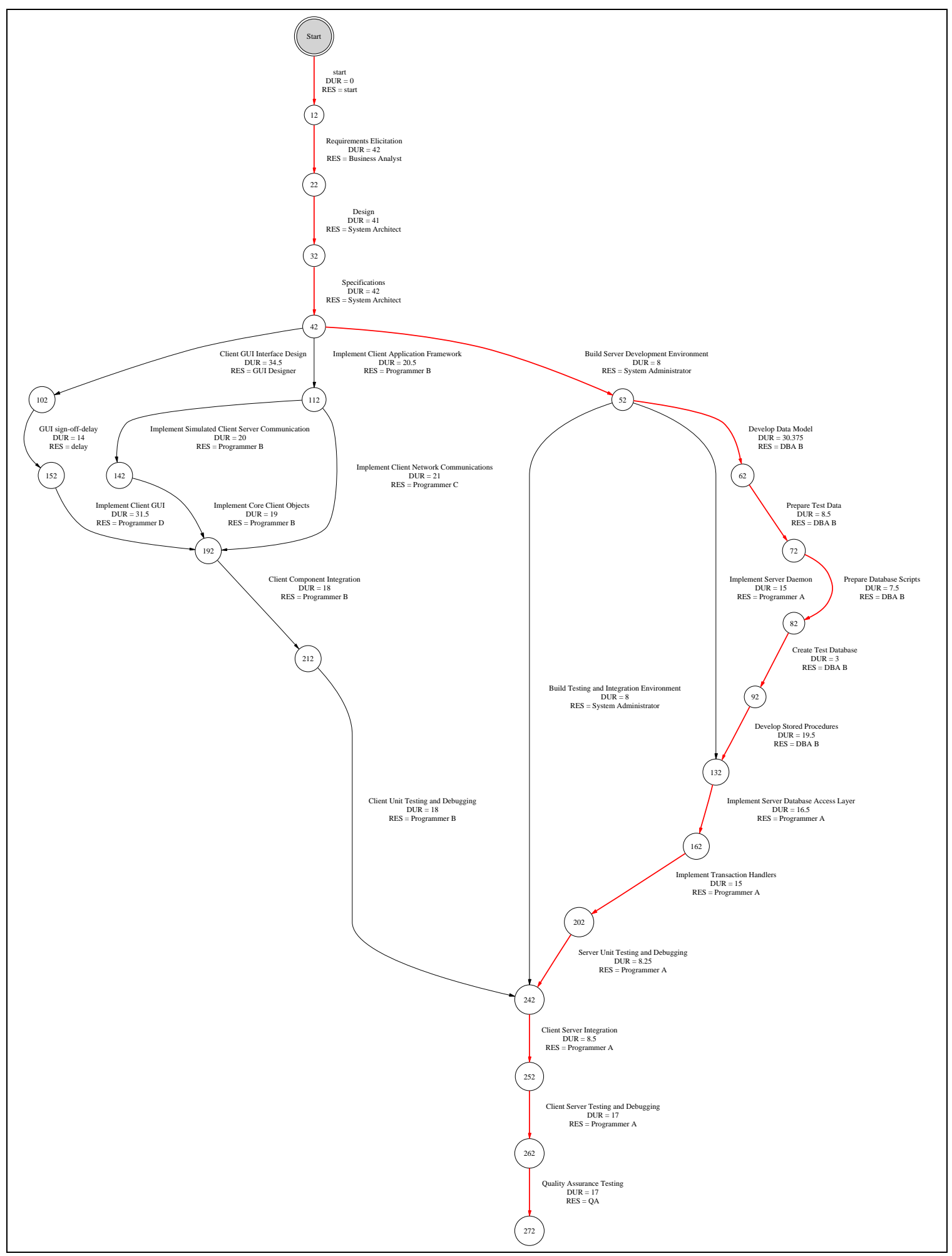

Figure 6-14 Client Server Application v2 - Scenario 5 Project Network 
Client Server Application v2 - Scenario 6 Project Network.

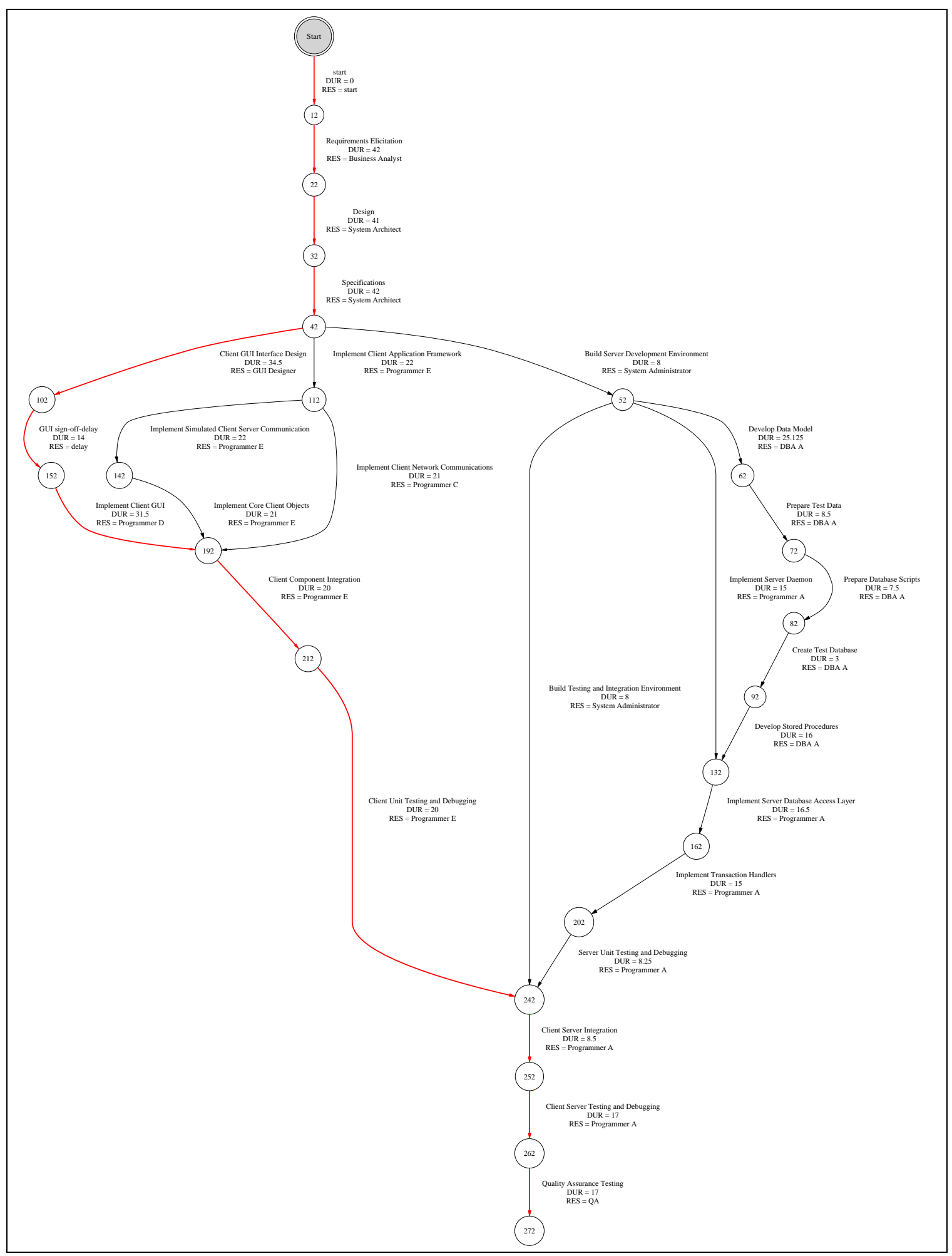

Figure 6-15 Client Server Application v2 - Scenario 6 Project Network 
Client Server Application v2 - Scenario 7 Project Network.

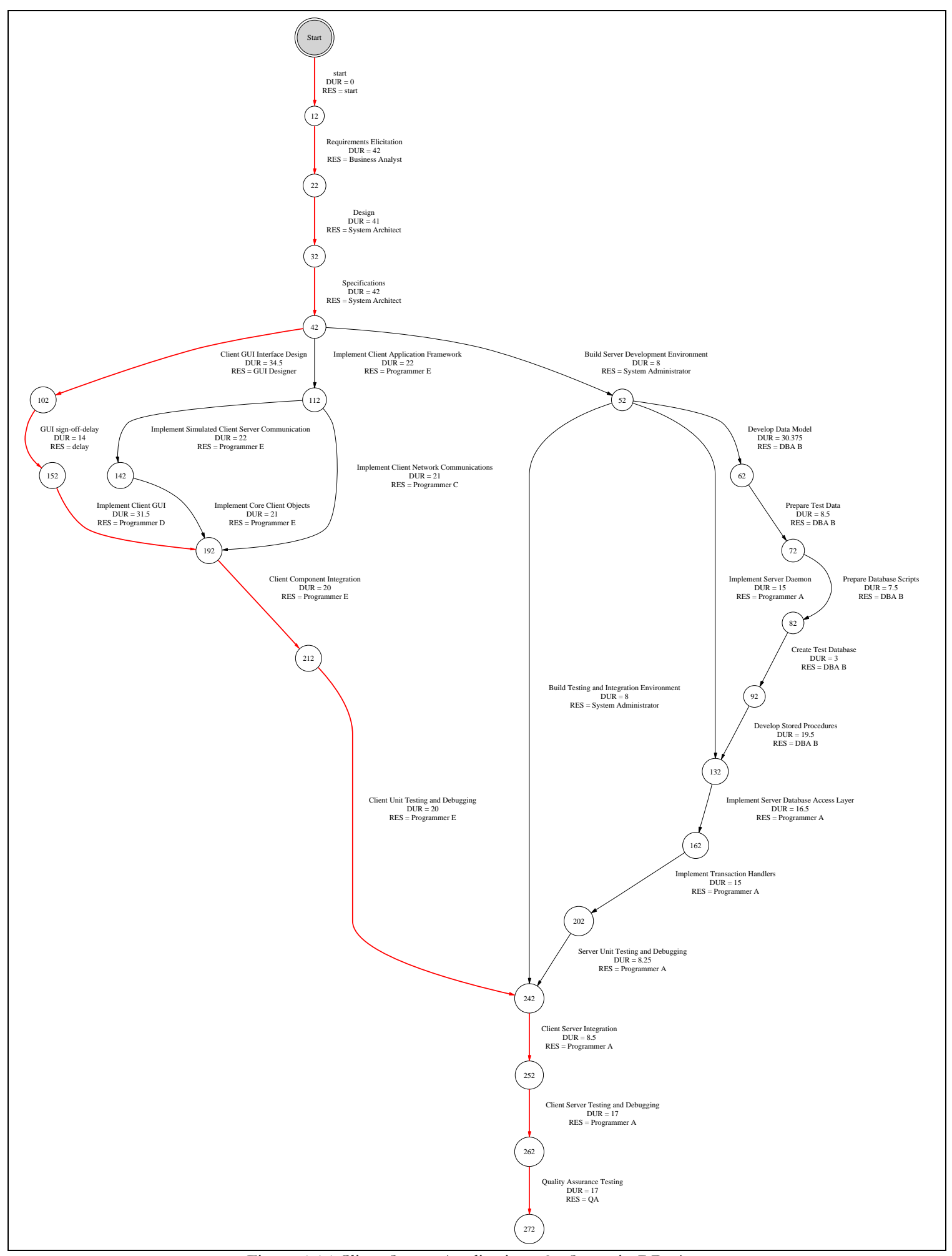

Figure 6-16 Client Server Application v2 - Scenario 7 Project Network 


\section{CPM Data and Schedules}

\section{Client Server Application v1 - Base Scenario CPM Data and Schedule}

Table 6-1 Client Server Application v1 - Base Scenario CPM Data

\begin{tabular}{|c|c|c|c|c|c|c|c|c|c|c|}
\hline CP & ES & EF & LS & LF & TS & FS & DUR & $\cos T$ & RESOURCE & TASK NAME \\
\hline * & 0 & 0 & 0 & 0 & 0 & 0 & 0 & $\$ 0.00$ & start & start \\
\hline * & 0 & 42 & 0 & 42 & 0 & 0 & 42 & $\$ 33,600.00$ & Business Analyst & Requirements Elicitation \\
\hline * & 42 & 83 & 42 & 83 & 0 & 0 & 41 & $\$ 41,000.00$ & System Architect & Design \\
\hline \multirow[t]{3}{*}{ * } & 83 & 125 & 83 & 125 & 0 & 0 & 42 & $\$ 42,000.00$ & System Architect & Specifications \\
\hline & 125 & 145.5 & 137.4 & 157.9 & 12.4 & 0 & 20.5 & $\$ 16,400.00$ & Programmer B & Implement Client Application Framework \\
\hline & 125 & 159.5 & 130.9 & 165.4 & 5.9 & 0 & 34.5 & $\$ 20,700.00$ & GUI Designer & Client GUI Interface Design \\
\hline \multirow[t]{3}{*}{ * } & 125 & 133 & 125 & 133 & 0 & 0 & 8 & $\$ 6,400.00$ & System Administrator & Build Server Development Environment \\
\hline & 133 & 148 & 178.1 & 193.1 & 45.1 & 45.1 & 15 & $\$ 18,000.00$ & Programmer A & Implement Server Daemon \\
\hline & 133 & 141 & 224.9 & 232.9 & 91.9 & 91.9 & 8 & $\$ 6,400.00$ & System Administrator & Build Testing and Integration Environment \\
\hline * & 133 & 158.1 & 133 & 158.1 & 0 & 0 & 25.1 & $\$ 25,125.00$ & DBA A & Develop Data Model \\
\hline * & 158.1 & 166.6 & 158.1 & 166.6 & 0 & 0 & 8.5 & $\$ 8,500.00$ & DBA A & Prepare Test Data \\
\hline * & 166.6 & 174.1 & 166.6 & 174.1 & 0 & 0 & 7.5 & $\$ 7,500.00$ & DBA A & Prepare Database Scripts \\
\hline * & 174.1 & 177.1 & 174.1 & 177.1 & 0 & 0 & 3 & $\$ 3,000.00$ & DBA A & Create Test Database \\
\hline * & 177.1 & 193.1 & 177.1 & 193.1 & 0 & 0 & 16 & $\$ 16,000.00$ & DBA A & Develop Stored Procedures \\
\hline * & 193.1 & 209.6 & 193.1 & 209.6 & 0 & 0 & 16.5 & $\$ 19,800.00$ & Programmer A & Implement Server Database Access Layer \\
\hline * & 209.6 & 224.6 & 209.6 & 224.6 & 0 & 0 & 15 & $\$ 18,000.00$ & Programmer A & Implement Transaction Handlers \\
\hline \multirow[t]{7}{*}{ * } & 224.6 & 232.9 & 224.6 & 232.9 & 0 & 0 & 8.3 & $\$ 9,900.00$ & Programmer A & Server Unit Testing and Debugging \\
\hline & 159.5 & 191 & 165.4 & 196.9 & 5.9 & 0 & 31.5 & $\$ 25,200.00$ & Programmer D & Implement Client GUI \\
\hline & 145.5 & 165.5 & 157.9 & 177.9 & 12.4 & 0 & 20 & $\$ 16,000.00$ & Programmer B & Implement Simulated Client Server Communication \\
\hline & 145.5 & 166.5 & 175.9 & 196.9 & 30.4 & 24.5 & 21 & $\$ 12,600.00$ & Programmer C & Implement Client Network Communications \\
\hline & 165.5 & 184.5 & 177.9 & 196.9 & 12.4 & 6.5 & 19 & $\$ 15,200.00$ & Programmer B & Implement Core Client Objects \\
\hline & 191 & 209 & 196.9 & 214.9 & 5.9 & 0 & 18 & $\$ 14,400.00$ & Programmer B & Client Component Integration \\
\hline & 209 & 227 & 214.9 & 232.9 & 5.9 & 5.9 & 18 & $\$ 14,400.00$ & Programmer B & Client Unit Testing and Debugging \\
\hline * & 232.9 & 241.4 & 232.9 & 241.4 & 0 & 0 & 8.5 & $\$ 10,200.00$ & Programmer A & Client Server Integration \\
\hline * & 241.4 & 258.4 & 241.4 & 258.4 & 0 & 0 & 17 & $\$ 20,400.00$ & Programmer A & Client Server Testing and Debugging \\
\hline \multirow[t]{4}{*}{ * } & 258.4 & 275.4 & 258.4 & 275.4 & 0 & 0 & 17 & $\$ 6,800.00$ & QA & Quality Assurance Testing \\
\hline & & & & & & & & & & \\
\hline & & & & & & & & & & Project Length (non-adjusted): 275.4 days \\
\hline & & & & & & & & & & Total Cost: $\$ 427525.00$ \\
\hline
\end{tabular}


Table 6-2 Client Server Application v1 - Base Scenario Schedule

\begin{tabular}{|l|l|l|l|}
\hline \multicolumn{1}{|c|}{ ES } & \multicolumn{1}{|c|}{ EF } & \multicolumn{1}{|c|}{ RESOURCE } & \multicolumn{1}{c|}{ TASK NAME } \\
\hline 0 & 0 & start & start \\
\hline 0 & 42 & Business Analyst & Requirements Elicitation \\
\hline 42 & 83 & System Architect & Design \\
\hline 83 & 125 & System Architect & Specifications \\
\hline 125 & 133 & System Administrator & Build Server Development Environment \\
\hline 125 & 159.5 & GUI Designer & Client GUI Interface Design \\
\hline 125 & 145.5 & Programmer B & Implement Client Application Framework \\
\hline 133 & 158.1 & DBA A & Develop Data Model \\
\hline 159.5 & 191 & Programmer D & Implement Client GUI \\
\hline 145.5 & 165.5 & Programmer B & Implement Simulated Client Server Communication \\
\hline 145.5 & 166.5 & Programmer C & Implement Client Network Communications \\
\hline 133 & 148 & Programmer A & Implement Server Daemon \\
\hline 133 & 141 & System Administrator & Build Testing and Integration Environment \\
\hline 158.1 & 166.6 & DBA A & Prepare Test Data \\
\hline 165.5 & 184.5 & Programmer B & Implement Core Client Objects \\
\hline 166.6 & 174.1 & DBA A & Prepare Database Scripts \\
\hline 191 & 209 & Programmer B & Client Component Integration \\
\hline 174.1 & 177.1 & DBA A & Create Test Database \\
\hline 209 & 227 & Programmer B & Client Unit Testing and Debugging \\
\hline 177.1 & 193.1 & DBA A & Develop Stored Procedures \\
\hline 193.1 & 209.6 & Programmer A & Implement Server Database Access Layer \\
\hline 209.6 & 224.6 & Programmer A & Implement Transaction Handlers \\
\hline 224.6 & 232.9 & Programmer A & Server Unit Testing and Debugging \\
\hline 232.9 & 241.4 & Programmer A & Client Server Integration \\
\hline 241.4 & 258.4 & Programmer A & Client Server Testing and Debugging \\
\hline 258.4 & 275.4 & QA & Quality Assurance Testing \\
\hline & & & \\
\hline & & & Project Length (adjusted): 275.4 days \\
\hline & & & Total Cost: \$427525.00 \\
\hline & & & \\
\hline & & & \\
\hline
\end{tabular}


Client Server Application v1 - Scenario 1 CPM Data and Schedule

Table 6-3 Client Server Application v1 - Scenario 1 CPM Data

\begin{tabular}{|c|c|c|c|c|c|c|c|c|c|c|}
\hline CP & ES & $\mathrm{EF}$ & LS & LF & TS & FS & DUR & $\cos \mathrm{T}$ & RESOURCE & TASK \\
\hline * & 0 & 0 & 0 & 0 & 0 & 0 & 0 & $\$ 0.00$ & start & start \\
\hline * & 0 & 42 & 0 & 42 & 0 & 0 & 42 & $\$ 33,600.00$ & Business Analyst & Requirements Elicitation \\
\hline * & 42 & 83 & 42 & 83 & 0 & 0 & 41 & $\$ 41,000.00$ & System Architect & Design \\
\hline \multirow[t]{3}{*}{ * } & 83 & 125 & 83 & 125 & 0 & 0 & 42 & $\$ 42,000.00$ & System Architect & Specifications \\
\hline & 125 & 145.5 & 161.3 & 181.8 & 36.3 & 0 & 20.5 & $\$ 16,400.00$ & Programmer B & Implement Client Application Framework \\
\hline & 125 & 159.5 & 154.8 & 189.3 & 29.8 & 0 & 34.5 & $\$ 20,700.00$ & GUI Designer & Client GUI Interface Design \\
\hline \multirow[t]{3}{*}{ * } & 125 & 133 & 125 & 133 & 0 & 0 & 8 & $\$ 6,400.00$ & System Administrator & Build Server Development Environment \\
\hline & 133 & 148 & 202.1 & 217.1 & 69.1 & 69.1 & 15 & $\$ 18,000.00$ & Programmer A & Implement Server Daemon \\
\hline & 133 & 141 & 248.8 & 256.8 & 115.8 & 115.8 & 8 & $\$ 6,400.00$ & System Administrator & Build Testing and Integration Environment \\
\hline * & 133 & 167.9 & 133 & 167.9 & 0 & 0 & 34.9 & $\$ 41,850.00$ & Programmer A & Develop Data Model \\
\hline * & 167.9 & 178.4 & 167.9 & 178.4 & 0 & 0 & 10.5 & $\$ 12,600.00$ & Programmer A & Prepare Test Data \\
\hline * & 178.4 & 189.3 & 178.4 & 189.3 & 0 & 0 & 10.9 & $\$ 13,050.00$ & Programmer A & Prepare Database Scripts \\
\hline * & 189.3 & 194.1 & 189.3 & 194.1 & 0 & 0 & 4.8 & $\$ 5,760.00$ & Programmer A & Create Test Database \\
\hline * & 194.1 & 217.1 & 194.1 & 217.1 & 0 & 0 & 23 & $\$ 27,600.00$ & Programmer A & Develop Stored Procedures \\
\hline * & 217.1 & 233.6 & 217.1 & 233.6 & 0 & 0 & 16.5 & $\$ 19,800.00$ & Programmer A & Implement Server Database Access Layer \\
\hline * & 233.6 & 248.6 & 233.6 & 248.6 & 0 & 0 & 15 & $\$ 18,000.00$ & Programmer A & Implement Transaction Handlers \\
\hline \multirow[t]{7}{*}{ * } & 248.6 & 256.8 & 248.6 & 256.8 & 0 & 0 & 8.3 & $\$ 9,900.00$ & Programmer A & Server Unit Testing and Debugging \\
\hline & 159.5 & 191 & 189.3 & 220.8 & 29.8 & 0 & 31.5 & $\$ 25,200.00$ & Programmer D & Implement Client GUI \\
\hline & 145.5 & 165.5 & 181.8 & 201.8 & 36.3 & 0 & 20 & $\$ 16,000.00$ & Programmer B & Implement Simulated Client Server Communication \\
\hline & 145.5 & 166.5 & 199.8 & 220.8 & 54.3 & 24.5 & 21 & $\$ 12,600.00$ & Programmer C & Implement Client Network Communications \\
\hline & 165.5 & 184.5 & 201.8 & 220.8 & 36.3 & 6.5 & 19 & $\$ 15,200.00$ & Programmer B & Implement Core Client Objects \\
\hline & 191 & 209 & 220.8 & 238.8 & 29.8 & 0 & 18 & $\$ 14,400.00$ & Programmer B & Client Component Integration \\
\hline & 209 & 227 & 238.8 & 256.8 & 29.8 & 29.8 & 18 & $\$ 14,400.00$ & Programmer B & Client Unit Testing and Debugging \\
\hline * & 256.8 & 265.3 & 256.8 & 265.3 & 0 & 0 & 8.5 & $\$ 10,200.00$ & Programmer A & Client Server Integration \\
\hline * & 265.3 & 282.3 & 265.3 & 282.3 & 0 & 0 & 17 & $\$ 20,400.00$ & Programmer A & Client Server Testing and Debugging \\
\hline \multirow[t]{4}{*}{ * } & 282.3 & 299.3 & 282.3 & 299.3 & 0 & 0 & 17 & $\$ 6,800.00$ & QA & Quality Assurance Testing \\
\hline & & & & & & & & & & \\
\hline & & & & & & & & & & Project Length (non-adjusted): 299.3 days \\
\hline & & & & & & & & & & Total Cost: $\$ 468260.00$ \\
\hline
\end{tabular}


Table 6-4 Client Server Application v1 - Scenario 1 Schedule

\begin{tabular}{|l|l|l|l|}
\hline \multicolumn{1}{|c|}{ ES } & \multicolumn{1}{|c|}{ EF } & \multicolumn{1}{|c|}{ RESOURCE } & \multicolumn{1}{c|}{ TASK NAME } \\
\hline 0 & 0 & start & start \\
\hline 0 & 42 & Business Analyst & Requirements Elicitation \\
\hline 42 & 83 & System Architect & Design \\
\hline 83 & 125 & System Architect & Specifications \\
\hline 125 & 133 & System Administrator & Build Server Development Environment \\
\hline 125 & 159.5 & GUI Designer & Client GUI Interface Design \\
\hline 125 & 145.5 & Programmer B & Implement Client Application Framework \\
\hline 133 & 167.9 & Programmer A & Develop Data Model \\
\hline 159.5 & 191 & Programmer D & Implement Client GUI \\
\hline 145.5 & 165.5 & Programmer B & Implement Simulated Client Server Communication \\
\hline 145.5 & 166.5 & Programmer C & Implement Client Network Communications \\
\hline 167.9 & 182.9 & Programmer A & Implement Server Daemon \\
\hline 133 & 141 & System Administrator & Build Testing and Integration Environment \\
\hline 182.9 & 193.4 & Programmer A & Prepare Test Data \\
\hline 165.5 & 184.5 & Programmer B & Implement Core Client Objects \\
\hline 193.4 & 204.3 & Programmer A & Prepare Database Scripts \\
\hline 191 & 209 & Programmer B & Client Component Integration \\
\hline 204.3 & 209.1 & Programmer A & Create Test Database \\
\hline 209 & 227 & Programmer B & Client Unit Testing and Debugging \\
\hline 209.1 & 232.1 & Programmer A & Develop Stored Procedures \\
\hline 232.1 & 248.6 & Programmer A & Implement Server Database Access Layer \\
\hline 248.6 & 263.6 & Programmer A & Implement Transaction Handlers \\
\hline 263.6 & 271.8 & Programmer A & Server Unit Testing and Debugging \\
\hline 271.8 & 280.3 & Programmer A & Client Server Integration \\
\hline 280.3 & 297.3 & Programmer A & Client Server Testing and Debugging \\
\hline 297.3 & 314.3 & QA & Quality Assurance Testing \\
\hline & & & \\
\hline & & & Project Length (adjusted): 314.3 days \\
\hline & & & Total Cost: \$468260.00 \\
\hline
\end{tabular}


Client Server Application v1 - Scenario 2 CPM Data and Schedule

Table 6-5 Client Server Application v1 - Scenario 2 CPM Data

\begin{tabular}{|c|c|c|c|c|c|c|c|c|c|c|}
\hline CP & ES & $\mathrm{EF}$ & LS & LF & TS & FS & DUR & $\cos \mathrm{T}$ & RESOURCE & TASK \\
\hline * & 0 & 0 & 0 & 0 & 0 & 0 & 0 & $\$ 0.00$ & start & start \\
\hline * & 0 & 42 & 0 & 42 & 0 & 0 & 42 & $\$ 33,600.00$ & Business Analyst & Requirements Elicitation \\
\hline * & 42 & 83 & 42 & 83 & 0 & 0 & 41 & $\$ 41,000.00$ & System Architect & Design \\
\hline * & 83 & 125 & 83 & 125 & 0 & 0 & 42 & $\$ 42,000.00$ & System Architect & Specifications \\
\hline \multirow[t]{14}{*}{ * } & 125 & 150 & 125 & 150 & 0 & 0 & 25 & $\$ 15,000.00$ & Programmer $\mathrm{C}$ & Implement Client Application Framework \\
\hline & 125 & 159.5 & 130 & 164.5 & 5 & 0 & 34.5 & $\$ 20,700.00$ & GUI Designer & Client GUI Interface Design \\
\hline & 125 & 133 & 138.1 & 146.1 & 13.1 & 0 & 8 & $\$ 6,400.00$ & System Administrator & Build Server Development Environment \\
\hline & 133 & 148 & 191.3 & 206.3 & 58.3 & 45.1 & 15 & $\$ 18,000.00$ & Programmer A & Implement Server Daemon \\
\hline & 133 & 141 & 238 & 246 & 105 & 105 & 8 & $\$ 6,400.00$ & System Administrator & Build Testing and Integration Environment \\
\hline & 133 & 158.1 & 146.1 & 171.3 & 13.1 & 0 & 25.1 & $\$ 25,125.00$ & DBA A & Develop Data Model \\
\hline & 158.1 & 166.6 & 171.3 & 179.8 & 13.1 & 0 & 8.5 & $\$ 8,500.00$ & DBA A & Prepare Test Data \\
\hline & 166.6 & 174.1 & 179.8 & 187.3 & 13.1 & 0 & 7.5 & $\$ 7,500.00$ & DBA A & Prepare Database Scripts \\
\hline & 174.1 & 177.1 & 187.3 & 190.3 & 13.1 & 0 & 3 & $\$ 3,000.00$ & DBA A & Create Test Database \\
\hline & 177.1 & 193.1 & 190.3 & 206.3 & 13.1 & 0 & 16 & $\$ 16,000.00$ & DBA A & Develop Stored Procedures \\
\hline & 193.1 & 209.6 & 206.3 & 222.8 & 13.1 & 0 & 16.5 & $\$ 19,800.00$ & Programmer A & Implement Server Database Access Layer \\
\hline & 209.6 & 224.6 & 222.8 & 237.8 & 13.1 & 0 & 15 & $\$ 18,000.00$ & Programmer A & Implement Transaction Handlers \\
\hline & 224.6 & 232.9 & 237.8 & 246 & 13.1 & 13.1 & 8.3 & $\$ 9,900.00$ & Programmer A & Server Unit Testing and Debugging \\
\hline & 159.5 & 191 & 164.5 & 196 & 5 & 5 & 31.5 & $\$ 25,200.00$ & Programmer D & Implement Client GUI \\
\hline \multirow[t]{2}{*}{ * } & 150 & 171 & 150 & 171 & 0 & 0 & 21 & $\$ 12,600.00$ & Programmer $\mathrm{C}$ & Implement Simulated Client Server Communication \\
\hline & 150 & 171 & 175 & 196 & 25 & 25 & 21 & $\$ 12,600.00$ & Programmer C & Implement Client Network Communications \\
\hline * & 171 & 196 & 171 & 196 & 0 & 0 & 25 & $\$ 15,000.00$ & Programmer C & Implement Core Client Objects \\
\hline * & 196 & 221 & 196 & 221 & 0 & 0 & 25 & $\$ 15,000.00$ & Programmer C & Client Component Integration \\
\hline * & 221 & 246 & 221 & 246 & 0 & 0 & 25 & $\$ 15,000.00$ & Programmer C & Client Unit Testing and Debugging \\
\hline * & 246 & 254.5 & 246 & 254.5 & 0 & 0 & 8.5 & $\$ 10,200.00$ & Programmer A & Client Server Integration \\
\hline * & 254.5 & 271.5 & 254.5 & 271.5 & 0 & 0 & 17 & $\$ 20,400.00$ & Programmer A & Client Server Testing and Debugging \\
\hline \multirow[t]{4}{*}{ * } & 271.5 & 288.5 & 271.5 & 288.5 & 0 & 0 & 17 & $\$ 6,800.00$ & QA & Quality Assurance Testing \\
\hline & & & & & & & & & & \\
\hline & & & & & & & & & & Project Length (non-adjusted): 288.5 days \\
\hline & & & & & & & & & & Total Cost: $\$ 423725.00$ \\
\hline
\end{tabular}


Table 6-6 Client Server Application v1 - Scenario 2 Schedule

\begin{tabular}{|l|l|l|l|}
\hline ES & \multicolumn{1}{|c|}{ EF } & \multicolumn{1}{|c|}{ RESOURCE } & \multicolumn{1}{c|}{ TASK NAME } \\
\hline 0 & 0 & start & start \\
\hline 0 & 42 & Business Analyst & Requirements Elicitation \\
\hline 42 & 83 & System Architect & Design \\
\hline 83 & 125 & System Architect & Specifications \\
\hline 125 & 150 & Programmer C & Implement Client Application Framework \\
\hline 125 & 159.5 & GUI Designer & Client GUI Interface Design \\
\hline 125 & 133 & System Administrator & Build Server Development Environment \\
\hline 150 & 171 & Programmer C & Implement Simulated Client Server Communication \\
\hline 159.5 & 191 & Programmer D & Implement Client GUI \\
\hline 133 & 158.1 & DBA A & Develop Data Model \\
\hline 171 & 192 & Programmer C & Implement Client Network Communications \\
\hline 133 & 148 & Programmer A & Implement Server Daemon \\
\hline 133 & 141 & System Administrator & Build Testing and Integration Environment \\
\hline 192 & 217 & Programmer C & Implement Core Client Objects \\
\hline 158.1 & 166.6 & DBA A & Prepare Test Data \\
\hline 217 & 242 & Programmer C & Client Component Integration \\
\hline 166.6 & 174.1 & DBA A & Prepare Database Scripts \\
\hline 242 & 267 & Programmer C & Client Unit Testing and Debugging \\
\hline 174.1 & 177.1 & DBA A & Create Test Database \\
\hline 177.1 & 193.1 & DBA A & Develop Stored Procedures \\
\hline 193.1 & 209.6 & Programmer A & Implement Server Database Access Layer \\
\hline 209.6 & 224.6 & Programmer A & Implement Transaction Handlers \\
\hline 224.6 & 232.9 & Programmer A & Server Unit Testing and Debugging \\
\hline 267 & 275.5 & Programmer A & Client Server Integration \\
\hline 275.5 & 292.5 & Programmer A & Client Server Testing and Debugging \\
\hline 292.5 & 309.5 & QA & Quality Assurance Testing \\
\hline & & & \\
\hline & & & Project Length (adjusted): 309.5 days \\
\hline & & & Total Cost: \$423725.00 \\
\hline
\end{tabular}


Client Server Application v1 - Scenario 3 CPM Data and Schedule

Table 6-7 Client Server Application v1 - Scenario 3 CPM Data

\begin{tabular}{|c|c|c|c|c|c|c|c|c|c|c|}
\hline CP & ES & EF & LS & LF & TS & FS & DUR & $\operatorname{cost}$ & RESOURCE & TASK \\
\hline * & 0 & 0 & 0 & 0 & 0 & 0 & 0 & $\$ 0.00$ & start & start \\
\hline * & 0 & 42 & 0 & 42 & 0 & 0 & 42 & $\$ 33,600.00$ & Business Analyst & Requirements Elicitation \\
\hline * & 42 & 83 & 42 & 83 & 0 & 0 & 41 & $\$ 41,000.00$ & System Architect & Design \\
\hline * & 83 & 125 & 83 & 125 & 0 & 0 & 42 & $\$ 42,000.00$ & System Architect & Specifications \\
\hline \multirow[t]{16}{*}{ * } & 125 & 159.5 & 125 & 159.5 & 0 & 0 & 34.5 & $\$ 20,700.00$ & GUI Designer & Client GUI Interface Design \\
\hline & 125 & 145.5 & 145.5 & 166 & 20.5 & 0 & 20.5 & $\$ 16,400.00$ & Programmer B & Implement Client Application Framework \\
\hline & 125 & 133 & 133.1 & 141.1 & 8.1 & 0 & 8 & $\$ 6,400.00$ & System Administrator & Build Server Development Environment \\
\hline & 133 & 148 & 186.3 & 201.3 & 53.3 & 45.1 & 15 & $\$ 18,000.00$ & Programmer A & Implement Server Daemon \\
\hline & 133 & 141 & 233 & 241 & 100 & 100 & 8 & $\$ 6,400.00$ & System Administrator & Build Testing and Integration Environment \\
\hline & 133 & 158.1 & 141.1 & 166.3 & 8.1 & 0 & 25.1 & $\$ 25,125.00$ & DBA A & Develop Data Model \\
\hline & 158.1 & 166.6 & 166.3 & 174.8 & 8.1 & 0 & 8.5 & $\$ 8,500.00$ & DBA A & Prepare Test Data \\
\hline & 166.6 & 174.1 & 174.8 & 182.3 & 8.1 & 0 & 7.5 & $\$ 7,500.00$ & DBA A & Prepare Database Scripts \\
\hline & 174.1 & 177.1 & 182.3 & 185.3 & 8.1 & 0 & 3 & $\$ 3,000.00$ & DBA A & Create Test Database \\
\hline & 177.1 & 193.1 & 185.3 & 201.3 & 8.1 & 0 & 16 & $\$ 16,000.00$ & DBA A & Develop Stored Procedures \\
\hline & 193.1 & 209.6 & 201.3 & 217.8 & 8.1 & 0 & 16.5 & $\$ 19,800.00$ & Programmer A & Implement Server Database Access Layer \\
\hline & 209.6 & 224.6 & 217.8 & 232.8 & 8.1 & 0 & 15 & $\$ 18,000.00$ & Programmer A & Implement Transaction Handlers \\
\hline & 224.6 & 232.9 & 232.8 & 241 & 8.1 & 8.1 & 8.3 & $\$ 9,900.00$ & Programmer A & Server Unit Testing and Debugging \\
\hline & 145.5 & 165.5 & 166 & 186 & 20.5 & 0 & 20 & $\$ 16,000.00$ & Programmer B & Implement Simulated Client Server Communication \\
\hline & 145.5 & 166.5 & 184 & 205 & 38.5 & 38.5 & 21 & $\$ 12,600.00$ & Programmer C & Implement Client Network Communications \\
\hline & 165.5 & 184.5 & 186 & 205 & 20.5 & 20.5 & 19 & $\$ 15,200.00$ & Programmer B & Implement Core Client Objects \\
\hline * & 159.5 & 173.5 & 159.5 & 173.5 & 0 & 0 & 14 & $\$ 0.00$ & delay & GUI sign-off delay \\
\hline * & 173.5 & 205 & 173.5 & 205 & 0 & 0 & 31.5 & $\$ 25,200.00$ & Programmer D & Implement Client GUI \\
\hline * & 205 & 223 & 205 & 223 & 0 & 0 & 18 & $\$ 14,400.00$ & Programmer B & Client Component Integration \\
\hline * & 223 & 241 & 223 & 241 & 0 & 0 & 18 & $\$ 14,400.00$ & Programmer B & Client Unit Testing and Debugging \\
\hline * & 241 & 249.5 & 241 & 249.5 & 0 & 0 & 8.5 & $\$ 10,200.00$ & Programmer A & Client Server Integration \\
\hline * & 249.5 & 266.5 & 249.5 & 266.5 & 0 & 0 & 17 & $\$ 20,400.00$ & Programmer A & Client Server Testing and Debugging \\
\hline \multirow[t]{4}{*}{ * } & 266.5 & 283.5 & 266.5 & 283.5 & 0 & 0 & 17 & $\$ 6,800.00$ & QA & Quality Assurance Testing \\
\hline & & & & & & & & & & \\
\hline & & & & & & & & & & Project Length (non-adjusted): 283.5 days \\
\hline & & & & & & & & & & Total Cost: $\$ 427525.00$ \\
\hline
\end{tabular}


Table 6-8 Client Server Application v1 - Scenario 3 Schedule

\begin{tabular}{|l|l|l|l|}
\hline \multicolumn{1}{|c|}{ ES } & \multicolumn{1}{|c|}{ EF } & \multicolumn{1}{c|}{ RESOURCE } & \multicolumn{1}{c|}{ TASK NAME } \\
\hline 0 & 0 & start & start \\
\hline 0 & 42 & Business Analyst & Requirements Elicitation \\
\hline 42 & 83 & System Architect & Design \\
\hline 83 & 125 & System Architect & Specifications \\
\hline 125 & 159.5 & GUI Designer & Client GUI Interface Design \\
\hline 125 & 133 & System Administrator & Build Server Development Environment \\
\hline 125 & 145.5 & Programmer B & Implement Client Application Framework \\
\hline 159.5 & 173.5 & delay & GUI sign-off delay \\
\hline 133 & 158.1 & DBA A & Develop Data Model \\
\hline 145.5 & 165.5 & Programmer B & Implement Simulated Client Server Communication \\
\hline 145.5 & 166.5 & Programmer C & Implement Client Network Communications \\
\hline 133 & 148 & Programmer A & Implement Server Daemon \\
\hline 133 & 141 & System Administrator & Build Testing and Integration Environment \\
\hline 173.5 & 205 & Programmer D & Implement Client GUI \\
\hline 158.1 & 166.6 & DBA A & Prepare Test Data \\
\hline 165.5 & 184.5 & Programmer B & Implement Core Client Objects \\
\hline 205 & 223 & Programmer B & Client Component Integration \\
\hline 166.6 & 174.1 & DBA A & Prepare Database Scripts \\
\hline 223 & 241 & Programmer B & Client Unit Testing and Debugging \\
\hline 174.1 & 177.1 & DBA A & Create Test Database \\
\hline 177.1 & 193.1 & DBA A & Develop Stored Procedures \\
\hline 193.1 & 209.6 & Programmer A & Implement Server Database Access Layer \\
\hline 209.6 & 224.6 & Programmer A & Implement Transaction Handlers \\
\hline 224.6 & 232.9 & Programmer A & Server Unit Testing and Debugging \\
\hline 241 & 249.5 & Programmer A & Client Server Integration \\
\hline 249.5 & 266.5 & Programmer A & Client Server Testing and Debugging \\
\hline 266.5 & 283.5 & QA & Quality Assurance Testing \\
\hline & & & \\
\hline & & & Project Length (adjusted): 283.5 days \\
\hline & & & Total Cost: \$427525.00 \\
\hline
\end{tabular}


Client Server Application v1 - Scenario 4 CPM Data and Schedule

Table 6-9 Client Server Application v1 - Scenario 4 CPM Data

\begin{tabular}{|c|c|c|c|c|c|c|c|c|c|c|}
\hline CP & ES & $\mathrm{EF}$ & LS & LF & TS & FS & DUR & $\cos \mathrm{T}$ & RESOURCE & TASK \\
\hline * & 0 & 0 & 0 & 0 & 0 & 0 & 0 & $\$ 0.00$ & start & start \\
\hline * & 0 & 42 & 0 & 42 & 0 & 0 & 42 & $\$ 33,600.00$ & Business Analyst & Requirements Elicitation \\
\hline * & 42 & 83 & 42 & 83 & 0 & 0 & 41 & $\$ 41,000.00$ & System Architect & Design \\
\hline \multirow[t]{3}{*}{ * } & 83 & 125 & 83 & 125 & 0 & 0 & 42 & $\$ 42,000.00$ & System Architect & Specifications \\
\hline & 125 & 150 & 135.8 & 160.8 & 10.8 & 0 & 25 & $\$ 15,000.00$ & Programmer C & Implement Client Application Framework \\
\hline & 125 & 159.5 & 140.8 & 175.3 & 15.8 & 0 & 34.5 & $\$ 20,700.00$ & GUI Designer & Client GUI Interface Design \\
\hline \multirow[t]{3}{*}{ * } & 125 & 133 & 125 & 133 & 0 & 0 & 8 & $\$ 6,400.00$ & System Administrator & Build Server Development Environment \\
\hline & 133 & 148 & 202.1 & 217.1 & 69.1 & 69.1 & 15 & $\$ 18,000.00$ & Programmer A & Implement Server Daemon \\
\hline & 133 & 141 & 248.8 & 256.8 & 115.8 & 115.8 & 8 & $\$ 6,400.00$ & System Administrator & Build Testing and Integration Environment \\
\hline * & 133 & 167.9 & 133 & 167.9 & 0 & 0 & 34.9 & $\$ 41,850.00$ & Programmer A & Develop Data Model \\
\hline * & 167.9 & 178.4 & 167.9 & 178.4 & 0 & 0 & 10.5 & $\$ 12,600.00$ & Programmer A & Prepare Test Data \\
\hline * & 178.4 & 189.3 & 178.4 & 189.3 & 0 & 0 & 10.9 & $\$ 13,050.00$ & Programmer A & Prepare Database Scripts \\
\hline * & 189.3 & 194.1 & 189.3 & 194.1 & 0 & 0 & 4.8 & $\$ 5,760.00$ & Programmer A & Create Test Database \\
\hline * & 194.1 & 217.1 & 194.1 & 217.1 & 0 & 0 & 23 & $\$ 27,600.00$ & Programmer A & Develop Stored Procedures \\
\hline * & 217.1 & 233.6 & 217.1 & 233.6 & 0 & 0 & 16.5 & $\$ 19,800.00$ & Programmer A & Implement Server Database Access Layer \\
\hline * & 233.6 & 248.6 & 233.6 & 248.6 & 0 & 0 & 15 & $\$ 18,000.00$ & Programmer A & Implement Transaction Handlers \\
\hline \multirow[t]{7}{*}{ * } & 248.6 & 256.8 & 248.6 & 256.8 & 0 & 0 & 8.3 & $\$ 9,900.00$ & Programmer A & Server Unit Testing and Debugging \\
\hline & 159.5 & 191 & 175.3 & 206.8 & 15.8 & 5 & 31.5 & $\$ 25,200.00$ & Programmer D & Implement Client GUI \\
\hline & 150 & 171 & 160.8 & 181.8 & 10.8 & 0 & 21 & $\$ 12,600.00$ & Programmer C & Implement Simulated Client Server Communication \\
\hline & 150 & 171 & 185.8 & 206.8 & 35.8 & 25 & 21 & $\$ 12,600.00$ & Programmer $\mathrm{C}$ & Implement Client Network Communications \\
\hline & 171 & 196 & 181.8 & 206.8 & 10.8 & 0 & 25 & $\$ 15,000.00$ & Programmer C & Implement Core Client Objects \\
\hline & 196 & 221 & 206.8 & 231.8 & 10.8 & 0 & 25 & $\$ 15,000.00$ & Programmer $\mathrm{C}$ & Client Component Integration \\
\hline & 221 & 246 & 231.8 & 256.8 & 10.8 & 10.8 & 25 & $\$ 15,000.00$ & Programmer C & Client Unit Testing and Debugging \\
\hline * & 256.8 & 265.3 & 256.8 & 265.3 & 0 & 0 & 8.5 & $\$ 10,200.00$ & Programmer A & Client Server Integration \\
\hline * & 265.3 & 282.3 & 265.3 & 282.3 & 0 & 0 & 17 & $\$ 20,400.00$ & Programmer A & Client Server Testing and Debugging \\
\hline \multirow[t]{4}{*}{ * } & 282.3 & 299.3 & 282.3 & 299.3 & 0 & 0 & 17 & $\$ 6,800.00$ & QA & Quality Assurance Testing \\
\hline & & & & & & & & & & \\
\hline & & & & & & & & & & Project Length (non-adjusted): 299.3 days \\
\hline & & & & & & & & & & Total Cost: $\$ 464460.00$ \\
\hline
\end{tabular}


Table 6-10 Client Server Application v1 - Scenario 4 Schedule

\begin{tabular}{|l|l|l|l|}
\hline \multicolumn{1}{|c|}{ ES } & \multicolumn{1}{|c|}{ EF } & \multicolumn{1}{|c|}{ RESOURCE } & \multicolumn{1}{c|}{ TASK NAME } \\
\hline 0 & 0 & start & start \\
\hline 0 & 42 & Business Analyst & Requirements Elicitation \\
\hline 42 & 83 & System Architect & Design \\
\hline 83 & 125 & System Architect & Specifications \\
\hline 125 & 133 & System Administrator & Build Server Development Environment \\
\hline 125 & 150 & Programmer C & Implement Client Application Framework \\
\hline 125 & 159.5 & GUI Designer & Client GUI Interface Design \\
\hline 133 & 167.9 & Programmer A & Develop Data Model \\
\hline 150 & 171 & Programmer C & Implement Simulated Client Server Communication \\
\hline 159.5 & 191 & Programmer D & Implement Client GUI \\
\hline 171 & 192 & Programmer C & Implement Client Network Communications \\
\hline 167.9 & 182.9 & Programmer A & Implement Server Daemon \\
\hline 133 & 141 & System Administrator & Build Testing and Integration Environment \\
\hline 182.9 & 193.4 & Programmer A & Prepare Test Data \\
\hline 192 & 217 & Programmer C & Implement Core Client Objects \\
\hline 193.4 & 204.3 & Programmer A & Prepare Database Scripts \\
\hline 217 & 242 & Programmer C & Client Component Integration \\
\hline 204.3 & 209.1 & Programmer A & Create Test Database \\
\hline 242 & 267 & Programmer C & Client Unit Testing and Debugging \\
\hline 209.1 & 232.1 & Programmer A & Develop Stored Procedures \\
\hline 232.1 & 248.6 & Programmer A & Implement Server Database Access Layer \\
\hline 248.6 & 263.6 & Programmer A & Implement Transaction Handlers \\
\hline 263.6 & 271.8 & Programmer A & Server Unit Testing and Debugging \\
\hline 271.8 & 280.3 & Programmer A & Client Server Integration \\
\hline 280.3 & 297.3 & Programmer A & Client Server Testing and Debugging \\
\hline 297.3 & 314.3 & QA & Quality Assurance Testing \\
\hline & & & \\
\hline & & & Project Length (adjusted): 314.3 days \\
\hline & & & Total Cost: \$464460.00 \\
\hline
\end{tabular}


Client Server Application v1 - Scenario 5 CPM Data and Schedule

Table 6-11 Client Server Application v1 - Scenario 5 CPM Data

\begin{tabular}{|c|c|c|c|c|c|c|c|c|c|c|}
\hline CP & ES & EF & LS & LF & TS & FS & DUR & $\operatorname{cost}$ & RESOURCE & TASK \\
\hline * & 0 & 0 & 0 & 0 & 0 & 0 & 0 & $\$ 0.00$ & start & start \\
\hline * & 0 & 42 & 0 & 42 & 0 & 0 & 42 & $\$ 33,600.00$ & Business Analyst & Requirements Elicitation \\
\hline * & 42 & 83 & 42 & 83 & 0 & 0 & 41 & $\$ 41,000.00$ & System Architect & Design \\
\hline \multirow[t]{3}{*}{ * } & 83 & 125 & 83 & 125 & 0 & 0 & 42 & $\$ 42,000.00$ & System Architect & Specifications \\
\hline & 125 & 159.5 & 140.8 & 175.3 & 15.8 & 0 & 34.5 & $\$ 20,700.00$ & GUI Designer & Client GUI Interface Design \\
\hline & 125 & 145.5 & 161.3 & 181.8 & 36.3 & 0 & 20.5 & $\$ 16,400.00$ & Programmer B & Implement Client Application Framework \\
\hline \multirow[t]{3}{*}{ * } & 125 & 133 & 125 & 133 & 0 & 0 & 8 & $\$ 6,400.00$ & System Administrator & Build Server Development Environment \\
\hline & 133 & 148 & 202.1 & 217.1 & 69.1 & 69.1 & 15 & $\$ 18,000.00$ & Programmer A & Implement Server Daemon \\
\hline & 133 & 141 & 248.8 & 256.8 & 115.8 & 115.8 & 8 & $\$ 6,400.00$ & System Administrator & Build Testing and Integration Environment \\
\hline * & 133 & 167.9 & 133 & 167.9 & 0 & 0 & 34.9 & $\$ 41,850.00$ & Programmer A & Develop Data Model \\
\hline * & 167.9 & 178.4 & 167.9 & 178.4 & 0 & 0 & 10.5 & $\$ 12,600.00$ & Programmer A & Prepare Test Data \\
\hline * & 178.4 & 189.3 & 178.4 & 189.3 & 0 & 0 & 10.9 & $\$ 13,050.00$ & Programmer A & Prepare Database Scripts \\
\hline * & 189.3 & 194.1 & 189.3 & 194.1 & 0 & 0 & 4.8 & $\$ 5,760.00$ & Programmer A & Create Test Database \\
\hline * & 194.1 & 217.1 & 194.1 & 217.1 & 0 & 0 & 23 & $\$ 27,600.00$ & Programmer A & Develop Stored Procedures \\
\hline * & 217.1 & 233.6 & 217.1 & 233.6 & 0 & 0 & 16.5 & $\$ 19,800.00$ & Programmer A & Implement Server Database Access Layer \\
\hline * & 233.6 & 248.6 & 233.6 & 248.6 & 0 & 0 & 15 & $\$ 18,000.00$ & Programmer A & Implement Transaction Handlers \\
\hline \multirow[t]{8}{*}{ * } & 248.6 & 256.8 & 248.6 & 256.8 & 0 & 0 & 8.3 & $\$ 9,900.00$ & Programmer A & Server Unit Testing and Debugging \\
\hline & 145.5 & 165.5 & 181.8 & 201.8 & 36.3 & 0 & 20 & $\$ 16,000.00$ & Programmer B & Implement Simulated Client Server Communication \\
\hline & 145.5 & 166.5 & 199.8 & 220.8 & 54.3 & 38.5 & 21 & $\$ 12,600.00$ & Programmer C & Implement Client Network Communications \\
\hline & 165.5 & 184.5 & 201.8 & 220.8 & 36.3 & 20.5 & 19 & $\$ 15,200.00$ & Programmer B & Implement Core Client Objects \\
\hline & 159.5 & 173.5 & 175.3 & 189.3 & 15.8 & 0 & 14 & $\$ 0.00$ & delay & GUI sign-off delay \\
\hline & 173.5 & 205 & 189.3 & 220.8 & 15.8 & 0 & 31.5 & $\$ 25,200.00$ & Programmer D & Implement Client GUI \\
\hline & 205 & 223 & 220.8 & 238.8 & 15.8 & 0 & 18 & $\$ 14,400.00$ & Programmer B & Client Component Integration \\
\hline & 223 & 241 & 238.8 & 256.8 & 15.8 & 15.8 & 18 & $\$ 14,400.00$ & Programmer B & Client Unit Testing and Debugging \\
\hline * & 256.8 & 265.3 & 256.8 & 265.3 & 0 & 0 & 8.5 & $\$ 10,200.00$ & Programmer A & Client Server Integration \\
\hline * & 265.3 & 282.3 & 265.3 & 282.3 & 0 & 0 & 17 & $\$ 20,400.00$ & Programmer A & Client Server Testing and Debugging \\
\hline \multirow[t]{4}{*}{ * } & 282.3 & 299.3 & 282.3 & 299.3 & 0 & 0 & 17 & $\$ 6,800.00$ & QA & Quality Assurance Testing \\
\hline & & & & & & & & & & \\
\hline & & & & & & & & & & Project Length (non-adjusted): 299.3 days \\
\hline & & & & & & & & & & Total Cost: $\$ 468260.00$ \\
\hline
\end{tabular}


Table 6-12 Client Server Application v1 - Scenario 5 Schedule

\begin{tabular}{|l|l|l|l|}
\hline \multicolumn{1}{|c|}{ ES } & \multicolumn{1}{|c|}{ EF } & \multicolumn{1}{|c|}{ RESOURCE } & \multicolumn{1}{c|}{ TASK NAME } \\
\hline 0 & 0 & start & start \\
\hline 0 & 42 & Business Analyst & Requirements Elicitation \\
\hline 42 & 83 & System Architect & Design \\
\hline 83 & 125 & System Architect & Specifications \\
\hline 125 & 133 & System Administrator & Build Server Development Environment \\
\hline 125 & 159.5 & GUI Designer & Client GUI Interface Design \\
\hline 125 & 145.5 & Programmer B & Implement Client Application Framework \\
\hline 133 & 167.9 & Programmer A & Develop Data Model \\
\hline 159.5 & 173.5 & delay & GUI sign-off delay \\
\hline 145.5 & 165.5 & Programmer B & Implement Simulated Client Server Communication \\
\hline 145.5 & 166.5 & Programmer C & Implement Client Network Communications \\
\hline 167.9 & 182.9 & Programmer A & Implement Server Daemon \\
\hline 133 & 141 & System Administrator & Build Testing and Integration Environment \\
\hline 182.9 & 193.4 & Programmer A & Prepare Test Data \\
\hline 173.5 & 205 & Programmer D & Implement Client GUI \\
\hline 165.5 & 184.5 & Programmer B & Implement Core Client Objects \\
\hline 193.4 & 204.3 & Programmer A & Prepare Database Scripts \\
\hline 205 & 223 & Programmer B & Client Component Integration \\
\hline 204.3 & 209.1 & Programmer A & Create Test Database \\
\hline 223 & 241 & Programmer B & Client Unit Testing and Debugging \\
\hline 209.1 & 232.1 & Programmer A & Develop Stored Procedures \\
\hline 232.1 & 248.6 & Programmer A & Implement Server Database Access Layer \\
\hline 248.6 & 263.6 & Programmer A & Implement Transaction Handlers \\
\hline 263.6 & 271.8 & Programmer A & Server Unit Testing and Debugging \\
\hline 271.8 & 280.3 & Programmer A & Client Server Integration \\
\hline 280.3 & 297.3 & Programmer A & Client Server Testing and Debugging \\
\hline 297.3 & 314.3 & QA & Quality Assurance Testing \\
\hline & & & \\
\hline & & & Project Length (adjusted): 314.3 days \\
\hline & & & Total Cost: \$468260.00 \\
\hline
\end{tabular}


Client Server Application v1 - Scenario 6 CPM Data and Schedule

Table 6-13 Client Server Application v1 - Scenario 6 CPM Data

\begin{tabular}{|c|c|c|c|c|c|c|c|c|c|c|}
\hline CP & ES & EF & LS & LF & TS & FS & DUR & $\operatorname{cost}$ & RESOURCE & TASK \\
\hline * & 0 & 0 & 0 & 0 & 0 & 0 & 0 & $\$ 0.00$ & start & start \\
\hline * & 0 & 42 & 0 & 42 & 0 & 0 & 42 & $\$ 33,600.00$ & Business Analyst & Requirements Elicitation \\
\hline * & 42 & 83 & 42 & 83 & 0 & 0 & 41 & $\$ 41,000.00$ & System Architect & Design \\
\hline * & 83 & 125 & 83 & 125 & 0 & 0 & 42 & $\$ 42,000.00$ & System Architect & Specifications \\
\hline \multirow[t]{16}{*}{ * } & 125 & 159.5 & 125 & 159.5 & 0 & 0 & 34.5 & $\$ 20,700.00$ & GUI Designer & Client GUI Interface Design \\
\hline & 125 & 150 & 134 & 159 & 9 & 0 & 25 & $\$ 15,000.00$ & Programmer C & Implement Client Application Framework \\
\hline & 125 & 133 & 147.1 & 155.1 & 22.1 & 0 & 8 & $\$ 6,400.00$ & System Administrator & Build Server Development Environment \\
\hline & 133 & 148 & 200.3 & 215.3 & 67.3 & 45.1 & 15 & $\$ 18,000.00$ & Programmer A & Implement Server Daemon \\
\hline & 133 & 141 & 247 & 255 & 114 & 114 & 8 & $\$ 6,400.00$ & System Administrator & Build Testing and Integration Environment \\
\hline & 133 & 158.1 & 155.1 & 180.3 & 22.1 & 0 & 25.1 & $\$ 25,125.00$ & DBA A & Develop Data Model \\
\hline & 158.1 & 166.6 & 180.3 & 188.8 & 22.1 & 0 & 8.5 & $\$ 8,500.00$ & DBA A & Prepare Test Data \\
\hline & 166.6 & 174.1 & 188.8 & 196.3 & 22.1 & 0 & 7.5 & $\$ 7,500.00$ & DBA A & Prepare Database Scripts \\
\hline & 174.1 & 177.1 & 196.3 & 199.3 & 22.1 & 0 & 3 & $\$ 3,000.00$ & DBA A & Create Test Database \\
\hline & 177.1 & 193.1 & 199.3 & 215.3 & 22.1 & 0 & 16 & $\$ 16,000.00$ & DBA A & Develop Stored Procedures \\
\hline & 193.1 & 209.6 & 215.3 & 231.8 & 22.1 & 0 & 16.5 & $\$ 19,800.00$ & Programmer A & Implement Server Database Access Layer \\
\hline & 209.6 & 224.6 & 231.8 & 246.8 & 22.1 & 0 & 15 & $\$ 18,000.00$ & Programmer A & Implement Transaction Handlers \\
\hline & 224.6 & 232.9 & 246.8 & 255 & 22.1 & 22.1 & 8.3 & $\$ 9,900.00$ & Programmer A & Server Unit Testing and Debugging \\
\hline & 150 & 171 & 159 & 180 & 9 & 0 & 21 & $\$ 12,600.00$ & Programmer C & Implement Simulated Client Server Communication \\
\hline & 150 & 171 & 184 & 205 & 34 & 34 & 21 & $\$ 12,600.00$ & Programmer C & Implement Client Network Communications \\
\hline & 171 & 196 & 180 & 205 & 9 & 9 & 25 & $\$ 15,000.00$ & Programmer $\mathrm{C}$ & Implement Core Client Objects \\
\hline * & 159.5 & 173.5 & 159.5 & 173.5 & 0 & 0 & 14 & $\$ 0.00$ & delay & GUI sign-off delay \\
\hline * & 173.5 & 205 & 173.5 & 205 & 0 & 0 & 31.5 & $\$ 25,200.00$ & Programmer D & Implement Client GUI \\
\hline * & 205 & 230 & 205 & 230 & 0 & 0 & 25 & $\$ 15,000.00$ & Programmer C & Client Component Integration \\
\hline * & 230 & 255 & 230 & 255 & 0 & 0 & 25 & $\$ 15,000.00$ & Programmer C & Client Unit Testing and Debugging \\
\hline * & 255 & 263.5 & 255 & 263.5 & 0 & 0 & 8.5 & $\$ 10,200.00$ & Programmer A & Client Server Integration \\
\hline * & 263.5 & 280.5 & 263.5 & 280.5 & 0 & 0 & 17 & $\$ 20,400.00$ & Programmer A & Client Server Testing and Debugging \\
\hline \multirow[t]{4}{*}{ * } & 280.5 & 297.5 & 280.5 & 297.5 & 0 & 0 & 17 & $\$ 6,800.00$ & QA & Quality Assurance Testing \\
\hline & & & & & & & & & & \\
\hline & & & & & & & & & & Project Length (non-adjusted): 297.5 days \\
\hline & & & & & & & & & & Total Cost: $\$ 423725.00$ \\
\hline
\end{tabular}


Table 6-14 Client Server Application v1 - Scenario 6 Schedule

\begin{tabular}{|l|l|l|l|}
\hline \multicolumn{1}{|c|}{ ES } & \multicolumn{1}{|c|}{ EF } & \multicolumn{1}{c|}{ RESOURCE } & \multicolumn{1}{c|}{ TASK NAME } \\
\hline 0 & 0 & start & start \\
\hline 0 & 42 & Business Analyst & Requirements Elicitation \\
\hline 42 & 83 & System Architect & Design \\
\hline 83 & 125 & System Architect & Specifications \\
\hline 125 & 159.5 & GUI Designer & Client GUI Interface Design \\
\hline 125 & 150 & Programmer C & Implement Client Application Framework \\
\hline 125 & 133 & System Administrator & Build Server Development Environment \\
\hline 159.5 & 173.5 & delay & GUI sign-off delay \\
\hline 150 & 171 & Programmer C & Implement Simulated Client Server Communication \\
\hline 133 & 158.1 & DBA A & Develop Data Model \\
\hline 171 & 192 & Programmer C & Implement Client Network Communications \\
\hline 133 & 148 & Programmer A & Implement Server Daemon \\
\hline 133 & 141 & System Administrator & Build Testing and Integration Environment \\
\hline 173.5 & 205 & Programmer D & Implement Client GUI \\
\hline 192 & 217 & Programmer C & Implement Core Client Objects \\
\hline 158.1 & 166.6 & DBA A & Prepare Test Data \\
\hline 217 & 242 & Programmer C & Client Component Integration \\
\hline 166.6 & 174.1 & DBA A & Prepare Database Scripts \\
\hline 242 & 267 & Programmer C & Client Unit Testing and Debugging \\
\hline 174.1 & 177.1 & DBA A & Create Test Database \\
\hline 177.1 & 193.1 & DBA A & Develop Stored Procedures \\
\hline 193.1 & 209.6 & Programmer A & Implement Server Database Access Layer \\
\hline 209.6 & 224.6 & Programmer A & Implement Transaction Handlers \\
\hline 224.6 & 232.9 & Programmer A & Server Unit Testing and Debugging \\
\hline 267 & 275.5 & Programmer A & Client Server Integration \\
\hline 275.5 & 292.5 & Programmer A & Client Server Testing and Debugging \\
\hline 292.5 & 309.5 & QA & Quality Assurance Testing \\
\hline & & & \\
\hline & & & Project Length (adjusted): 309.5 days \\
\hline & & & Total Cost: \$423725.00 \\
\hline
\end{tabular}


Client Server Application v1 - Scenario 7 CPM Data and Schedule

Table 6-15 Client Server Application v1 - Scenario 7 CPM Data

\begin{tabular}{|c|c|c|c|c|c|c|c|c|c|c|}
\hline CP & ES & EF & LS & LF & TS & FS & DUR & $\operatorname{cost}$ & RESOURCE & TASK \\
\hline * & 0 & 0 & 0 & 0 & 0 & 0 & 0 & $\$ 0.00$ & start & start \\
\hline * & 0 & 42 & 0 & 42 & 0 & 0 & 42 & $\$ 33,600.00$ & Business Analyst & Requirements Elicitation \\
\hline * & 42 & 83 & 42 & 83 & 0 & 0 & 41 & $\$ 41,000.00$ & System Architect & Design \\
\hline \multirow[t]{3}{*}{ * } & 83 & 125 & 83 & 125 & 0 & 0 & 42 & $\$ 42,000.00$ & System Architect & Specifications \\
\hline & 125 & 159.5 & 126.8 & 161.3 & 1.8 & 0 & 34.5 & $\$ 20,700.00$ & GUI Designer & Client GUI Interface Design \\
\hline & 125 & 150 & 135.8 & 160.8 & 10.8 & 0 & 25 & $\$ 15,000.00$ & Programmer C & Implement Client Application Framework \\
\hline \multirow[t]{3}{*}{ * } & 125 & 133 & 125 & 133 & 0 & 0 & 8 & $\$ 6,400.00$ & System Administrator & Build Server Development Environment \\
\hline & 133 & 148 & 202.1 & 217.1 & 69.1 & 69.1 & 15 & $\$ 18,000.00$ & Programmer A & Implement Server Daemon \\
\hline & 133 & 141 & 248.8 & 256.8 & 115.8 & 115.8 & 8 & $\$ 6,400.00$ & System Administrator & Build Testing and Integration Environment \\
\hline * & 133 & 167.9 & 133 & 167.9 & 0 & 0 & 34.9 & $\$ 41,850.00$ & Programmer A & Develop Data Model \\
\hline * & 167.9 & 178.4 & 167.9 & 178.4 & 0 & 0 & 10.5 & $\$ 12,600.00$ & Programmer A & Prepare Test Data \\
\hline * & 178.4 & 189.3 & 178.4 & 189.3 & 0 & 0 & 10.9 & $\$ 13,050.00$ & Programmer A & Prepare Database Scripts \\
\hline * & 189.3 & 194.1 & 189.3 & 194.1 & 0 & 0 & 4.8 & $\$ 5,760.00$ & Programmer A & Create Test Database \\
\hline * & 194.1 & 217.1 & 194.1 & 217.1 & 0 & 0 & 23 & $\$ 27,600.00$ & Programmer A & Develop Stored Procedures \\
\hline * & 217.1 & 233.6 & 217.1 & 233.6 & 0 & 0 & 16.5 & $\$ 19,800.00$ & Programmer A & Implement Server Database Access Layer \\
\hline * & 233.6 & 248.6 & 233.6 & 248.6 & 0 & 0 & 15 & $\$ 18,000.00$ & Programmer A & Implement Transaction Handlers \\
\hline \multirow[t]{8}{*}{ * } & 248.6 & 256.8 & 248.6 & 256.8 & 0 & 0 & 8.3 & $\$ 9,900.00$ & Programmer A & Server Unit Testing and Debugging \\
\hline & 150 & 171 & 160.8 & 181.8 & 10.8 & 0 & 21 & $\$ 12,600.00$ & Programmer C & Implement Simulated Client Server Communication \\
\hline & 150 & 171 & 185.8 & 206.8 & 35.8 & 34 & 21 & $\$ 12,600.00$ & Programmer C & Implement Client Network Communications \\
\hline & 171 & 196 & 181.8 & 206.8 & 10.8 & 9 & 25 & $\$ 15,000.00$ & Programmer C & Implement Core Client Objects \\
\hline & 159.5 & 173.5 & 161.3 & 175.3 & 1.8 & 0 & 14 & $\$ 0.00$ & delay & GUI sign-off delay \\
\hline & 173.5 & 205 & 175.3 & 206.8 & 1.8 & 0 & 31.5 & $\$ 25,200.00$ & Programmer D & Implement Client GUI \\
\hline & 205 & 230 & 206.8 & 231.8 & 1.8 & 0 & 25 & $\$ 15,000.00$ & Programmer C & Client Component Integration \\
\hline & 230 & 255 & 231.8 & 256.8 & 1.8 & 1.8 & 25 & $\$ 15,000.00$ & Programmer C & Client Unit Testing and Debugging \\
\hline * & 256.8 & 265.3 & 256.8 & 265.3 & 0 & 0 & 8.5 & $\$ 10,200.00$ & Programmer A & Client Server Integration \\
\hline * & 265.3 & 282.3 & 265.3 & 282.3 & 0 & 0 & 17 & $\$ 20,400.00$ & Programmer A & Client Server Testing and Debugging \\
\hline \multirow[t]{4}{*}{ * } & 282.3 & 299.3 & 282.3 & 299.3 & 0 & 0 & 17 & $\$ 6,800.00$ & QA & Quality Assurance Testing \\
\hline & & & & & & & & & & \\
\hline & & & & & & & & & & Project Length (non-adjusted): 299.3 days \\
\hline & & & & & & & & & & Total Cost: $\$ 464460.00$ \\
\hline
\end{tabular}


Table 6-16 Client Server Application v1 - Scenario 7 Schedule

\begin{tabular}{|l|l|l|l|}
\hline \multicolumn{1}{|c|}{ ES } & \multicolumn{1}{|c|}{ EF } & \multicolumn{1}{c|}{ RESOURCE } & \multicolumn{1}{c|}{ TASK NAME } \\
\hline 0 & 0 & start & start \\
\hline 0 & 42 & Business Analyst & Requirements Elicitation \\
\hline 42 & 83 & System Architect & Design \\
\hline 83 & 125 & System Architect & Specifications \\
\hline 125 & 133 & System Administrator & Build Server Development Environment \\
\hline 125 & 159.5 & GUI Designer & Client GUI Interface Design \\
\hline 125 & 150 & Programmer C & Implement Client Application Framework \\
\hline 133 & 167.9 & Programmer A & Develop Data Model \\
\hline 159.5 & 173.5 & delay & GUI sign-off delay \\
\hline 150 & 171 & Programmer C & Implement Simulated Client Server Communication \\
\hline 171 & 192 & Programmer C & Implement Client Network Communications \\
\hline 167.9 & 182.9 & Programmer A & Implement Server Daemon \\
\hline 133 & 141 & System Administrator & Build Testing and Integration Environment \\
\hline 182.9 & 193.4 & Programmer A & Prepare Test Data \\
\hline 173.5 & 205 & Programmer D & Implement Client GUI \\
\hline 192 & 217 & Programmer C & Implement Core Client Objects \\
\hline 193.4 & 204.3 & Programmer A & Prepare Database Scripts \\
\hline 217 & 242 & Programmer C & Client Component Integration \\
\hline 204.3 & 209.1 & Programmer A & Create Test Database \\
\hline 242 & 267 & Programmer C & Client Unit Testing and Debugging \\
\hline 209.1 & 232.1 & Programmer A & Develop Stored Procedures \\
\hline 232.1 & 248.6 & Programmer A & Implement Server Database Access Layer \\
\hline 248.6 & 263.6 & Programmer A & Implement Transaction Handlers \\
\hline 263.6 & 271.8 & Programmer A & Server Unit Testing and Debugging \\
\hline 271.8 & 280.3 & Programmer A & Client Server Integration \\
\hline 280.3 & 297.3 & Programmer A & Client Server Testing and Debugging \\
\hline 297.3 & 314.3 & QA & Quality Assurance Testing \\
\hline & & & \\
\hline & & & Project Length (adjusted): 314.3 days \\
\hline & & & Total Cost: \$464460.00 \\
\hline
\end{tabular}


Client Server Application v2 - Base Scenario CPM Data and Schedule

Table 6-17 Client Server Application v2 - Base Scenario CPM

\begin{tabular}{|c|c|c|c|c|c|c|c|c|c|c|}
\hline CP & ES & $\mathrm{EF}$ & LS & LF & TS & FS & DUR & cost & RESOURCE & TASK NAME \\
\hline * & 0 & 0 & 0 & 0 & 0 & 0 & 0 & $\$ 0.00$ & start & start \\
\hline * & 0 & 42 & 0 & 42 & 0 & 0 & 42 & $\$ 33,600.00$ & Business Analyst & Requirements Elicitation \\
\hline * & 42 & 83 & 42 & 83 & 0 & 0 & 41 & $\$ 41,000.00$ & System Architect & Design \\
\hline \multirow[t]{3}{*}{ * } & 83 & 125 & 83 & 125 & 0 & 0 & 42 & $\$ 42,000.00$ & System Architect & Specifications \\
\hline & 125 & 145.5 & 137.4 & 157.9 & 12.4 & 0 & 20.5 & $\$ 16,400.00$ & Programmer B & Implement Client Application Framework \\
\hline & 125 & 159.5 & 130.9 & 165.4 & 5.9 & 0 & 34.5 & $\$ 20,700.00$ & GUI Designer & Client GUI Interface Design \\
\hline \multirow[t]{3}{*}{ * } & 125 & 133 & 125 & 133 & 0 & 0 & 8 & $\$ 6,400.00$ & System Administrator & Build Server Development Environment \\
\hline & 133 & 148 & 178.1 & 193.1 & 45.1 & 45.1 & 15 & $\$ 18,000.00$ & Programmer A & Implement Server Daemon \\
\hline & 133 & 141 & 224.9 & 232.9 & 91.9 & 91.9 & 8 & $\$ 6,400.00$ & System Administrator & Build Testing and Integration Environment \\
\hline * & 133 & 158.1 & 133 & 158.1 & 0 & 0 & 25.1 & $\$ 25,125.00$ & DBA A & Develop Data Model \\
\hline * & 158.1 & 166.6 & 158.1 & 166.6 & 0 & 0 & 8.5 & $\$ 8,500.00$ & DBA A & Prepare Test Data \\
\hline * & 166.6 & 174.1 & 166.6 & 174.1 & 0 & 0 & 7.5 & $\$ 7,500.00$ & DBA A & Prepare Database Scripts \\
\hline * & 174.1 & 177.1 & 174.1 & 177.1 & 0 & 0 & 3 & $\$ 3,000.00$ & DBA A & Create Test Database \\
\hline * & 177.1 & 193.1 & 177.1 & 193.1 & 0 & 0 & 16 & $\$ 16,000.00$ & DBA A & Develop Stored Procedures \\
\hline * & 193.1 & 209.6 & 193.1 & 209.6 & 0 & 0 & 16.5 & $\$ 19,800.00$ & Programmer A & Implement Server Database Access Layer \\
\hline * & 209.6 & 224.6 & 209.6 & 224.6 & 0 & 0 & 15 & $\$ 18,000.00$ & Programmer A & Implement Transaction Handlers \\
\hline \multirow[t]{7}{*}{ * } & 224.6 & 232.9 & 224.6 & 232.9 & 0 & 0 & 8.3 & $\$ 9,900.00$ & Programmer A & Server Unit Testing and Debugging \\
\hline & 159.5 & 191 & 165.4 & 196.9 & 5.9 & 0 & 31.5 & $\$ 25,200.00$ & Programmer D & Implement Client GUI \\
\hline & 145.5 & 165.5 & 157.9 & 177.9 & 12.4 & 0 & 20 & $\$ 16,000.00$ & Programmer B & Implement Simulated Client Server Communication \\
\hline & 145.5 & 166.5 & 175.9 & 196.9 & 30.4 & 24.5 & 21 & $\$ 12,600.00$ & Programmer C & Implement Client Network Communications \\
\hline & 165.5 & 184.5 & 177.9 & 196.9 & 12.4 & 6.5 & 19 & $\$ 15,200.00$ & Programmer B & Implement Core Client Objects \\
\hline & 191 & 209 & 196.9 & 214.9 & 5.9 & 0 & 18 & $\$ 14,400.00$ & Programmer B & Client Component Integration \\
\hline & 209 & 227 & 214.9 & 232.9 & 5.9 & 5.9 & 18 & $\$ 14,400.00$ & Programmer B & Client Unit Testing and Debugging \\
\hline * & 232.9 & 241.4 & 232.9 & 241.4 & 0 & 0 & 8.5 & $\$ 10,200.00$ & Programmer A & Client Server Integration \\
\hline * & 241.4 & 258.4 & 241.4 & 258.4 & 0 & 0 & 17 & $\$ 20,400.00$ & Programmer A & Client Server Testing and Debugging \\
\hline \multirow[t]{4}{*}{ * } & 258.4 & 275.4 & 258.4 & 275.4 & 0 & 0 & 17 & $\$ 6,800.00$ & QA & Quality Assurance Testing \\
\hline & & & & & & & & & & \\
\hline & & & & & & & & & & Project Length (non-adjusted): 275.4 days \\
\hline & & & & & & & & & & Total Cost: $\$ 427525.00$ \\
\hline
\end{tabular}


Table 6-18 Client Server Application v2 - Base Scenario Schedule

\begin{tabular}{|l|l|l|l|}
\hline \multicolumn{1}{|c|}{ ES } & \multicolumn{1}{|c|}{ EF } & \multicolumn{1}{|c|}{ RESOURCE } & \\
\hline 0 & 0 & start & start \\
\hline 0 & 42 & Business Analyst & Requirements Elicitation \\
\hline 42 & 83 & System Architect & Design \\
\hline 83 & 125 & System Architect & Specifications \\
\hline 125 & 133 & System Administrator & Build Server Development Environment \\
\hline 125 & 159.5 & GUI Designer & Client GUI Interface Design \\
\hline 125 & 145.5 & Programmer B & Implement Client Application Framework \\
\hline 133 & 158.1 & DBA A & Develop Data Model \\
\hline 159.5 & 191 & Programmer D & Implement Client GUI \\
\hline 145.5 & 165.5 & Programmer B & Implement Simulated Client Server Communication \\
\hline 145.5 & 166.5 & Programmer C & Implement Client Network Communications \\
\hline 133 & 148 & Programmer A & Implement Server Daemon \\
\hline 133 & 141 & System Administrator & Build Testing and Integration Environment \\
\hline 158.1 & 166.6 & DBA A & Prepare Test Data \\
\hline 165.5 & 184.5 & Programmer B & Implement Core Client Objects \\
\hline 166.6 & 174.1 & DBA A & Prepare Database Scripts \\
\hline 191 & 209 & Programmer B & Client Component Integration \\
\hline 174.1 & 177.1 & DBA A & Create Test Database \\
\hline 209 & 227 & Programmer B & Client Unit Testing and Debugging \\
\hline 177.1 & 193.1 & DBA A & Develop Stored Procedures \\
\hline 193.1 & 209.6 & Programmer A & Implement Server Database Access Layer \\
\hline 209.6 & 224.6 & Programmer A & Implement Transaction Handlers \\
\hline 224.6 & 232.9 & Programmer A & Server Unit Testing and Debugging \\
\hline 232.9 & 241.4 & Programmer A & Client Server Integration \\
\hline 241.4 & 258.4 & Programmer A & Client Server Testing and Debugging \\
\hline 258.4 & 275.4 & QA & Quality Assurance Testing \\
\hline & & & \\
\hline & & & Project Length (adjusted): 275.4 days \\
\hline & & & Total Cost: \$427525.00 \\
\hline & & & \\
\hline
\end{tabular}


Client Server Application v2 - Scenario 1 CPM Data and Schedule

Table 6-19 Client Server Application v2 - Scenario 1 CPM Data

\begin{tabular}{|c|c|c|c|c|c|c|c|c|c|c|}
\hline $\mathrm{CP}$ & ES & EF & LS & LF & TS & FS & DUR & $\cos T$ & RESOURCE & TASK NAME \\
\hline * & 0 & 0 & 0 & 0 & 0 & 0 & 0 & $\$ 0.00$ & start & start \\
\hline * & 0 & 42 & 0 & 42 & 0 & 0 & 42 & $\$ 33,600.00$ & Business Analyst & Requirements Elicitation \\
\hline * & 42 & 83 & 42 & 83 & 0 & 0 & 41 & $\$ 41,000.00$ & System Architect & Design \\
\hline \multirow[t]{3}{*}{ * } & 83 & 125 & 83 & 125 & 0 & 0 & 42 & $\$ 42,000.00$ & System Architect & Specifications \\
\hline & 125 & 145.5 & 146.1 & 166.6 & 21.1 & 0 & 20.5 & $\$ 16,400.00$ & Programmer B & Implement Client Application Framework \\
\hline & 125 & 159.5 & 139.6 & 174.1 & 14.6 & 0 & 34.5 & $\$ 20,700.00$ & GUI Designer & Client GUI Interface Design \\
\hline \multirow[t]{3}{*}{ * } & 125 & 133 & 125 & 133 & 0 & 0 & 8 & $\$ 6,400.00$ & System Administrator & Build Server Development Environment \\
\hline & 133 & 148 & 186.9 & 201.9 & 53.9 & 53.9 & 15 & $\$ 18,000.00$ & Programmer A & Implement Server Daemon \\
\hline & 133 & 141 & 233.6 & 241.6 & 100.6 & 100.6 & 8 & $\$ 6,400.00$ & System Administrator & Build Testing and Integration Environment \\
\hline * & 133 & 163.4 & 133 & 163.4 & 0 & 0 & 30.4 & $\$ 24,300.00$ & DBA B & Develop Data Model \\
\hline * & 163.4 & 171.9 & 163.4 & 171.9 & 0 & 0 & 8.5 & $\$ 6,800.00$ & DBA B & Prepare Test Data \\
\hline * & 171.9 & 179.4 & 171.9 & 179.4 & 0 & 0 & 7.5 & $\$ 6,000.00$ & DBA B & Prepare Database Scripts \\
\hline * & 179.4 & 182.4 & 179.4 & 182.4 & 0 & 0 & 3 & $\$ 2,400.00$ & DBA B & Create Test Database \\
\hline * & 182.4 & 201.9 & 182.4 & 201.9 & 0 & 0 & 19.5 & $\$ 15,600.00$ & DBA B & Develop Stored Procedures \\
\hline * & 201.9 & 218.4 & 201.9 & 218.4 & 0 & 0 & 16.5 & $\$ 19,800.00$ & Programmer A & Implement Server Database Access Layer \\
\hline * & 218.4 & 233.4 & 218.4 & 233.4 & 0 & 0 & 15 & $\$ 18,000.00$ & Programmer A & Implement Transaction Handlers \\
\hline \multirow[t]{7}{*}{ * } & 233.4 & 241.6 & 233.4 & 241.6 & 0 & 0 & 8.3 & $\$ 9,900.00$ & Programmer A & Server Unit Testing and Debugging \\
\hline & 159.5 & 191 & 174.1 & 205.6 & 14.6 & 0 & 31.5 & $\$ 25,200.00$ & Programmer D & Implement Client GUI \\
\hline & 145.5 & 165.5 & 166.6 & 186.6 & 21.1 & 0 & 20 & $\$ 16,000.00$ & Programmer B & Implement Simulated Client Server Communication \\
\hline & 145.5 & 166.5 & 184.6 & 205.6 & 39.1 & 24.5 & 21 & $\$ 12,600.00$ & Programmer $\mathrm{C}$ & Implement Client Network Communications \\
\hline & 165.5 & 184.5 & 186.6 & 205.6 & 21.1 & 6.5 & 19 & $\$ 15,200.00$ & Programmer B & Implement Core Client Objects \\
\hline & 191 & 209 & 205.6 & 223.6 & 14.6 & 0 & 18 & $\$ 14,400.00$ & Programmer B & Client Component Integration \\
\hline & 209 & 227 & 223.6 & 241.6 & 14.6 & 14.6 & 18 & $\$ 14,400.00$ & Programmer B & Client Unit Testing and Debugging \\
\hline * & 241.6 & 250.1 & 241.6 & 250.1 & 0 & 0 & 8.5 & $\$ 10,200.00$ & Programmer A & Client Server Integration \\
\hline * & 250.1 & 267.1 & 250.1 & 267.1 & 0 & 0 & 17 & $\$ 20,400.00$ & Programmer A & Client Server Testing and Debugging \\
\hline \multirow[t]{4}{*}{ * } & 267.1 & 284.1 & 267.1 & 284.1 & 0 & 0 & 17 & $\$ 6,800.00$ & QA & Quality Assurance Testing \\
\hline & & & & & & & & & & \\
\hline & & & & & & & & & & Project Length (non-adjusted): 284.1 days \\
\hline & & & & & & & & & & Total Cost: $\$ 422500.00$ \\
\hline
\end{tabular}


Table 6-20 Client Server Application v2 - Scenario 1 Schedule

\begin{tabular}{|l|l|l|l|}
\hline \multicolumn{1}{|c|}{ ES } & \multicolumn{1}{|c|}{ EF } & \multicolumn{1}{|c|}{ RESOURCE } & \multicolumn{1}{c|}{ TASK NAME } \\
\hline 0 & 0 & start & start \\
\hline 0 & 42 & Business Analyst & Requirements Elicitation \\
\hline 42 & 83 & System Architect & Design \\
\hline 83 & 125 & System Architect & Specifications \\
\hline 125 & 133 & System Administrator & Build Server Development Environment \\
\hline 125 & 159.5 & GUI Designer & Client GUI Interface Design \\
\hline 125 & 145.5 & Programmer B & Implement Client Application Framework \\
\hline 133 & 163.4 & DBA B & Develop Data Model \\
\hline 159.5 & 191 & Programmer D & Implement Client GUI \\
\hline 145.5 & 165.5 & Programmer B & Implement Simulated Client Server Communication \\
\hline 145.5 & 166.5 & Programmer C & Implement Client Network Communications \\
\hline 133 & 148 & Programmer A & Implement Server Daemon \\
\hline 133 & 141 & System Administrator & Build Testing and Integration Environment \\
\hline 163.4 & 171.9 & DBA B & Prepare Test Data \\
\hline 165.5 & 184.5 & Programmer B & Implement Core Client Objects \\
\hline 171.9 & 179.4 & DBA B & Prepare Database Scripts \\
\hline 191 & 209 & Programmer B & Client Component Integration \\
\hline 179.4 & 182.4 & DBA B & Create Test Database \\
\hline 209 & 227 & Programmer B & Client Unit Testing and Debugging \\
\hline 182.4 & 201.9 & DBA B & Develop Stored Procedures \\
\hline 201.9 & 218.4 & Programmer A & Implement Server Database Access Layer \\
\hline 218.4 & 233.4 & Programmer A & Implement Transaction Handlers \\
\hline 233.4 & 241.6 & Programmer A & Server Unit Testing and Debugging \\
\hline 241.6 & 250.1 & Programmer A & Client Server Integration \\
\hline 250.1 & 267.1 & Programmer A & Client Server Testing and Debugging \\
\hline 267.1 & 284.1 & QA & Quality Assurance Testing \\
\hline & & & \\
\hline & & & Project Length (adjusted): 284.1 days \\
\hline & & & Total Cost: \$422500.00 \\
\hline
\end{tabular}


Client Server Application v2 - Scenario 2 CPM Data and Schedule

Table 6-21 Client Server Application v2 - Scenario 2 CPM Data

\begin{tabular}{|c|c|c|c|c|c|c|c|c|c|c|}
\hline CP & ES & EF & LS & LF & TS & FS & DUR & $\cos T$ & RESOURCE & TASK NAME \\
\hline * & 0 & 0 & 0 & 0 & 0 & 0 & 0 & $\$ 0.00$ & start & start \\
\hline * & 0 & 42 & 0 & 42 & 0 & 0 & 42 & $\$ 33,600.00$ & Business Analyst & Requirements Elicitation \\
\hline * & 42 & 83 & 42 & 83 & 0 & 0 & 41 & $\$ 41,000.00$ & System Architect & Design \\
\hline \multirow[t]{3}{*}{ * } & 83 & 125 & 83 & 125 & 0 & 0 & 42 & $\$ 42,000.00$ & System Architect & Specifications \\
\hline & 125 & 147 & 127.9 & 149.9 & 2.9 & 0 & 22 & $\$ 14,960.00$ & Programmer E & Implement Client Application Framework \\
\hline & 125 & 159.5 & 126.9 & 161.4 & 1.9 & 0 & 34.5 & $\$ 20,700.00$ & GUI Designer & Client GUI Interface Design \\
\hline \multirow[t]{3}{*}{ * } & 125 & 133 & 125 & 133 & 0 & 0 & 8 & $\$ 6,400.00$ & System Administrator & Build Server Development Environment \\
\hline & 133 & 148 & 178.1 & 193.1 & 45.1 & 45.1 & 15 & $\$ 18,000.00$ & Programmer A & Implement Server Daemon \\
\hline & 133 & 141 & 224.9 & 232.9 & 91.9 & 91.9 & 8 & $\$ 6,400.00$ & System Administrator & Build Testing and Integration Environment \\
\hline * & 133 & 158.1 & 133 & 158.1 & 0 & 0 & 25.1 & $\$ 25,125.00$ & DBA A & Develop Data Model \\
\hline * & 158.1 & 166.6 & 158.1 & 166.6 & 0 & 0 & 8.5 & $\$ 8,500.00$ & DBA A & Prepare Test Data \\
\hline * & 166.6 & 174.1 & 166.6 & 174.1 & 0 & 0 & 7.5 & $\$ 7,500.00$ & DBA A & Prepare Database Scripts \\
\hline * & 174.1 & 177.1 & 174.1 & 177.1 & 0 & 0 & 3 & $\$ 3,000.00$ & DBA A & Create Test Database \\
\hline * & 177.1 & 193.1 & 177.1 & 193.1 & 0 & 0 & 16 & $\$ 16,000.00$ & DBA A & Develop Stored Procedures \\
\hline * & 193.1 & 209.6 & 193.1 & 209.6 & 0 & 0 & 16.5 & $\$ 19,800.00$ & Programmer A & Implement Server Database Access Layer \\
\hline * & 209.6 & 224.6 & 209.6 & 224.6 & 0 & 0 & 15 & $\$ 18,000.00$ & Programmer A & Implement Transaction Handlers \\
\hline \multirow[t]{7}{*}{ * } & 224.6 & 232.9 & 224.6 & 232.9 & 0 & 0 & 8.3 & $\$ 9,900.00$ & Programmer A & Server Unit Testing and Debugging \\
\hline & 159.5 & 191 & 161.4 & 192.9 & 1.9 & 0 & 31.5 & $\$ 25,200.00$ & Programmer D & Implement Client GUI \\
\hline & 147 & 169 & 149.9 & 171.9 & 2.9 & 0 & 22 & $\$ 14,960.00$ & Programmer E & Implement Simulated Client Server Communication \\
\hline & 147 & 168 & 171.9 & 192.9 & 24.9 & 23 & 21 & $\$ 12,600.00$ & Programmer C & Implement Client Network Communications \\
\hline & 169 & 190 & 171.9 & 192.9 & 2.9 & 1 & 21 & $\$ 14,280.00$ & Programmer E & Implement Core Client Objects \\
\hline & 191 & 211 & 192.9 & 212.9 & 1.9 & 0 & 20 & $\$ 13,600.00$ & Programmer E & Client Component Integration \\
\hline & 211 & 231 & 212.9 & 232.9 & 1.9 & 1.9 & 20 & $\$ 13,600.00$ & Programmer E & Client Unit Testing and Debugging \\
\hline * & 232.9 & 241.4 & 232.9 & 241.4 & 0 & 0 & 8.5 & $\$ 10,200.00$ & Programmer A & Client Server Integration \\
\hline * & 241.4 & 258.4 & 241.4 & 258.4 & 0 & 0 & 17 & $\$ 20,400.00$ & Programmer A & Client Server Testing and Debugging \\
\hline \multirow[t]{4}{*}{ * } & 258.4 & 275.4 & 258.4 & 275.4 & 0 & 0 & 17 & $\$ 6,800.00$ & QA & Quality Assurance Testing \\
\hline & & & & & & & & & & \\
\hline & & & & & & & & & & Project Length (non-adjusted): 275.4 days \\
\hline & & & & & & & & & & Total Cost: $\$ 422525.00$ \\
\hline
\end{tabular}


Table 6-22 Client Server Application v2 - Scenario 2 Schedule

\begin{tabular}{|l|l|l|l|}
\hline \multicolumn{1}{|c|}{ ES } & \multicolumn{1}{|c|}{ EF } & \multicolumn{1}{|c|}{ RESOURCE } & \\
\hline 0 & 0 & start & start \\
\hline 0 & 42 & Business Analyst & Requirements Elicitation \\
\hline 42 & 83 & System Architect & Design \\
\hline 83 & 125 & System Architect & Specifications \\
\hline 125 & 133 & System Administrator & Build Server Development Environment \\
\hline 125 & 159.5 & GUI Designer & Client GUI Interface Design \\
\hline 125 & 147 & Programmer E & Implement Client Application Framework \\
\hline 133 & 158.1 & DBA A & Develop Data Model \\
\hline 159.5 & 191 & Programmer D & Implement Client GUI \\
\hline 147 & 169 & Programmer E & Implement Simulated Client Server Communication \\
\hline 147 & 168 & Programmer C & Implement Client Network Communications \\
\hline 133 & 148 & Programmer A & Implement Server Daemon \\
\hline 133 & 141 & System Administrator & Build Testing and Integration Environment \\
\hline 158.1 & 166.6 & DBA A & Prepare Test Data \\
\hline 169 & 190 & Programmer E & Implement Core Client Objects \\
\hline 166.6 & 174.1 & DBA A & Prepare Database Scripts \\
\hline 191 & 211 & Programmer E & Client Component Integration \\
\hline 174.1 & 177.1 & DBA A & Create Test Database \\
\hline 211 & 231 & Programmer E & Client Unit Testing and Debugging \\
\hline 177.1 & 193.1 & DBA A & Develop Stored Procedures \\
\hline 193.1 & 209.6 & Programmer A & Implement Server Database Access Layer \\
\hline 209.6 & 224.6 & Programmer A & Implement Transaction Handlers \\
\hline 224.6 & 232.9 & Programmer A & Server Unit Testing and Debugging \\
\hline 232.9 & 241.4 & Programmer A & Client Server Integration \\
\hline 241.4 & 258.4 & Programmer A & Client Server Testing and Debugging \\
\hline 258.4 & 275.4 & QA & Quality Assurance Testing \\
\hline & & & \\
\hline & & & Project Length (adjusted): 275.4 days \\
\hline & & & Total Cost: \$422525.00 \\
\hline
\end{tabular}


Client Server Application v2 - Scenario 3 CPM Data and Schedule

Table 6-23 Client Server Application v2 - Scenario 3 CPM Data

\begin{tabular}{|c|c|c|c|c|c|c|c|c|c|c|}
\hline CP & ES & $\mathrm{EF}$ & LS & LF & TS & FS & DUR & $\cos T$ & RESOURCE & TASK NAME \\
\hline * & 0 & 0 & 0 & 0 & 0 & 0 & 0 & $\$ 0.00$ & start & start \\
\hline * & 0 & 42 & 0 & 42 & 0 & 0 & 42 & $\$ 33,600.00$ & Business Analyst & Requirements Elicitation \\
\hline * & 42 & 83 & 42 & 83 & 0 & 0 & 41 & $\$ 41,000.00$ & System Architect & Design \\
\hline * & 83 & 125 & 83 & 125 & 0 & 0 & 42 & $\$ 42,000.00$ & System Architect & Specifications \\
\hline \multirow[t]{16}{*}{ * } & 125 & 159.5 & 125 & 159.5 & 0 & 0 & 34.5 & $\$ 20,700.00$ & GUI Designer & Client GUI Interface Design \\
\hline & 125 & 145.5 & 145.5 & 166 & 20.5 & 0 & 20.5 & $\$ 16,400.00$ & Programmer B & Implement Client Application Framework \\
\hline & 125 & 133 & 133.1 & 141.1 & 8.1 & 0 & 8 & $\$ 6,400.00$ & System Administrator & Build Server Development Environment \\
\hline & 133 & 148 & 186.3 & 201.3 & 53.3 & 45.1 & 15 & $\$ 18,000.00$ & Programmer A & Implement Server Daemon \\
\hline & 133 & 141 & 233 & 241 & 100 & 100 & 8 & $\$ 6,400.00$ & System Administrator & Build Testing and Integration Environment \\
\hline & 133 & 158.1 & 141.1 & 166.3 & 8.1 & 0 & 25.1 & $\$ 25,125.00$ & DBA A & Develop Data Model \\
\hline & 158.1 & 166.6 & 166.3 & 174.8 & 8.1 & 0 & 8.5 & $\$ 8,500.00$ & DBA A & Prepare Test Data \\
\hline & 166.6 & 174.1 & 174.8 & 182.3 & 8.1 & 0 & 7.5 & $\$ 7,500.00$ & DBA A & Prepare Database Scripts \\
\hline & 174.1 & 177.1 & 182.3 & 185.3 & 8.1 & 0 & 3 & $\$ 3,000.00$ & DBA A & Create Test Database \\
\hline & 177.1 & 193.1 & 185.3 & 201.3 & 8.1 & 0 & 16 & $\$ 16,000.00$ & DBA A & Develop Stored Procedures \\
\hline & 193.1 & 209.6 & 201.3 & 217.8 & 8.1 & 0 & 16.5 & $\$ 19,800.00$ & Programmer A & Implement Server Database Access Layer \\
\hline & 209.6 & 224.6 & 217.8 & 232.8 & 8.1 & 0 & 15 & $\$ 18,000.00$ & Programmer A & Implement Transaction Handlers \\
\hline & 224.6 & 232.9 & 232.8 & 241 & 8.1 & 8.1 & 8.3 & $\$ 9,900.00$ & Programmer A & Server Unit Testing and Debugging \\
\hline & 145.5 & 165.5 & 166 & 186 & 20.5 & 0 & 20 & $\$ 16,000.00$ & Programmer B & Implement Simulated Client Server Communication \\
\hline & 145.5 & 166.5 & 184 & 205 & 38.5 & 38.5 & 21 & $\$ 12,600.00$ & Programmer C & Implement Client Network Communications \\
\hline & 165.5 & 184.5 & 186 & 205 & 20.5 & 20.5 & 19 & $\$ 15,200.00$ & Programmer B & Implement Core Client Objects \\
\hline * & 159.5 & 173.5 & 159.5 & 173.5 & 0 & 0 & 14 & $\$ 0.00$ & delay & GUI sign-off-delay \\
\hline * & 173.5 & 205 & 173.5 & 205 & 0 & 0 & 31.5 & $\$ 25,200.00$ & Programmer D & Implement Client GUI \\
\hline * & 205 & 223 & 205 & 223 & 0 & 0 & 18 & $\$ 14,400.00$ & Programmer B & Client Component Integration \\
\hline * & 223 & 241 & 223 & 241 & 0 & 0 & 18 & $\$ 14,400.00$ & Programmer B & Client Unit Testing and Debugging \\
\hline * & 241 & 249.5 & 241 & 249.5 & 0 & 0 & 8.5 & $\$ 10,200.00$ & Programmer A & Client Server Integration \\
\hline * & 249.5 & 266.5 & 249.5 & 266.5 & 0 & 0 & 17 & $\$ 20,400.00$ & Programmer A & Client Server Testing and Debugging \\
\hline \multirow[t]{4}{*}{ * } & 266.5 & 283.5 & 266.5 & 283.5 & 0 & 0 & 17 & $\$ 6,800.00$ & QA & Quality Assurance Testing \\
\hline & & & & & & & & & & \\
\hline & & & & & & & & & & Project Length (non-adjusted): 283.5 days \\
\hline & & & & & & & & & & Total Cost: $\$ 427525.00$ \\
\hline
\end{tabular}


Table 6-24 Client Server Application v2 - Scenario 3 Schedule

\begin{tabular}{|l|l|l|l|}
\hline ES & \multicolumn{1}{|c|}{ EF } & \multicolumn{1}{|c|}{ RESOURCE } & \\
\hline 0 & 0 & start & start \\
\hline 0 & 42 & Business Analyst & Requirements Elicitation \\
\hline 42 & 83 & System Architect & Design \\
\hline 83 & 125 & System Architect & Specifications \\
\hline 125 & 159.5 & GUI Designer & Client GUI Interface Design \\
\hline 125 & 133 & System Administrator & Build Server Development Environment \\
\hline 125 & 145.5 & Programmer B & Implement Client Application Framework \\
\hline 159.5 & 173.5 & delay & GUI sign-off delay \\
\hline 133 & 158.1 & DBA A & Develop Data Model \\
\hline 145.5 & 165.5 & Programmer B & Implement Simulated Client Server Communication \\
\hline 145.5 & 166.5 & Programmer C & Implement Client Network Communications \\
\hline 133 & 148 & Programmer A & Implement Server Daemon \\
\hline 133 & 141 & System Administrator & Build Testing and Integration Environment \\
\hline 173.5 & 205 & Programmer D & Implement Client GUI \\
\hline 158.1 & 166.6 & DBA A & Prepare Test Data \\
\hline 165.5 & 184.5 & Programmer B & Implement Core Client Objects \\
\hline 205 & 223 & Programmer B & Client Component Integration \\
\hline 166.6 & 174.1 & DBA A & Prepare Database Scripts \\
\hline 223 & 241 & Programmer B & Client Unit Testing and Debugging \\
\hline 174.1 & 177.1 & DBA A & Create Test Database \\
\hline 177.1 & 193.1 & DBA A & Develop Stored Procedures \\
\hline 193.1 & 209.6 & Programmer A & Implement Server Database Access Layer \\
\hline 209.6 & 224.6 & Programmer A & Implement Transaction Handlers \\
\hline 224.6 & 232.9 & Programmer A & Server Unit Testing and Debugging \\
\hline 241 & 249.5 & Programmer A & Client Server Integration \\
\hline 249.5 & 266.5 & Programmer A & Client Server Testing and Debugging \\
\hline 266.5 & 283.5 & QA & Quality Assurance Testing \\
\hline & & & \\
\hline & & & Project Length (adjusted): 283.5 days \\
\hline & & & Total Cost: \$427525.00 \\
\hline & & & \\
\hline
\end{tabular}


Client Server Application v2 - Scenario 4 CPM Data and Schedule

Table 6-25 Client Server Application v2 - Scenario 4 CPM Data

\begin{tabular}{|c|c|c|c|c|c|c|c|c|c|c|}
\hline CP & ES & $\mathrm{EF}$ & LS & LF & TS & FS & DUR & cost & RESOURCE & TASK NAME \\
\hline * & 0 & 0 & 0 & 0 & 0 & 0 & 0 & $\$ 0.00$ & start & start \\
\hline * & 0 & 42 & 0 & 42 & 0 & 0 & 42 & $\$ 33,600.00$ & Business Analyst & Requirements Elicitation \\
\hline * & 42 & 83 & 42 & 83 & 0 & 0 & 41 & $\$ 41,000.00$ & System Architect & Design \\
\hline \multirow[t]{3}{*}{ * } & 83 & 125 & 83 & 125 & 0 & 0 & 42 & $\$ 42,000.00$ & System Architect & Specifications \\
\hline & 125 & 147 & 136.6 & 158.6 & 11.6 & 0 & 22 & $\$ 14,960.00$ & Programmer E & Implement Client Application Framework \\
\hline & 125 & 159.5 & 135.6 & 170.1 & 10.6 & 0 & 34.5 & $\$ 20,700.00$ & GUI Designer & Client GUI Interface Design \\
\hline \multirow[t]{3}{*}{ * } & 125 & 133 & 125 & 133 & 0 & 0 & 8 & $\$ 6,400.00$ & System Administrator & Build Server Development Environment \\
\hline & 133 & 148 & 186.9 & 201.9 & 53.9 & 53.9 & 15 & $\$ 18,000.00$ & Programmer A & Implement Server Daemon \\
\hline & 133 & 141 & 233.6 & 241.6 & 100.6 & 100.6 & 8 & $\$ 6,400.00$ & System Administrator & Build Testing and Integration Environment \\
\hline * & 133 & 163.4 & 133 & 163.4 & 0 & 0 & 30.4 & $\$ 24,300.00$ & DBA B & Develop Data Model \\
\hline * & 163.4 & 171.9 & 163.4 & 171.9 & 0 & 0 & 8.5 & $\$ 6,800.00$ & DBA B & Prepare Test Data \\
\hline * & 171.9 & 179.4 & 171.9 & 179.4 & 0 & 0 & 7.5 & $\$ 6,000.00$ & DBA B & Prepare Database Scripts \\
\hline * & 179.4 & 182.4 & 179.4 & 182.4 & 0 & 0 & 3 & $\$ 2,400.00$ & DBA B & Create Test Database \\
\hline * & 182.4 & 201.9 & 182.4 & 201.9 & 0 & 0 & 19.5 & $\$ 15,600.00$ & DBA B & Develop Stored Procedures \\
\hline * & 201.9 & 218.4 & 201.9 & 218.4 & 0 & 0 & 16.5 & $\$ 19,800.00$ & Programmer A & Implement Server Database Access Layer \\
\hline * & 218.4 & 233.4 & 218.4 & 233.4 & 0 & 0 & 15 & $\$ 18,000.00$ & Programmer A & Implement Transaction Handlers \\
\hline \multirow[t]{7}{*}{ * } & 233.4 & 241.6 & 233.4 & 241.6 & 0 & 0 & 8.3 & $\$ 9,900.00$ & Programmer A & Server Unit Testing and Debugging \\
\hline & 159.5 & 191 & 170.1 & 201.6 & 10.6 & 0 & 31.5 & $\$ 25,200.00$ & Programmer D & Implement Client GUI \\
\hline & 147 & 169 & 158.6 & 180.6 & 11.6 & 0 & 22 & $\$ 14,960.00$ & Programmer E & Implement Simulated Client Server Communication \\
\hline & 147 & 168 & 180.6 & 201.6 & 33.6 & 23 & 21 & $\$ 12,600.00$ & Programmer C & Implement Client Network Communications \\
\hline & 169 & 190 & 180.6 & 201.6 & 11.6 & 1 & 21 & $\$ 14,280.00$ & Programmer E & Implement Core Client Objects \\
\hline & 191 & 211 & 201.6 & 221.6 & 10.6 & 0 & 20 & $\$ 13,600.00$ & Programmer E & Client Component Integration \\
\hline & 211 & 231 & 221.6 & 241.6 & 10.6 & 10.6 & 20 & $\$ 13,600.00$ & Programmer E & Client Unit Testing and Debugging \\
\hline * & 241.6 & 250.1 & 241.6 & 250.1 & 0 & 0 & 8.5 & $\$ 10,200.00$ & Programmer A & Client Server Integration \\
\hline * & 250.1 & 267.1 & 250.1 & 267.1 & 0 & 0 & 17 & $\$ 20,400.00$ & Programmer A & Client Server Testing and Debugging \\
\hline \multirow[t]{4}{*}{ * } & 267.1 & 284.1 & 267.1 & 284.1 & 0 & 0 & 17 & $\$ 6,800.00$ & QA & Quality Assurance Testing \\
\hline & & & & & & & & & & \\
\hline & & & & & & & & & & Project Length (non-adjusted): 284.1 days \\
\hline & & & & & & & & & & Total Cost: $\$ 417500.00$ \\
\hline
\end{tabular}


Table 6-26 Client Server Application v2 - Scenario 4 Schedule

\begin{tabular}{|l|l|l|l|}
\hline \multicolumn{1}{|c|}{ ES } & \multicolumn{1}{|c|}{ EF } & \multicolumn{1}{|c|}{ RESOURCE } & \\
\hline 0 & 0 & start & start \\
\hline 0 & 42 & Business Analyst & Requirements Elicitation \\
\hline 42 & 83 & System Architect & Design \\
\hline 83 & 125 & System Architect & Specifications \\
\hline 125 & 133 & System Administrator & Build Server Development Environment \\
\hline 125 & 159.5 & GUI Designer & Client GUI Interface Design \\
\hline 125 & 147 & Programmer E & Implement Client Application Framework \\
\hline 133 & 163.4 & DBA B & Develop Data Model \\
\hline 159.5 & 191 & Programmer D & Implement Client GUI \\
\hline 147 & 169 & Programmer E & Implement Simulated Client Server Communication \\
\hline 147 & 168 & Programmer C & Implement Client Network Communications \\
\hline 133 & 148 & Programmer A & Implement Server Daemon \\
\hline 133 & 141 & System Administrator & Build Testing and Integration Environment \\
\hline 163.4 & 171.9 & DBA B & Prepare Test Data \\
\hline 169 & 190 & Programmer E & Implement Core Client Objects \\
\hline 171.9 & 179.4 & DBA B & Prepare Database Scripts \\
\hline 191 & 211 & Programmer E & Client Component Integration \\
\hline 179.4 & 182.4 & DBA B & Create Test Database \\
\hline 211 & 231 & Programmer E & Client Unit Testing and Debugging \\
\hline 182.4 & 201.9 & DBA B & Develop Stored Procedures \\
\hline 201.9 & 218.4 & Programmer A & Implement Server Database Access Layer \\
\hline 218.4 & 233.4 & Programmer A & Implement Transaction Handlers \\
\hline 233.4 & 241.6 & Programmer A & Server Unit Testing and Debugging \\
\hline 241.6 & 250.1 & Programmer A & Client Server Integration \\
\hline 250.1 & 267.1 & Programmer A & Client Server Testing and Debugging \\
\hline 267.1 & 284.1 & QA & Quality Assurance Testing \\
\hline & & & \\
\hline & & & Project Length (adjusted): 284.1 days \\
\hline & & & Total Cost: \$417500.00 \\
\hline
\end{tabular}


Client Server Application v2 - Scenario 5 CPM Data and Schedule

Table 6-27 Client Server Application v2 - Scenario 5 CPM Data

\begin{tabular}{|c|c|c|c|c|c|c|c|c|c|c|}
\hline CP & ES & $\mathrm{EF}$ & LS & LF & TS & FS & DUR & $\cos T$ & RESOURCE & TASK NAME \\
\hline * & 0 & 0 & 0 & 0 & 0 & 0 & 0 & $\$ 0.00$ & start & start \\
\hline * & 0 & 42 & 0 & 42 & 0 & 0 & 42 & $\$ 33,600.00$ & Business Analyst & Requirements Elicitation \\
\hline * & 42 & 83 & 42 & 83 & 0 & 0 & 41 & $\$ 41,000.00$ & System Architect & Design \\
\hline \multirow[t]{3}{*}{ * } & 83 & 125 & 83 & 125 & 0 & 0 & 42 & $\$ 42,000.00$ & System Architect & Specifications \\
\hline & 125 & 159.5 & 125.6 & 160.1 & 0.6 & 0 & 34.5 & $\$ 20,700.00$ & GUI Designer & Client GUI Interface Design \\
\hline & 125 & 145.5 & 146.1 & 166.6 & 21.1 & 0 & 20.5 & $\$ 16,400.00$ & Programmer B & Implement Client Application Framework \\
\hline \multirow[t]{3}{*}{ * } & 125 & 133 & 125 & 133 & 0 & 0 & 8 & $\$ 6,400.00$ & System Administrator & Build Server Development Environment \\
\hline & 133 & 148 & 186.9 & 201.9 & 53.9 & 53.9 & 15 & $\$ 18,000.00$ & Programmer A & Implement Server Daemon \\
\hline & 133 & 141 & 233.6 & 241.6 & 100.6 & 100.6 & 8 & $\$ 6,400.00$ & System Administrator & Build Testing and Integration Environment \\
\hline * & 133 & 163.4 & 133 & 163.4 & 0 & 0 & 30.4 & $\$ 24,300.00$ & DBA B & Develop Data Model \\
\hline * & 163.4 & 171.9 & 163.4 & 171.9 & 0 & 0 & 8.5 & $\$ 6,800.00$ & DBA B & Prepare Test Data \\
\hline * & 171.9 & 179.4 & 171.9 & 179.4 & 0 & 0 & 7.5 & $\$ 6,000.00$ & DBA B & Prepare Database Scripts \\
\hline * & 179.4 & 182.4 & 179.4 & 182.4 & 0 & 0 & 3 & $\$ 2,400.00$ & DBA B & Create Test Database \\
\hline * & 182.4 & 201.9 & 182.4 & 201.9 & 0 & 0 & 19.5 & $\$ 15,600.00$ & DBA B & Develop Stored Procedures \\
\hline * & 201.9 & 218.4 & 201.9 & 218.4 & 0 & 0 & 16.5 & $\$ 19,800.00$ & Programmer A & Implement Server Database Access Layer \\
\hline * & 218.4 & 233.4 & 218.4 & 233.4 & 0 & 0 & 15 & $\$ 18,000.00$ & Programmer A & Implement Transaction Handlers \\
\hline \multirow[t]{8}{*}{ * } & 233.4 & 241.6 & 233.4 & 241.6 & 0 & 0 & 8.3 & $\$ 9,900.00$ & Programmer A & Server Unit Testing and Debugging \\
\hline & 145.5 & 165.5 & 166.6 & 186.6 & 21.1 & 0 & 20 & $\$ 16,000.00$ & Programmer B & Implement Simulated Client Server Communication \\
\hline & 145.5 & 166.5 & 184.6 & 205.6 & 39.1 & 38.5 & 21 & $\$ 12,600.00$ & Programmer C & Implement Client Network Communications \\
\hline & 165.5 & 184.5 & 186.6 & 205.6 & 21.1 & 20.5 & 19 & $\$ 15,200.00$ & Programmer B & Implement Core Client Objects \\
\hline & 159.5 & 173.5 & 160.1 & 174.1 & 0.6 & 0 & 14 & $\$ 0.00$ & delay & GUI sign-off-delay \\
\hline & 173.5 & 205 & 174.1 & 205.6 & 0.6 & 0 & 31.5 & $\$ 25,200.00$ & Programmer D & Implement Client GUI \\
\hline & 205 & 223 & 205.6 & 223.6 & 0.6 & 0 & 18 & $\$ 14,400.00$ & Programmer B & Client Component Integration \\
\hline & 223 & 241 & 223.6 & 241.6 & 0.6 & 0.6 & 18 & $\$ 14,400.00$ & Programmer B & Client Unit Testing and Debugging \\
\hline * & 241.6 & 250.1 & 241.6 & 250.1 & 0 & 0 & 8.5 & $\$ 10,200.00$ & Programmer A & Client Server Integration \\
\hline * & 250.1 & 267.1 & 250.1 & 267.1 & 0 & 0 & 17 & $\$ 20,400.00$ & Programmer A & Client Server Testing and Debugging \\
\hline \multirow[t]{4}{*}{ * } & 267.1 & 284.1 & 267.1 & 284.1 & 0 & 0 & 17 & $\$ 6,800.00$ & QA & Quality Assurance Testing \\
\hline & & & & & & & & & & \\
\hline & & & & & & & & & & Project Length (non-adjusted): 284.1 days \\
\hline & & & & & & & & & & Total Cost: $\$ 422500.00$ \\
\hline
\end{tabular}


Table 6-28 Client Server Application v2 - Scenario 5 Schedule

\begin{tabular}{|l|l|l|l|}
\hline ES & \multicolumn{1}{|c|}{ EF } & \multicolumn{1}{|c|}{ RESOURCE } & \\
\hline 0 & 0 & start & start \\
\hline 0 & 42 & Business Analyst & Requirements Elicitation \\
\hline 42 & 83 & System Architect & Design \\
\hline 83 & 125 & System Architect & Specifications \\
\hline 125 & 133 & System Administrator & Build Server Development Environment \\
\hline 125 & 159.5 & GUI Designer & Client GUI Interface Design \\
\hline 125 & 145.5 & Programmer B & Implement Client Application Framework \\
\hline 133 & 163.4 & DBA B & Develop Data Model \\
\hline 159.5 & 173.5 & delay & GUI sign-off delay \\
\hline 145.5 & 165.5 & Programmer B & Implement Simulated Client Server Communication \\
\hline 145.5 & 166.5 & Programmer C & Implement Client Network Communications \\
\hline 133 & 148 & Programmer A & Implement Server Daemon \\
\hline 133 & 141 & System Administrator & Build Testing and Integration Environment \\
\hline 163.4 & 171.9 & DBA B & Prepare Test Data \\
\hline 173.5 & 205 & Programmer D & Implement Client GUI \\
\hline 165.5 & 184.5 & Programmer B & Implement Core Client Objects \\
\hline 171.9 & 179.4 & DBA B & Prepare Database Scripts \\
\hline 205 & 223 & Programmer B & Client Component Integration \\
\hline 179.4 & 182.4 & DBA B & Create Test Database \\
\hline 223 & 241 & Programmer B & Client Unit Testing and Debugging \\
\hline 182.4 & 201.9 & DBA B & Develop Stored Procedures \\
\hline 201.9 & 218.4 & Programmer A & Implement Server Database Access Layer \\
\hline 218.4 & 233.4 & Programmer A & Implement Transaction Handlers \\
\hline 233.4 & 241.6 & Programmer A & Server Unit Testing and Debugging \\
\hline 241.6 & 250.1 & Programmer A & Client Server Integration \\
\hline 250.1 & 267.1 & Programmer A & Client Server Testing and Debugging \\
\hline 267.1 & 284.1 & QA & Quality Assurance Testing \\
\hline & & & \\
\hline & & & Project Length (adjusted): 284.1 days \\
\hline & & & Total Cost: \$422500.00 \\
\hline
\end{tabular}


Client Server Application v2 - Scenario 6 CPM Data and Schedule

Table 6-29 Client Server Application v2 - Scenario 6 CPM Data

\begin{tabular}{|c|c|c|c|c|c|c|c|c|c|c|}
\hline CP & ES & $\mathrm{EF}$ & LS & LF & TS & FS & DUR & $\cos T$ & RESOURCE & TASK NAME \\
\hline * & 0 & 0 & 0 & 0 & 0 & 0 & 0 & $\$ 0.00$ & start & start \\
\hline * & 0 & 42 & 0 & 42 & 0 & 0 & 42 & $\$ 33,600.00$ & Business Analyst & Requirements Elicitation \\
\hline * & 42 & 83 & 42 & 83 & 0 & 0 & 41 & $\$ 41,000.00$ & System Architect & Design \\
\hline * & 83 & 125 & 83 & 125 & 0 & 0 & 42 & $\$ 42,000.00$ & System Architect & Specifications \\
\hline \multirow[t]{16}{*}{ * } & 125 & 159.5 & 125 & 159.5 & 0 & 0 & 34.5 & $\$ 20,700.00$ & GUI Designer & Client GUI Interface Design \\
\hline & 125 & 147 & 140 & 162 & 15 & 0 & 22 & $\$ 14,960.00$ & Programmer E & Implement Client Application Framework \\
\hline & 125 & 133 & 137.1 & 145.1 & 12.1 & 0 & 8 & $\$ 6,400.00$ & System Administrator & Build Server Development Environment \\
\hline & 133 & 148 & 190.3 & 205.3 & 57.3 & 45.1 & 15 & $\$ 18,000.00$ & Programmer A & Implement Server Daemon \\
\hline & 133 & 141 & 237 & 245 & 104 & 104 & 8 & $\$ 6,400.00$ & System Administrator & Build Testing and Integration Environment \\
\hline & 133 & 158.1 & 145.1 & 170.3 & 12.1 & 0 & 25.1 & $\$ 25,125.00$ & DBA A & Develop Data Model \\
\hline & 158.1 & 166.6 & 170.3 & 178.8 & 12.1 & 0 & 8.5 & $\$ 8,500.00$ & DBA A & Prepare Test Data \\
\hline & 166.6 & 174.1 & 178.8 & 186.3 & 12.1 & 0 & 7.5 & $\$ 7,500.00$ & DBA A & Prepare Database Scripts \\
\hline & 174.1 & 177.1 & 186.3 & 189.3 & 12.1 & 0 & 3 & $\$ 3,000.00$ & DBA A & Create Test Database \\
\hline & 177.1 & 193.1 & 189.3 & 205.3 & 12.1 & 0 & 16 & $\$ 16,000.00$ & DBA A & Develop Stored Procedures \\
\hline & 193.1 & 209.6 & 205.3 & 221.8 & 12.1 & 0 & 16.5 & $\$ 19,800.00$ & Programmer A & Implement Server Database Access Layer \\
\hline & 209.6 & 224.6 & 221.8 & 236.8 & 12.1 & 0 & 15 & $\$ 18,000.00$ & Programmer A & Implement Transaction Handlers \\
\hline & 224.6 & 232.9 & 236.8 & 245 & 12.1 & 12.1 & 8.3 & $\$ 9,900.00$ & Programmer A & Server Unit Testing and Debugging \\
\hline & 147 & 169 & 162 & 184 & 15 & 0 & 22 & $\$ 14,960.00$ & Programmer E & Implement Simulated Client Server Communication \\
\hline & 147 & 168 & 184 & 205 & 37 & 37 & 21 & $\$ 12,600.00$ & Programmer C & Implement Client Network Communications \\
\hline & 169 & 190 & 184 & 205 & 15 & 15 & 21 & $\$ 14,280.00$ & Programmer E & Implement Core Client Objects \\
\hline * & 159.5 & 173.5 & 159.5 & 173.5 & 0 & 0 & 14 & $\$ 0.00$ & delay & GUI sign-off-delay \\
\hline * & 173.5 & 205 & 173.5 & 205 & 0 & 0 & 31.5 & $\$ 25,200.00$ & Programmer D & Implement Client GUI \\
\hline * & 205 & 225 & 205 & 225 & 0 & 0 & 20 & $\$ 13,600.00$ & Programmer E & Client Component Integration \\
\hline * & 225 & 245 & 225 & 245 & 0 & 0 & 20 & $\$ 13,600.00$ & Programmer E & Client Unit Testing and Debugging \\
\hline * & 245 & 253.5 & 245 & 253.5 & 0 & 0 & 8.5 & $\$ 10,200.00$ & Programmer A & Client Server Integration \\
\hline * & 253.5 & 270.5 & 253.5 & 270.5 & 0 & 0 & 17 & $\$ 20,400.00$ & Programmer A & Client Server Testing and Debugging \\
\hline \multirow[t]{4}{*}{ * } & 270.5 & 287.5 & 270.5 & 287.5 & 0 & 0 & 17 & $\$ 6,800.00$ & QA & Quality Assurance Testing \\
\hline & & & & & & & & & & \\
\hline & & & & & & & & & & Project Length (non-adjusted): 287.5 days \\
\hline & & & & & & & & & & Total Cost: $\$ 422525.00$ \\
\hline
\end{tabular}


Table 6-30 Client Server Application v2 - Scenario 6 Schedule

\begin{tabular}{|l|l|l|l|}
\hline ES & \multicolumn{1}{|c|}{ EF } & \multicolumn{1}{|c|}{ RESOURCE } & \\
\hline 0 & 0 & start & start \\
\hline 0 & 42 & Business Analyst & Requirements Elicitation \\
\hline 42 & 83 & System Architect & Design \\
\hline 83 & 125 & System Architect & Specifications \\
\hline 125 & 159.5 & GUI Designer & Client GUI Interface Design \\
\hline 125 & 133 & System Administrator & Build Server Development Environment \\
\hline 125 & 147 & Programmer E & Implement Client Application Framework \\
\hline 159.5 & 173.5 & delay & GUI sign-off delay \\
\hline 133 & 158.1 & DBA A & Develop Data Model \\
\hline 147 & 169 & Programmer E & Implement Simulated Client Server Communication \\
\hline 147 & 168 & Programmer C & Implement Client Network Communications \\
\hline 133 & 148 & Programmer A & Implement Server Daemon \\
\hline 133 & 141 & System Administrator & Build Testing and Integration Environment \\
\hline 173.5 & 205 & Programmer D & Implement Client GUI \\
\hline 158.1 & 166.6 & DBA A & Prepare Test Data \\
\hline 169 & 190 & Programmer E & Implement Core Client Objects \\
\hline 205 & 225 & Programmer E & Client Component Integration \\
\hline 166.6 & 174.1 & DBA A & Prepare Database Scripts \\
\hline 225 & 245 & Programmer E & Client Unit Testing and Debugging \\
\hline 174.1 & 177.1 & DBA A & Create Test Database \\
\hline 177.1 & 193.1 & DBA A & Develop Stored Procedures \\
\hline 193.1 & 209.6 & Programmer A & Implement Server Database Access Layer \\
\hline 209.6 & 224.6 & Programmer A & Implement Transaction Handlers \\
\hline 224.6 & 232.9 & Programmer A & Server Unit Testing and Debugging \\
\hline 245 & 253.5 & Programmer A & Client Server Integration \\
\hline 253.5 & 270.5 & Programmer A & Client Server Testing and Debugging \\
\hline 270.5 & 287.5 & QA & Quality Assurance Testing \\
\hline & & & \\
\hline & & & Project Length (adjusted): 287.5 days \\
\hline & & & Total Cost: \$422525.00 \\
\hline
\end{tabular}


Client Server Application v2 - Scenario 7 CPM Data and Schedule

Table 6-31 Client Server Application v2 - Scenario 7 CPM Data

\begin{tabular}{|c|c|c|c|c|c|c|c|c|c|c|}
\hline CP & ES & EF & LS & LF & TS & FS & DUR & $\cos T$ & RESOURCE & TASK NAME \\
\hline * & 0 & 0 & 0 & 0 & 0 & 0 & 0 & $\$ 0.00$ & start & start \\
\hline * & 0 & 42 & 0 & 42 & 0 & 0 & 42 & $\$ 33,600.00$ & Business Analyst & Requirements Elicitation \\
\hline * & 42 & 83 & 42 & 83 & 0 & 0 & 41 & $\$ 41,000.00$ & System Architect & Design \\
\hline * & 83 & 125 & 83 & 125 & 0 & 0 & 42 & $\$ 42,000.00$ & System Architect & Specifications \\
\hline \multirow[t]{16}{*}{ * } & 125 & 159.5 & 125 & 159.5 & 0 & 0 & 34.5 & $\$ 20,700.00$ & GUI Designer & Client GUI Interface Design \\
\hline & 125 & 147 & 140 & 162 & 15 & 0 & 22 & $\$ 14,960.00$ & Programmer E & Implement Client Application Framework \\
\hline & 125 & 133 & 128.4 & 136.4 & 3.4 & 0 & 8 & $\$ 6,400.00$ & System Administrator & Build Server Development Environment \\
\hline & 133 & 148 & 190.3 & 205.3 & 57.3 & 53.9 & 15 & $\$ 18,000.00$ & Programmer A & Implement Server Daemon \\
\hline & 133 & 141 & 237 & 245 & 104 & 104 & 8 & $\$ 6,400.00$ & System Administrator & Build Testing and Integration Environment \\
\hline & 133 & 163.4 & 136.4 & 166.8 & 3.4 & 0 & 30.4 & $\$ 24,300.00$ & DBA B & Develop Data Model \\
\hline & 163.4 & 171.9 & 166.8 & 175.3 & 3.4 & 0 & 8.5 & $\$ 6,800.00$ & DBA B & Prepare Test Data \\
\hline & 171.9 & 179.4 & 175.3 & 182.8 & 3.4 & 0 & 7.5 & $\$ 6,000.00$ & DBA B & Prepare Database Scripts \\
\hline & 179.4 & 182.4 & 182.8 & 185.8 & 3.4 & 0 & 3 & $\$ 2,400.00$ & DBA B & Create Test Database \\
\hline & 182.4 & 201.9 & 185.8 & 205.3 & 3.4 & 0 & 19.5 & $\$ 15,600.00$ & DBA B & Develop Stored Procedures \\
\hline & 201.9 & 218.4 & 205.3 & 221.8 & 3.4 & 0 & 16.5 & $\$ 19,800.00$ & Programmer A & Implement Server Database Access Layer \\
\hline & 218.4 & 233.4 & 221.8 & 236.8 & 3.4 & 0 & 15 & $\$ 18,000.00$ & Programmer A & Implement Transaction Handlers \\
\hline & 233.4 & 241.6 & 236.8 & 245 & 3.4 & 3.4 & 8.3 & $\$ 9,900.00$ & Programmer A & Server Unit Testing and Debugging \\
\hline & 147 & 169 & 162 & 184 & 15 & 0 & 22 & $\$ 14,960.00$ & Programmer $\mathrm{E}$ & Implement Simulated Client Server Communication \\
\hline & 147 & 168 & 184 & 205 & 37 & 37 & 21 & $\$ 12,600.00$ & Programmer $\mathrm{C}$ & Implement Client Network Communications \\
\hline & 169 & 190 & 184 & 205 & 15 & 15 & 21 & $\$ 14,280.00$ & Programmer E & Implement Core Client Objects \\
\hline * & 159.5 & 173.5 & 159.5 & 173.5 & 0 & 0 & 14 & $\$ 0.00$ & delay & GUI sign-off-delay \\
\hline * & 173.5 & 205 & 173.5 & 205 & 0 & 0 & 31.5 & $\$ 25,200.00$ & Programmer D & Implement Client GUI \\
\hline * & 205 & 225 & 205 & 225 & 0 & 0 & 20 & $\$ 13,600.00$ & Programmer $\mathrm{E}$ & Client Component Integration \\
\hline * & 225 & 245 & 225 & 245 & 0 & 0 & 20 & $\$ 13,600.00$ & Programmer $\mathrm{E}$ & Client Unit Testing and Debugging \\
\hline * & 245 & 253.5 & 245 & 253.5 & 0 & 0 & 8.5 & $\$ 10,200.00$ & Programmer A & Client Server Integration \\
\hline * & 253.5 & 270.5 & 253.5 & 270.5 & 0 & 0 & 17 & $\$ 20,400.00$ & Programmer A & Client Server Testing and Debugging \\
\hline \multirow[t]{4}{*}{ * } & 270.5 & 287.5 & 270.5 & 287.5 & 0 & 0 & 17 & $\$ 6,800.00$ & QA & Quality Assurance Testing \\
\hline & & & & & & & & & & \\
\hline & & & & & & & & & & Project Length (non-adjusted): 287.5 days \\
\hline & & & & & & & & & & Total Cost: $\$ 417500.00$ \\
\hline
\end{tabular}


Table 6-32 Client Server Application v2 - Scenario 7 Schedule

\begin{tabular}{|l|l|l|l|}
\hline ES & \multicolumn{1}{|c|}{ EF } & \multicolumn{1}{|c|}{ RESOURCE } & \\
\hline 0 & 0 & start & start \\
\hline 0 & 42 & Business Analyst & Requirements Elicitation \\
\hline 42 & 83 & System Architect & Design \\
\hline 83 & 125 & System Architect & Specifications \\
\hline 125 & 159.5 & GUI Designer & Client GUI Interface Design \\
\hline 125 & 133 & System Administrator & Build Server Development Environment \\
\hline 125 & 147 & Programmer E & Implement Client Application Framework \\
\hline 159.5 & 173.5 & delay & GUI sign-off delay \\
\hline 133 & 163.4 & DBA B & Develop Data Model \\
\hline 147 & 169 & Programmer E & Implement Simulated Client Server Communication \\
\hline 147 & 168 & Programmer C & Implement Client Network Communications \\
\hline 133 & 148 & Programmer A & Implement Server Daemon \\
\hline 133 & 141 & System Administrator & Build Testing and Integration Environment \\
\hline 173.5 & 205 & Programmer D & Implement Client GUI \\
\hline 163.4 & 171.9 & DBA B & Prepare Test Data \\
\hline 169 & 190 & Programmer E & Implement Core Client Objects \\
\hline 205 & 225 & Programmer E & Client Component Integration \\
\hline 171.9 & 179.4 & DBA B & Prepare Database Scripts \\
\hline 225 & 245 & Programmer E & Client Unit Testing and Debugging \\
\hline 179.4 & 182.4 & DBA B & Create Test Database \\
\hline 182.4 & 201.9 & DBA B & Develop Stored Procedures \\
\hline 201.9 & 218.4 & Programmer A & Implement Server Database Access Layer \\
\hline 218.4 & 233.4 & Programmer A & Implement Transaction Handlers \\
\hline 233.4 & 241.6 & Programmer A & Server Unit Testing and Debugging \\
\hline 245 & 253.5 & Programmer A & Client Server Integration \\
\hline 253.5 & 270.5 & Programmer A & Client Server Testing and Debugging \\
\hline 270.5 & 287.5 & QA & Quality Assurance Testing \\
\hline & & & \\
\hline & & & Project Length (adjusted): 287.5 days \\
\hline & & & Total Cost: \$417500.00 \\
\hline
\end{tabular}




\section{Gantt Charts}

Client Server Application v1 - Base Scenario Gantt Chart

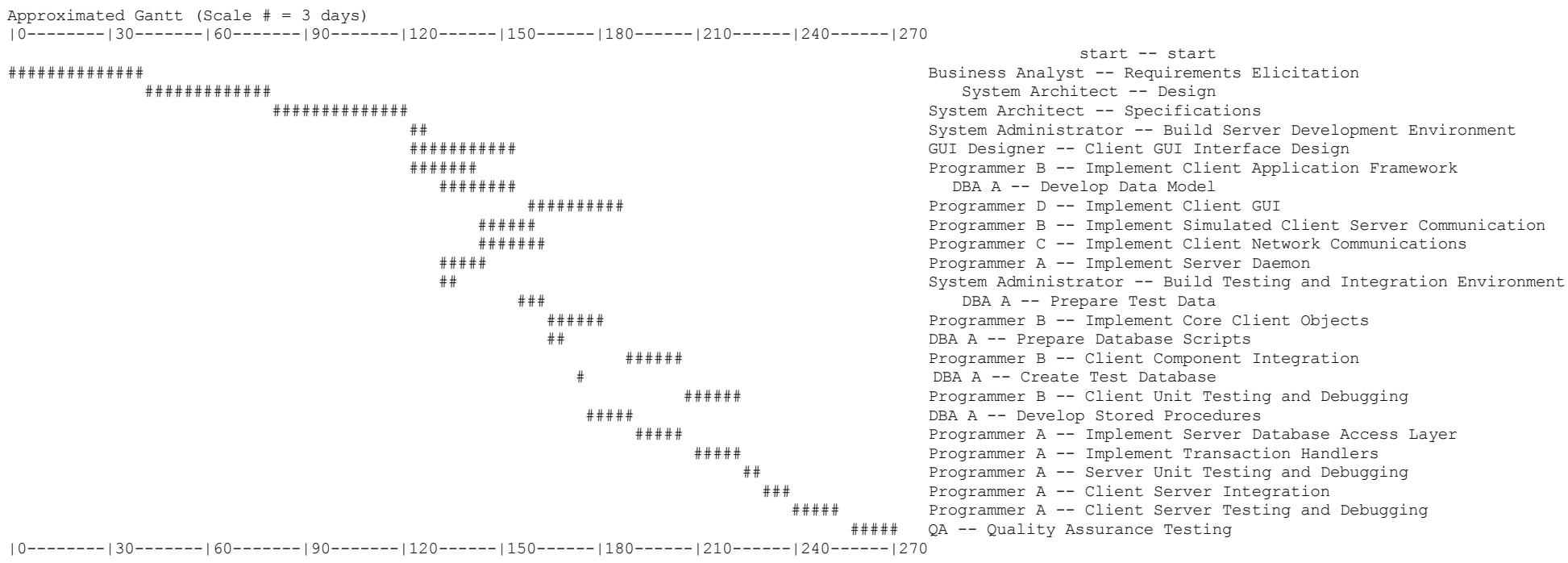


Client Server Application v1 - Scenario 1 Gantt Chart

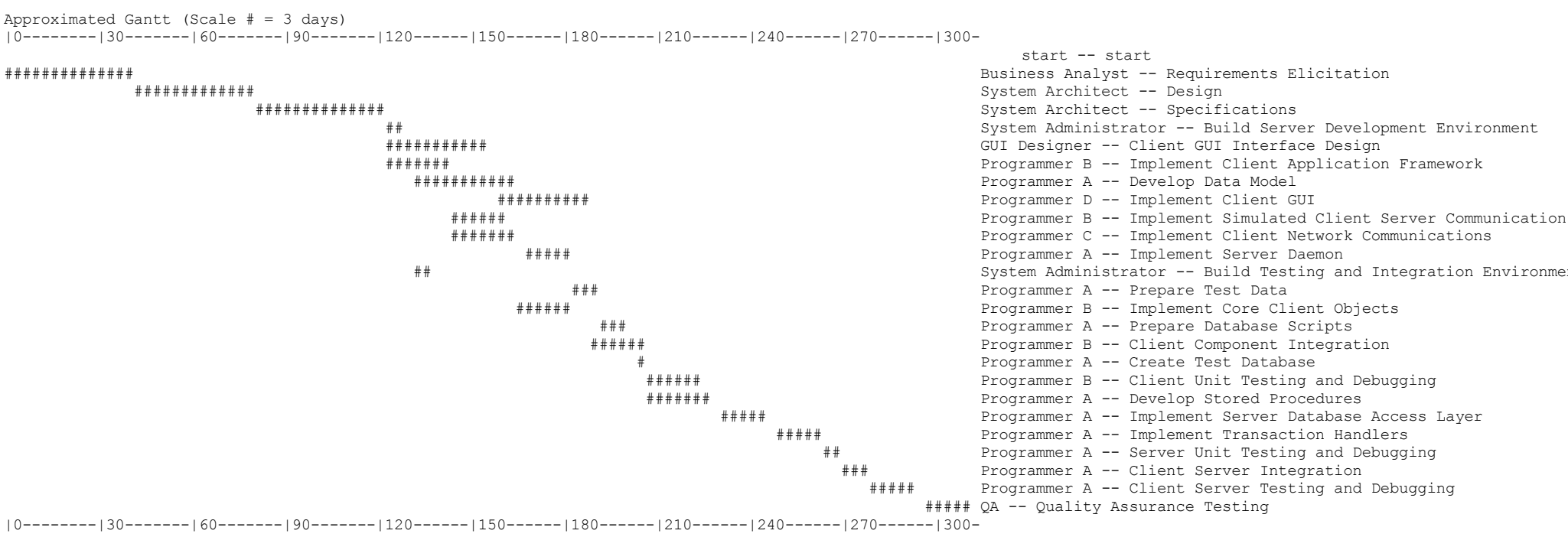

start -- start Business Analyst -- Requirements Elicitation System Architect -- Design

System Architect -- Specifications

Server Development Environment Interface Design Programmer A -- Develop Data Model
Programmer D -- Implement Client GUI

Programmer B -- Implement Simulated Client Server Communication Programmer -- Implement Client Network Communication

Thesting and I Programmer A -- Prepare Test Data

Programmer B -- Implement Core Client objects

Programmer A -- Prepare Database Scripts

Programmer B - Client Component integration

t Database

Programmer B -- Client Unit Testing and Debugging

Programmer A -- Implement Server Database Access Layer

Programmer A -- Server Unit Testing and Debugging

Programer A -- Client Server Testing and Debugging

Programmer A -- Client Server Testing and Debugging 
Client Server Application v1 - Scenario 2 Gantt Chart

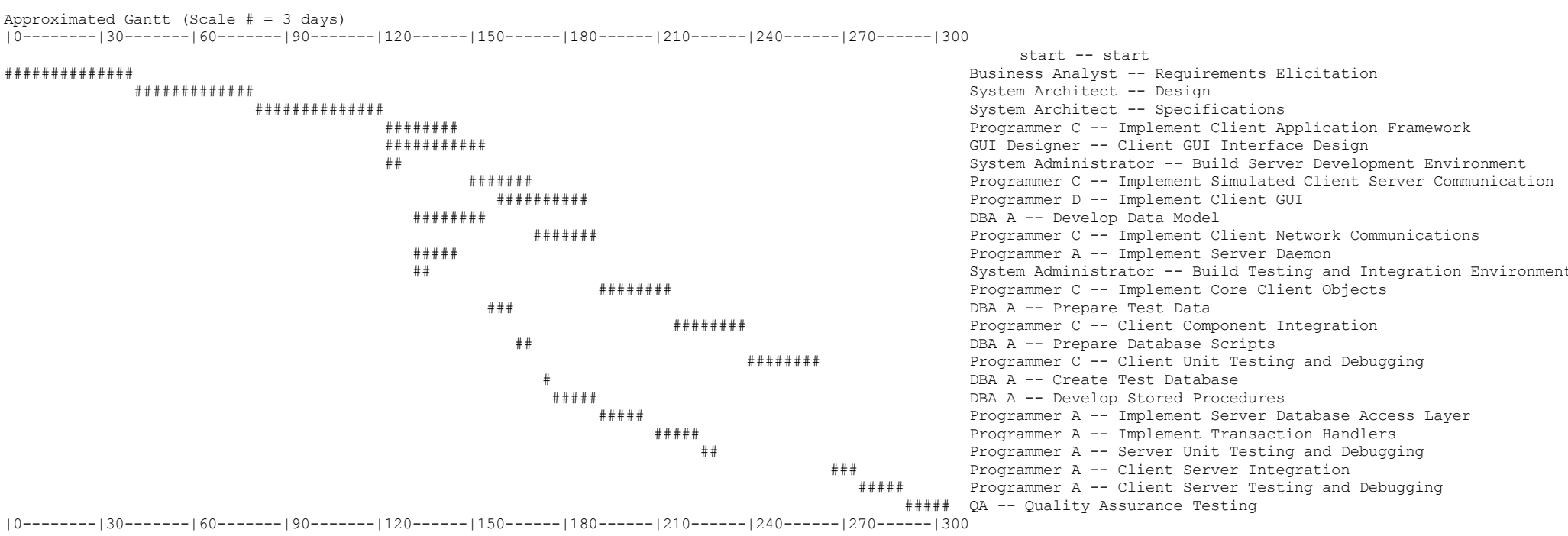

\#\#\#\#\# Programmer A -- Client Server Testing and Debugging 
Client Server Application v1 - Scenario 3 Gantt Chart

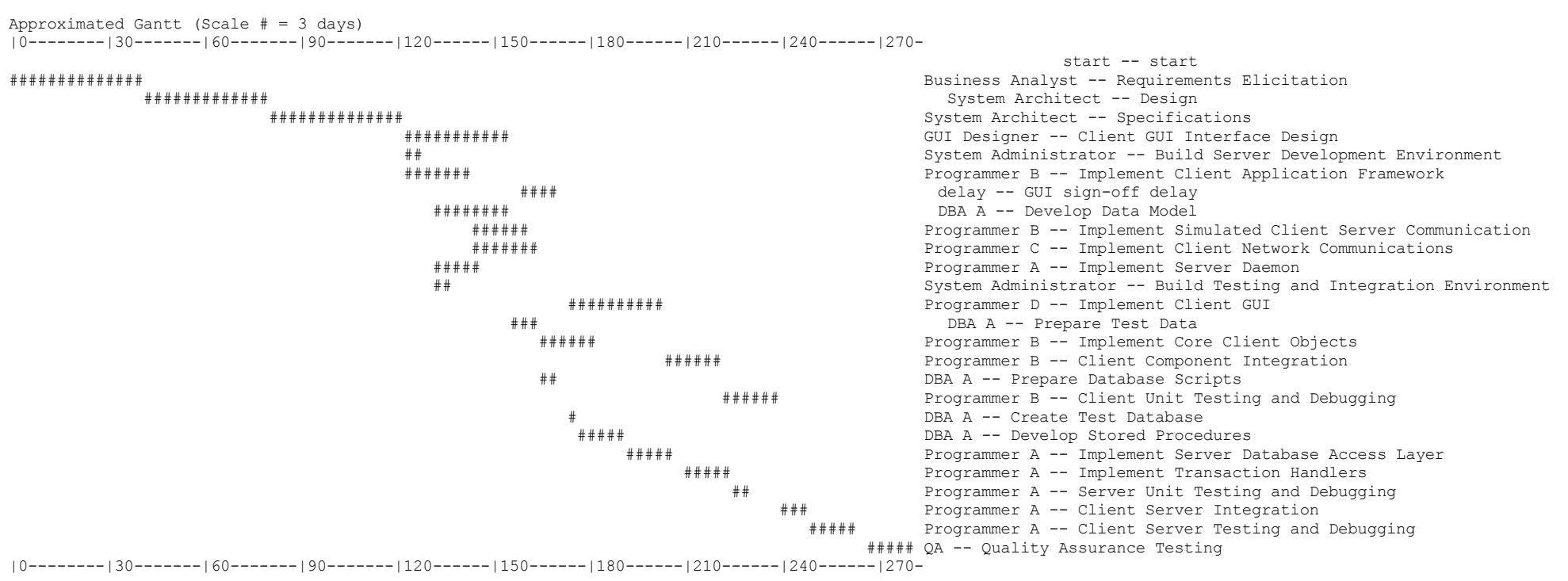




\section{Client Server Application v1 - Scenario 4 Gantt Chart}

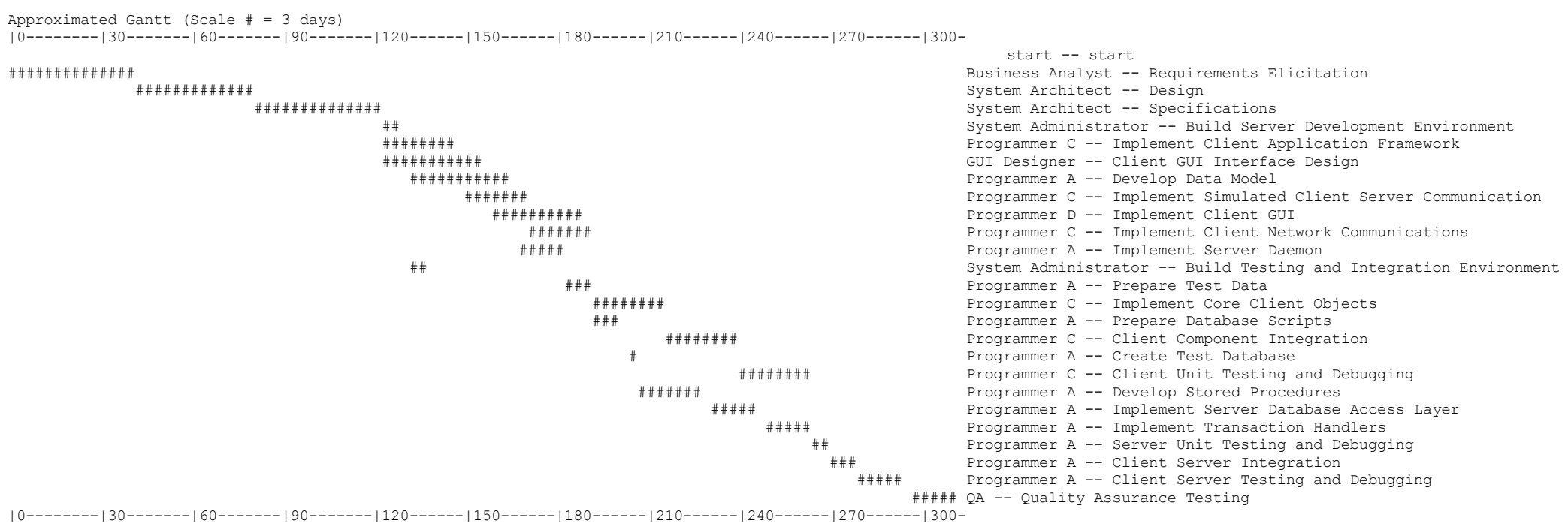


Client Server Application v1 - Scenario 5 Gantt Chart

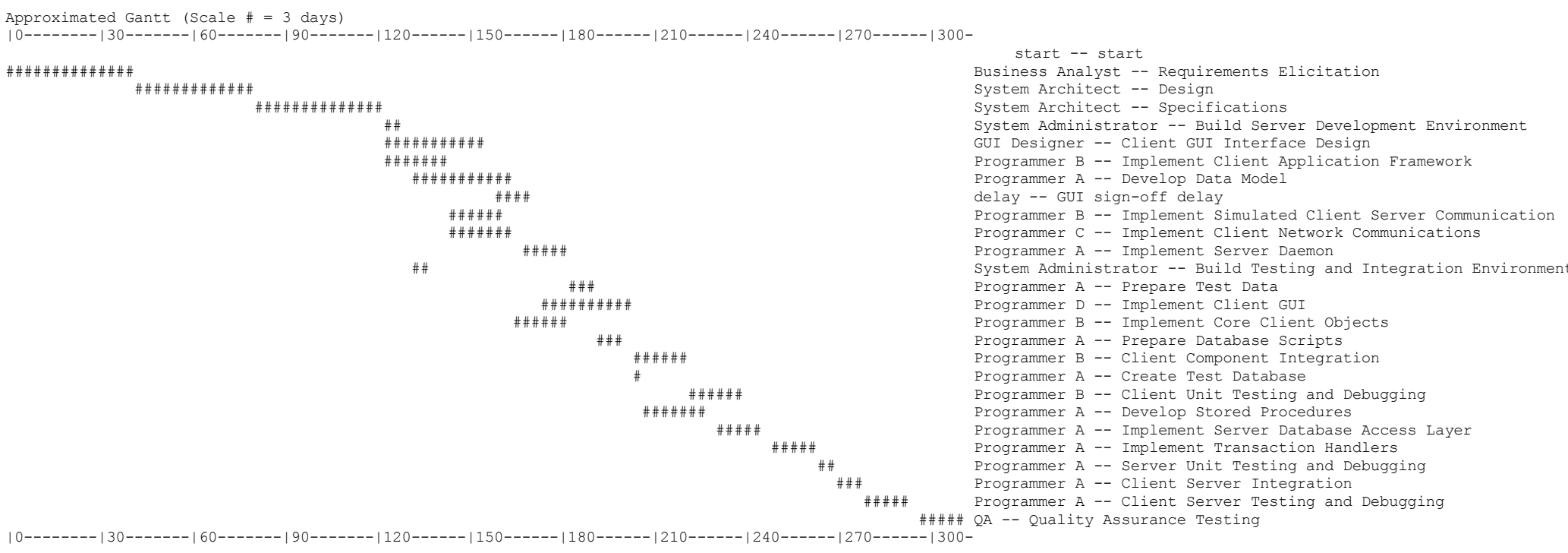

$\begin{array}{ll}\text { \# } & \text { Programmer A -- Client Server Integration } \\ \text { \#\#\#\#\# } & \text { Programmer A -- Client Server Testing and Debugging }\end{array}$

Busintart -- start

System Architect -- Design
System Architect -- Specifications

System Administrator -- Build Server Development Environment

Design

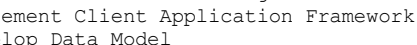

delay -- GUI sign-off delay

Programmer B - Implement Simulated Client Server Communication

Programmer $C^{-}$- Implement Client Network Communication

System Administrator -- Build Testing and Integration Environment

Programmer A -- Prepare Test Data

Programmer D -- Implement Client GUI
Programmer B -- Implement Core Client objects

Programmer A -- Prepare Database Scripts

Programmer B -- Client Unit Testing and Debugging

Programmer A -- Develop Stored Procedures 
Client Server Application v1 - Scenario 6 Gantt Chart

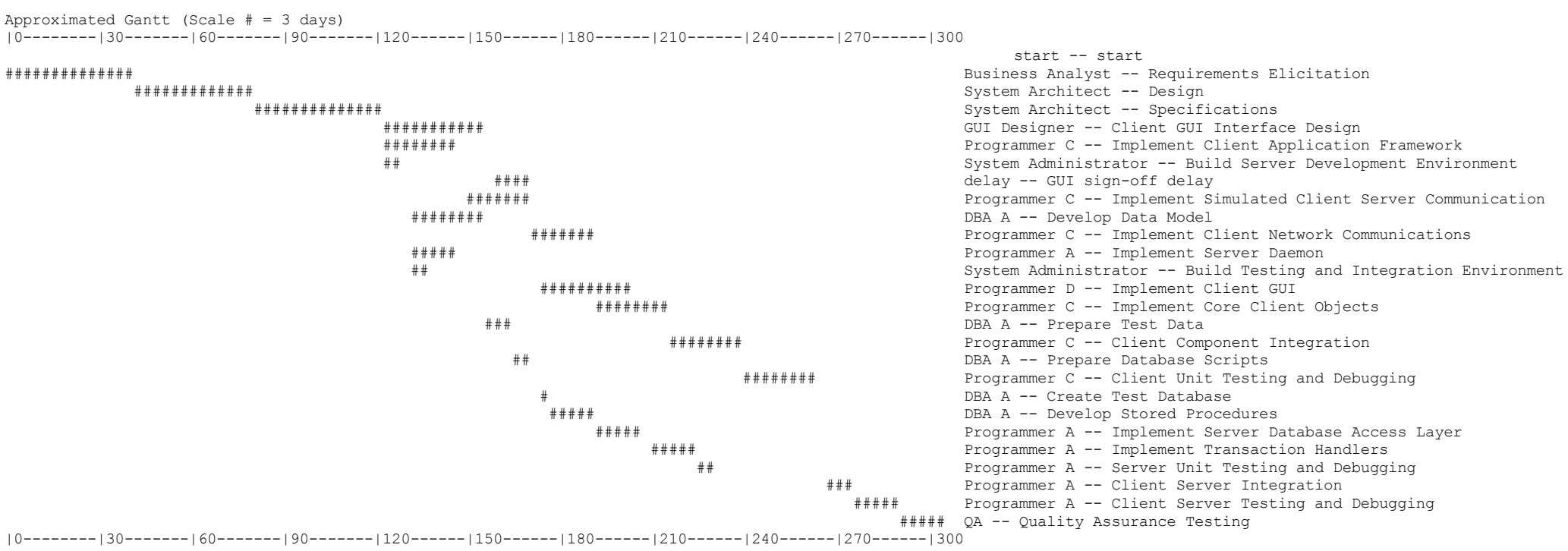


Client Server Application v1 - Scenario 7 Gantt Chart

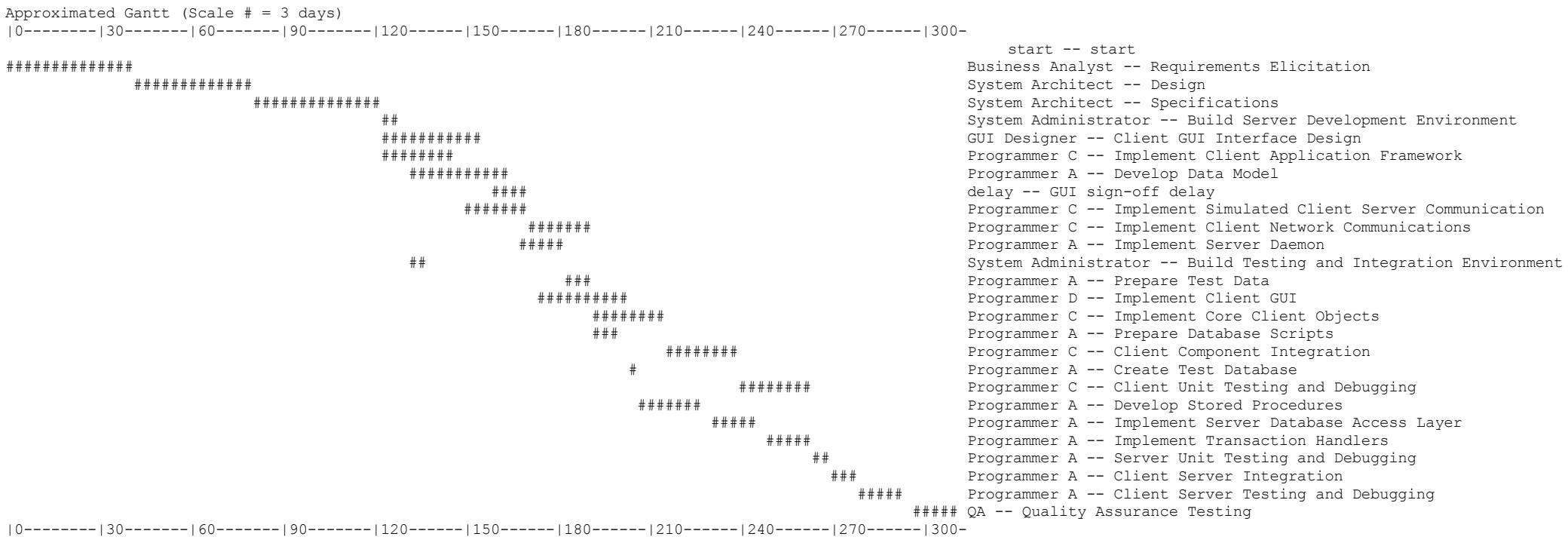


Client Server Application v2 - Base Scenario Gantt Chart

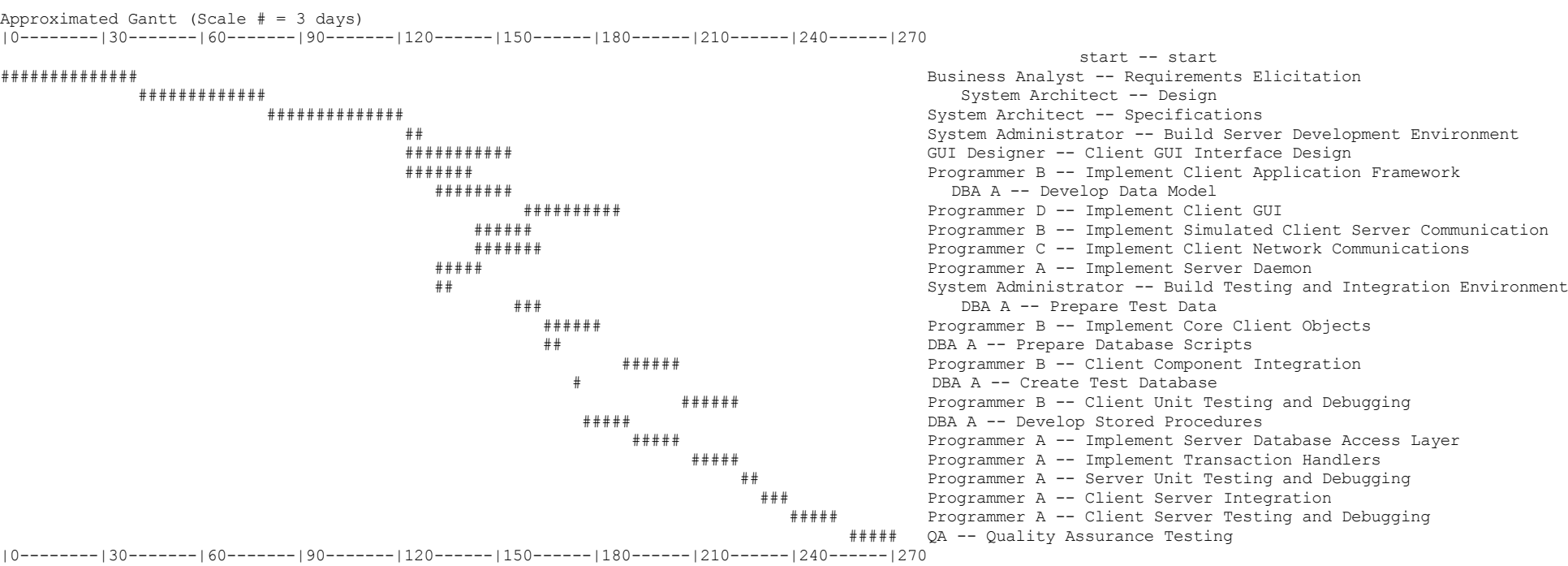


Client Server Application v2 - Scenario 1 Gantt Chart

Approximated Gantt (Scale \# = 3 days)
|


Client Server Application v2 - Scenario 2 Gantt Chart

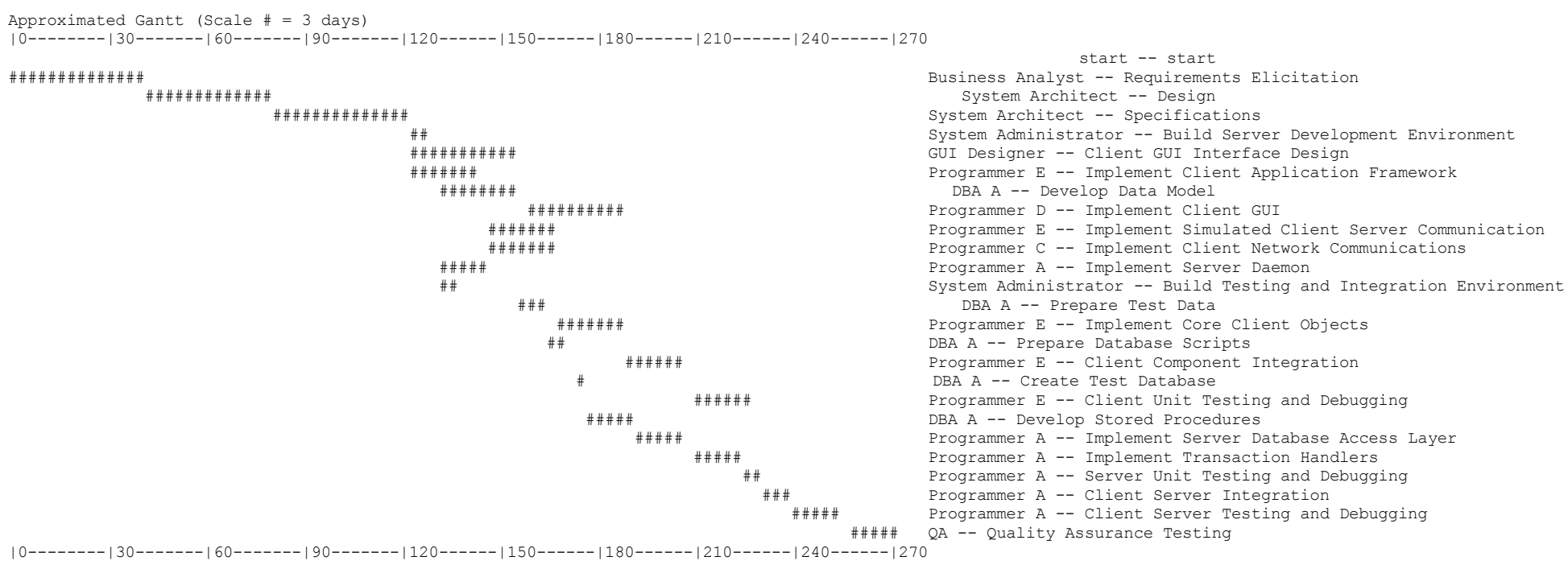


Client Server Application v2 - Scenario 3 Gantt Chart

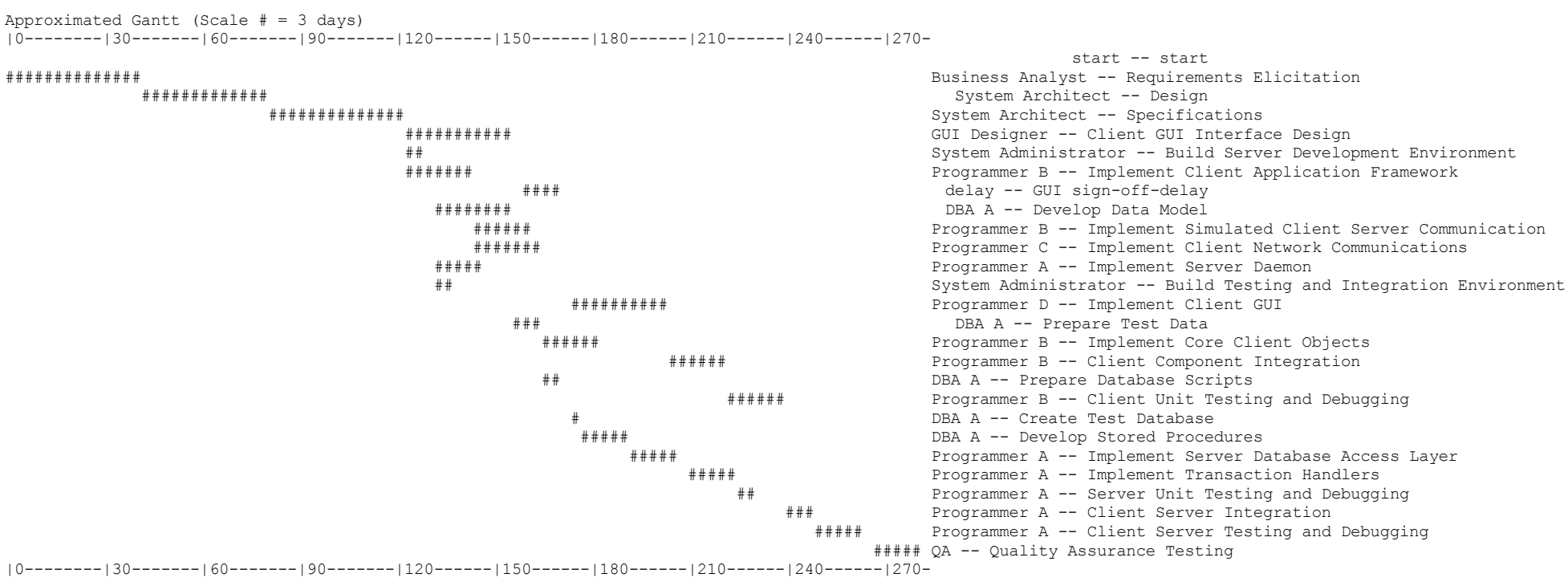


Client Server Application v2 - Scenario 4 Gantt Chart

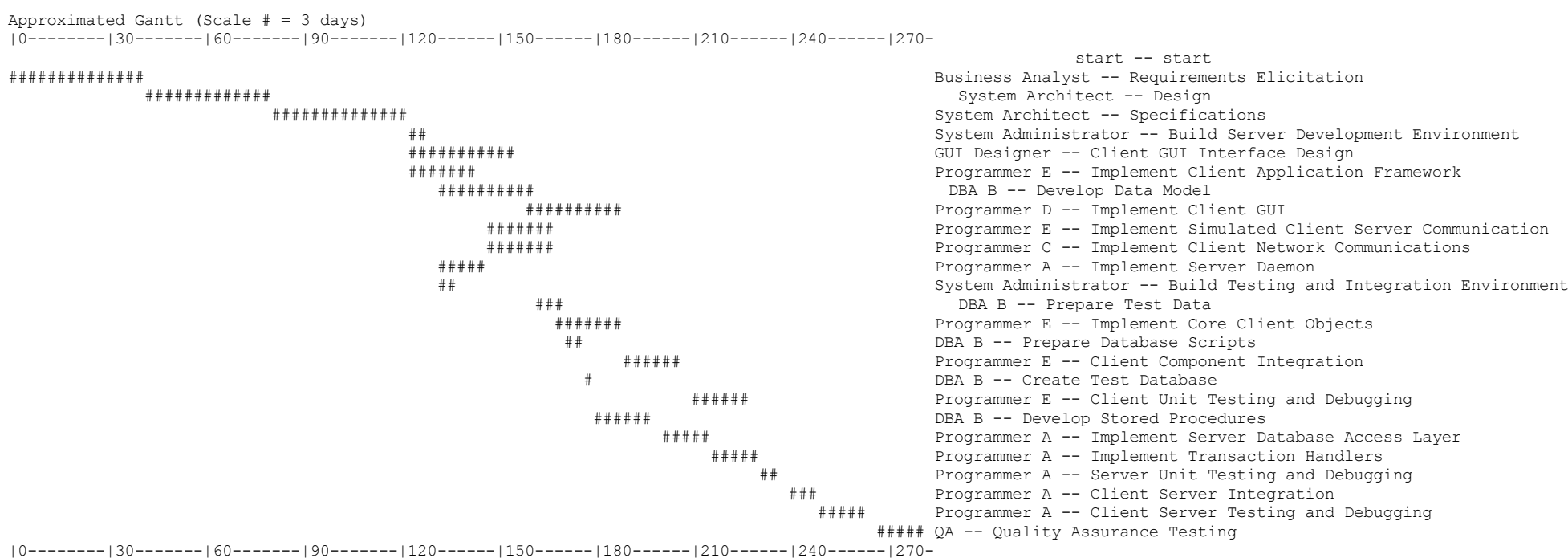


Client Server Application v2 - Scenario 5 Gantt Chart

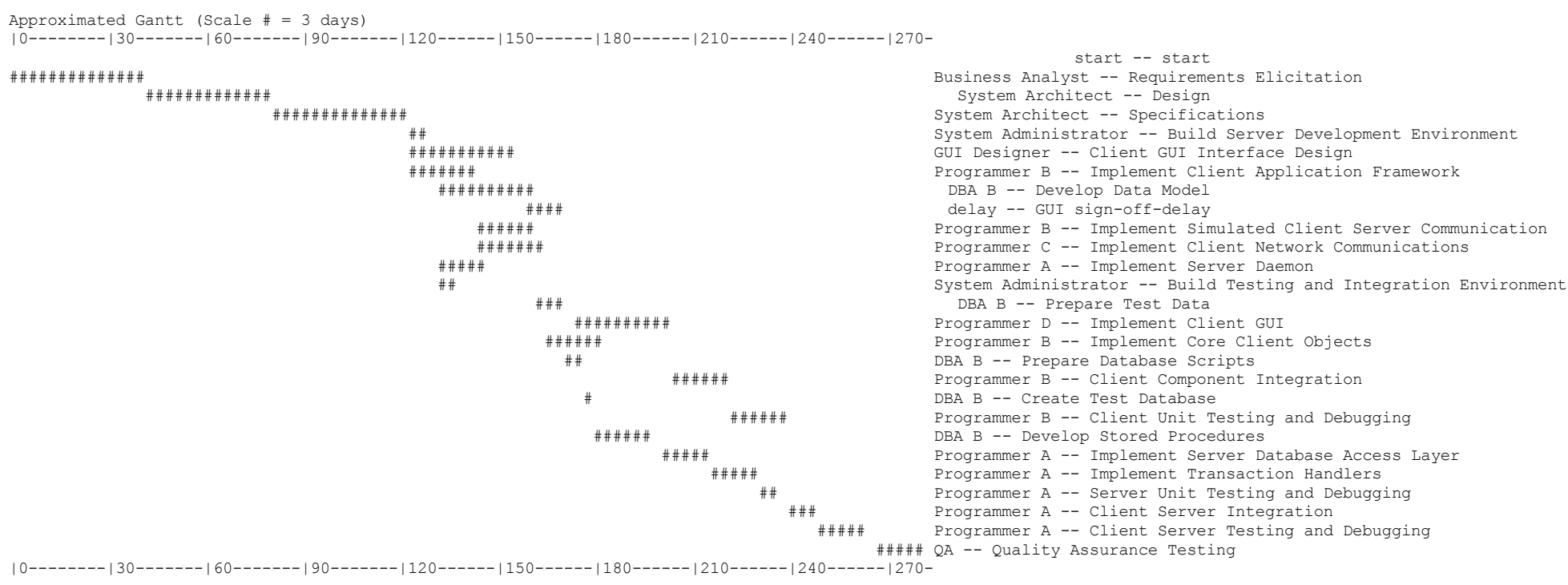


Client Server Application v2 - Scenario 6 Gantt Chart

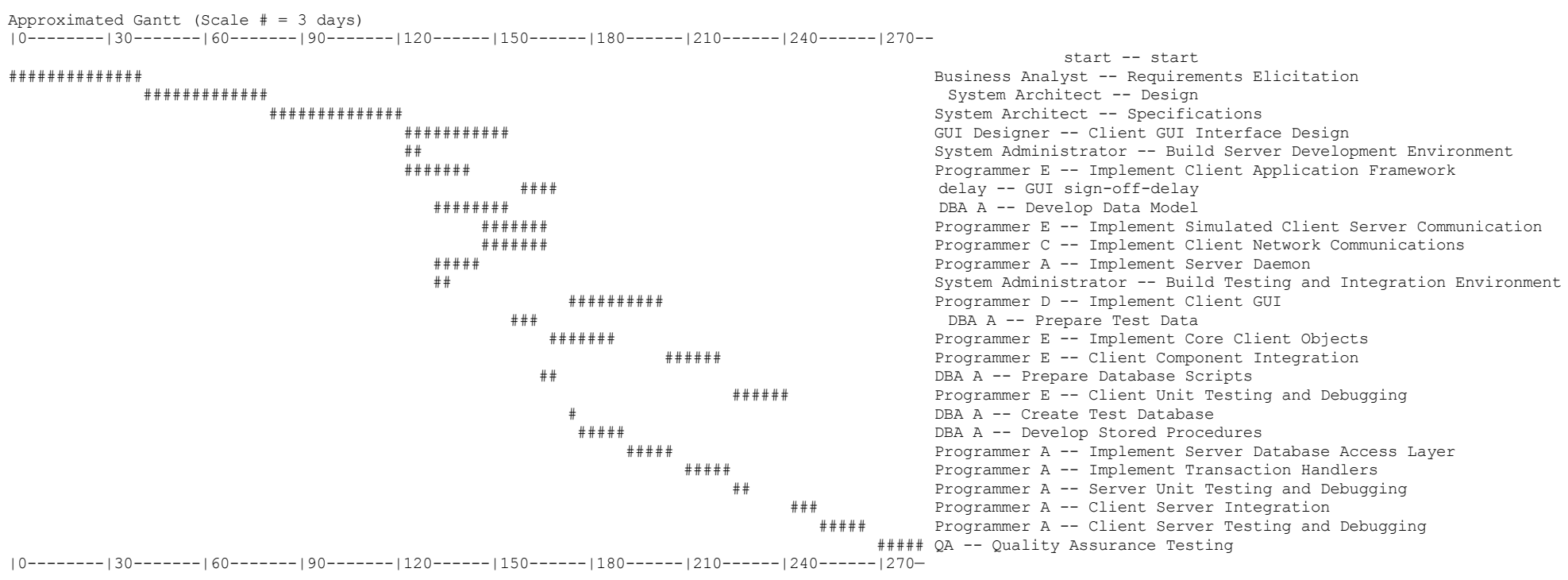


Client Server Application v2 - Scenario 7 Gantt Chart

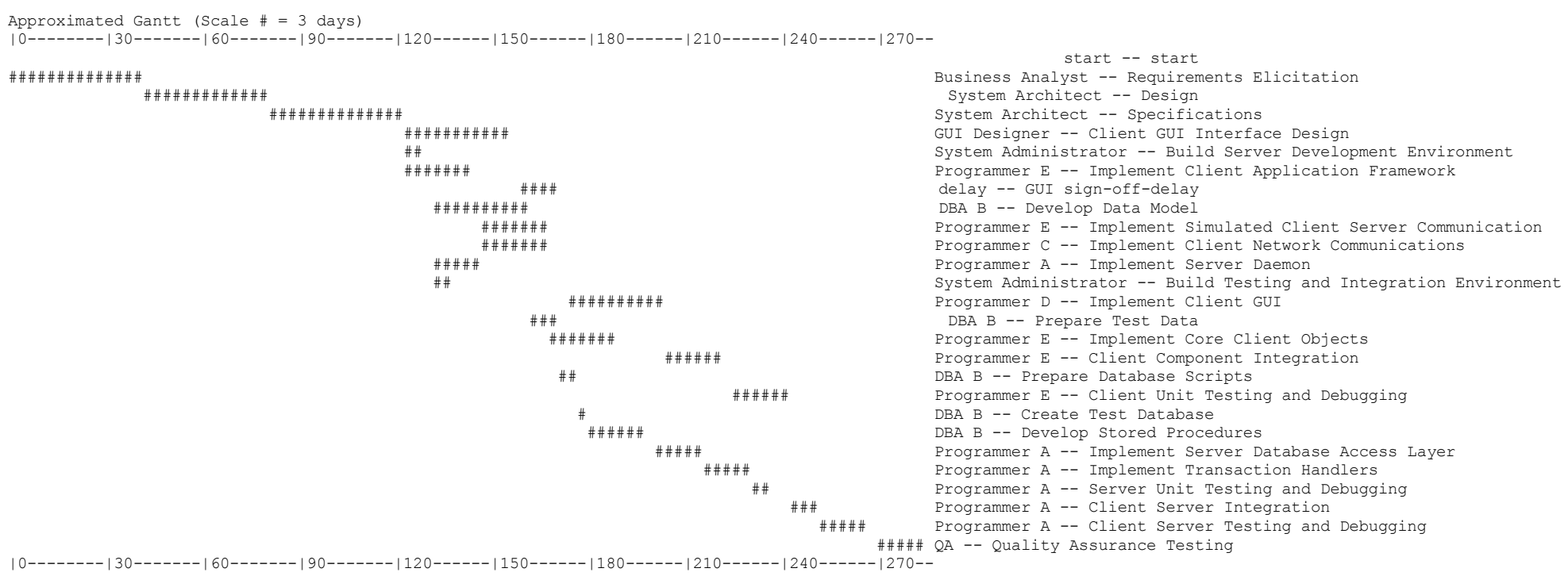




\section{Appendix B - Example Database}

\section{DS_PROJECTS}

\begin{tabular}{|r|l|r|r|}
\hline \multicolumn{1}{|c|}{ PROJ_ID } & \multicolumn{1}{|c|}{ PROJ_NAME } & PROJ_END_DATE & PROJ_START_DATE \\
\hline 1 & Simple Project 1 & 0 & 0 \\
\hline 2 & Simple Project 2 & 0 & 0 \\
\hline 3 & Client Server Application v1 & 0 & 0 \\
\hline 4 & Client Server Application v2 & 0 & 0 \\
\hline
\end{tabular}

\section{DS_SKILLS}

\begin{tabular}{|r|l|}
\hline \multicolumn{1}{|c|}{ SKILL_ID } & \multicolumn{1}{|c|}{ SKILL_NAME } \\
\hline 1 & NA \\
\hline 2 & s1 \\
\hline 3 & s2 \\
\hline 4 & Systems Analysis \\
\hline 5 & Requirements Analysis \\
\hline 6 & Graphic Design \\
\hline 7 & Usability \\
\hline 8 & Network Programming \\
\hline 9 & UNIX \\
\hline 10 & Networking \\
\hline 11 & Oracle 9i \\
\hline 12 & Server Hardware \\
\hline 13 & Data Modeling \\
\hline 14 & PL/SQL \\
\hline 15 & C++ \\
\hline 16 & UML \\
\hline 17 & XML \\
\hline 18 & QA Testing \\
\hline
\end{tabular}

\section{DS RESOURCES}

\begin{tabular}{|r|l|r|}
\hline \multicolumn{1}{|c|}{ RES_ID } & \multicolumn{1}{|c|}{ RES_NAME } & RES_RATE \\
\hline 1 & start & $\$ 0.00$ \\
\hline 2 & delay & $\$ 0.00$ \\
\hline 3 & r1 & $\$ 35.00$ \\
\hline 4 & r2 & $\$ 35.00$ \\
\hline 5 & Business Analyst & $\$ 100.00$ \\
\hline 6 & System Architect & $\$ 125.00$ \\
\hline 7 & System Administrator & $\$ 100.00$ \\
\hline 8 & DBA A & $\$ 125.00$ \\
\hline 9 & GUI Designer & $\$ 75.00$ \\
\hline 10 & Programmer A & $\$ 150.00$ \\
\hline 11 & Programmer B & $\$ 100.00$ \\
\hline 12 & Programmer C & $\$ 75.00$ \\
\hline 13 & Programmer D & $\$ 100.00$ \\
\hline 14 & QA & $\$ 50.00$ \\
\hline 15 & DBA B & $\$ 100.00$ \\
\hline 16 & Programmer E & $\$ 85.00$ \\
\hline R &
\end{tabular}

\section{DS_RISKS}

\begin{tabular}{|r|r|r|l|r|}
\hline \multicolumn{1}{|c|}{ RISK_ID } & \multicolumn{1}{|c|}{ PROJID } & \multicolumn{1}{|c|}{ RISK_TYPE_ID } & RISK_DESCRIPTION & \multicolumn{1}{c|}{ RISK_PROBABILITY } \\
\hline 1 & 3 & 1 & DBA A is unavailable & 0.5 \\
\hline 2 & 3 & 1 & Programmer B is unavailable & 0.3 \\
\hline 3 & 3 & 2 & Executive Sign-off on GUI is delayed & 0.7 \\
\hline 4 & 4 & 1 & DBA A is unavailable & 0.5 \\
\hline 5 & 4 & 1 & Programmer B is unavailable & 0.3 \\
\hline 6 & 4 & 2 & Executive Sign-off on GUI is delayed & 0.7 \\
\hline
\end{tabular}

\section{DS_RISK_TYPE}

\begin{tabular}{|r|l|}
\hline \multicolumn{1}{|c|}{ RISK_TYPE_ID } & RISK_TYPE_NAME \\
\hline 1 & Resource Unavailable \\
\hline 2 & Delay \\
\hline
\end{tabular}




\section{DS_TASKS}

\begin{tabular}{|c|c|c|c|c|c|c|c|}
\hline TASK_INDEX & TASK_ID & PROJ_ID & TASK_NAME & TASK_DURATION & IS_CONTINGENCY & RISK_ID & IS_RES_SCALABLE \\
\hline 1 & 1 & 1 & start & 0 & FALSE & & FALSE \\
\hline 2 & 2 & 1 & $a$ & 1 & FALSE & & TRUE \\
\hline 3 & 3 & 1 & $\mathrm{~b}$ & 1 & FALSE & & TRUE \\
\hline 4 & 4 & 1 & $\mathrm{c}$ & 2 & FALSE & & TRUE \\
\hline 5 & 5 & 1 & d & 1 & FALSE & & TRUE \\
\hline 6 & 1 & 2 & start & 0 & FALSE & & FALSE \\
\hline 7 & 2 & 2 & $a$ & 1 & FALSE & & TRUE \\
\hline 8 & 3 & 2 & $\mathrm{~b}$ & 1 & FALSE & & TRUE \\
\hline 9 & 4 & 2 & $\mathrm{c}$ & 2 & FALSE & & TRUE \\
\hline 10 & 5 & 2 & d & 1 & FALSE & & TRUE \\
\hline 11 & 1 & 3 & start & 0 & FALSE & & FALSE \\
\hline 12 & 2 & 3 & Requirements Elicitation & 40 & FALSE & & TRUE \\
\hline 13 & 3 & 3 & Design & 40 & FALSE & & TRUE \\
\hline 14 & 4 & 3 & Specifications & 40 & FALSE & & TRUE \\
\hline 15 & 5 & 3 & \begin{tabular}{|l|} 
Build Server Development \\
Environment
\end{tabular} & 10 & FALSE & & TRUE \\
\hline 16 & 6 & 3 & \begin{tabular}{|l|} 
Build Testing and \\
Integration Environment
\end{tabular} & 10 & FALSE & & TRUE \\
\hline 17 & 7 & 3 & Develop Data Model & 30 & FALSE & & TRUE \\
\hline 18 & 8 & 3 & Prepare Test Data & 10 & FALSE & & TRUE \\
\hline 19 & 9 & 3 & Prepare Database Scripts & 10 & FALSE & & TRUE \\
\hline 20 & 10 & 3 & Create Test Database & 4 & FALSE & & TRUE \\
\hline 21 & 11 & 3 & $\begin{array}{|ll|}\text { Develop } & \text { Stored } \\
\text { Procedures } & \\
\end{array}$ & 20 & FALSE & & TRUE \\
\hline 22 & 12 & 3 & Implement Server Daemon & 20 & FALSE & & TRUE \\
\hline 23 & 13 & 3 & $\begin{array}{|lc|}\text { Implement } & \text { Server } \\
\text { Database Access Layer }\end{array}$ & 20 & FALSE & & TRUE \\
\hline 24 & 14 & 3 & $\begin{array}{|ll|}\text { Implement } & \text { Transaction } \\
\text { Handlers } & \end{array}$ & 20 & FALSE & & TRUE \\
\hline 25 & 15 & 3 & \begin{tabular}{|l|}
$\begin{array}{l}\text { Server Unit Testing and } \\
\text { Debugging }\end{array}$ \\
\end{tabular} & 10 & FALSE & & TRUE \\
\hline 26 & 16 & 3 & $\begin{array}{|lll|}\begin{array}{l}\text { Client } \\
\text { Design }\end{array} & \text { GUI Interface } \\
\end{array}$ & 30 & FALSE & & TRUE \\
\hline 27 & 17 & 3 & $\begin{array}{|lr|}\text { Implement } & \text { Client } \\
\text { Application Framework }\end{array}$ & 20 & FALSE & & TRUE \\
\hline 28 & 18 & 3 & $\begin{array}{|lr|}\text { Implement } & \text { Simulated } \\
\text { Client } & \text { Server } \\
\text { Communication } & \\
\end{array}$ & 20 & FALSE & & TRUE \\
\hline 29 & 19 & 3 & $\begin{array}{l}\text { Implement Client Network } \\
\text { Communications }\end{array}$ & 20 & FALSE & & TRUE \\
\hline 30 & 20 & 3 & Implement Client GUI & 30 & FALSE & & TRUE \\
\hline 31 & 21 & 3 & $\begin{array}{|lcc|}\begin{array}{l}\text { Implement Core Client } \\
\text { Objects }\end{array} \\
\end{array}$ & 20 & FALSE & & TRUE \\
\hline 32 & 22 & 3 & $\begin{array}{|ll|}\begin{array}{l}\text { Client } \\
\text { Integration }\end{array} & \text { Component } \\
\end{array}$ & 20 & FALSE & & TRUE \\
\hline 33 & 23 & 3 & \begin{tabular}{|l|} 
Client Unit Testing and \\
Debugging
\end{tabular} & 20 & FALSE & & TRUE \\
\hline 34 & 24 & 3 & Client Server Integration & 10 & FALSE & & TRUE \\
\hline 35 & 25 & 3 & $\begin{array}{l}\text { Client Server Testing and } \\
\text { Debugging }\end{array}$ & 20 & FALSE & & TRUE \\
\hline 36 & 26 & 3 & Quality Assurance Testing & 20 & FALSE & & TRUE \\
\hline 37 & 1 & 4 & start & 0 & FALSE & & FALSE \\
\hline 38 & 2 & 4 & Requirements Elicitation & 40 & FALSE & & TRUE \\
\hline 39 & 3 & 4 & Design & 40 & FALSE & & TRUE \\
\hline 40 & 4 & 4 & Specifications & 40 & FALSE & & TRUE \\
\hline 41 & 5 & 4 & $\begin{array}{l}\text { Build Server Development } \\
\text { Environment }\end{array}$ & 10 & FALSE & & TRUE \\
\hline 42 & 6 & 4 & \begin{tabular}{|l|} 
Build Testing and \\
Integration Environment
\end{tabular} & 10 & FALSE & & TRUE \\
\hline 43 & 7 & 4 & Develop Data Model & 30 & FALSE & & TRUE \\
\hline 44 & 8 & 4 & Prepare Test Data & 10 & FALSE & & TRUE \\
\hline 45 & 9 & 4 & Prepare Database Scripts & 10 & FALSE & & TRUE \\
\hline 46 & 10 & 4 & Create Test Database & 4 & FALSE & & TRUE \\
\hline 47 & 11 & 4 & $\begin{array}{|ll|}\text { Develop } & \text { Stored } \\
\text { Procedures } & \\
\end{array}$ & 20 & FALSE & & TRUE \\
\hline 48 & 12 & 4 & Implement Server Daemon & 20 & FALSE & & TRUE \\
\hline 49 & 13 & 4 & $\begin{array}{|lc|}\text { Implement } & \text { Server } \\
\text { Database Access Layer }\end{array}$ & 20 & FALSE & & TRUE \\
\hline 50 & 14 & 4 & $\begin{array}{|ll|}\begin{array}{l}\text { Implement } \\
\text { Handlers }\end{array} & \text { Transaction } \\
\end{array}$ & 20 & FALSE & & TRUE \\
\hline 51 & 15 & 4 & \begin{tabular}{|l|} 
Server Unit Testing and \\
Debugging
\end{tabular} & 10 & FALSE & & TRUE \\
\hline 52 & 16 & 4 & $\begin{array}{|lll|}\begin{array}{l}\text { Client } \\
\text { Design }\end{array} & \text { GUI Interface } \\
\end{array}$ & 30 & FALSE & & TRUE \\
\hline 53 & 17 & 4 & $\begin{array}{|lc|}\text { Implement } & \text { Client } \\
\text { Application Framework }\end{array}$ & 20 & FALSE & & TRUE \\
\hline 54 & 18 & 4 & $\begin{array}{|lr|}\text { Implement } & \text { Simulated } \\
\text { Client } & \text { Server } \\
\text { Communication } & \\
\end{array}$ & 20 & FALSE & & TRUE \\
\hline 55 & 19 & 4 & \begin{tabular}{|l|} 
Implement Client Network \\
Communications
\end{tabular} & 20 & FALSE & & TRUE \\
\hline
\end{tabular}




\begin{tabular}{|l|l|l|l|l|l|l|l|}
\hline TASK_INDEX & TASK_ID & PROJ_ID & \multicolumn{1}{|c|}{ TASK_NAME } & TASK_DURATION & IS_CONTINGENCY & RISK_ID & IS_RES_SCALABLE \\
\hline 56 & 20 & 4 & Implement Client GUI & 30 & FALSE & & TRUE \\
\hline 57 & 21 & 4 & $\begin{array}{l}\text { Implement Core Client } \\
\text { Objects }\end{array}$ & 20 & FALSE & & TRUE \\
\hline 58 & 22 & 4 & $\begin{array}{l}\text { Client } \\
\text { Integration Component }\end{array}$ & 20 & & & TRUE \\
\hline 59 & 23 & 4 & $\begin{array}{l}\text { Client Unit Testing and } \\
\text { Debugging }\end{array}$ & 20 & FALSE & & TRUE \\
\hline 60 & 24 & 4 & Client Server Integration & 10 & FALSE & & TRUE \\
\hline 61 & 25 & 4 & $\begin{array}{l}\text { Client Server Testing and } \\
\text { Debugging } 20\end{array}$ & FALSE & & TRUE \\
\hline 62 & 26 & 4 & Quality Assurance Testing & 20 & FALSE & TRUE \\
\hline 63 & 27 & 3 & GUI sign-off delay & 14 & TRUE & 3 & FALSE \\
\hline 64 & 27 & 4 & GUI sign-off-delay & 14 & TRUE & 6 & FALSE \\
\hline
\end{tabular}




\section{DS_TASK_RELATIONSHIPS}

\begin{tabular}{|c|c|c|c|c|c|}
\hline TREL_ID & PROJ_ID & TASK_ID & TASK_SUCC_ID & IS_CONTINGENCY & RISK_ID \\
\hline 1 & 1 & 1 & 2 & FALSE & \\
\hline 2 & 1 & 2 & 3 & FALSE & \\
\hline 3 & 1 & 2 & 4 & FALSE & \\
\hline 4 & 1 & 3 & 5 & FALSE & \\
\hline 5 & 1 & 4 & & FALSE & \\
\hline 6 & 1 & 5 & & FALSE & \\
\hline 7 & 2 & 1 & 2 & FALSE & \\
\hline 8 & 2 & 2 & 3 & FALSE & \\
\hline 9 & 2 & 2 & 4 & FALSE & \\
\hline 10 & 2 & 3 & 5 & FALSE & \\
\hline 11 & 2 & 4 & & FALSE & \\
\hline 12 & 2 & 5 & & FALSE & \\
\hline 13 & 3 & 1 & 2 & FALSE & \\
\hline 14 & 3 & 2 & 3 & FALSE & \\
\hline 15 & 3 & 3 & 4 & FALSE & \\
\hline 16 & 3 & 4 & 5 & FALSE & \\
\hline 17 & 3 & 5 & 6 & FALSE & \\
\hline 18 & 3 & 5 & 7 & FALSE & \\
\hline 19 & 3 & 7 & 8 & FALSE & \\
\hline 20 & 3 & 8 & 9 & FALSE & \\
\hline 21 & 3 & 5 & 10 & FALSE & \\
\hline 22 & 3 & 9 & 10 & FALSE & \\
\hline 23 & 3 & 10 & 11 & FALSE & \\
\hline 24 & 3 & 5 & 12 & FALSE & \\
\hline 25 & 3 & 11 & 13 & FALSE & \\
\hline 26 & 3 & 12 & 13 & FALSE & \\
\hline 27 & 3 & 13 & 14 & FALSE & \\
\hline 28 & 3 & 14 & 15 & FALSE & \\
\hline 29 & 3 & 4 & 16 & FALSE & \\
\hline 30 & 3 & 4 & 17 & FALSE & \\
\hline 31 & 3 & 17 & 18 & FALSE & \\
\hline 32 & 3 & 17 & 19 & FALSE & \\
\hline 33 & 3 & 16 & 20 & FALSE & \\
\hline 34 & 3 & 18 & 21 & FALSE & \\
\hline 35 & 3 & 17 & 22 & FALSE & \\
\hline 36 & 3 & 18 & 22 & FALSE & \\
\hline 37 & 3 & 19 & 22 & FALSE & \\
\hline 38 & 3 & 20 & 22 & FALSE & \\
\hline 39 & 3 & 21 & 22 & FALSE & \\
\hline 40 & 3 & 22 & 23 & FALSE & \\
\hline 41 & 3 & 6 & 24 & FALSE & \\
\hline 42 & 3 & 15 & 24 & FALSE & \\
\hline 43 & 3 & 23 & 24 & FALSE & \\
\hline 44 & 3 & 24 & 25 & FALSE & \\
\hline 45 & 3 & 25 & 26 & FALSE & \\
\hline 46 & 3 & 26 & & FALSE & \\
\hline 47 & 4 & 1 & 2 & FALSE & \\
\hline 48 & 4 & 2 & 3 & FALSE & \\
\hline 49 & 4 & 3 & 4 & FALSE & \\
\hline 50 & 4 & 4 & 5 & FALSE & \\
\hline 51 & 4 & 5 & 6 & FALSE & \\
\hline 52 & 4 & 5 & 7 & FALSE & \\
\hline 53 & 4 & 7 & 8 & FALSE & \\
\hline 54 & 4 & 8 & 9 & FALSE & \\
\hline 55 & 4 & 5 & 10 & FALSE & \\
\hline 56 & 4 & 9 & 10 & FALSE & \\
\hline 57 & 4 & 10 & 11 & FALSE & \\
\hline 58 & 4 & 5 & 12 & FALSE & \\
\hline 59 & 4 & 11 & 13 & FALSE & \\
\hline 60 & 4 & 12 & 13 & FALSE & \\
\hline 61 & 4 & 13 & 14 & FALSE & \\
\hline 62 & 4 & 14 & 15 & FALSE & \\
\hline 63 & 4 & 4 & 16 & FALSE & \\
\hline 64 & 4 & 4 & 17 & FALSE & \\
\hline 65 & 4 & 17 & 18 & FALSE & \\
\hline 66 & 4 & 17 & 19 & FALSE & \\
\hline 67 & 4 & 16 & 20 & FALSE & \\
\hline 68 & 4 & 18 & 21 & FALSE & \\
\hline
\end{tabular}




\begin{tabular}{|r|r|r|r|r|r|}
\hline \multicolumn{1}{|c|}{ TREL_ID } & \multicolumn{1}{|l|}{ PROJ_ID } & \multicolumn{1}{|c|}{ TASK_ID } & \multicolumn{1}{l|}{ TASK_SUCC_ID } & IS_CONTINGENCY & RISK_ID \\
\hline 69 & 4 & 17 & 22 & FALSE & \\
\hline 70 & 4 & 18 & 22 & FALSE & \\
\hline 71 & 4 & 19 & 22 & FALSE & \\
\hline 72 & 4 & 20 & 22 & FALSE & \\
\hline 73 & 4 & 21 & 22 & FALSE & \\
\hline 74 & 4 & 22 & 23 & FALSE & \\
\hline 75 & 4 & 6 & 24 & FALSE & \\
\hline 76 & 4 & 15 & 24 & FALSE & \\
\hline 77 & 4 & 23 & 24 & FALSE & \\
\hline 78 & 4 & 24 & 25 & FALSE & \\
\hline 79 & 4 & 25 & 26 & FALSE & \\
\hline 80 & 4 & 26 & & FALSE & \\
\hline 81 & 3 & 16 & 27 & TRUE & \\
\hline 82 & 3 & 27 & 20 & TRUE & 3 \\
\hline 83 & 4 & 16 & 27 & TRUE & 6 \\
\hline 84 & 4 & 27 & 20 & TRUE & 6 \\
\hline
\end{tabular}




\section{DS_ASSIGNMENTS}

\begin{tabular}{|c|c|c|c|c|}
\hline PROJ_ID & TASK_ID & RES_ID & IS_CONTINGENCY & RISK_ID \\
\hline 1 & 1 & 1 & FALSE & \\
\hline 2 & 1 & 1 & FALSE & \\
\hline 3 & 1 & 1 & FALSE & \\
\hline 4 & 1 & 1 & FALSE & \\
\hline 3 & 27 & 2 & TRUE & $\overline{3}$ \\
\hline 4 & 27 & 2 & TRUE & $\overline{6}$ \\
\hline 1 & 3 & 3 & FALSE & \\
\hline 1 & 5 & 3 & FALSE & \\
\hline 2 & 3 & 3 & FALSE & \\
\hline 2 & 4 & 3 & FALSE & \\
\hline 1 & 2 & 4 & FALSE & \\
\hline 1 & 4 & 4 & FALSE & \\
\hline 2 & 2 & 4 & FALSE & \\
\hline 2 & 5 & 4 & FALSE & \\
\hline 3 & 2 & 5 & FALSE & \\
\hline 4 & 2 & 5 & FALSE & \\
\hline 3 & 3 & 6 & FALSE & \\
\hline 3 & 4 & 6 & FALSE & \\
\hline 4 & 3 & 6 & FALSE & \\
\hline 4 & 4 & 6 & FALSE & \\
\hline 3 & 5 & 7 & FALSE & \\
\hline 3 & 6 & 7 & FALSE & \\
\hline 4 & 5 & 7 & FALSE & \\
\hline 4 & 6 & 7 & FALSE & \\
\hline 3 & 7 & 8 & FALSE & \\
\hline 3 & 8 & 8 & FALSE & \\
\hline 3 & 9 & 8 & FALSE & \\
\hline 3 & 10 & 8 & FALSE & \\
\hline 3 & 11 & 8 & FALSE & \\
\hline 4 & 7 & 8 & FALSE & \\
\hline 4 & 8 & 8 & FALSE & \\
\hline 4 & 9 & 8 & FALSE & \\
\hline 4 & 10 & 8 & FALSE & \\
\hline 4 & 11 & 8 & FALSE & \\
\hline 3 & 16 & 9 & FALSE & \\
\hline 4 & 16 & 9 & FALSE & \\
\hline 3 & 12 & 10 & FALSE & \\
\hline 3 & 13 & 10 & FALSE & \\
\hline 3 & 14 & 10 & FALSE & \\
\hline 3 & 15 & 10 & FALSE & \\
\hline 3 & 24 & 10 & FALSE & \\
\hline 3 & 25 & 10 & FALSE & \\
\hline 4 & 12 & 10 & FALSE & \\
\hline 4 & 13 & 10 & FALSE & \\
\hline 4 & 14 & 10 & FALSE & \\
\hline 4 & 15 & 10 & FALSE & \\
\hline 4 & 24 & 10 & FALSE & \\
\hline 4 & 25 & 10 & FALSE & \\
\hline 3 & 7 & 10 & TRUE & 1 \\
\hline 3 & 8 & 10 & TRUE & 1 \\
\hline 3 & 9 & 10 & TRUE & 1 \\
\hline 3 & 10 & 10 & TRUE & 1 \\
\hline 3 & 11 & 10 & TRUE & 1 \\
\hline 3 & 17 & 11 & FALSE & \\
\hline 3 & 18 & 11 & FALSE & \\
\hline 3 & 21 & 11 & FALSE & \\
\hline 3 & 22 & 11 & $\overline{F A L S E}$ & \\
\hline 3 & 23 & 11 & FALSE & \\
\hline 4 & 17 & 11 & FALSE & \\
\hline 4 & 18 & 11 & FALSE & \\
\hline 4 & 21 & 11 & FALSE & \\
\hline 4 & 22 & 11 & FALSE & \\
\hline 4 & 23 & 11 & FALSE & \\
\hline 3 & 19 & 12 & FALSE & \\
\hline 4 & 19 & 12 & FALSE & \\
\hline 3 & 17 & 12 & TRUE & 2 \\
\hline 3 & 18 & 12 & TRUE & 2 \\
\hline
\end{tabular}




\begin{tabular}{|r|r|r|r|r|}
\hline \multicolumn{1}{|c|}{ PROJ_ID } & \multicolumn{1}{|c|}{ TASK_ID } & RES_ID & IS_CONTINGENCY & RISK_ID \\
\hline 3 & 21 & 12 & TRUE & 2 \\
\hline 3 & 22 & 12 & TRUE & 2 \\
\hline 3 & 23 & 12 & TRUE & 2 \\
\hline 3 & 20 & 13 & FALSE & \\
\hline 4 & 20 & 13 & FALSE & \\
\hline 3 & 26 & 14 & FALSE & \\
\hline 4 & 26 & 14 & FALSE & \\
\hline 4 & 7 & 15 & TRUE & 4 \\
\hline 4 & 8 & 15 & TRUE & 4 \\
\hline 4 & 9 & 15 & TRUE & 4 \\
\hline 4 & 10 & 15 & TRUE & 4 \\
\hline 4 & 11 & 15 & TRUE & 4 \\
\hline 4 & 17 & 16 & TRUE & 5 \\
\hline 4 & 18 & 16 & TRUE & 5 \\
\hline 4 & 21 & 16 & TRUE & 5 \\
\hline 4 & 22 & 16 & TRUE & 5 \\
\hline 4 & 23 & 16 & TRUE & 5 \\
\hline
\end{tabular}


DS_RES_SKILLS

\begin{tabular}{|c|c|c|}
\hline RES_ID & SKILL_ID & RES_SKILL_LVL \\
\hline 1 & 1 & 3 \\
\hline 2 & 1 & 3 \\
\hline 3 & 2 & 4 \\
\hline 3 & 3 & 2 \\
\hline 4 & 2 & 2 \\
\hline 4 & 3 & 4 \\
\hline 5 & 5 & 3 \\
\hline 5 & 16 & 2 \\
\hline 6 & 4 & 4 \\
\hline 6 & 5 & 4 \\
\hline 6 & 13 & 2 \\
\hline 6 & 16 & 3 \\
\hline 7 & 5 & 2 \\
\hline 7 & 9 & 4 \\
\hline 7 & 10 & 4 \\
\hline 7 & 11 & 2 \\
\hline 7 & 12 & 4 \\
\hline 7 & 13 & 1 \\
\hline 7 & 14 & 3 \\
\hline 7 & 16 & 2 \\
\hline 8 & 5 & 3 \\
\hline 8 & 9 & 3 \\
\hline 8 & 11 & 5 \\
\hline 8 & 13 & 5 \\
\hline 8 & 14 & 5 \\
\hline 8 & 16 & 2 \\
\hline 8 & 17 & 3 \\
\hline 9 & 5 & 2 \\
\hline 9 & 6 & 3 \\
\hline 9 & 7 & 4 \\
\hline 9 & 16 & 1 \\
\hline 10 & 4 & 4 \\
\hline 10 & 5 & 3 \\
\hline 10 & 8 & 5 \\
\hline 10 & 9 & 4 \\
\hline 10 & 13 & 2 \\
\hline 10 & 14 & 3 \\
\hline 10 & 15 & 4 \\
\hline 10 & 16 & 3 \\
\hline 10 & 17 & 4 \\
\hline 11 & 4 & 3 \\
\hline 11 & 5 & 2 \\
\hline 11 & 7 & 1 \\
\hline 11 & 8 & 2 \\
\hline 11 & 9 & 2 \\
\hline 11 & 14 & 2 \\
\hline 11 & 15 & 4 \\
\hline 11 & 16 & 1 \\
\hline 11 & 17 & 2 \\
\hline 12 & 4 & 2 \\
\hline 12 & 5 & 2 \\
\hline 12 & 8 & 5 \\
\hline 12 & 9 & 4 \\
\hline 12 & 15 & 2 \\
\hline 12 & 16 & 1 \\
\hline 12 & 17 & 2 \\
\hline 13 & 4 & 1 \\
\hline 13 & 5 & 2 \\
\hline 13 & 7 & 4 \\
\hline 13 & 9 & 1 \\
\hline 13 & 15 & 1 \\
\hline 14 & 7 & 3 \\
\hline 14 & 18 & 5 \\
\hline 15 & 5 & 3 \\
\hline 15 & 9 & 3 \\
\hline 15 & 11 & 4 \\
\hline 15 & 13 & 4 \\
\hline 15 & 14 & 4 \\
\hline
\end{tabular}




\begin{tabular}{|r|r|r|}
\hline \multicolumn{1}{|c|}{ RES_ID } & \multicolumn{1}{|c|}{ SKILL_ID } & \multicolumn{1}{|c|}{ RES_SKILL_LVL } \\
\hline 15 & 16 & 2 \\
\hline 15 & 17 & 3 \\
\hline 16 & 4 & 3 \\
\hline 16 & 5 & 2 \\
\hline 16 & 7 & 1 \\
\hline 16 & 8 & 2 \\
\hline 16 & 9 & 2 \\
\hline 16 & 14 & 2 \\
\hline 16 & 15 & 3 \\
\hline 16 & 16 & 1 \\
\hline 16 & 17 & 2 \\
\hline
\end{tabular}




\section{DS TASK SKILLS}

\begin{tabular}{|c|c|c|c|c|}
\hline PROJ_ID & TASK_ID & SKILL_ID & TASK_SKILL_LVL & TASK_SKILL_WEIGHT \\
\hline 1 & 1 & 1 & 3 & 1 \\
\hline 1 & 2 & 3 & 3 & 1 \\
\hline 1 & 3 & 2 & 3 & 1 \\
\hline 1 & 4 & 3 & 3 & 1 \\
\hline 1 & 5 & $\overline{2}$ & $\overline{3}$ & 1 \\
\hline 2 & 1 & $\overline{1}$ & $\overline{3}$ & 1 \\
\hline 2 & 2 & 3 & 3 & 1 \\
\hline 2 & 3 & 2 & 3 & 1 \\
\hline 2 & 4 & $\overline{3}$ & 3 & 1 \\
\hline 2 & 5 & $\overline{3}$ & 3 & 1 \\
\hline 3 & 1 & 1 & 3 & 1 \\
\hline 3 & 2 & 5 & 3 & 0.8 \\
\hline 3 & 2 & 16 & 3 & 0.2 \\
\hline 3 & 3 & 4 & 4 & 0.4 \\
\hline 3 & 3 & 5 & 4 & 0.4 \\
\hline 3 & 3 & 13 & 2 & 0.1 \\
\hline 3 & 3 & 16 & 4 & 0.1 \\
\hline 3 & 4 & 4 & 4 & 0.3 \\
\hline 3 & 4 & 5 & 4 & 0.4 \\
\hline 3 & 4 & 13 & 2 & 0.1 \\
\hline 3 & 4 & 16 & 4 & 0.2 \\
\hline 3 & 5 & 9 & 3 & 0.4 \\
\hline 3 & 5 & 10 & 3 & 0.1 \\
\hline 3 & 5 & 11 & 3 & 0.1 \\
\hline 3 & 5 & 12 & 3 & 0.4 \\
\hline 3 & 6 & 9 & 3 & 0.4 \\
\hline 3 & 6 & 10 & 3 & 0.1 \\
\hline 3 & 6 & 11 & 3 & 0.1 \\
\hline 3 & 6 & 12 & 3 & 0.4 \\
\hline 3 & 7 & $\overline{5}$ & 3 & 0.2 \\
\hline 3 & 7 & 9 & 3 & 0.05 \\
\hline 3 & 7 & 11 & 4 & 0.2 \\
\hline 3 & 7 & 13 & 4 & 0.3 \\
\hline 3 & 7 & 14 & 4 & 0.2 \\
\hline 3 & 7 & 16 & 3 & 0.05 \\
\hline 3 & 8 & 5 & 3 & 0.3 \\
\hline 3 & 8 & 9 & 3 & 0.1 \\
\hline 3 & 8 & 11 & 3 & 0.3 \\
\hline 3 & 8 & 14 & 3 & 0.3 \\
\hline 3 & 9 & 9 & 2 & 0.1 \\
\hline 3 & 9 & 11 & $\overline{2}$ & 0.45 \\
\hline 3 & 9 & 14 & 3 & 0.45 \\
\hline 3 & 10 & 9 & 2 & 0.1 \\
\hline 3 & 10 & 11 & 3 & 0.9 \\
\hline 3 & 11 & $\overline{5}$ & 3 & 0.2 \\
\hline 3 & 11 & 9 & 2 & 0.1 \\
\hline 3 & 11 & 11 & 4 & 0.3 \\
\hline 3 & 11 & 14 & 4 & 0.4 \\
\hline 3 & 12 & 4 & 3 & 0.2 \\
\hline 3 & 12 & 8 & 4 & 0.4 \\
\hline 3 & 12 & 9 & 2 & 0.1 \\
\hline 3 & 12 & 15 & 3 & 0.3 \\
\hline 3 & 13 & 4 & 3 & 0.2 \\
\hline 3 & 13 & $\overline{9}$ & $\overline{2}$ & 0.1 \\
\hline 3 & 13 & 14 & 3 & 0.3 \\
\hline 3 & 13 & 15 & 3 & 0.4 \\
\hline 3 & 14 & 4 & 3 & 0.2 \\
\hline 3 & 14 & 8 & 4 & 0.4 \\
\hline 3 & 14 & 9 & 2 & 0.1 \\
\hline 3 & 14 & 15 & 3 & 0.3 \\
\hline 3 & 15 & 8 & 3 & 0.3 \\
\hline 3 & 15 & $\overline{9}$ & 2 & 0.1 \\
\hline 3 & 15 & 14 & 3 & 0.3 \\
\hline 3 & 15 & 15 & 3 & 0.3 \\
\hline 3 & 16 & 5 & 3 & 0.4 \\
\hline 3 & 16 & 6 & 3 & 0.2 \\
\hline 3 & 16 & 7 & 4 & 0.2 \\
\hline 3 & 16 & 16 & 2 & 0.2 \\
\hline
\end{tabular}




\begin{tabular}{|c|c|c|c|c|}
\hline PROJ_ID & TASK_ID & SKILL_ID & TASK_SKILL_LVL & TASK_SKILL_WEIGHT \\
\hline 3 & 17 & 4 & 3 & 0.3 \\
\hline 3 & 17 & 7 & 3 & 0.1 \\
\hline 3 & 17 & 15 & 3 & 0.3 \\
\hline 3 & 17 & 16 & 2 & 0.3 \\
\hline 3 & 18 & 4 & 3 & 0.2 \\
\hline 3 & 18 & 8 & 3 & 0.4 \\
\hline 3 & 18 & 15 & 3 & 0.4 \\
\hline 3 & 19 & 4 & 3 & 0.2 \\
\hline 3 & 19 & 8 & 3 & 0.4 \\
\hline 3 & 19 & $\overline{15}$ & $\overline{3}$ & 0.4 \\
\hline 3 & 20 & 7 & 3 & 0.4 \\
\hline 3 & 20 & 15 & 3 & 0.6 \\
\hline 3 & 21 & 4 & 3 & 0.4 \\
\hline 3 & 21 & 15 & 3 & 0.4 \\
\hline 3 & 21 & 16 & $\overline{2}$ & 0.2 \\
\hline 3 & 22 & 4 & 3 & 0.6 \\
\hline 3 & 22 & 15 & 3 & 0.4 \\
\hline 3 & 23 & 4 & 3 & 0.6 \\
\hline 3 & 23 & 15 & 3 & 0.4 \\
\hline 3 & 24 & 4 & 4 & 0.3 \\
\hline 3 & 24 & 8 & 3 & 0.2 \\
\hline 3 & 24 & $\overline{9}$ & $\overline{3}$ & 0.1 \\
\hline 3 & 24 & 14 & $\overline{3}$ & 0.1 \\
\hline 3 & 24 & 15 & 3 & 0.3 \\
\hline 3 & 25 & 4 & 4 & 0.3 \\
\hline 3 & 25 & 8 & 3 & 0.2 \\
\hline 3 & 25 & $\overline{9}$ & $\overline{3}$ & 0.1 \\
\hline 3 & 25 & 14 & 3 & 0.1 \\
\hline 3 & 25 & 15 & 3 & 0.3 \\
\hline 3 & 26 & 7 & 3 & 0.4 \\
\hline 3 & 26 & 18 & 3 & 0.6 \\
\hline 4 & 1 & 1 & 3 & 1 \\
\hline 4 & 2 & 5 & 3 & 0.8 \\
\hline 4 & 2 & 16 & $\overline{3}$ & 0.2 \\
\hline 4 & 3 & $\overline{4}$ & 4 & 0.4 \\
\hline 4 & 3 & 5 & 4 & 0.4 \\
\hline 4 & 3 & 13 & 2 & 0.1 \\
\hline 4 & 3 & 16 & 4 & 0.1 \\
\hline 4 & 4 & 4 & 4 & 0.3 \\
\hline 4 & 4 & 5 & 4 & 0.4 \\
\hline 4 & 4 & 13 & 2 & 0.1 \\
\hline 4 & 4 & 16 & 4 & 0.2 \\
\hline 4 & 5 & $\overline{9}$ & $\overline{3}$ & 0.4 \\
\hline 4 & 5 & 10 & 3 & 0.1 \\
\hline 4 & 5 & 11 & 3 & 0.1 \\
\hline 4 & 5 & 12 & $\overline{3}$ & 0.4 \\
\hline 4 & 6 & $\overline{9}$ & 3 & 0.4 \\
\hline 4 & 6 & 10 & 3 & 0.1 \\
\hline 4 & 6 & 11 & 3 & 0.1 \\
\hline 4 & 6 & 12 & 3 & 0.4 \\
\hline 4 & 7 & 5 & 3 & 0.2 \\
\hline 4 & 7 & 9 & 3 & 0.05 \\
\hline 4 & 7 & 11 & 4 & 0.2 \\
\hline 4 & 7 & $\overline{13}$ & 4 & 0.3 \\
\hline 4 & 7 & 14 & 4 & 0.2 \\
\hline 4 & 7 & 16 & 3 & 0.05 \\
\hline 4 & 8 & 5 & 3 & 0.3 \\
\hline 4 & 8 & 9 & 3 & 0.1 \\
\hline 4 & 8 & 11 & $\overline{3}$ & 0.3 \\
\hline 4 & 8 & 14 & 3 & 0.3 \\
\hline 4 & 9 & 9 & 2 & 0.1 \\
\hline 4 & 9 & 11 & 2 & 0.45 \\
\hline 4 & 9 & 14 & 3 & 0.45 \\
\hline 4 & 10 & 9 & 2 & 0.1 \\
\hline 4 & 10 & 11 & 3 & 0.9 \\
\hline 4 & 11 & $\overline{5}$ & 3 & 0.2 \\
\hline 4 & 11 & $\overline{9}$ & 2 & 0.1 \\
\hline 4 & 11 & 11 & 4 & 0.3 \\
\hline 4 & 11 & 14 & 4 & 0.4 \\
\hline 4 & 12 & $\overline{4}$ & $\overline{3}$ & 0.2 \\
\hline
\end{tabular}




\begin{tabular}{|c|c|c|c|c|}
\hline PROJ_ID & TASK_ID & SKILL_ID & TASK_SKILL_LVL & TASK_SKILL_WEIGHT \\
\hline 4 & 12 & 8 & 4 & 0.4 \\
\hline 4 & 12 & 9 & 2 & 0.1 \\
\hline 4 & 12 & 15 & 3 & 0.3 \\
\hline 4 & 13 & 4 & 3 & 0.2 \\
\hline 4 & 13 & 9 & 2 & 0.1 \\
\hline 4 & 13 & 14 & 3 & 0.3 \\
\hline 4 & 13 & 15 & 3 & 0.4 \\
\hline 4 & 14 & 4 & 3 & 0.2 \\
\hline 4 & 14 & 8 & 4 & 0.4 \\
\hline 4 & 14 & 9 & 2 & 0.1 \\
\hline 4 & 14 & 15 & 3 & 0.3 \\
\hline 4 & 15 & 8 & 3 & 0.3 \\
\hline 4 & 15 & 9 & 2 & 0.1 \\
\hline 4 & 15 & 14 & 3 & 0.3 \\
\hline 4 & 15 & 15 & 3 & 0.3 \\
\hline 4 & 16 & 5 & 3 & 0.4 \\
\hline 4 & 16 & 6 & 3 & 0.2 \\
\hline 4 & 16 & 7 & 4 & 0.2 \\
\hline 4 & 16 & \begin{tabular}{|l|}
16 \\
\end{tabular} & 2 & 0.2 \\
\hline 4 & 17 & 4 & 3 & 0.3 \\
\hline 4 & 17 & 7 & 3 & 0.1 \\
\hline 4 & 17 & 15 & 3 & 0.3 \\
\hline 4 & 17 & 16 & 2 & 0.3 \\
\hline 4 & 18 & 4 & 3 & 0.2 \\
\hline 4 & 18 & 8 & 3 & 0.4 \\
\hline 4 & 18 & 15 & 3 & 0.4 \\
\hline 4 & 19 & 4 & 3 & 0.2 \\
\hline 4 & 19 & 8 & 3 & 0.4 \\
\hline 4 & 19 & 15 & 3 & 0.4 \\
\hline 4 & 20 & 7 & 3 & 0.4 \\
\hline 4 & 20 & 15 & 3 & 0.6 \\
\hline 4 & 21 & 4 & 3 & 0.4 \\
\hline 4 & 21 & 15 & 3 & 0.4 \\
\hline 4 & 21 & 16 & 2 & 0.2 \\
\hline 4 & 22 & 4 & 3 & 0.6 \\
\hline 4 & 22 & 15 & 3 & 0.4 \\
\hline 4 & 23 & 4 & 3 & 0.6 \\
\hline 4 & 23 & 15 & 3 & 0.4 \\
\hline 4 & 24 & 4 & 4 & 0.3 \\
\hline 4 & 24 & 8 & 3 & 0.2 \\
\hline 4 & 24 & 9 & 3 & 0.1 \\
\hline 4 & 24 & 14 & 3 & 0.1 \\
\hline 4 & 24 & 15 & 3 & 0.3 \\
\hline 4 & 25 & 4 & 4 & 0.3 \\
\hline 4 & 25 & 8 & 3 & 0.2 \\
\hline 4 & 25 & 9 & 3 & 0.1 \\
\hline 4 & 25 & 14 & 3 & 0.1 \\
\hline 4 & 25 & 15 & 3 & 0.3 \\
\hline 4 & 26 & 7 & 3 & 0.4 \\
\hline 4 & 26 & 18 & 3 & 0.6 \\
\hline
\end{tabular}




\section{Appendix C - Source Code}

\section{The PM Eye Risk Projection Application}

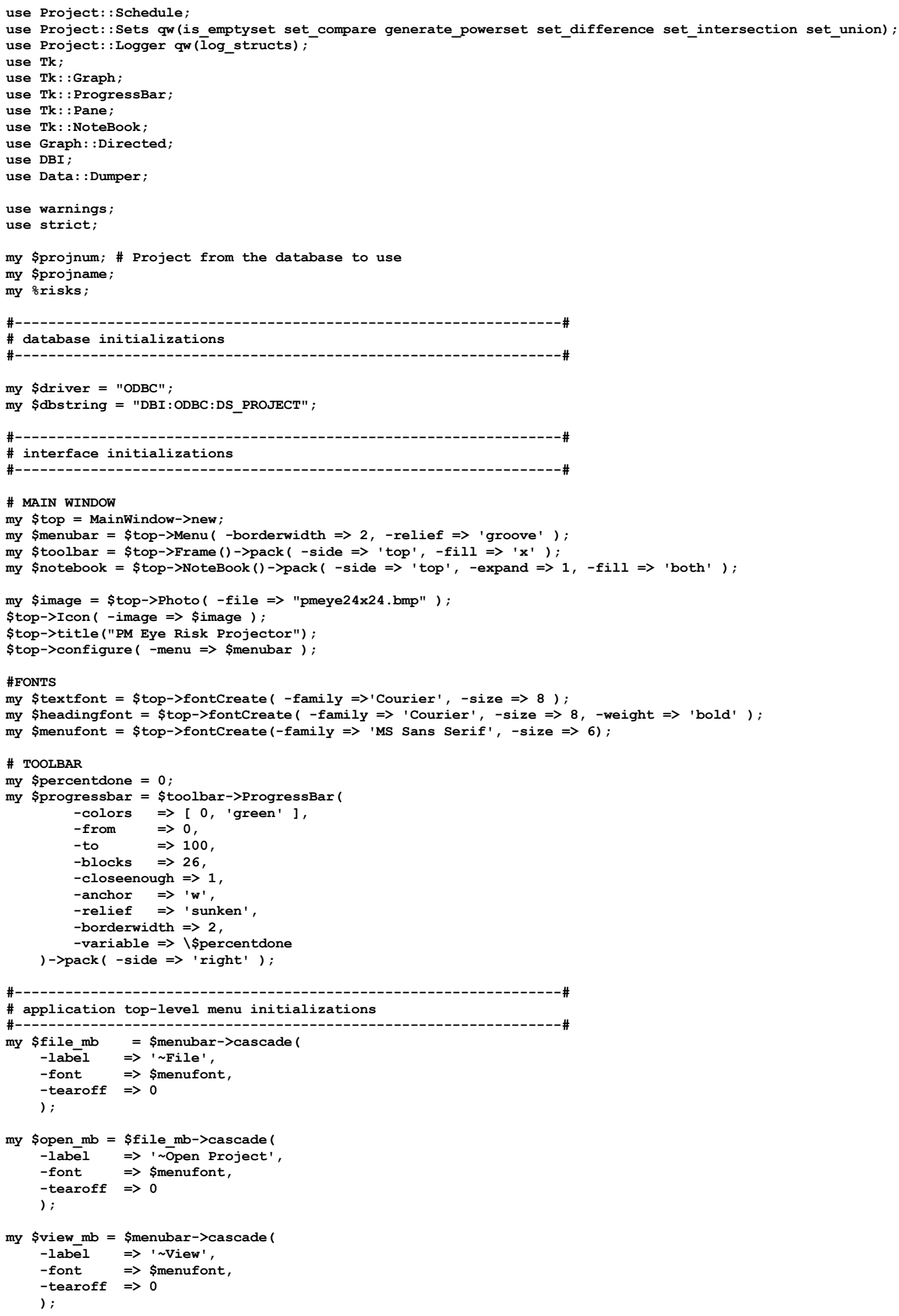


my \$options_mb = \$menubar->cascade (

-label - $\Rightarrow$ ' Options',

-font $\quad \Rightarrow$ \$menufont

-tearoff $\Rightarrow 0$

);

my $\$$ help_mb $=$ \$menubar->cascade (

-label $\Rightarrow$ ' Help',

-font $\quad \Rightarrow$ \$menufont,

-tearoff $\Rightarrow 0$

) ;

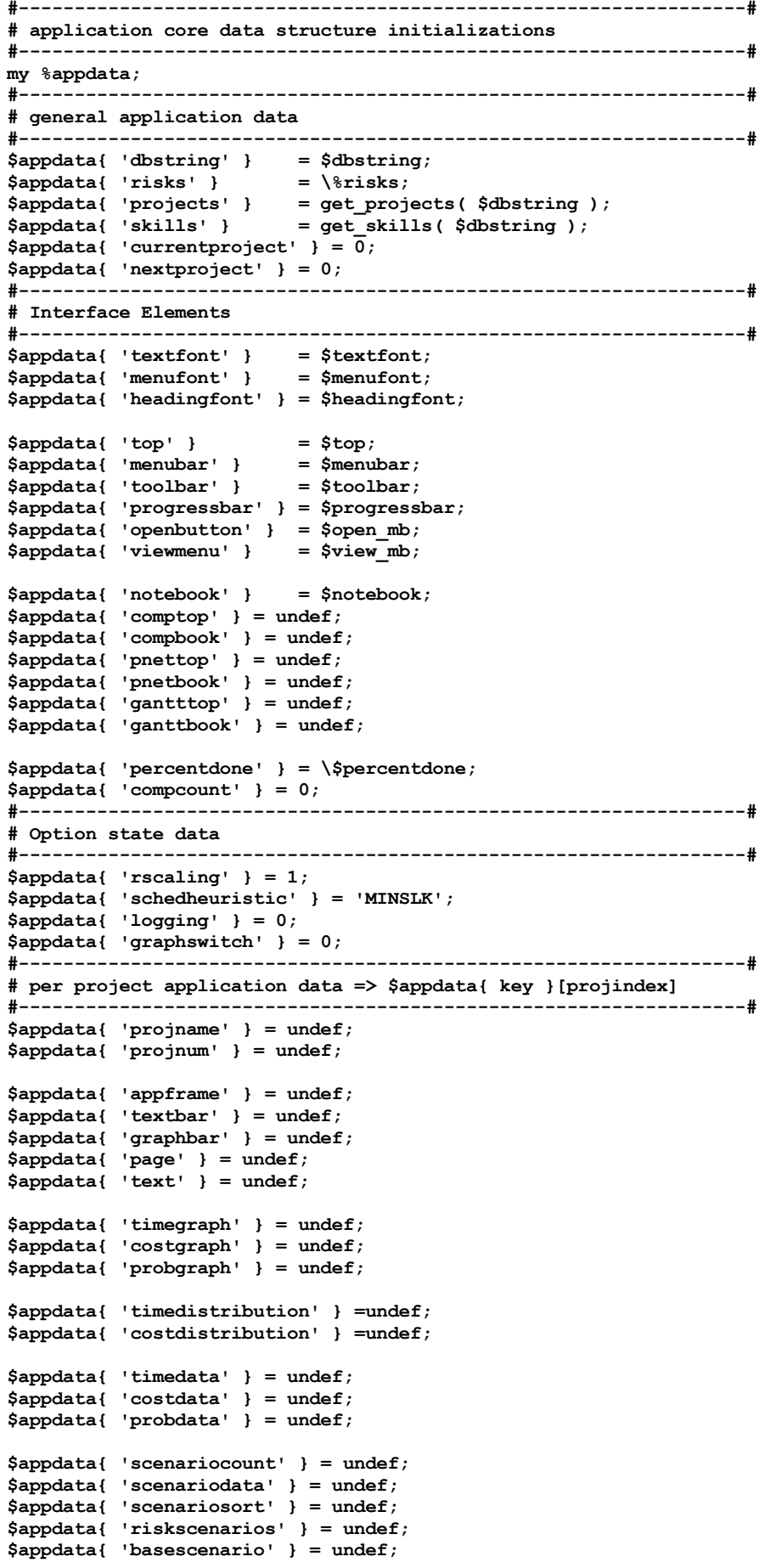

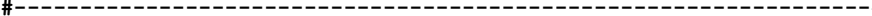

\# keys relating to document management 


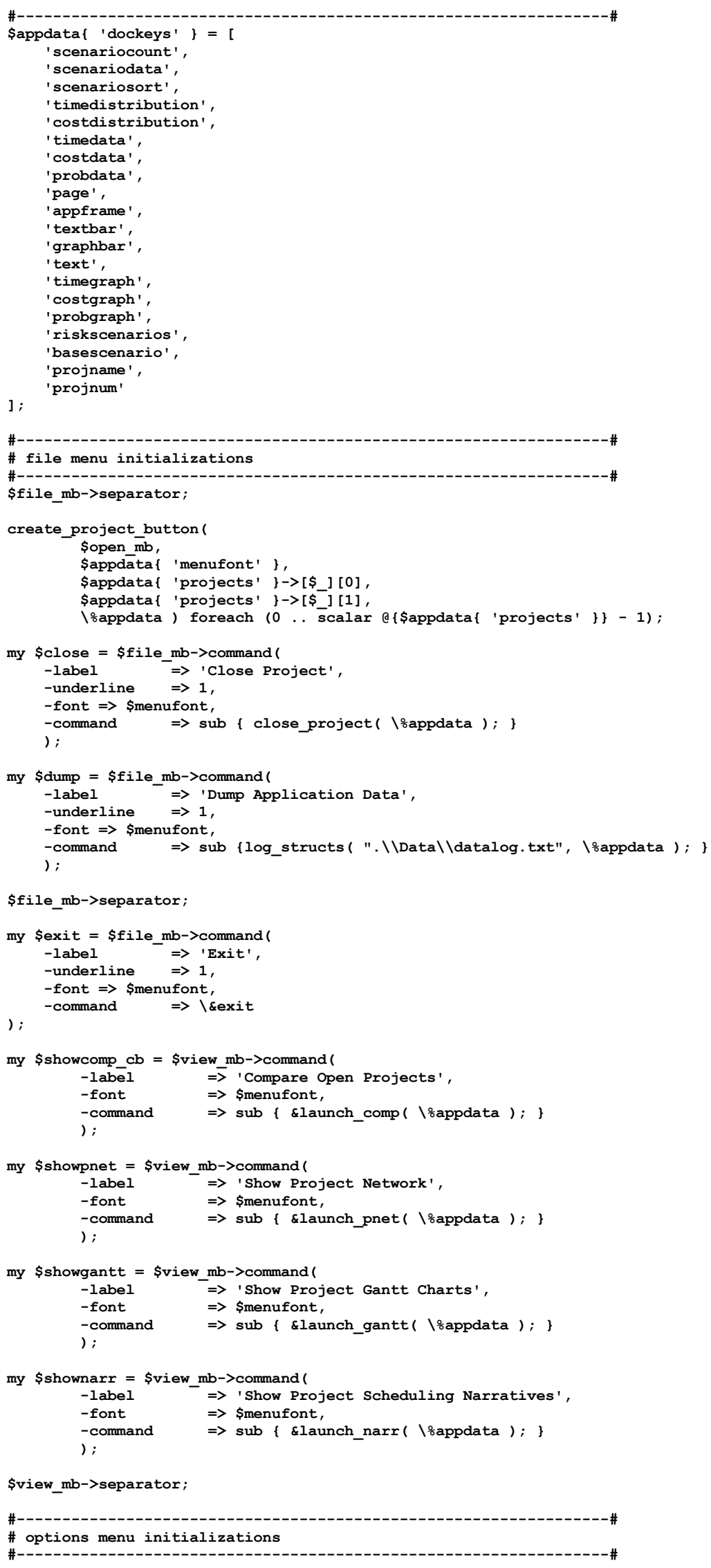




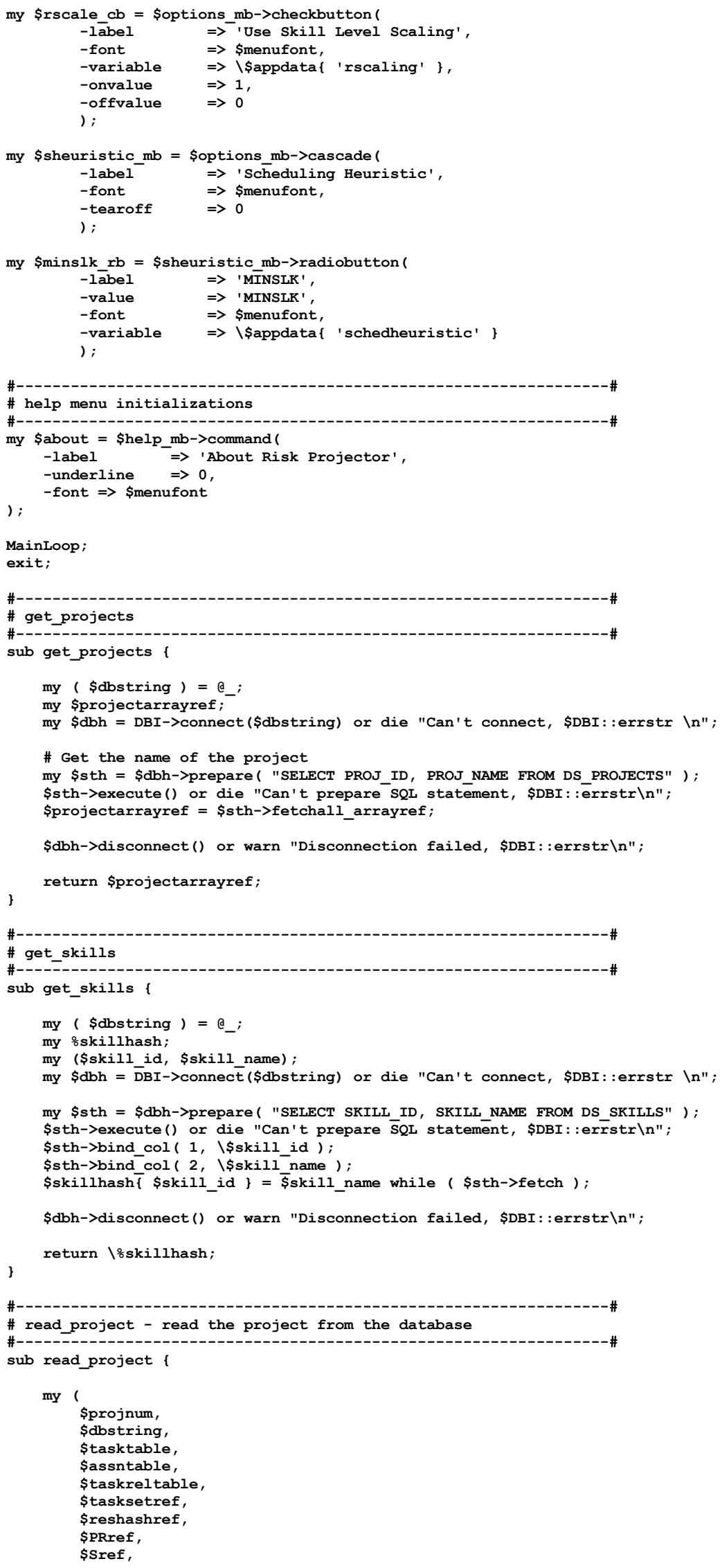




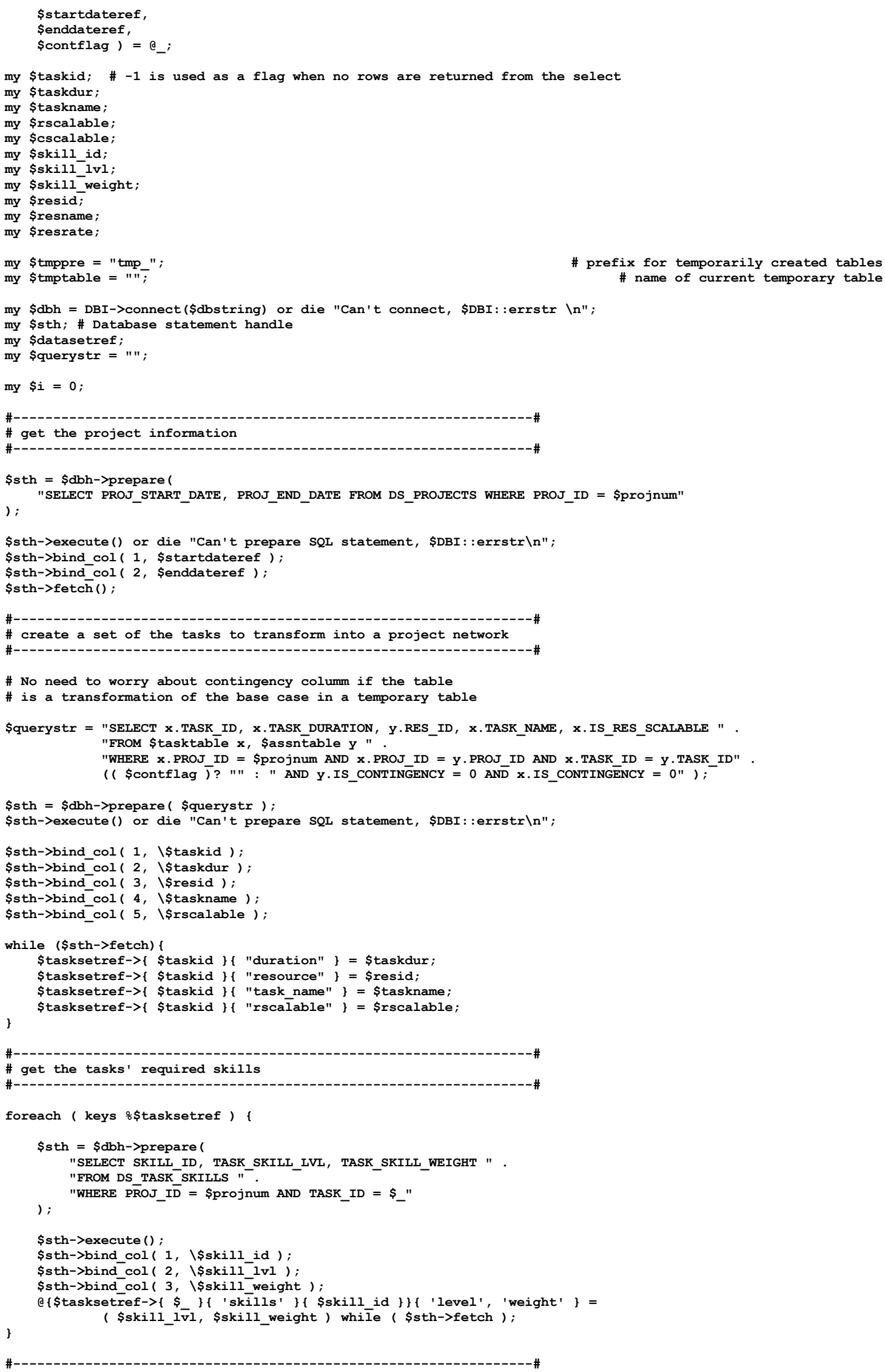




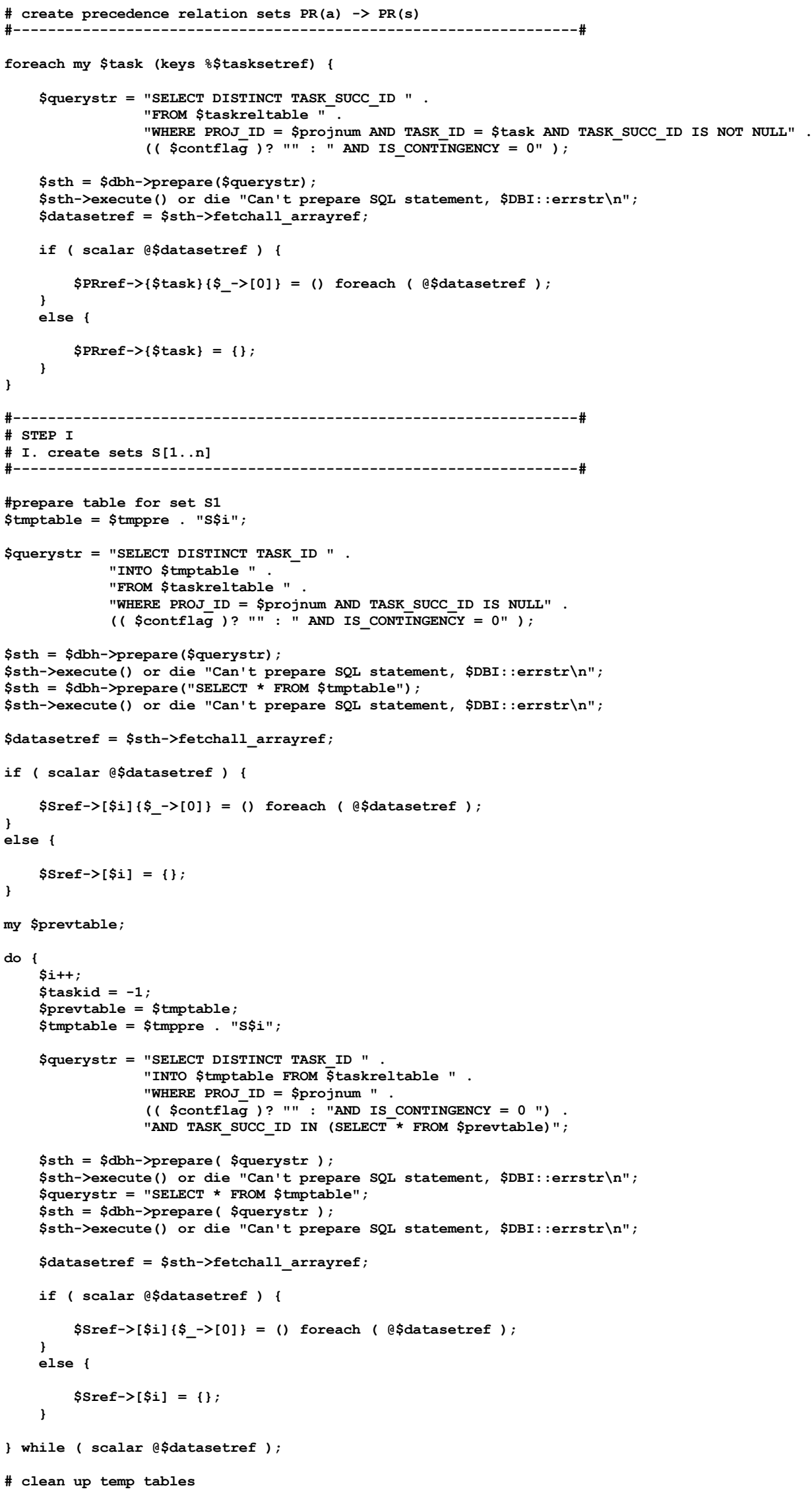


for my $\$ n(\$[\ldots i) \quad\{$

$\$ s t h=\$ d b h->$ prepare ("DROP TABLE " . \$tmppre . "S\$n") ;

\}

\$sth->execute () :

\# \# get the project resources

\#---1 the project resources

\$sth $=$ \$dbh->prepare( "SELECT RES_ID, RES_NAME, RES_RATE " . "FROM DS_RESOURCES" ${ }^{-}$);

\$sth->execute ();

\$sth->bind col ( $1, \backslash$ \$resid );

\$sth->bind col ( 2, \\$resname );

\$sth->bind_col ( 3, \\$resrate);

Q $\{\$$ reshashref-> $\{$ resid $\}\}\{$ 'name', 'rate' $\}=$ ( \$resname, \$resrate ) while ( \$sth->fetch);

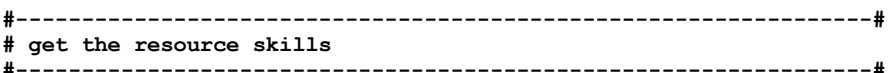

\#- get the resource skills

\$sth = \$dbh->prepare( "SELECT RES_ID, SKILL_ID, RES_SKILL LVL " "FROM DS_RES__SKILLS" ),

\$sth->execute () ;

sth->bind col( $1, \mid$ \$sesid );

\$sth->bind col ( 2, \\$skill id )

\$sth->bind_col( 3, \\$skill_lvl );

while ( \$sth->fetch ) \{

\$reshashref->\{ \$resid \}\{ 'skills' \}\{ \$skill id \}=\$skill lvl

if ( exists \$reshashref-> \{ \$resid \}):

$\$ d b h->d i s c o n n e c t()$ or warn "Disconnection failed, \$DBI: :errstr $\backslash n$ "

\# \# open_projects

sub open project

my ( \$projnum, \$projname, \$appdataref ) = $e_{-}$;

my \$thisproj= = \$appdataref->\{ 'nextproject' $\}$

my \$dbstring = \$appdataref-> $>$ 'dbstring' $\}$;

my \$top = \$appdataref $>$ \{ 'top' \};

my \$view mb = \$appdataref $->$ \{ 'viewmenu' \};

my \$open_mb = \$appdataref- $>$ \{ 'openbutton' $\}$;

my \$menufont = \$appdataref->\{ 'menufont' \};

my \$textfont = \$appdataref $->$ \{ 'textfont' $\}$;

my \$headingfont = \$appdataref $->\{$ 'headingfont' $\}$;

my \$timedata = \$appdataref- $>\{$ 'timedata' $\}$ [\$thisproj] $=\{\} ;$

my \$costdata= $=$ appdataref $>\{$ 'costdata' $\}[$ thisproj] $=\{\} ;$

my \$probdata = \$appdataref->\{ 'probdata' $\}$ [\$thisproj] $=\{\} ;$

my $\$$ notebook = \$appdataref-> $\{$ 'notebook' $\}$;

\$appdataref->\{ 'projname' \}[\$thisproj] = \$projname

\$appdataref- $>$ \{ 'projnum' \}[\$thisproj] = \$projnum:

\$appdataref-> \{ 'nextproject' \}++;

\$appdataref-> $\{$ 'currentproject' $\}=$ \$thisproj;

my r.sisks;

my \$riskarrayref ;

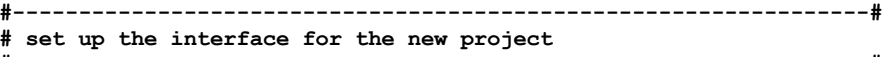

\#- set up the interface for the new project

my \$page $=\$$ notebook->add (

"\$thisproj"

-label $\Rightarrow$ "\$projname",

-anchor $\Rightarrow$ ' $e$ ',

-raisecmd $\Rightarrow$ sub $\{$ \$appdataref-> \{'currentproject' $\}=$ \$thisproj; $\}$

my \$appframe = \$page->Frame (

-relief $\Rightarrow$ 'groove'

) ->pack (

-side $\quad \Rightarrow$ 'bottom'

-expand $\Rightarrow 1$,

-fill $\Rightarrow$ 'both' 
) ;

my \$graphbar = \$appframe->Scrolled

"Pane",

-scrollbars $\quad \Rightarrow$ 's'

) ->pack (

-side $\Rightarrow$ 'top',

-expand $\Rightarrow 1$

) ;

fill $\Rightarrow$ 'both'

my \$textbar $=$ \$appframe->Frame ()->pack ( -side $\Rightarrow$ 'bottom',

-expand $\Rightarrow 1$.

fill $\Rightarrow$ 'both'

) ;

my \$text $=$ \$textbar->Scrolled (

"Text",

) ->pack (

-side $\quad \Rightarrow$ 'bottom',

-expand $\quad \Rightarrow>1$,

$\Rightarrow$ 'both'

\$open mb->configure ( -state $\Rightarrow$ 'disabled' );

\$text->configure ( -wrap $\Rightarrow>$ 'none' );

\&BindMouseWheel ( \$text );

my \$timegraph $=\$$ graphbar->Graph

-type $\quad \Rightarrow$ 'BARS',

-title $\quad \Rightarrow$ 'Time Comparison'

-balloon $\quad \Rightarrow 1$,

-wire $\quad \Rightarrow$ 'white',

-headroom $\quad \Rightarrow 35$

-ylabel $\quad \Rightarrow$ "Min Project Duration"

fill $\quad \Rightarrow$ 'both',

-ytick $\quad \Rightarrow 15$

-maxmin $\quad \Rightarrow 1$,

-barwidth $\quad \Rightarrow 15$

-yformat $\quad \Rightarrow$ ' $\%$ d days'

-xformat $\quad \Rightarrow$ ' $\%$ '

) ->pack (

-side $\quad \Rightarrow$ 'left',

-expand $\quad \Rightarrow 1$,

) ;

$\Rightarrow{ }^{\prime} y$ ',

my $\$$ costgraph $=$ \$graphbar->Graph (

-type $\quad \Rightarrow$ 'BARS',

-title $\quad \Rightarrow$ 'Cost Comparison',

-balloon $\quad \Rightarrow 1$,

-wire $\quad \Rightarrow$ 'white'

-headroom $\quad \Rightarrow 35$

-ylabel $\quad \Rightarrow$ "Min Project Cost",

fill $\quad \Rightarrow$ 'both',

-ytick $\quad \Rightarrow 10$

maxmin $\quad \Rightarrow 1$,

-barwidth $\quad \Rightarrow 15$

-yformat $\quad \Rightarrow$ ' $\$$ \% d',

-xpack (

-side $\quad \Rightarrow$ 'left',

-expand $\quad \Rightarrow 1$,

)

fill $\quad \Rightarrow$ ' $y$ ',

my $\$$ probgraph = \$graphbar->Graph (

$$
\begin{aligned}
& \begin{array}{ll}
\text {-type } & \Rightarrow \text { 'BARS', } \\
\text {-title } & \Rightarrow
\end{array} \text { 'Scenario Probability', } \\
& \rightarrow \max \quad \Rightarrow 100 \\
& \text {-balloon } \quad \Rightarrow 1 \text {, } \\
& \text {-wire } \quad \Rightarrow \text { 'white', } \\
& \text {-headroom } \quad \Rightarrow 15 \\
& \text {-ylabel } \quad \Rightarrow \text { "Probability", } \\
& \text { fill } \quad \Rightarrow \text { 'both', } \\
& \text {-ytick } \quad \Rightarrow 10 \\
& \text {-maxmin } \quad \Rightarrow 1 \text {, } \\
& \text {-barwidth } \quad \Rightarrow 15 \text {, } \\
& \text {-yformat } \quad \Rightarrow \text { ' } \frac{\circ}{8} \mathrm{~d} \% \text { \%', } \\
& \text {-xformat } \quad \Rightarrow \text { ' } \% \text { ' } \\
& \text { ) ->pack ( } \\
& \text {-side } \quad \Rightarrow \text { 'left', } \\
& \text {-expand } \quad \Rightarrow 1 \text {, } \\
& \Rightarrow \text { ' } y \text { ', }
\end{aligned}
$$




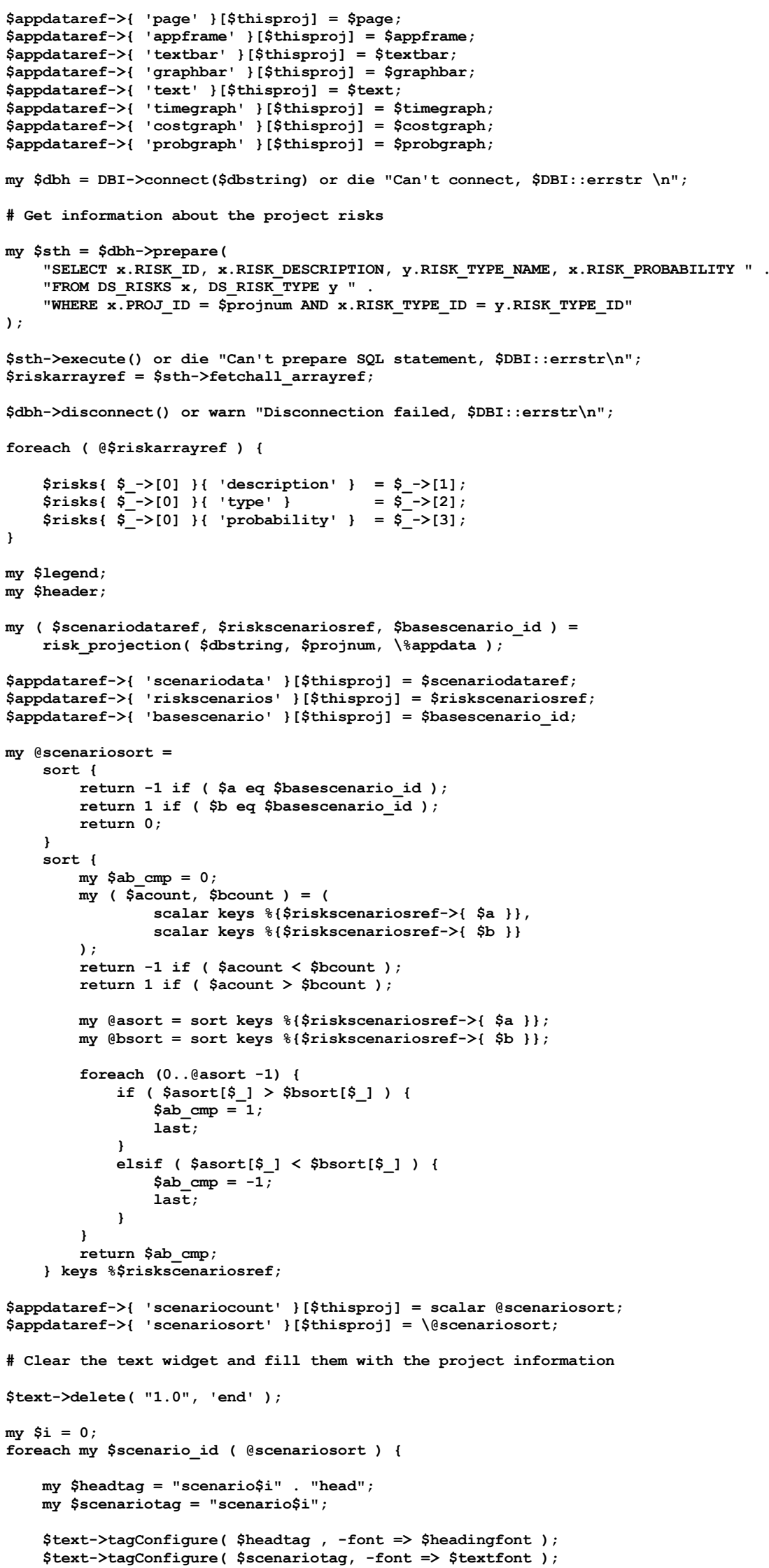




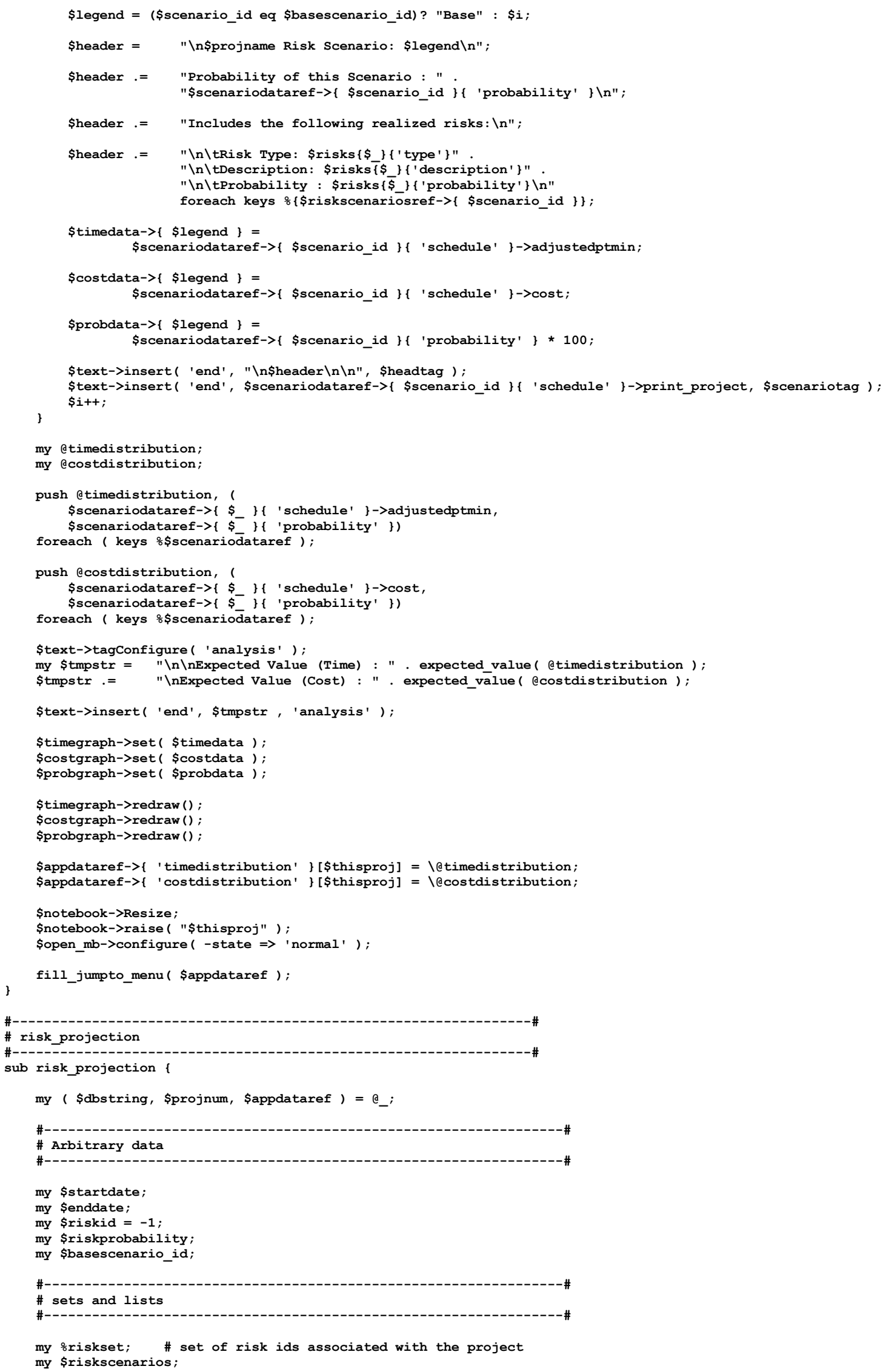


my $\$ d b h$;

my \$sth; \# Database statement handle

\# Read the project risk ids from the database

$\$ d b h=D B I->$ connect $(\$ d b s t r i n g)$ or die $"$ Can't connect, \$DBI::errstr $\backslash n "$;

$\$$ sth $=\$ \mathrm{dbh}->$ prepare (

"SELECT RISK ID, RISK PROBABILITY " .

) ;

"FROM DS_RISKS WHERE PROJ_ID = \$projnum"

\$sth->execute() or die "Can't prepare SQL statement, \$DBI: :errstr $\backslash n$ ";

\$sth->bind col ( $1, \backslash$ \$riskid ):

\$sth->bind_col( 2, \\$riskprobability);

( $($ riskid $!=-1)$ ? \$riskset $\{$ \$riskid $\}=$ \$riskprobability : 0 ) while ( \$sth->fetch);

$\$ d b h->d i s c o n n e c t()$ or warn "Disconnection failed, \$DBI::errstr $\backslash n$ ";

\# Generate the risk scenarios powerset of the risk set

\$riskscenarios $=$ generate_powerset $(\backslash \%$ riskset $)$ ；

\# Process each risk scenario

my oscenariodata:

my \$cummprob=0; \#cummulative probability of all scenarios

my \$probability $=1$;

my (

\$tasktable,

\$assntable,

)$=$ (

\$taskreltable

"DS_TASKS",

"DS-ASSIGNMENTS",

) ;

"DS_TASK_RELATIONSHIPS"

my (

\$tmptasktable,

\$tmpassntable,

)$=$ (

\$tmptaskreltable

"tmp_DS_TASKS"

"tmp DS ASSIGNMENTS",

) ;

"tmP_DS_TASK_RELATIONSHIPS"

my $\$$ tmpprefix = "tmp_" ;

my \$PRref ;

my \$Sref;

my \$tasksetref;

my \$reshashref

hash of resources and their rates

= \$appdataref->\{'skills'\}

my \$querystr $=" "$;

my \$firstiteration;

my \$scheduleref;

my increment $=100 /\left(\right.$ scalar keys $\frac{\circ}{0}$ \$riskscenarios $)$;

$\$\{$ \$appdataref- $>\{$ 'percentdone' $\}\}=0$;

\$appdataref->\{ 'toolbar' $\}->$ update;

foreach my \$scenario_id ( keys o\$riskscenarios ) f

print "Scenario : ", keys o $\{\$$ riskscenarios->\{\$scenario_id $\}\}, " \backslash n \backslash n "$;

\# Clear the related sets

\$PRref $=\{\} ;$

\$Sref $=[]$;

\$tasksetref $=\{\}$;

\$reshashref $=\{\}$;

\# Transform the original project for the current scenario

\# if there are no risk ids in the scenario it must be the base scenario

if ( is_emptyset ( \$riskscenarios->\{ \$scenario_id \}) ) \{

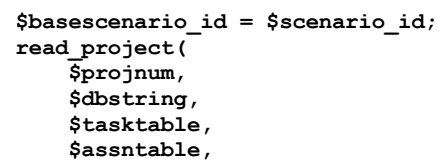




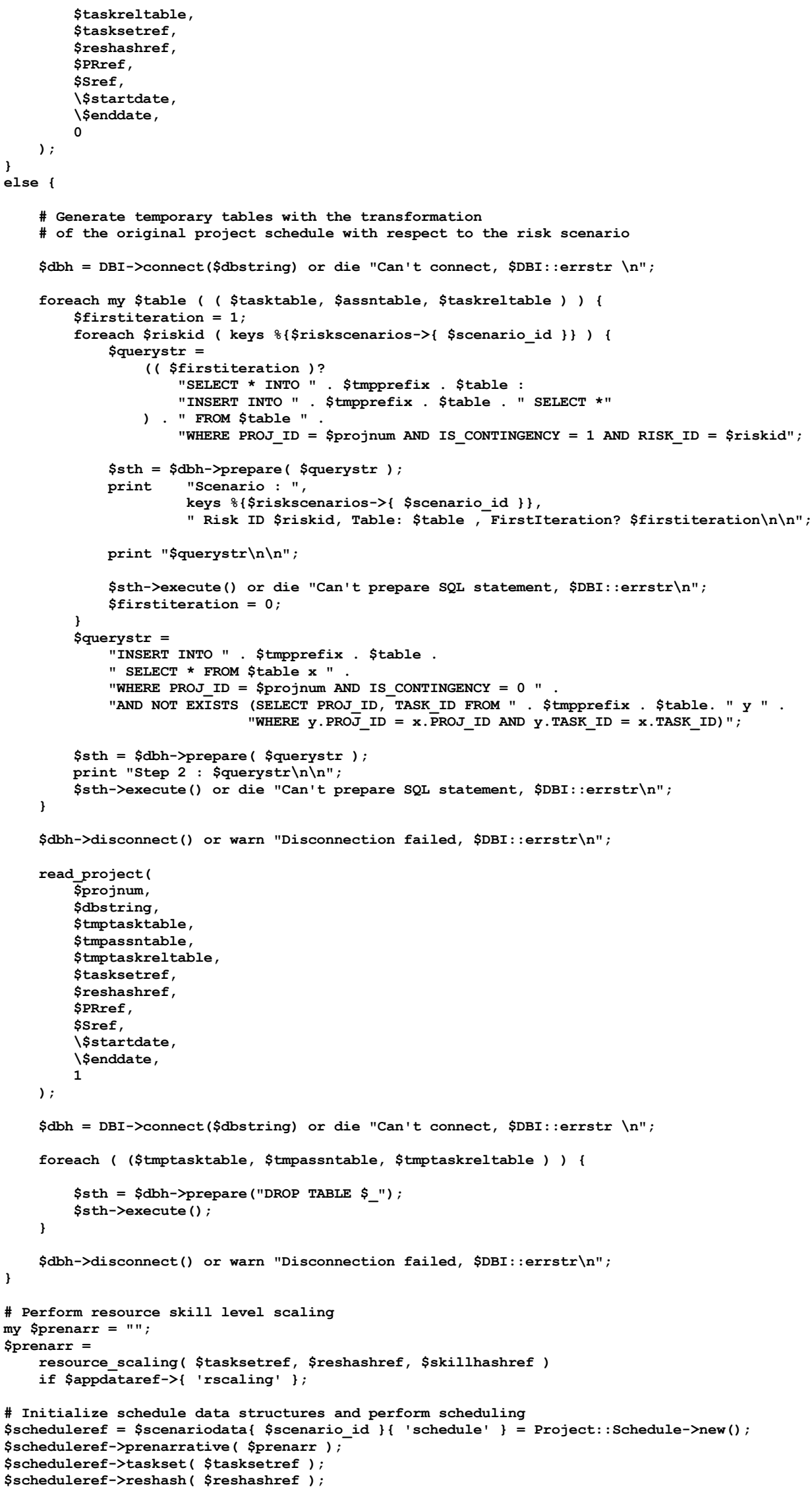




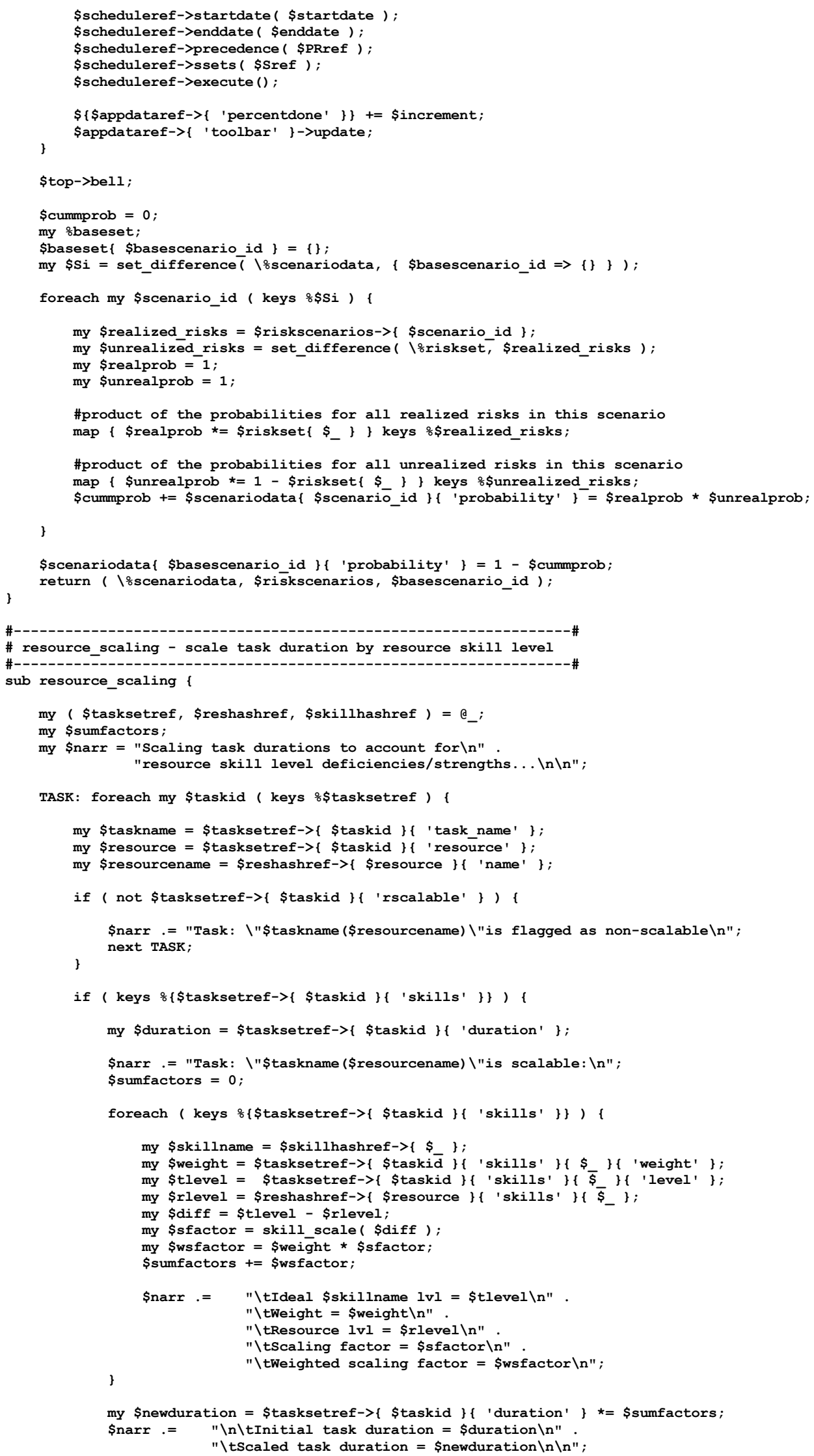




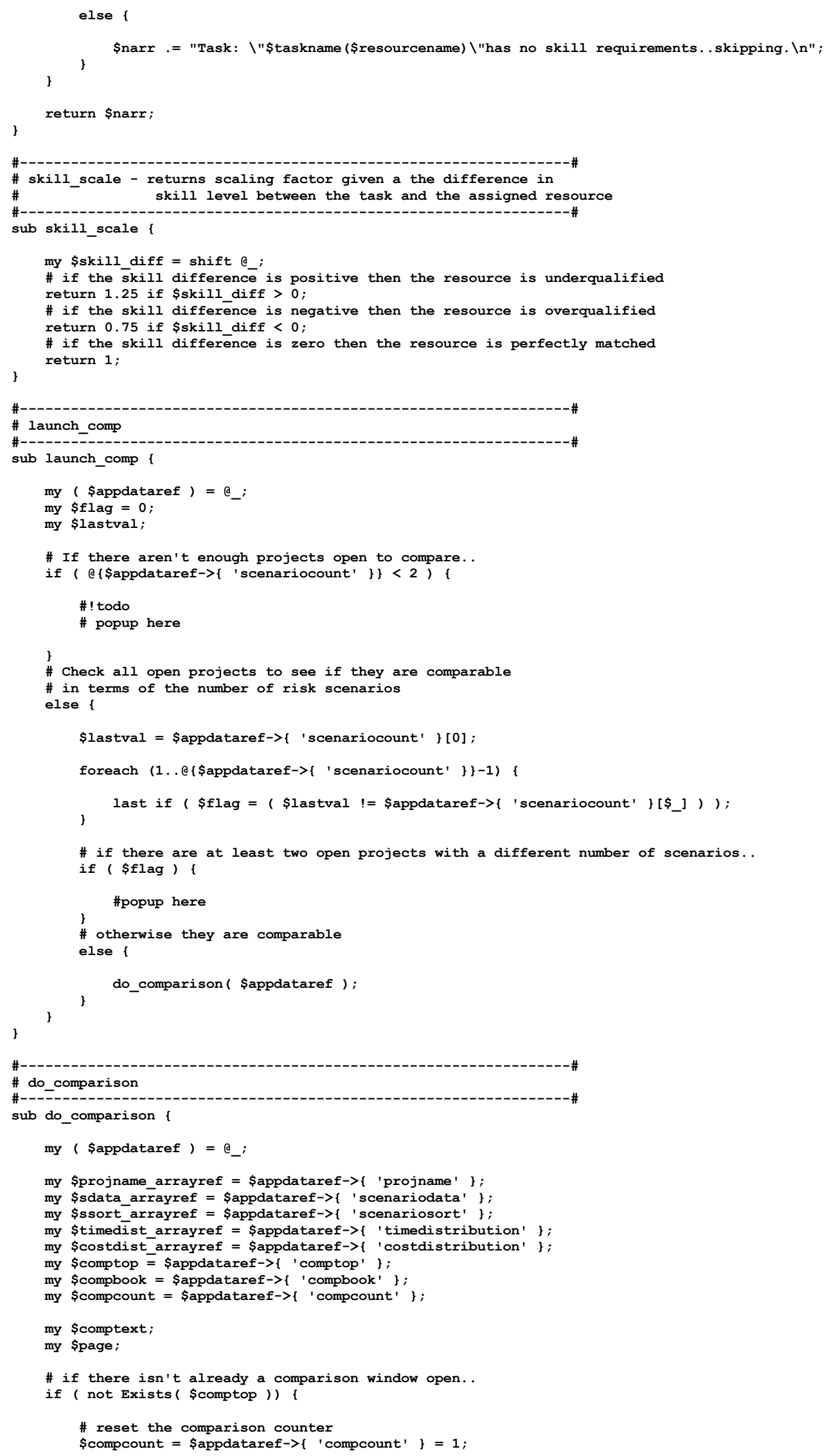




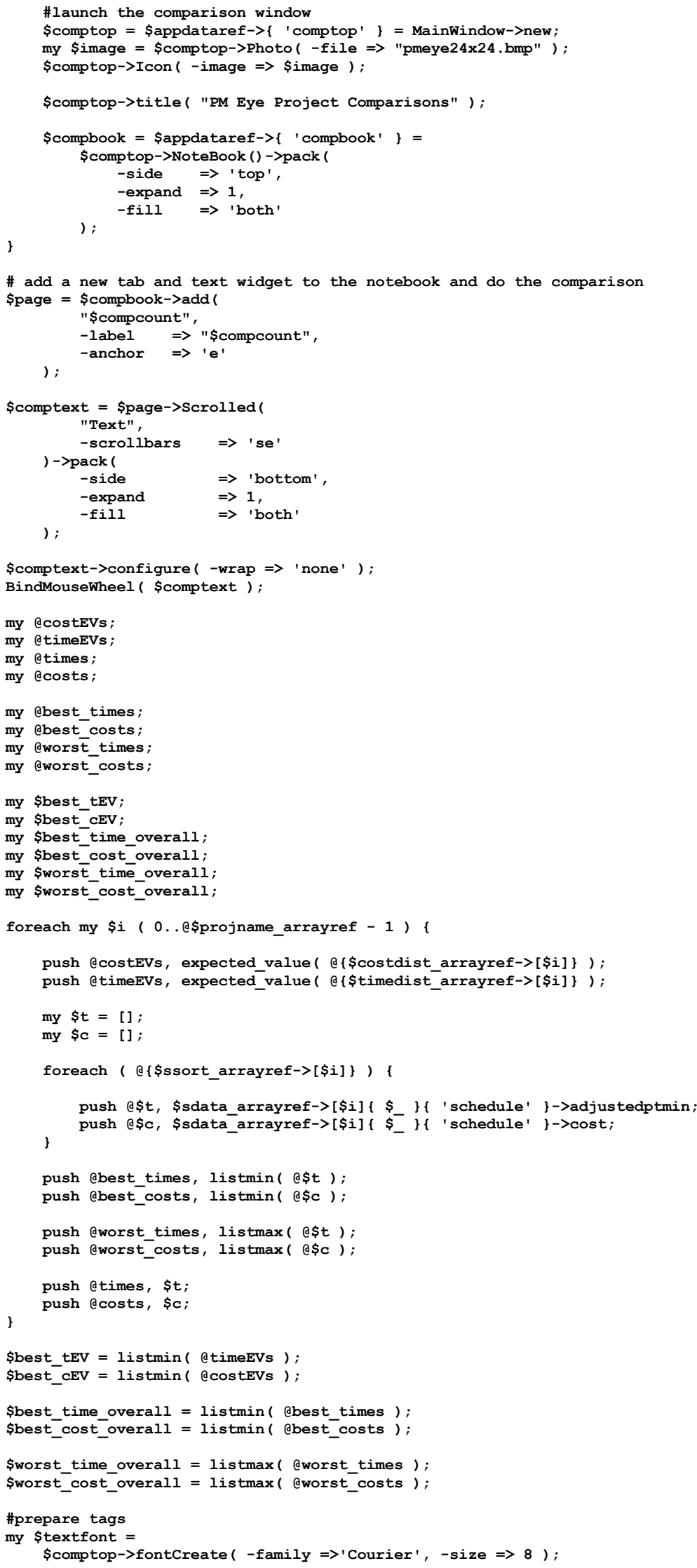




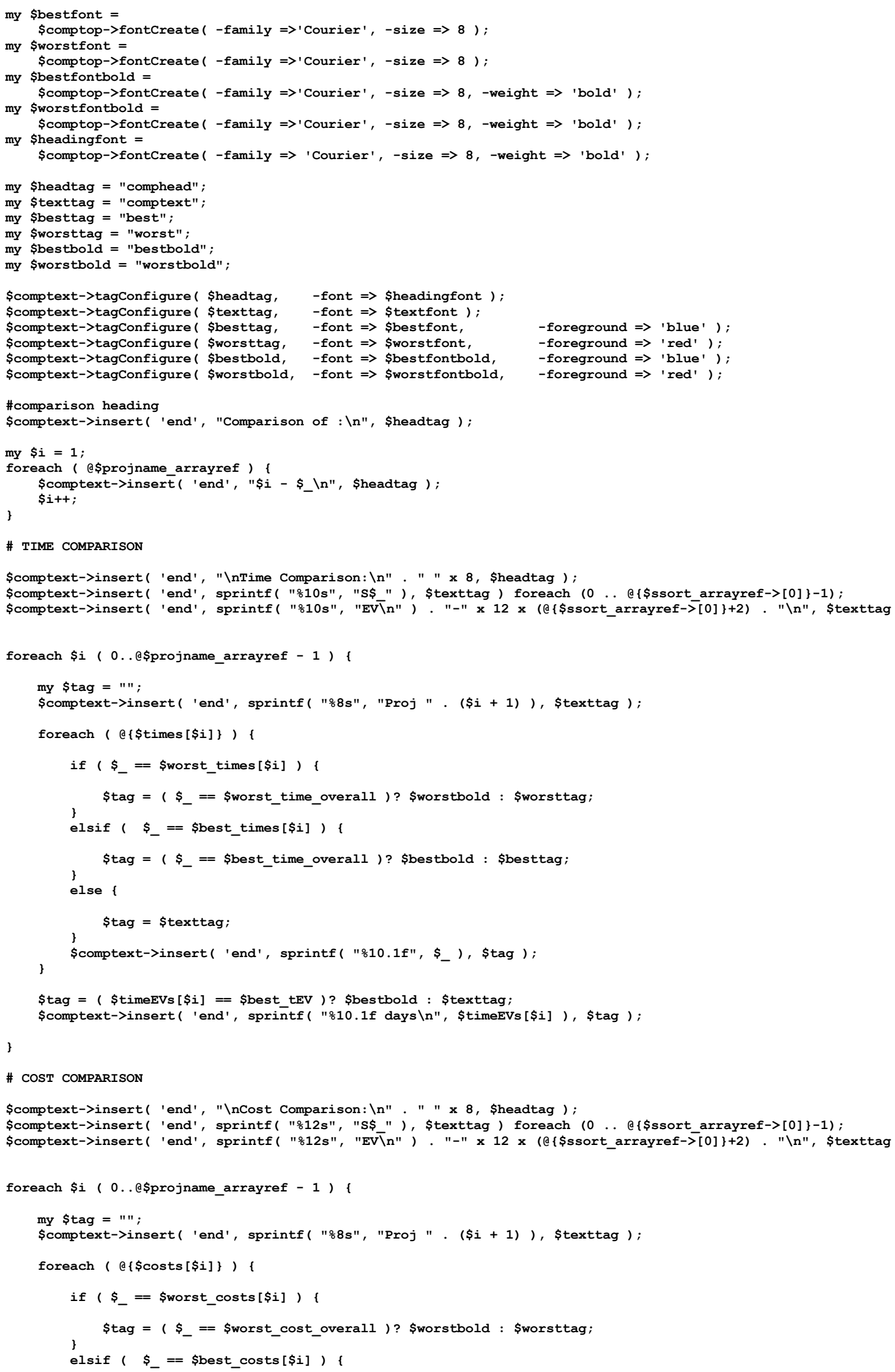




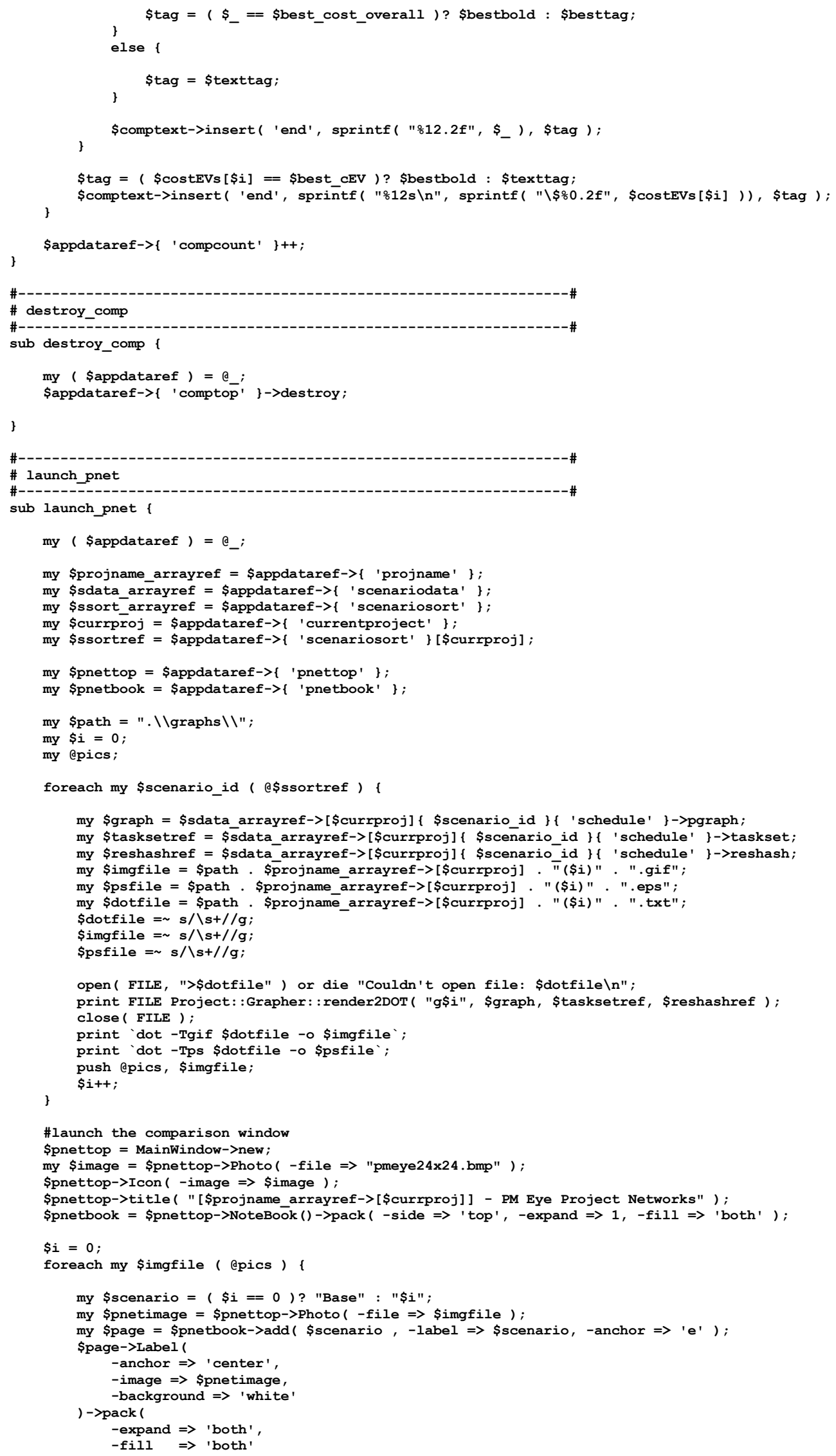




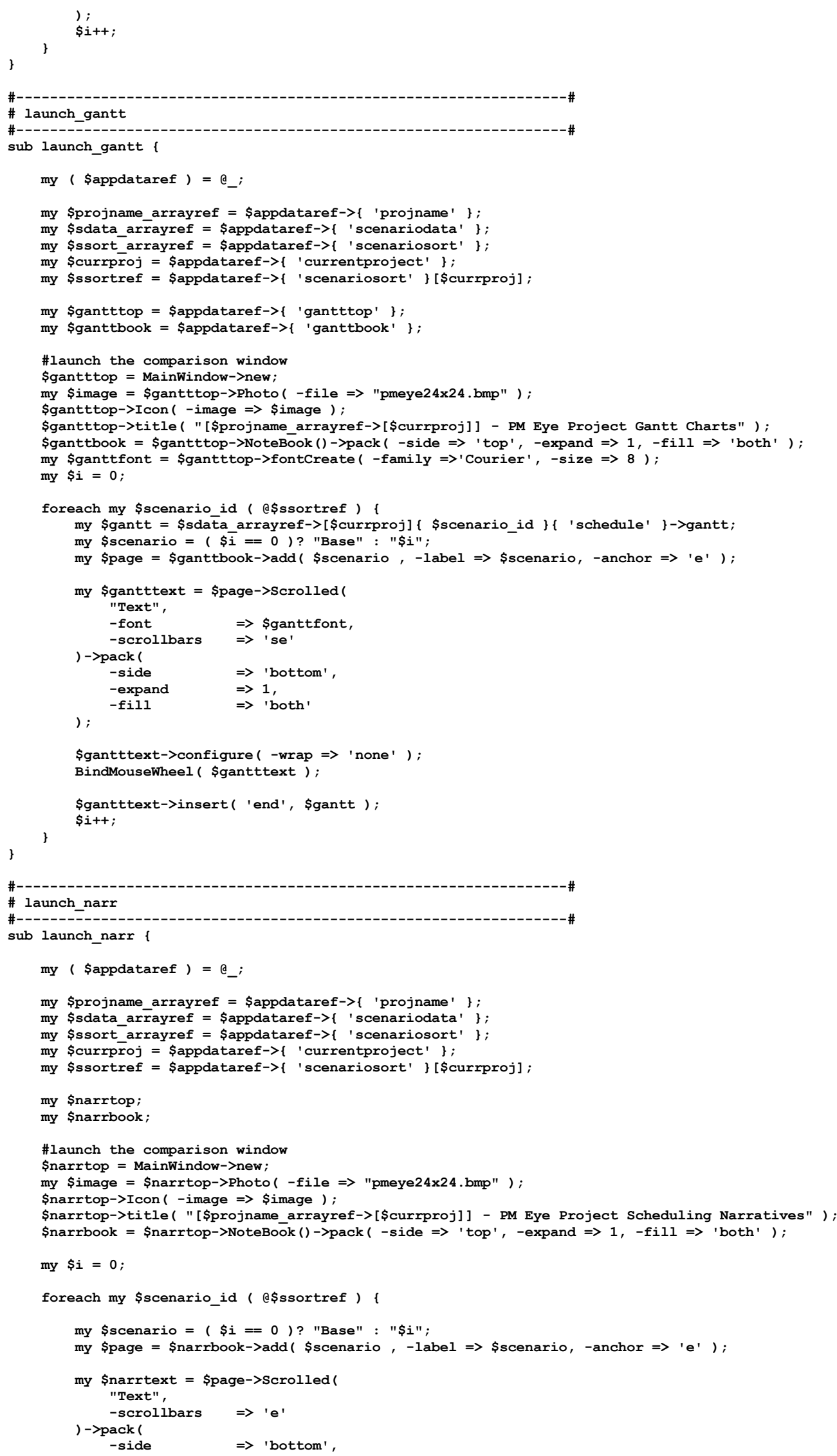




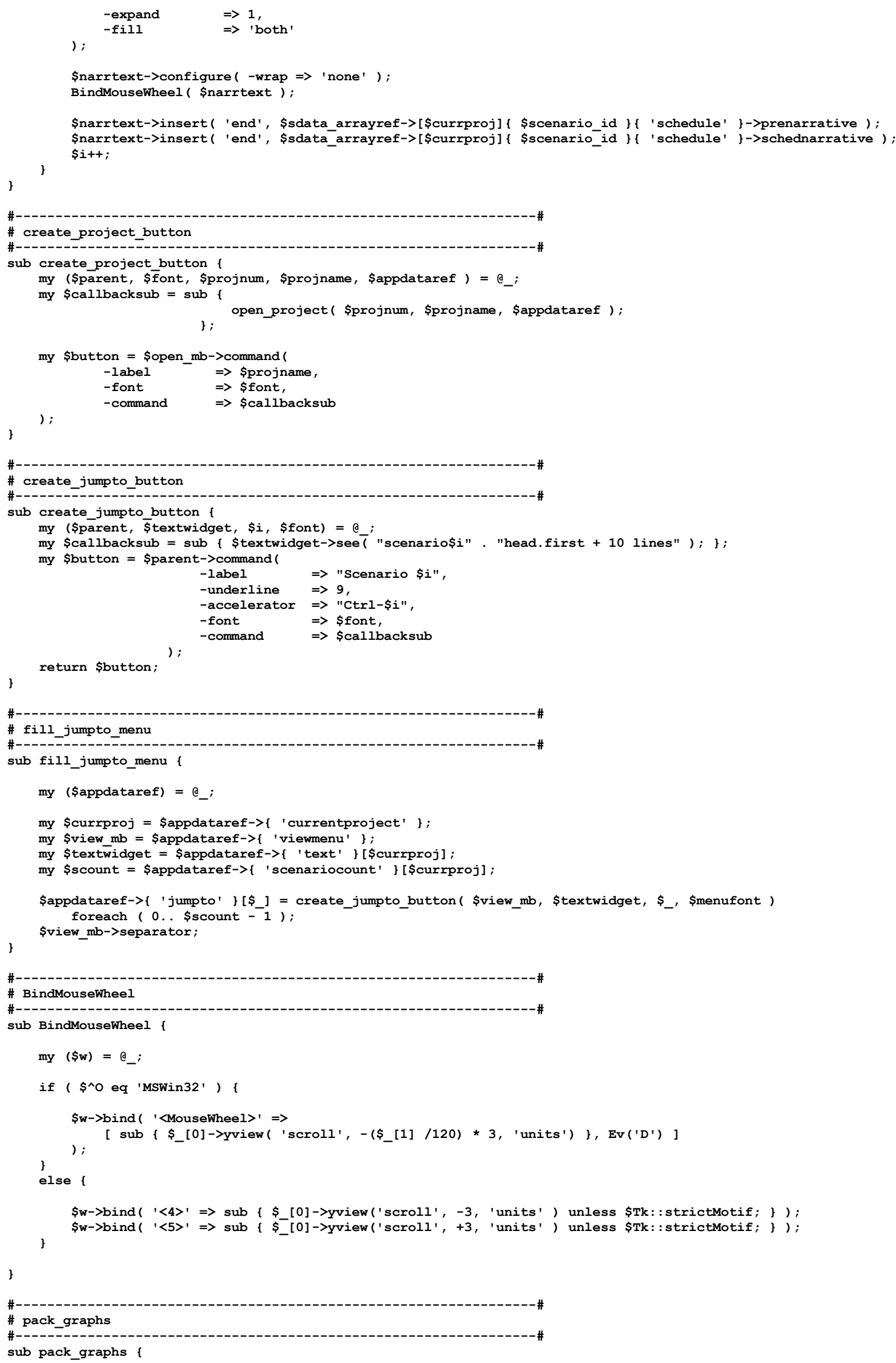




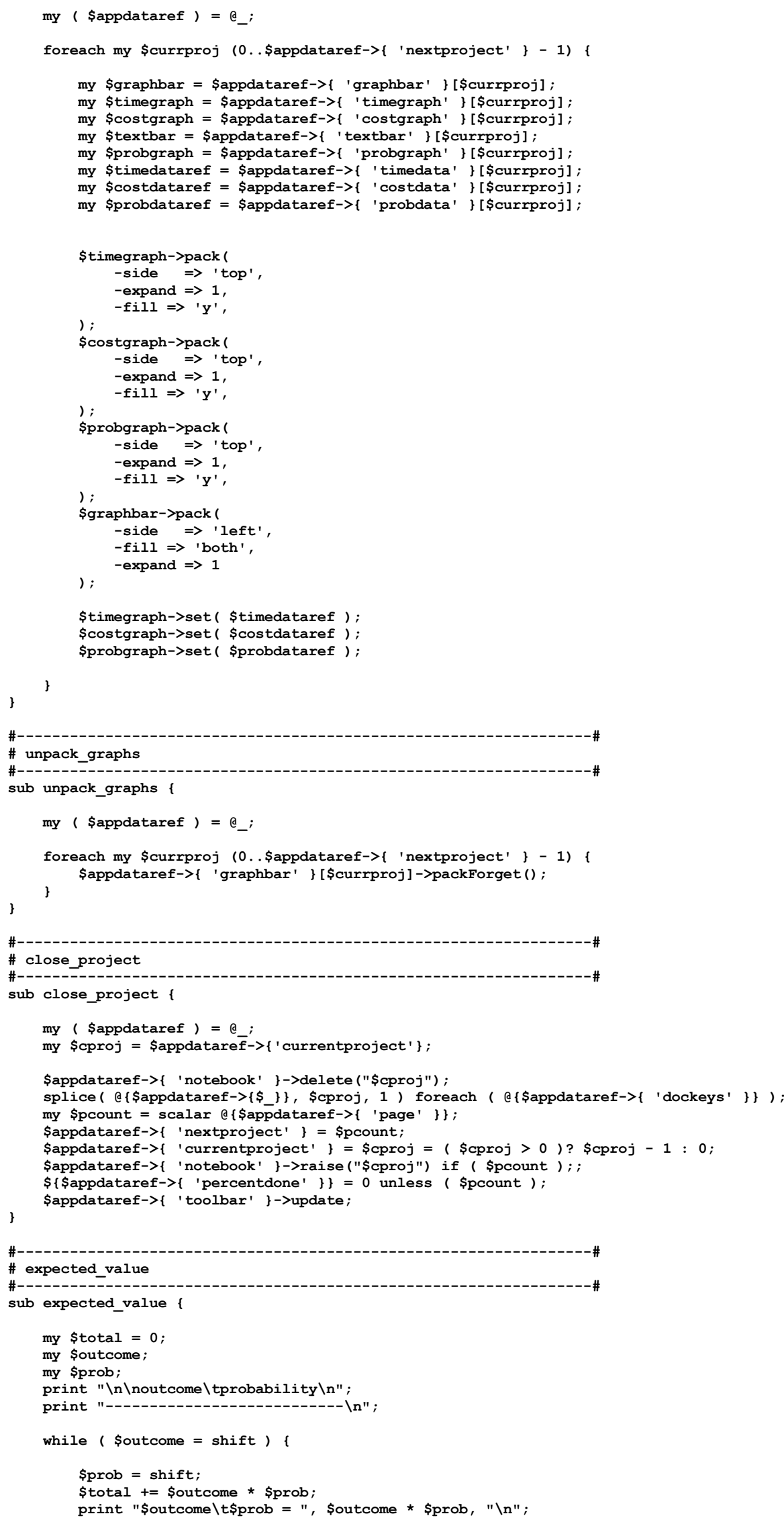


\}

print "\nTotal = \$total $\backslash n "$

return \$total

\}

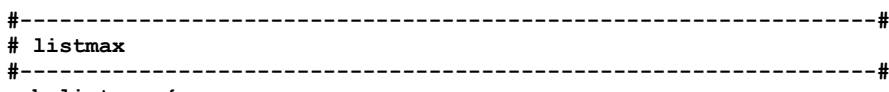

sub listmax

my \$maxval = shift;

my \$compval;

while (@_)

\$compval = shift;

\$maxval $=($ \$maxval $>$ \$compval $)$ ? \$maxval : \$compval

\$maxval

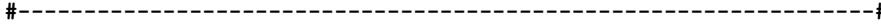

\# listmin

sub listmin \{

my $\$$ minval $=$ shift

my \$compval.

while (e) i

\$compval $=$ shift;

\$minval = $($ \$minval $<$ \$compval $)$ ? \$minval : \$compval;

\}

turn \$minval 


\section{The Project::Schedule Module}

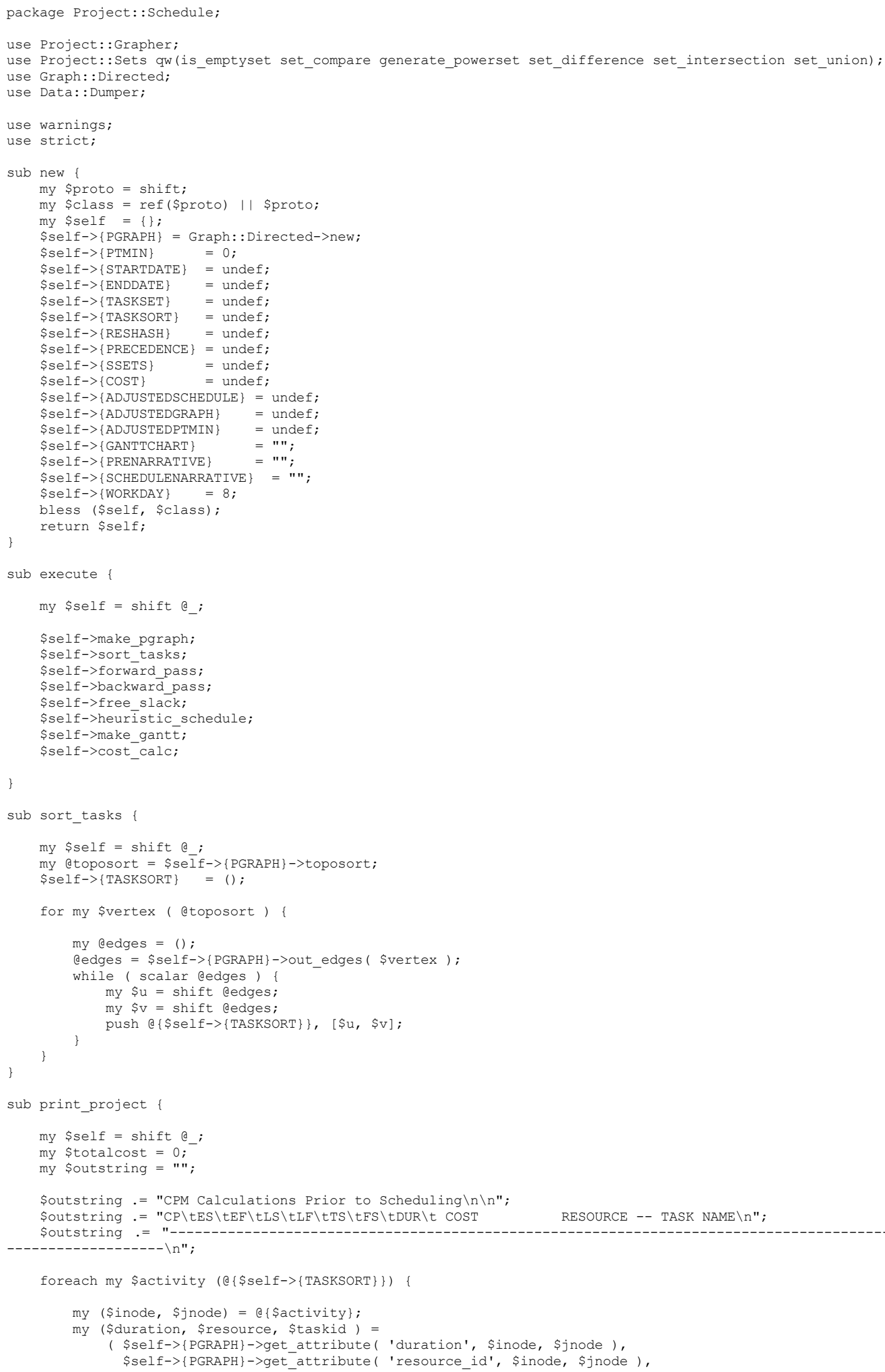


\$self->\{PGRAPH \}->get_attribute( 'task_id', \$inode, \$jnode ))；

my $\$$ cost $=(($ resource $!=-1)$ ?

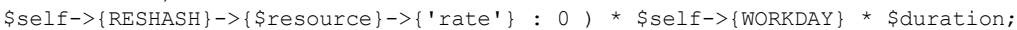

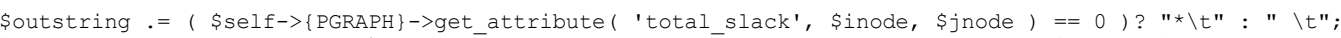

\$outstring.= sprintf "\%0.1f $\backslash t ", \$ s e l f->\{$ PGRAPH $\}->$ get_attribute( 'early_start', \$inode, \$jnode );

\$outstring.= sprintf "\%0.1f \t", \$self->\{PGRAPH $\}->$ get_attribute( 'early_finish', \$inode, \$jnode );

\$outstring .= sprintf "\%0.1f \t", \$self->\{PGRAPH $\}->$ get attribute ( 'late start', \$inode, \$jnode );

\$outstring.= sprintf "\%0.1f \t", \$self->\{PGRAPH $\}->$ get attribute( 'late finish', \$inode, \$jnode),

\$outstring.= sprintf "\%0.1f \t", \$self->\{PGRAPH $\}->$ get_attribute( 'totaI_slack', \$inode, \$jnode);

\$outstring.= sprintf "ㅇ․f \t", \$self->\{PGRAPH $\}->$ get_attribute( 'free_slack', \$inode, \$jnode);

my $\$$ tmpstr $=\$$ self $->\{$ RESHASH $\}\{\$$ resource $\}\{$ 'name' $\}$;

\$outstring = sprintf "\%0.1f $t$ ", Sduration;

\$outstring.= sprintf "으.2f ", (( \$resource != -1) ? "\$cost" : "n/a" )

\$outstring.= sprintf "\%s -- $\frac{\circ}{\mathrm{s}} \backslash \mathrm{n} "$,

( ( \$resource != -1)? "\$tmpstr" : "n/a"),

(( \$taskid !=-1)? \$self->\{TASKSET\}\{ \$taskid \}\{'task_name' \} : "dummy task" );

\$outstring. $="---$

\$outstring.= sprintf "Project Length (non-adjusted): ㅇ‥1f days $\backslash n ", \$$ self-> PTMIN $\}$;

\$outstring.= sprintf "Total Cost: $\backslash \$ \div 0.2 f \backslash n "$ " $\$$ self-> $\{$ COST $\}$;

\$outstring .= "\nAdjusted Schedule: $\backslash n \backslash n "$;

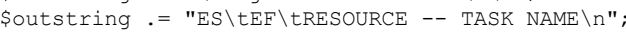

\$outstring . = "-------------

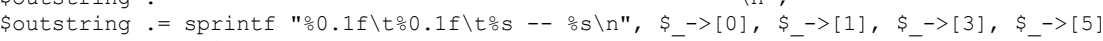

foreach ( @ $\{$ \$self->\{ADJUSTEDSCHEDULE $\}$ \});

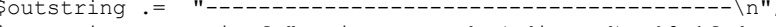

Soutstring.= sprintf "Project Length (adjusted): ㅇ.1f days $\backslash n ", \quad \$ s e l f->\{$ ADJUSTEDPTMIN $\}$

\$outstring .= sprintf "Total Cost: $\backslash \$ \% 0.2 f \backslash n ", \$$ self-> $\{$ COST $\}$;

return \$outstring;

sub make gantt

my $\$$ self = shift

my $\$$ ptmin $=\$$ self-> $\{$ ADJUSTEDPTMIN $\}$

my $\$$ scale $=($ ptmin $/ 100)$;

\$scale $=($ \$scale $>=1)$ ? int $($ \$scale +0.5$):($ \$scale $>=0.5)$ ? $1: 0.5$

my \$ganttstr $=" "$;

my \$tmpstr.

\$ganttstr .= "Approximated Gantt $($ Scale \# = \$scale days) $\backslash \mathrm{n}$ "

my $\$$ sepstr $=" "$;

for ( my $\$ i=0$; $\$ i<=$ Sptmin / \$scale; ) (

my $\$$ tick $=\$ i * \$ s c a l e$

\$tmpstr $=\left(\$ i \frac{0}{\circ} 10=0\right)$ ? "|\$tick" : "-"

$\$ i+=$ length $\$$ tmpstr;

\$sepstr. = \$tmpstr;

\$ganttstr .= \$sepstr. "\n";

my \$chartlen = length \$sepstr;

foreach ( @ $\{\$$ self-> AADJUSTEDSCHEDULE $\}\})$,

\$tmpstr $=1, \mathrm{x}(\operatorname{int}(\$->[0]+0.5) /$ \$scale $)$ :

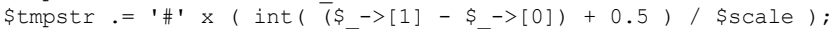

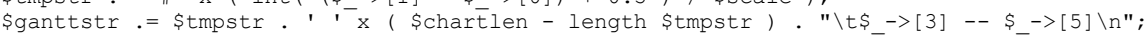

\$ganttstr.$=$ \$sepstr;

\$self-> $\{$ GANTTCHART $\}=$ \$ganttstr

sub forward_pass

my $\$$ self $=$ shift $0_{-}$;

$\$$ self-> PTMIN $\}=0 ;$

my \$activity;

\$self-> \{PGRAPH\}->set_attribute ( 'early_occurrence', \$_, \$self->\{STARTDATE $\}$ )

foreach ( \$self->\{PGRAPH $\}->$ vertices );

foreach \$activity (@\{\$self->\{TASKSORT $\}\}) \quad\{$

my $($ \$inode, \$jnode) $=$ @\$activity;

\$self->\{PGRAPH $\}->$ set_attribute( 'early_start', \$inode, \$jnode, \$self->\{PGRAPH \}->get_attribute('early_occurrence', \$inode) );

\$self->\{PGRAPH\}->set_attribute( 'early_finish', \$inode, \$jnode, \$self->\{PGRAPH $\}->$ get_attribute('early_start', \$inode, \$jnode) + \$self->\{PGRAPH\}->get_attribute('duration', \$inode, \$jnode ));

if (\$self->\{PGRAPH $\}->$ get_attribute( 'early_finish', \$inode, \$jnode ) \$self->\{PGRAPH $\}->$ get_attribute ( 'early_occurrence', \$jnode ) >0 ) 


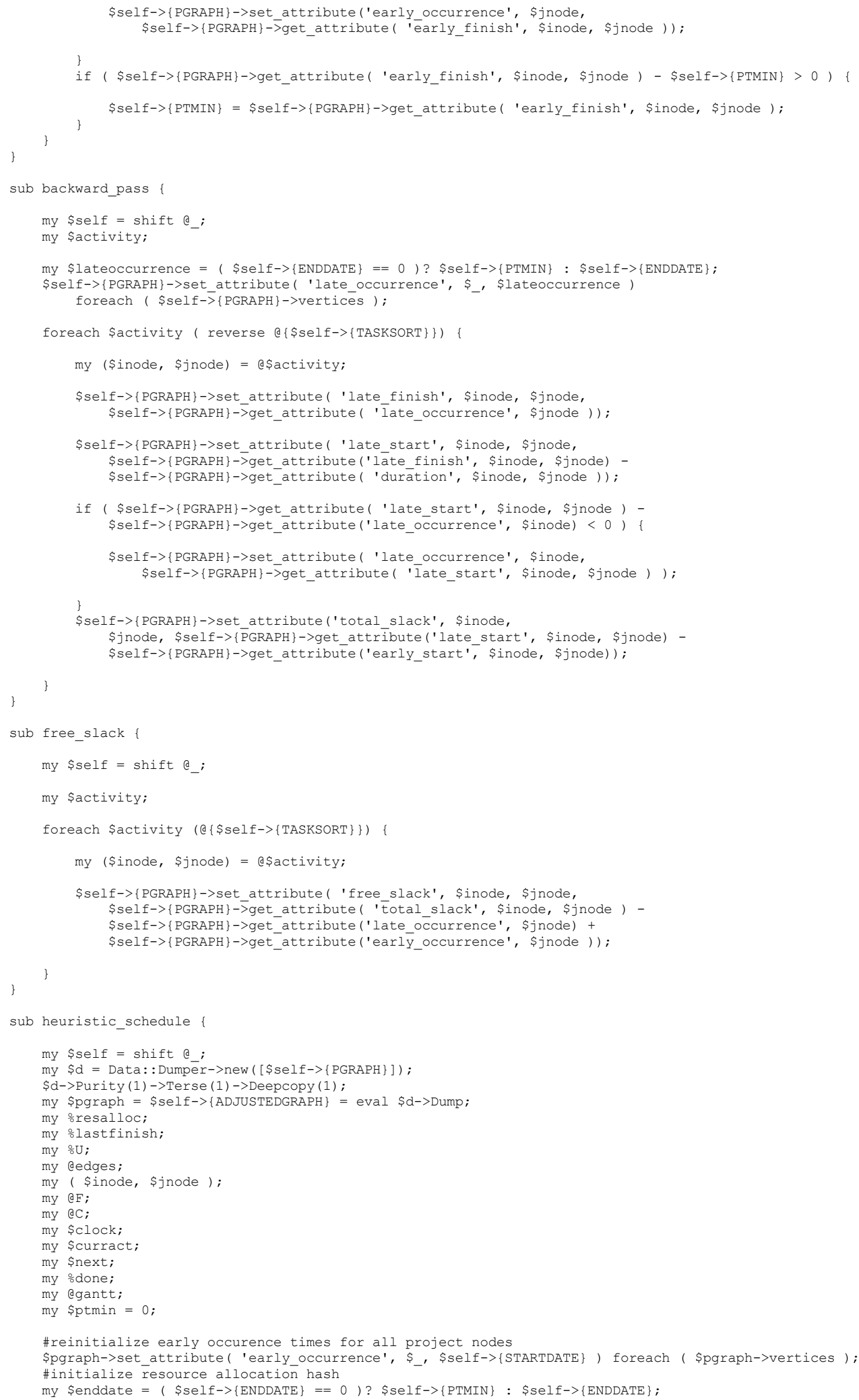




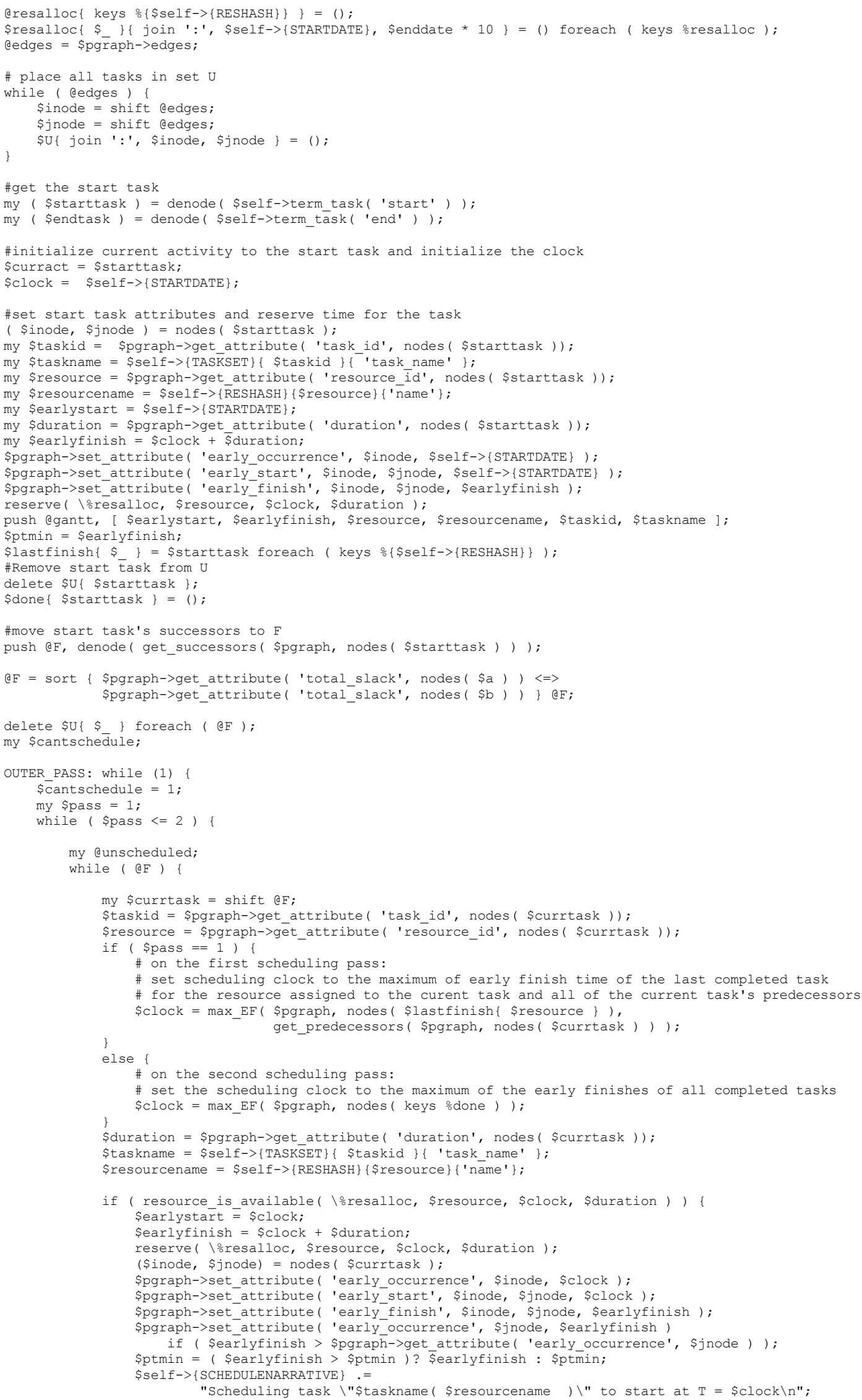




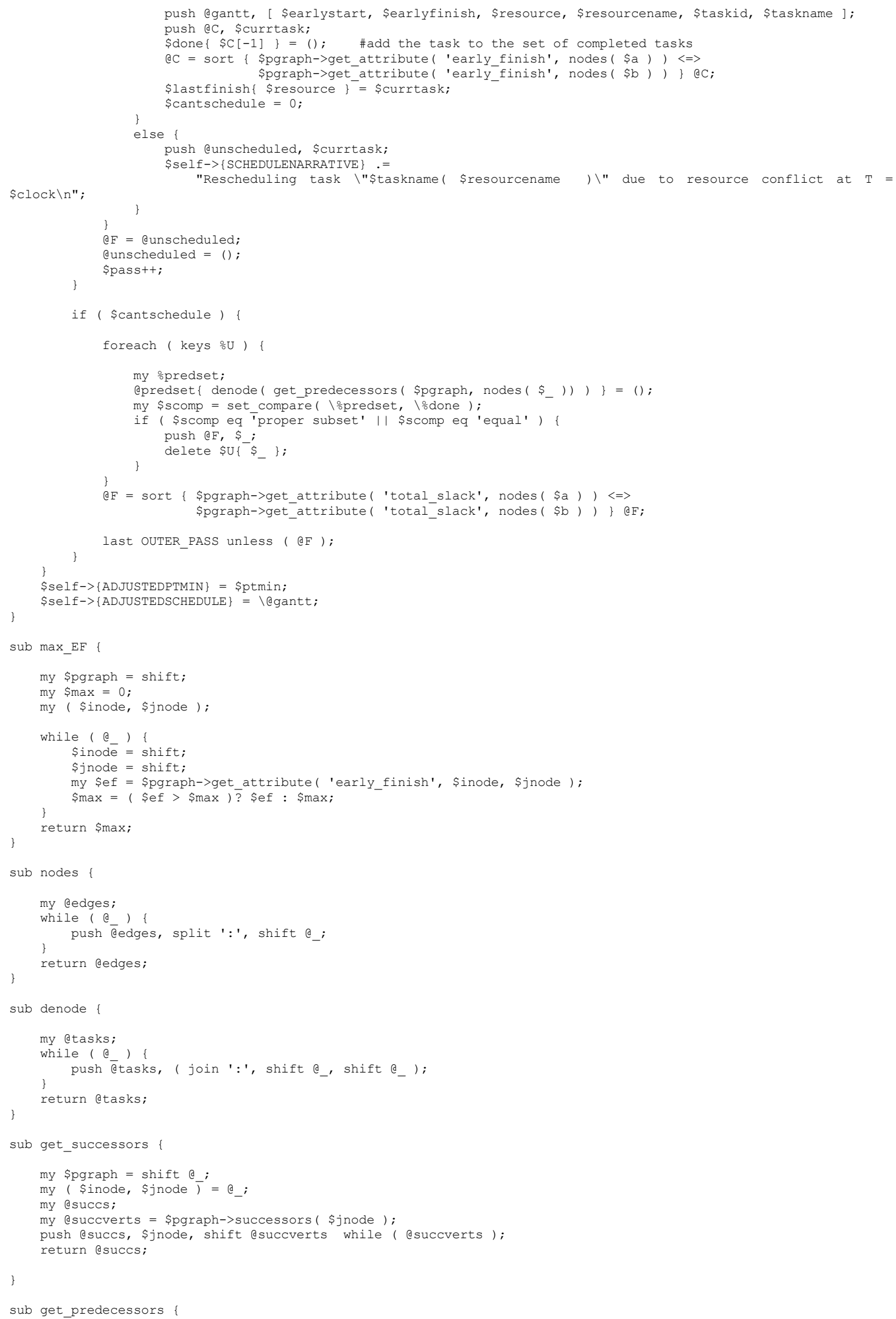




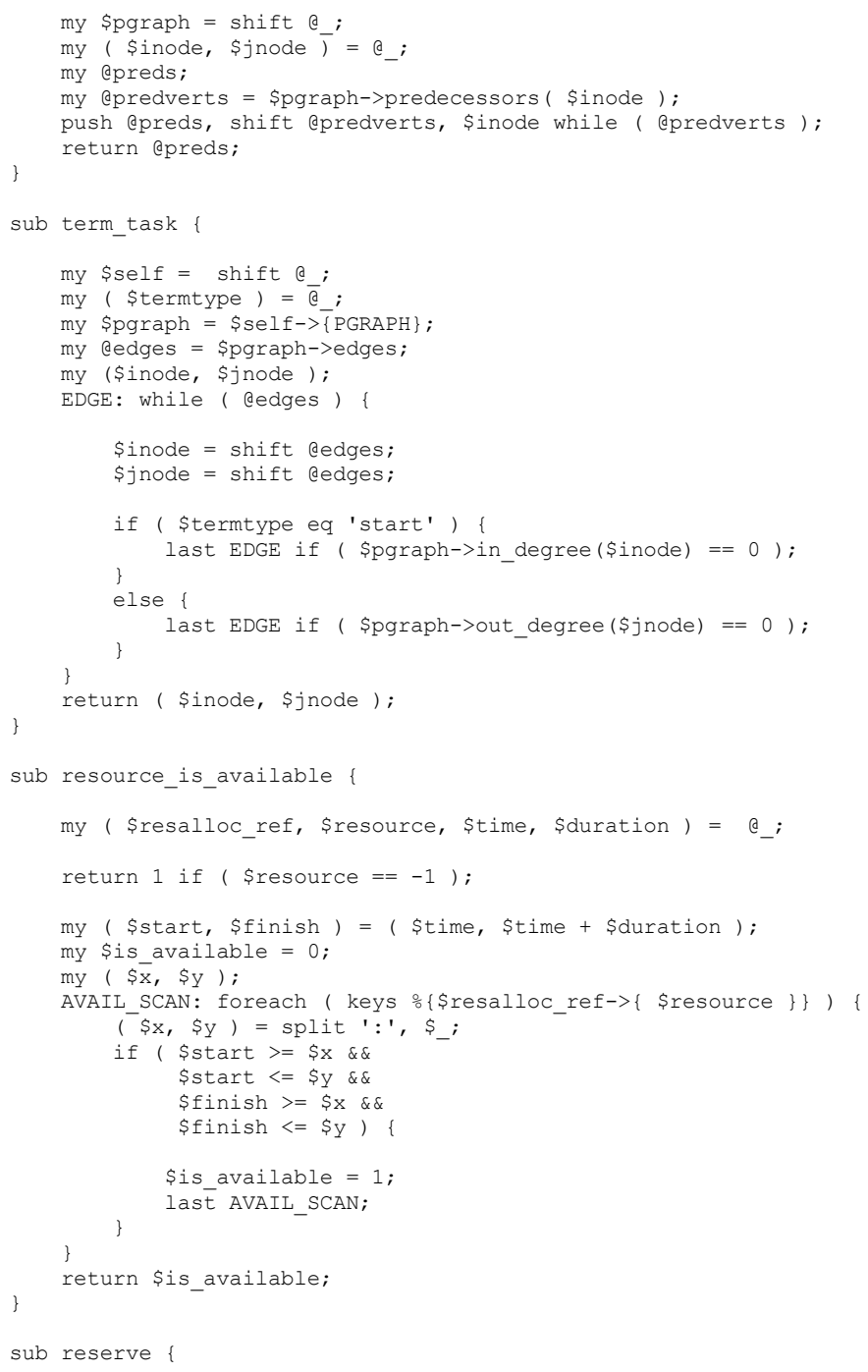




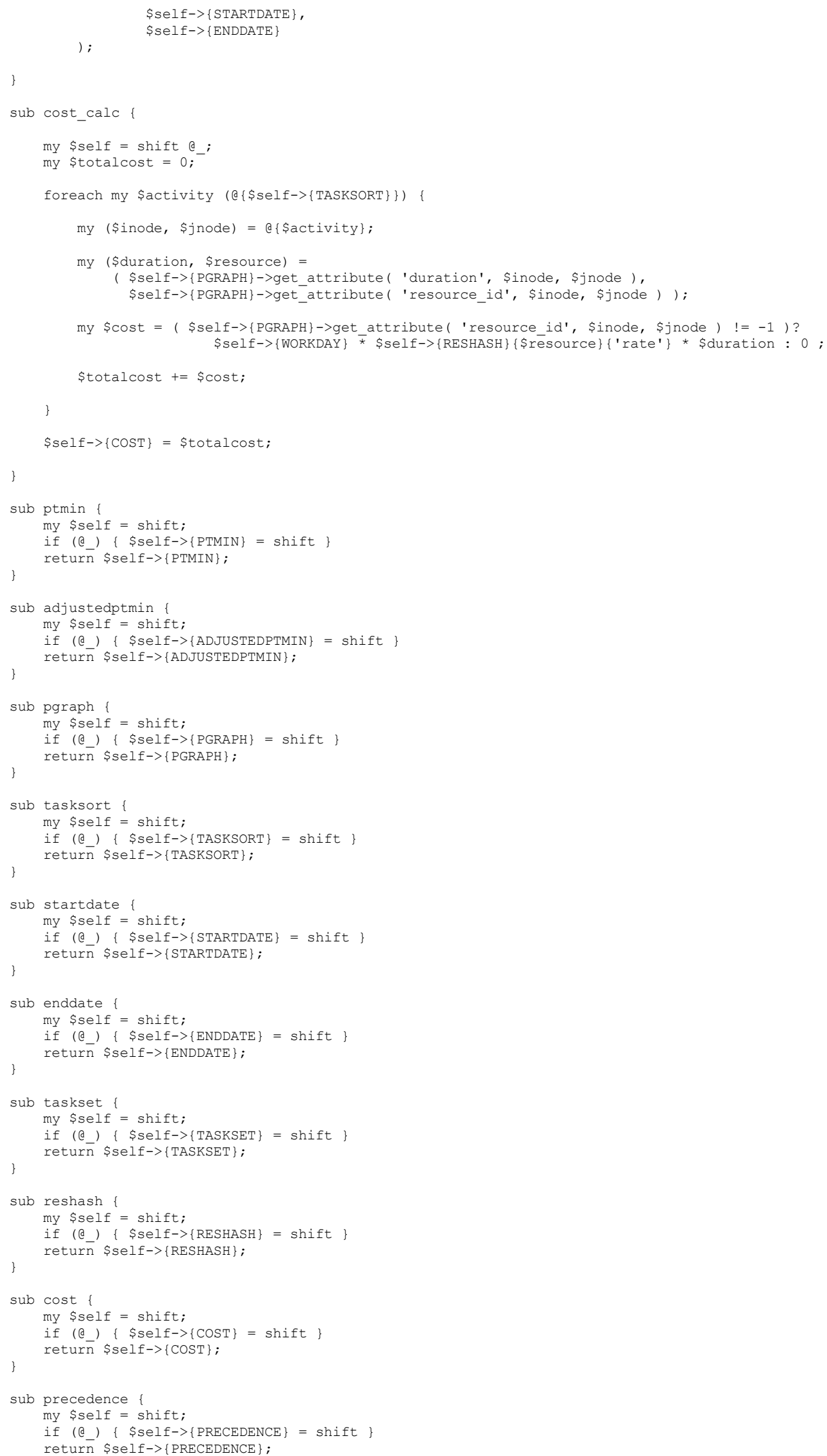




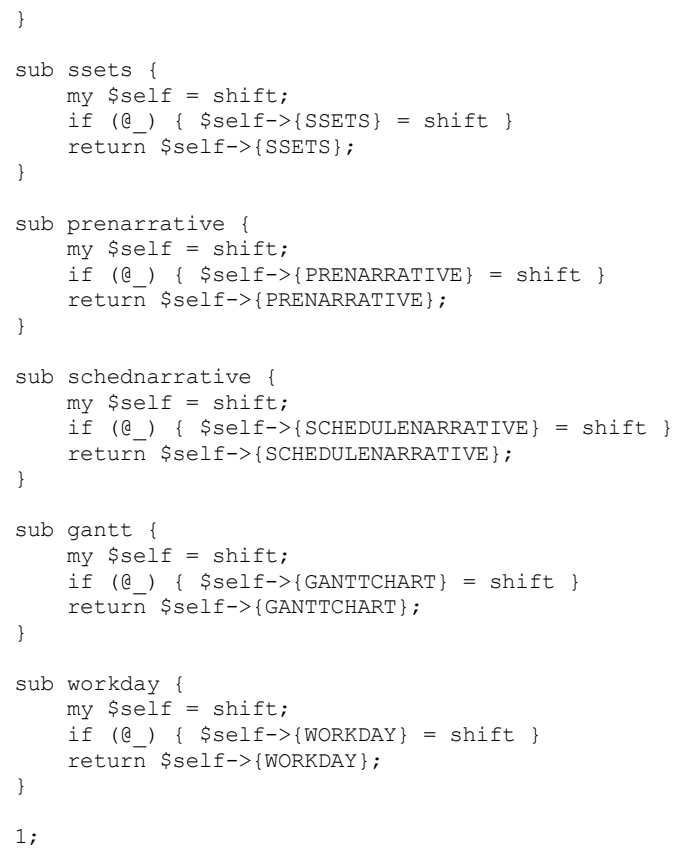




\section{The Project::Grapher Module}

package Project::Grapher

use Project::Sets qw(is_emptyset set_compare set_difference set_intersection set_union);
use Graph: :Directed;

use warnings;

use strict;

\# STEP I

\# I. create sets $S[1 \ldots n]$

\# STEP II

\# II. A. number activities in topological order

\# II. B. form the binary precedence matrix $\mathrm{R}$

\# II. C. convert R to toally redundant precedence matrix Rprime

\# II. D. reduce Rprime to the basic precedence matrix without redundancy R2prime

\# STEP III

\# III. A. Determine nonredundant sets A(i)

\# III. B. Determine totally redundant sets $A^{\prime}(i)$

\# III. C. Determine the sets B(i)

\# STEP IV

\# IV. Assign integer $F(i)$ to activity i

\# STEP V

\# V. Assign integer $T(i)$ to activity $i$

\# STEP VI

\# VI. Assign a preceding node number $\mathrm{P}(i)$ to activity $i$

\# STEP VII

\# VII. Assign a succeeding node number $Q(i)$ to activity $i$

\# STEP VIII

\# VIII. Create ordered pairs of nodes [Q(i), $P(j)]$

sub pgraph \{

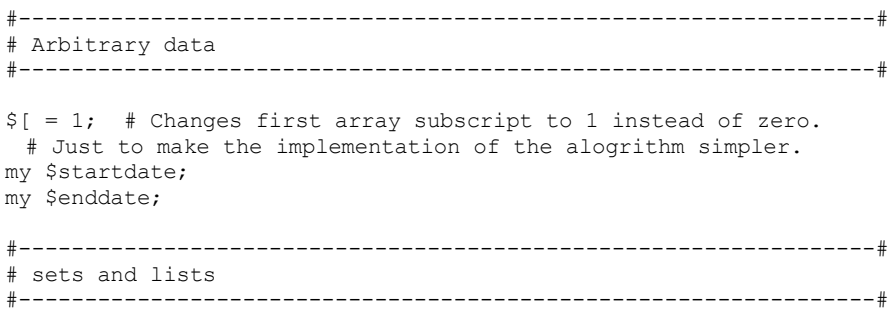

my \$PR; \# hash of task precedence relations

my $\$ S ; \# \mathrm{~S} 1=\{\mathrm{y} \mid \mathrm{y}$ has no followers $\}, \mathrm{S} 2=\{\mathrm{y} \mid \mathrm{y}$ has at least one follower in $\mathrm{S} 1\}$..etc

my \$taskset; \# set of all tasks in the project

my atsort = (); \# topologically sorted list of tasks in the project

my otmpset $=()$; \# temporary set used in the topological sort of tasks

my $@ R=() ; \#$ Precedence matrix

my @Rprime; \# Totally redundant precendence matrix

my eR2prime; \# Basic precedence matrix without redundancy

my @A; \# non redundant sets

my eAprime; \# totally redundant sets

my @B; \# ?

my $\frac{\circ}{D} ; \#$ ?

my @F; \# ?

my @т; \# ?

my @P; \# ?

my @Q; \# ?

my edummies; \# Dummy activities required for the project network

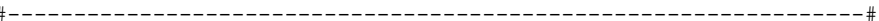

\# counters, temp variables, and flags

my \$taskid; \#-1 is used as a flag when no rows are returned from the select

my $\$ i=1 ;$ \# Initialize general counter

my $\$ j=1$;

my $\$ \mathrm{k}=1 ;$; \# ditto

my Sexhaustiveset $=0$; \# flag to indicate when exhaustive sets have been produced while creating $S[1 \ldots n]$

my $\$$ flag $=0$; \# General flag

my $\$ p g=$ Graph: : Directed->new ();

(\$taskset, \$PR, \$S, \$startdate, \$enddate) =

\#--

\# STEP II 


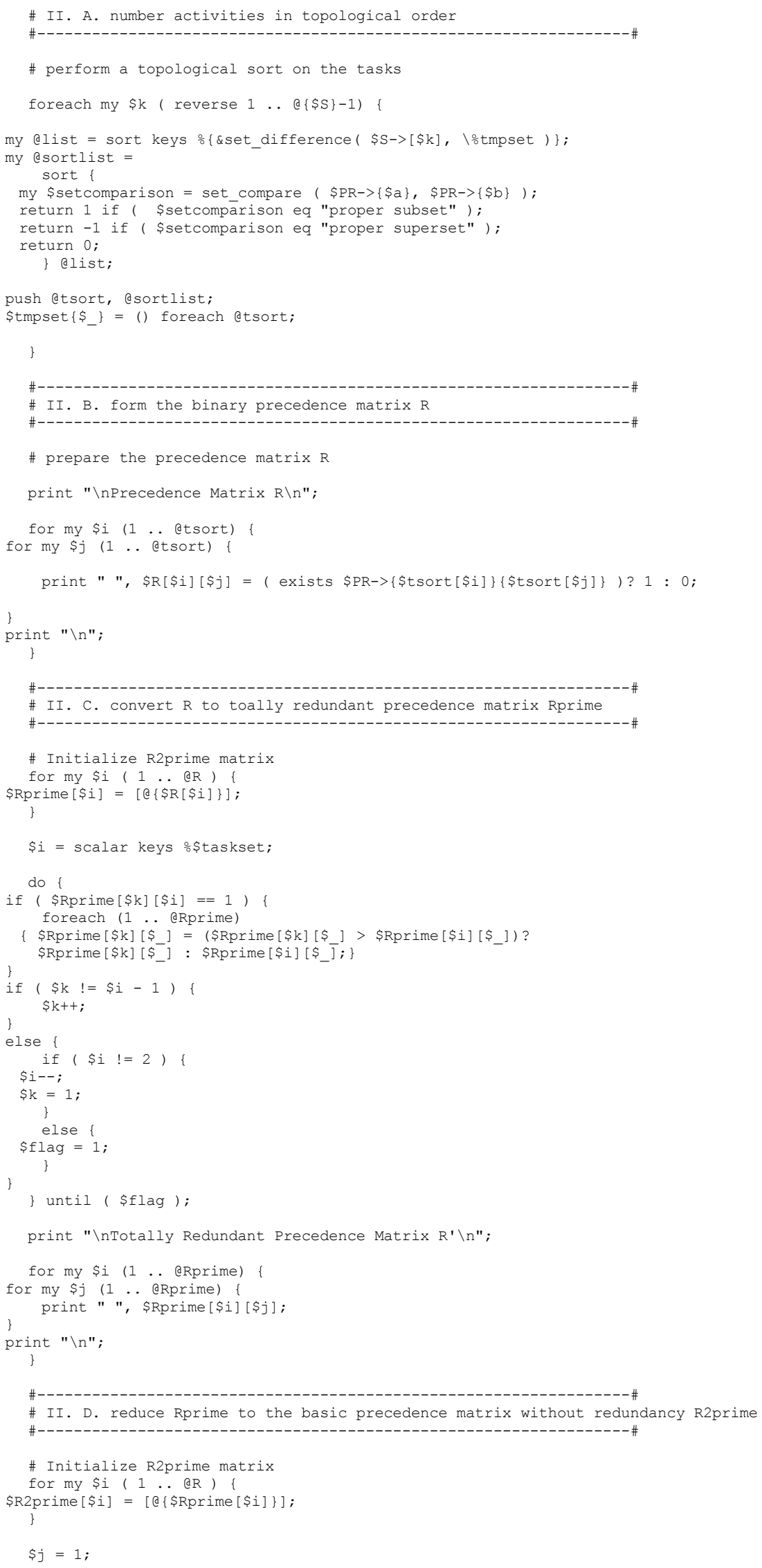




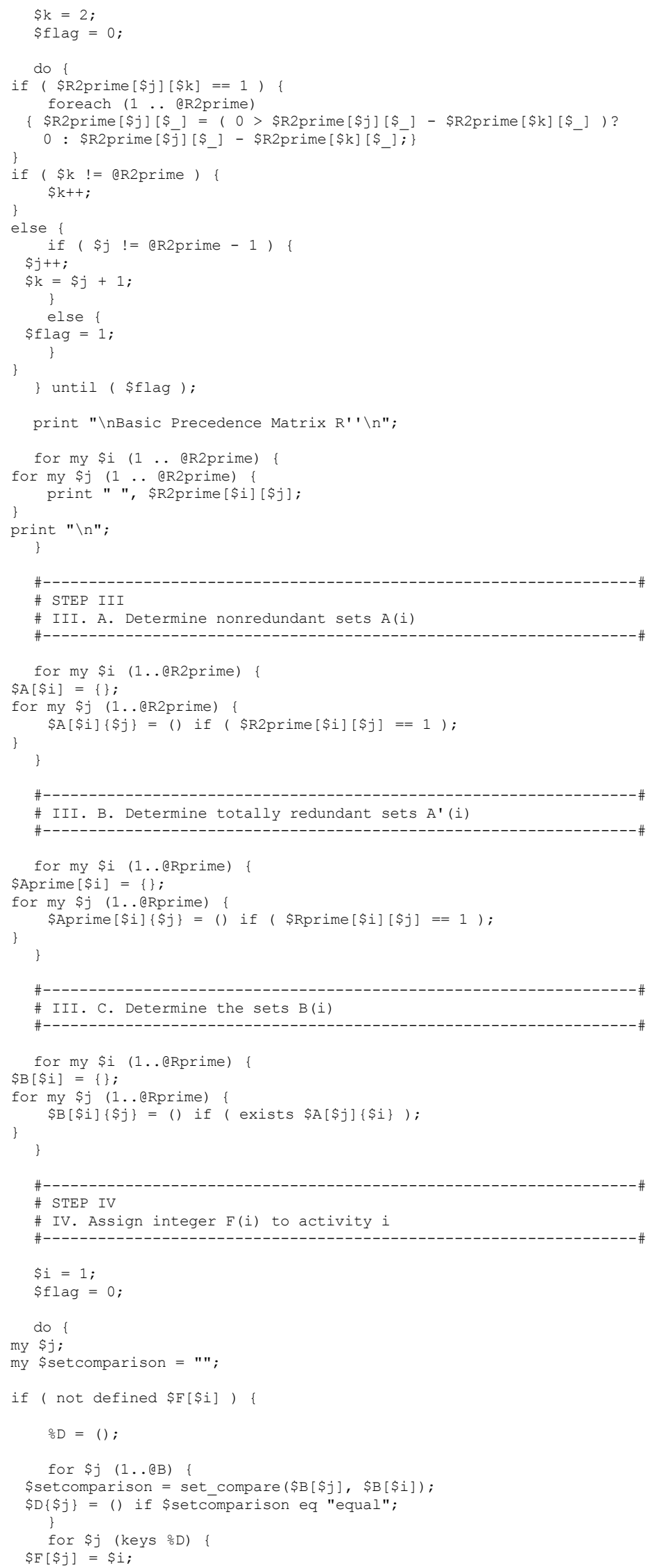




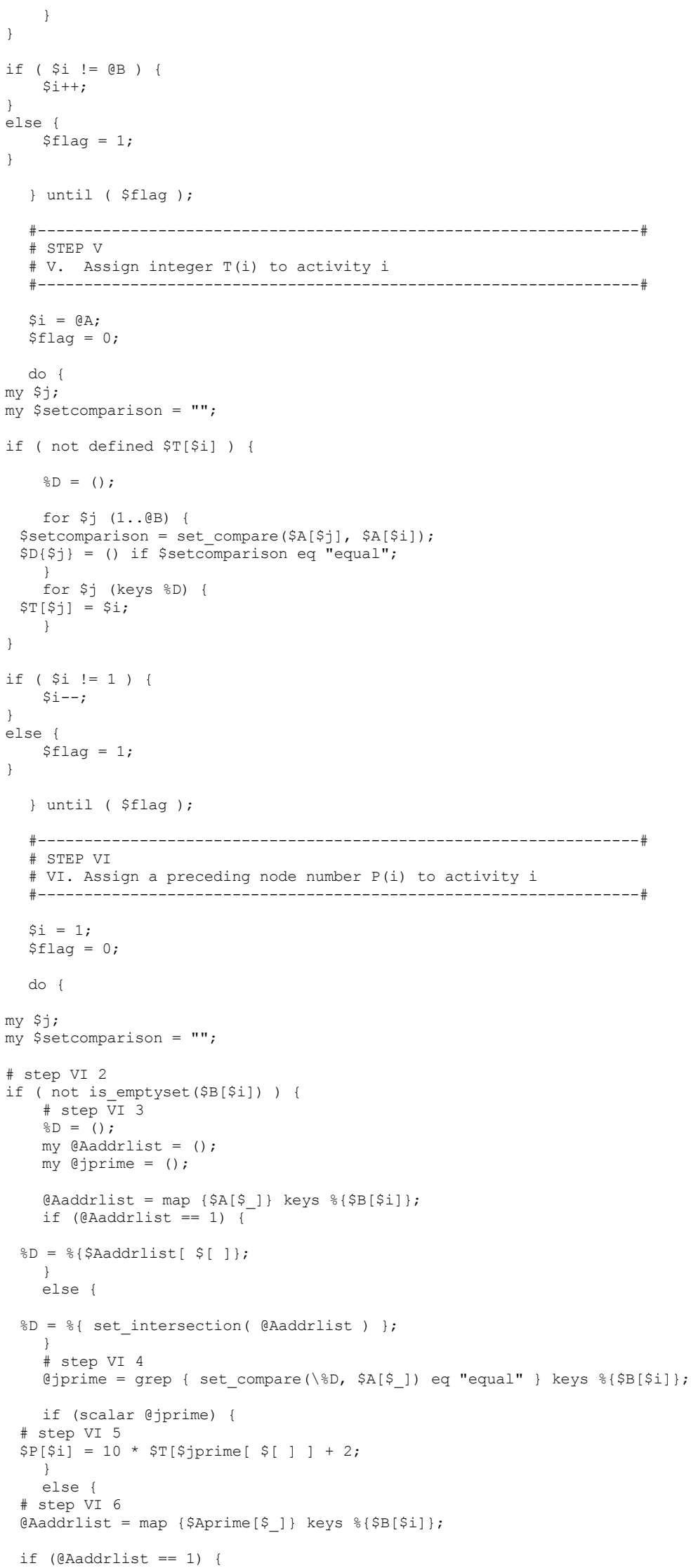




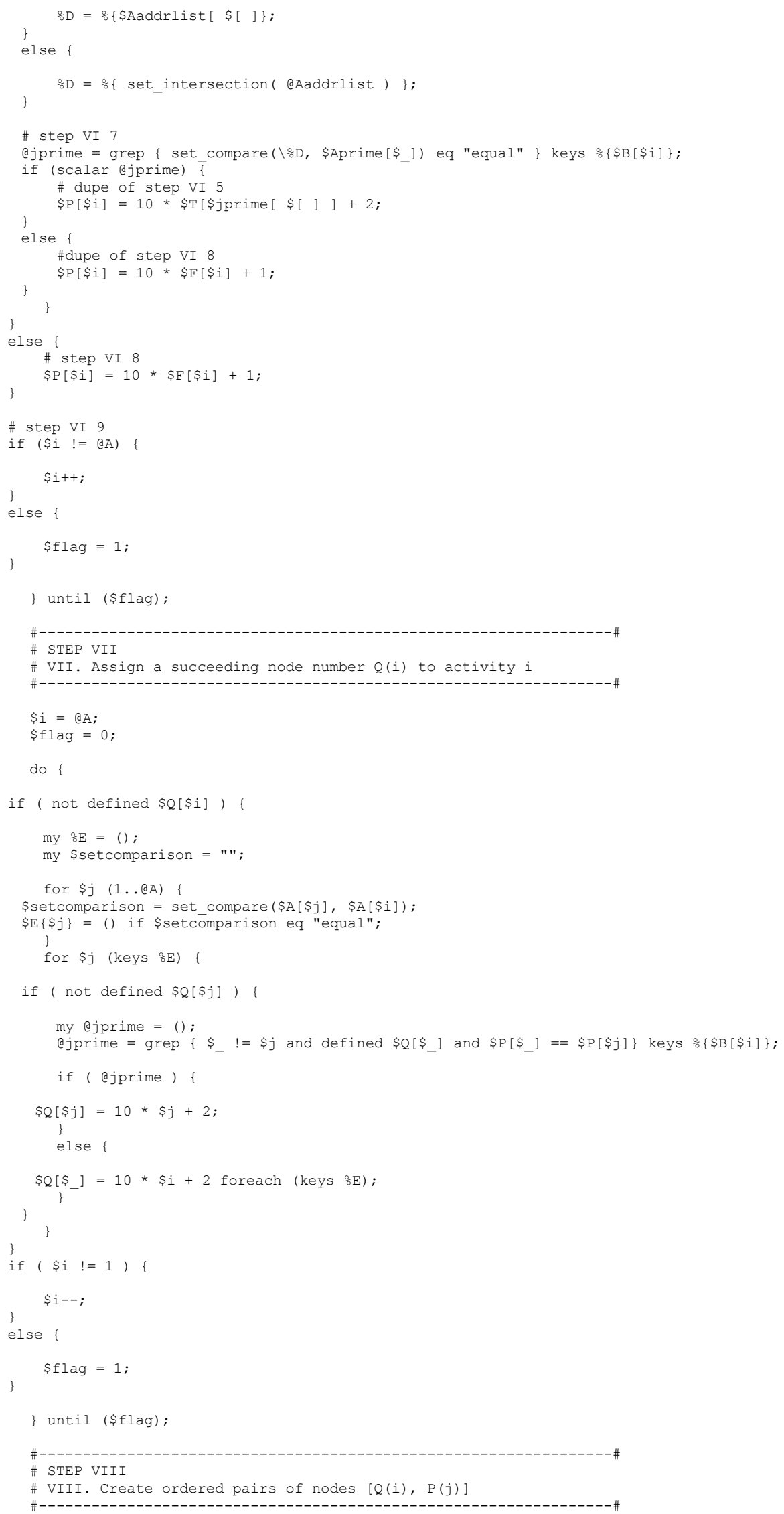




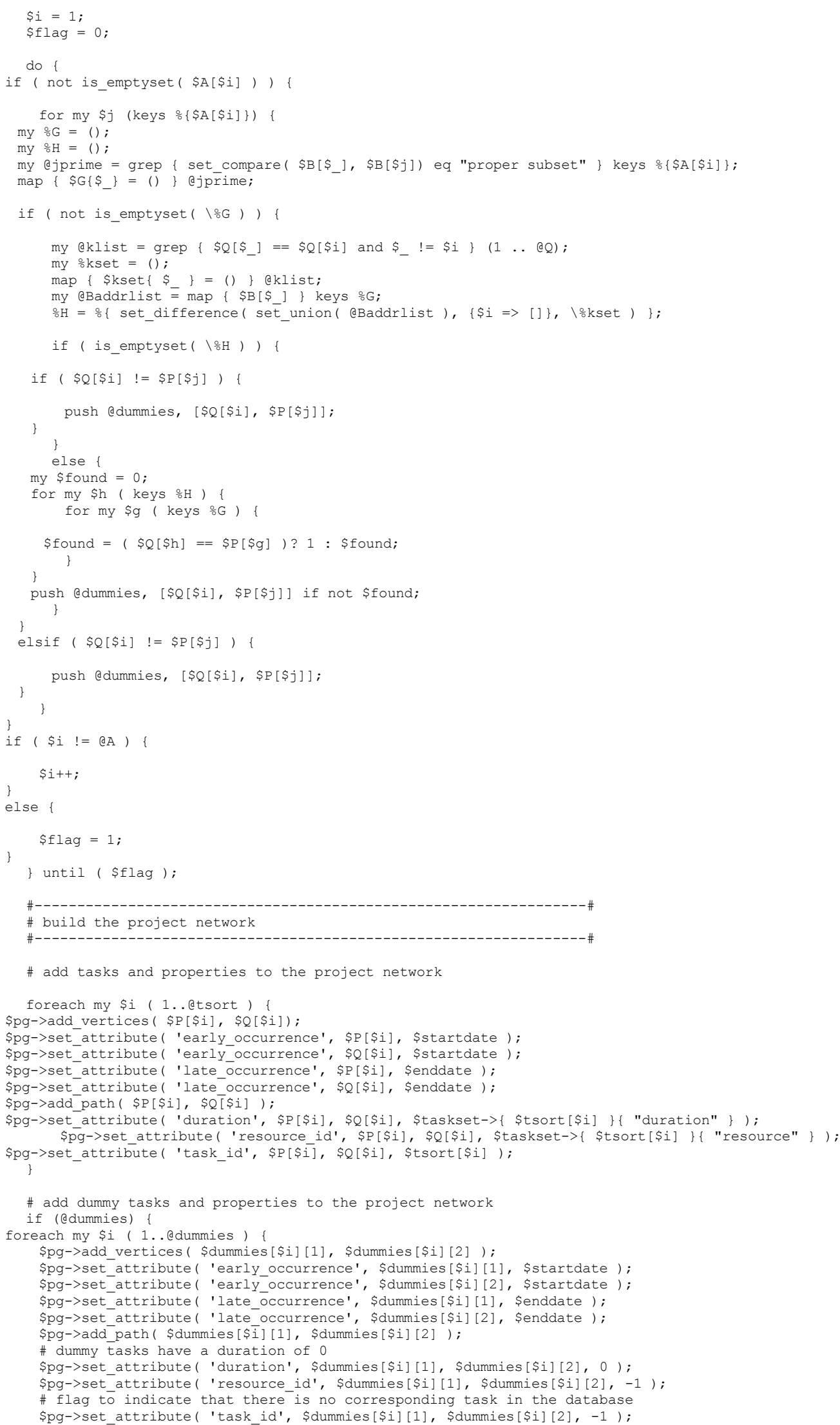

\# add tasks and properties to the project network

foreach my \$i ( 1 . etsort ) \{ 
\$ $[=0$;

return \$pg;

\}

sub render2DOT

my ( \$gname, \$pgraph, \$tasksetref, \$reshashref ) = e;

my $\$$ dotstr $=$ "digraph \$gname $\{\backslash n \backslash$ tsize= $\backslash " 8,10 \backslash " ; \backslash n " ;$

my $\$$ attr $=" "$

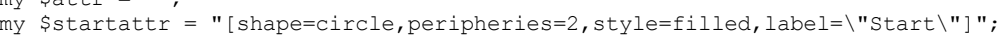

my \$nodeattr $=$ "[ shape=circle]";

foreach my \$node ( \$pgraph->vertices ) \{

\$attr $=($ pgraph->in_degree $($ \$node $)=0$ ) ? \$startattr : \$nodeattr

\$dotstr. = "\t\$node $\$ \overline{a t t r} ; \backslash n "$;

\}

my dedges $=\$$ pgraph->edges

while (dedges) \&

my \$inode = shift dedges;

my $\$$ jnode $=$ shift dedges;

my \$resource id = \$pgraph->get attribute ('resource id', \$inode, \$jnode)

my \$duration $=$ \$pgraph->get_atEribute ( 'duration', \$inode, \$jnode) );

my $\$$ slack = \$pgraph->get_attribute ( 'total_slack', \$inode, \$jnode),

my $\$$ taskid = \$pgraph->get_attribute ( 'task_id', \$inode, \$jnode);

my \$taskname $=($ \$taskid $=-1)$ ? "dummy" : \$tasksetref-> $\{$ taskid $\}$ 'task_name' $\}$;

my $\$$ resname $=($ taskid $==-1)$ ? "NA" : \$reshashref-> $\{$ \$resource $i d\}\{$ 'name' $\}$

my $\$$ color $=($ slack $==0)$ ? ", color=red, style=bold" : ", color=black";

my \$style $=($ \$taskid $=-1)$ ? "style=dotted," : "";

my \$edgeattr $="[$ style" . "label= $\backslash$ "\$taskname $\backslash \backslash$ nDUR $=$ \$duration $\backslash \backslash$ nRES $=$ \$resname $\backslash "$ color $] ; " ;$ \$dotstr . = "\t\$inode $->$ \$jnode \$edgeattr $\backslash n "$

return $\$ \operatorname{dotstr} .="\} "$;

\}

$1 ;$ 